\title{
Being Part of the Land: The Responsibility-Based Yucatec Maya Land Ethos
}

by

Miguel Paul Sastaretsi Sioui

A thesis submitted to the Faculty of Graduate and Postdoctoral Affairs in partial fulfillment of the requirements for the degree of

Doctor of Philosophy

in

Geography

Carleton University

Ottawa, Ontario

(C) 2018, Miguel Sioui 


\begin{abstract}
$\underline{\text { Abstract }}$
For millennia Indigenous peoples throughout the Americas have had spiritual relationships with their lands and the beings on them. Today, a variety of political, social and environmental factors are redefining many Indigenous groups' land-based sustenance practices and livelihoods. Through these changes and new developments, however, scholars have found cultural continuity. My doctoral research describes the land ethos of the residents of the Mayan community of Xuilub (Yucatan), Mexico, and explains how it is understood and put into practice by its members. This project, informed by postcolonial theory, Indigenous geographies, and Indigenous knowledges (IKs) research, is part of a broader attempt to decolonize colonial histories and understandings about Indigenous peoples and their relationships with their territories. Through experiential learning and interviews over five trips to the area from 2014-2016, I have come to understand the Mayan land ethos as "being part of the land." I argue that this land ethos is guided by the cultural precept of 'responsibility-based thinking.' This ethos reflects a non-hierarchical view of the place of humans within a larger society (or Circle) of all beings on the land, and speaks to the importance of ceremony, offerings, and reciprocal relationships. Furthermore, this worldview is not static, but is well suited to integrating new knowledges and innovations and adapting to changing social and environmental conditions, and is strongly connected to cultural identity and place. The Maya land ethos can be described as a spiritually informed way of seeing the world that informs and mediates personal and collective conduct by instilling in an individual and, by extension, a community, a sense of duty or responsibility to be part of the land, rather than a sense
\end{abstract}


of having rights to or on it.

This dissertation contributes to broader scholarly efforts to achieve deeper understandings of IKs, from a more Indigenous-centred research approach (and research questions), with the ultimate goal of expanding the disciplinary perspectives of postcolonial scholarship and Indigenous geographies. Such a responsibility-based mindset has the potential to enhance current mainstream (rights-based) environmental policy frameworks. 


\section{Acknowledgements}

As with every PhD journey and process, mine has been deeply stimulating and enriching on both an intellectual and personal level. Since beginning my doctoral studies in the fall of 2012, I have made countless new friends and acquaintances, some of whom have acted as academic mentors and others who have offered me support in a number of different ways. Each of these people has contributed to the success of my $\mathrm{PhD}$, but unfortunately due to space constraints, most of them will go unnamed.

The person who has, without a doubt, made the most significant contribution to my development as a scholar and to this dissertation is my doctoral advisor Dr. Derek Smith. Since 2012, Dr. Smith has been exceedingly generous with his time in providing me with guidance, feedback, and advice, and helping me to develop effective strategies to tackle complex dissertation-related tasks one by one. What is more, he is the one who suggested I accompany him on one of his research trips to the Yucatan in May of 2014, where he introduced me to the people of Xuilub. Quite literally, therefore, this research project would not have been possible without Dr. Smith. I am forever grateful for having had the chance to work under the guidance and wisdom of not only such a highly competent but more importantly always available and helpful doctoral advisor. I now consider Dr. Smith to be a good friend and colleague, and I hope to collaborate with him on future research projects. Moreover, in terms of direct academic mentorship, I offer my profound thanks to my other committee members Dr. Gita Ljubicic and Dr. Deborah McGregor. Both Dr. Ljubicic and Dr. McGregor possess great expertise in their fields, and their detailed comments and feedback were instrumental to the writing and revision 
of this document. As with Dr. Smith, however, it was their keen willingness to help and their approachability and availability throughout my six-year journey that I appreciate the most.

Next, I wish to acknowledge the community of Xuilub. Since my first trip to the area with Dr. Smith, the people of the community have shown me nothing but support, guidance, and friendship. In particular, I thank my community research partner (and now good friend) Demetrio Canche Dzib for working tirelessly with me while I was in the community as a guide, translator, and general expert on Maya culture and traditions. Without his extensive and intimate knowledge of the Maya culture and language, and his connections with almost all other community members, I would have been unable to bring this project to completion. I consider my relationship with Demetrio and the entire community to be life-long, and am looking forward to working with these people in the short- and long-term. I will continue to seek guidance and feedback from the community, as we continue to develop research projects together that will benefit Xuilub and the Yucatec Maya more broadly.

I must also acknowledge the contribution of my parents Georges and Bárbara. Together, they have supported and encouraged my scholarly pursuits since I was four years old and starting kindergarten. My father Georges, who is the first First Nations person in Canada to hold a $\mathrm{PhD}$ in history, has, ever since I can remember, been my academic hero. Without exaggeration, all of the academic ideas that I have developed over the years have been influenced and informed by his work and by our personal conversations and discussions about myriad subjects related to Indigenous people. As for my mother Bárbara, she has been unwavering in her support for my development as an 
academic. Her sharp wit and critical thinking skills, along with her strong work ethic and resolve (which she tells me she got from her mother-my late grandmother Amelia) have contributed to my personal development, and have taught me to forever stay focused on my purpose. She has also shown me how to, instead of complaining and resisting, learn from challenges and obstacles to grow and become stronger as a person, both intellectually and psychologically. In this regard, the importance of having the example of my late grandmother Dr. Éléonore Tecumseh Sioui CC., poet, international speaker, and a fiercely proud Huron-Wendat woman who obtained her $\mathrm{PhD}$ at the age of sixtyeight and was promoted from Officer to Companion of the Order of Canada in 2001, cannot be understated. Her outstanding goal of working toward achieving a doctorate degree and continuing her education at the high-school level in her early fifties after raising seven children (including my father Georges) is extraordinary, and I am truly grateful for having had such a strong role model in my life.

I also want to acknowledge four of my closest friends. One of those, Hugo Paradis, is a childhood friend. Two others, Adrian Gaanderse and Andrew Williams, are friends I met during my doctoral studies in geography at Carleton. Last but not least, I thank Shiva Mohan, whom I met through my work at Wilfrid Laurier University. Over the last year and a half, he has given me a great deal of friendly support in the final stages of my $\mathrm{PhD}$. These four people have been endlessly supportive of me in my doctoral pursuit, and I could always count on them to make me laugh and talk about things other than research and academia when I needed to.

Lastly, I want to underline the special support and contribution of my partner Karine Appolon, who has been by my side for the final third of my doctoral studies. Her 
tender encouragement, sense of humour, patience, love (and formatting skills!) have kept me afloat and upbeat over the last two years. These last two years have been the most academically challenging overall, and fraught with a number of different professional and personal challenges, which, thanks to her, I have been able to surmount and emerge from a stronger person. 


\section{Table of Contents}

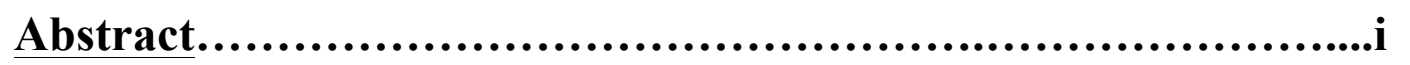

Acknowledgements.....................................................iii

Table of Contents........................................................vii

List of Figures...........................................................xi

List of Appendices..............................................................................................xii

Glossary...........................................................................................................

Chapter 1: Introduction ...................................................1

1.1 The Research's Prior Assumptions and Positions......................5

1.2 Colonialism and its Influence on Indigenous Peoples (Land-Based

Knowledges in the Americas.......................................11

1.3 The Yucatec Maya Land-Based Culture and Identity.................13

1.4 Postcolonial Theory and the Value of Non-Western Knowledges.....15

1.5 Investigating Indigenous Knowledges (IKs) .......................16

1.6 Dissertation Overview............................................. 19

\section{Chapter 2: Colonialism and the Evolution of the Relationships}

Between the Yucatec Maya and their Land .........................23

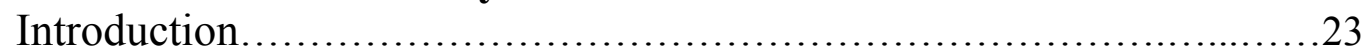

2.1 Colonialism and the Concept of Indigenous Rights and its

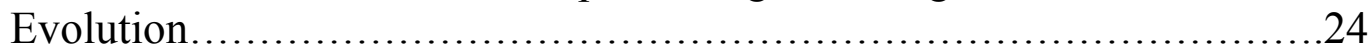

2.2 The Maya of the Yucatan Peninsula: Geographic and Historical

Context.................................................................. 31

2.2.1 The Geography and Climate of the Yucatan Peninsula..............31

2.2.2 The Historical Trajectory of the Maya..............................34

2.2.3 Demographic Profile of the Yucatec Maya.........................39

2.2.4 Past Understandings of the Relationships between the Yucatec

Maya and their Traditional Territory ..................................40

2.2.5 Past Research on Maya Spirituality and Land-Based Culture.......41

2.3 Milpa farming, Apiculture, Hunting, and Cattle Ranching:

The Main Current Maya Land-Use Practices in the Yucatan................43

2.3.1 The Milpa......................................................45

2.3.2 Apiculture........................................................ 
2.3.3 Hunting.

2.3.4 Cattle Ranching.........................................50

2.3.5 The Main Present-Day Outside Influences on the Yucatec Maya

Land Ethic and Land-Use Practices: A Look at the Tourism Industry...52

\section{Chapter 3: Theoretical Framework: Postcolonial Theory, Indigenous Geographies, and the Study of Indigenous}

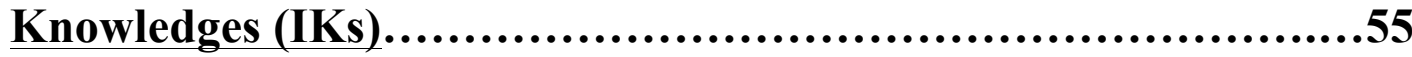

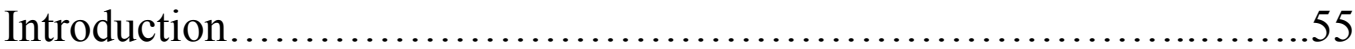

3.1 An Overview of Postcolonial Theory and How it Relates to

Research on Indigenous Land Use.

3.1.1 The Role of Postcolonial Theory in Contesting Colonial

Geographies and the Exercise of Territorial Control Over Indigenous

Peoples........................................................64

3.2 The Study of IKs..............................................69

3.3 The Contribution of this Research to Postcolonial and Indigenous

Geographies Scholarship............................................8 80

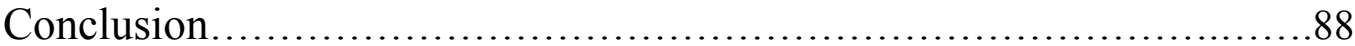

\section{Chapter 4: Research Design and Methodology......................92}

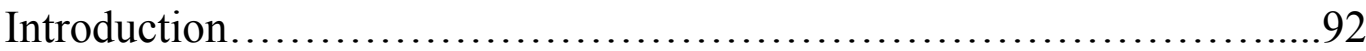

4.1 Aim of the Study............................................ 92

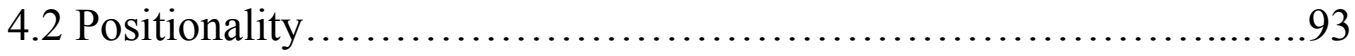

4.2.1 My Cultural Heritage and Family History and its Influence on

My Thinking ................................................... 93

4.2.2 How My Culture and Background Have Informed My Research

Methods..........................................................99

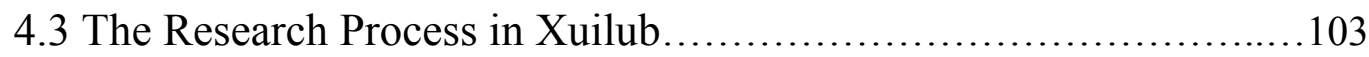

4.3.1 Indigenous Methods...........................................103

4.3.2 The Research Process: How I Applied Indigenous

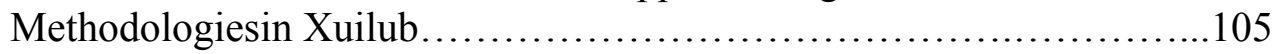

4.3.2.1 Developing Relationships............................108

4.3.2.2 Working Together.................................... 110

4.3.2.3 Seeking Feedback.....................................111

4.3.2.4 Maintaining my Relationships in Xuilub: How I

WorkedToward My Long-Term Accountability to the

Community and the Land.

4.4 Preliminary Planning Considerations for my Research in Xuilub:

A Geography and Brief History of the Community......................113

4.4.1 Xuilub: Past and Present.......................................115

4.5 My Field Research in Xuilub.................................. 117 
4.5.1 Recruitment of Research Partners................................ 120

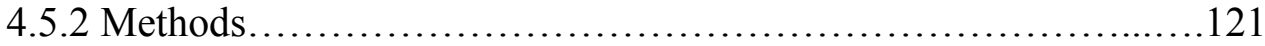

4.5.2.1 Experiential Learning .....................................121

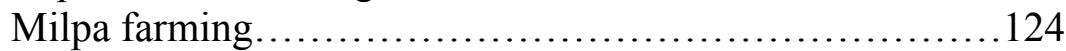

Apiculture ................................................ 125

Hunting............................................... 125

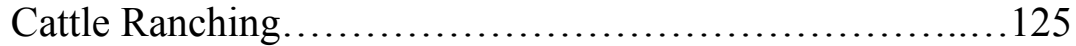

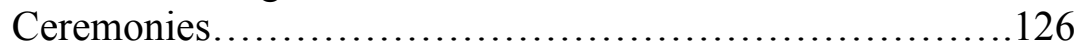

Miscellaneous..............................................126

4.5.2.2 Semi-Structured Interviews...............................126

4.5.3 Data Analysis (or Making Sense of My Learning Journey in

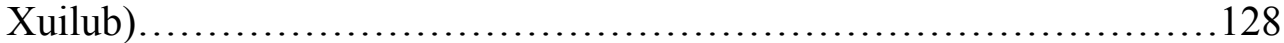

4.5.3.1 Hermeneutic Analysis..............................129

4.5.3.2 Basic Manual Coding.................................133

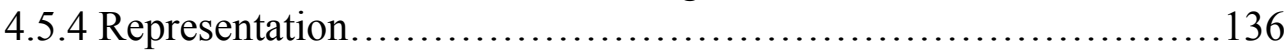

4.6 Research Contributions to the Xuilub Community......................137

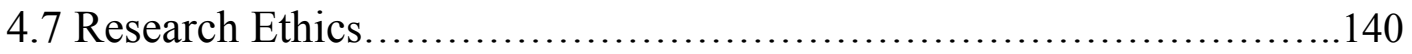

\section{Chapter 5: Responsibility-Based Thinking in Land-Use}

Practices.............................................................143

Introduction: Responsibility-Based Thinking in Xuilub....................143

5.1 The Milpa: The Linchpin of Maya Land-Based Culture.................146

5.1.1 Medicinal Plants................................................... 152

5.1.2 Milpa-Based Foods................................................ 155

5.1.3 Milpa-Related Ceremonies..........................................159

5.1.4 Working on the Milpa with a Maya Elder.............................165

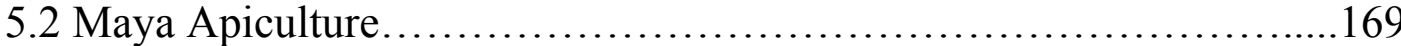

5.2.1 Apiculture with a Family From Xuilub............................176

5.3 Hunting and Maya Relationship with Wild Animals...................183

5.4 Cattle Ranching................................................ 187

5.4.1 A Day on a Maya Cattle Ranch................................190

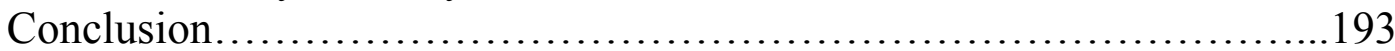

\section{Chapter 6: Being Part of the Land...................................198}

Introduction: Being Part of the Great Circle of Peoples of the Yucatan....198

6.1 The Spiritual Dimensions of Maya Relationships with the Land........206

6.1.1 Spirituality and Religious Syncretism in Xuilub.....................208

6.1.2 Daily Prayer as a Requirement for Being Part of the Land.............210

6.2 Maya Meanings and Representations of Place, Identity, and Social Organization........................................................216

6.2.1 Maya Identity and Understanding 'Place-as-Relationships' on the 


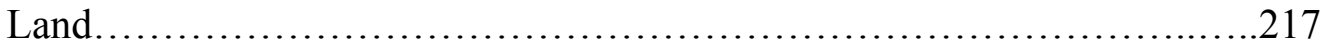

6.2.2 What it Means to be Part of the Great Circle of the Yucatan.............222

6.2.3 Gender and the Special Role of Elders (and Infants) in Xuilub..........224

6.2.4 Social Organization in Xuilub ("Convivir con respeto," or to

Co-Exist with Respect)..............................................233

6.3 The Broader Value of Learning to be Part of the Land.................240

6.3.1 The Limits of Current Mainstream Approaches to

Environmental Management..........................................240

6.3.2 Implications of Responsibility-Based Thinking and Being

Part of the Land for Mainstream Environmental Stewardship.

Chapter 7: Conclusions and Lasting Thoughts......................252

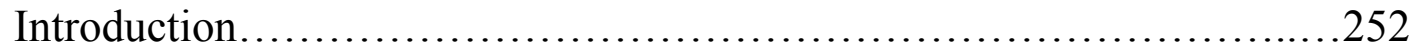

7.1 Learning to be Part of the Land: Directions for Scholars

Investigating Indigenous Environmental Thinking....................253

7.2 Rights- vs. Responsibility-Based Thinking: Implications for

Postcolonial Scholars...................................................256

7.3 Future Research Directions......................................258

7.3.1 Situating the Mayan Land Ethos within the Indigenous

(Responsibility-Based) Legal Literature.................................259

7.3.2 The Need for (Further) Comparative Studies on Different Indigenous IKs

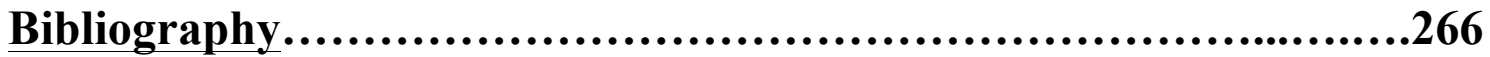

Appendices..............................................................287 


\section{List of Figures}

\section{Chapter 4}

Figure 4.1 Portrait of Michel Sioui (left) and two other Wendat chiefs in London (1825) .95

Figure 4.2 The author posing with his teenaged English students at the

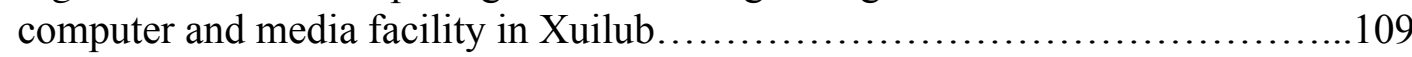

Figure 4.3 Map of the location of Xuilub in relation to the Yucatan..............114

Figure 4.4 Map of the boundaries of Xuilub and Xuilub's position in relation to Valladolid.

\section{Chapter 5}

Figure 5.1 The author standing with Mayan Elder and milpero on his milpa......150 Figure 5.2 The author standing with Xuilub's most highly esteemed men and curandero.

Figure 5.3 Elderly couple showing the author their solar.

Figure 5.4 Mother and her two daughters making tortillas by hand on the comal stove. 157

Figure 5.5 Looking down into the mouth of a cenote (and the freshwater at the bottom) in Xuilub... 161

Figure 5.6 The author being instructed on how to properly harvest a cassava root by a milpero.

Figure 5.7 Milpero in the process of harvesting some root vegetables on

his milpa or the evening's supper.

Figure 5.8 Family of apiculturists preparing the beehives to be moved to another apiary....

Figure 5.9 The author loading beehives onto the truck.

Figure 5.10 Honey merchant in Valladolid inspecting the quality of the honey 183

Figure 5.11 Cattle rancher greeting his cattle in the morning.

Figure 5.12 Cattle waiting for their enclosure to be opened in order to graze

Figure 5.13 The author and a cattle rancher getting ready to cut some grass to feed he cattle.

\section{Chapter 6}

Figure 6.1 Entrance of an ancient pyramid located in Xuilub...................221

Figure 6.2 Typical Mayan palapa................................................228

Figure 6.3 The author posing with an Elder (and great-grandmother).............230 


\section{List of Appendices}

Appendix A: Interview Questions...............................287

Appendix B: Written Consent Form...........................28

Appendix C: Oral Consent Form..............................290 


\section{Glossary of Frequently Used Words ${ }^{1234}$}

Alux: mythical dwarf being.

Cenote: sinkhole that is a source of potable (underground) water; a common feature in the Yucatan.

Cha-chac: Mayan god of rain.

Comisario: elected leader of the ejido.

Convivir: to co-exist.

Curandero: traditional Mayan healer with extensive knowledge about medicinal plants.

Ejido: an area of land used for communal agriculture; created after the agrarian land reforms in Mexico in 1910.

Hacienda: non-Indigenous land estate generally used for commercial ranching or agricultural production.

Men: shaman versed in magic, incantations; can be benevolent or malevolent.

Milpa: traditional Mayan system of rotational agriculture practiced in Mayan-occupied areas of Mesoamerica for millennia.

Milpero: man who works on the milpa.

Sachcab: sacred type of soil used for Mayan ceremonies.

Solar: Mayan home garden in which many varieties of vegetables and plants are grown, typically by women.

\footnotetext{
${ }^{1}$ For the purpose of clarity, in this dissertation Spanish words not commonly used in the English language (i.e. words that do not usually have an entry in an English-language dictionary) appear in bold font. Words commonly used in English, such as ejido, cenote, hacienda, and milpa, are not in bold. Words in the Mayan language are in italics.

${ }^{2}$ Throughout this document, I capitalize the word Indigenous, as I would any other cultural group or nationality. However, some authors who are quoted do not.

3 "Maya" will be used as a proper noun and in its adjectival form to describe the people and culturally related terms and concepts (e.g. Maya land ethos, Maya ceremony, etc.). "Mayan" will only be used to refer to the language of the Maya (e.g. the Mayan language, "the meaning of this term in Mayan," etc.). These usages of "Maya" and "Mayan" are the most accepted among scholars. Also, the plural of "Maya" does not change (e.g. two Maya men; three Maya).

${ }^{4}$ There is no universally accepted Yucatec Maya orthography. The words and terms that appear in Mayan in this text were translated and dictated to me in the Spanish alphabet by Demetrio, my local research partner.
} 


\section{Chapter 1: Introduction}

Today, a variety of political, social, and environmental factors are redefining many Indigenous groups' land-based sustenance practices and, more generally, livelihoods (Blaser, Feit \& McRae, 2004; Stocks, 2005; Yashar, 2005). Through these changes and new developments, however, scholars have found cultural continuity, and argue that Indigenous groups' involvement in more modern land-use activities should not be considered as a sign of cultural decline or the degeneration of so-called primeval and uncorrupted Indigenous cultures (Johnson et al., 2007; Moreton-Robinson, 2004). Their research reminds us that all human cultures and societies evolve through time, in response to changing conditions and contexts. We must therefore eschew regressive, romanticized conceptions of what constitutes "traditional" or "real" Indigenous cultures (De La Cadena and Starn, 2007). Numerous Indigenous groups have found creative ways to balance their economic needs with their culturally distinct land-based activities and livelihoods (Radcliffe, 2012; Wainwright, 2008). Keeping this in mind, through various political and socioeconomic changes, many of these Indigenous groups are maintaining certain core characteristics of their distinct land-use and management approaches (Johnson et al., 2007; Larsen and Johson, 2012).

Mexico's Yucatec Maya are one Indigenous group that is trying to adapt to present-day land-use change while maintaining a distinct cultural land ethos. To this day, many Yucatec Maya carry out cultural activities such as agriculture, apiculture, hunting and cattle ranching on their traditional lands in the Yucatan Peninsula (Anderson, 2005; 
Anderson and Medina-Tzuc, 2005). Their self-perceived position and role in relation to the environment-or 'land' - is informed by elements of Maya spirituality (ibid.; Gabbert, 2004). Spiritual teachings passed down through the generations have a significant influence on the ways in which the Yucatec Maya relate with the land and all its constituting elements and other-than-human beings ${ }^{1}$ (Anderson, 2005; Ankli, Stricher, \& Heinrich, 1999; Castellanos, 2010; Armstrong-Fumero, 2009 and many others).

The Yucatan Peninsula and its natural environment has been inhabited and managed by the Maya for centuries (Anderson, 2005). In the last decades, this region has been at the forefront of Mexico's tourism strategy and other development initiatives. My doctoral research project sought to document, interpret and elaborate a synthesis of the current state of the Yucatec Maya environmental ethos and land-use knowledges of an existing Maya community -in this case, Xuilub, Yucatan —and, with postcolonial, Indigenous geographies and Indigenous knowledges (IKs) concepts and theory, describe how they are understood by its members. The following research questions at once encapsulate the purpose of my doctoral thesis and guide my analysis: What are the spiritual/cultural motivations behind Maya individuals' personal relationships with the land? What is the Maya environmental ethos as manifested in Xuilub? How might it be influencing these Yucatec Maya individuals' present-day relationships with the land? Is

\footnotetext{
${ }^{1}$ I was not able to find a commonly used or accepted Maya term in the Xuilub community that reflects the notion of other-than-human beings (meaning animals, plants, spiritual beings, future/past generations, etc.). Therefore, I had to develop my own terminology based on what I felt was the most accurate representation of how the majority of the community would describe this concept. I use 'other-than-human' in this dissertation because I feel 'non-human' reflects the Western/colonial sentiment that humans are at the top of a hierarchy of beings, while 'more-thanhuman' (as used in Larsen and Johnson, 2017 and others) could be interpreted to mean the opposite by a non-initiated reader. I interpret 'other-than-human' as equal to (but not) human.
} 
this ethos consistent between different individuals in Xuilub? Are there discernible trends in their understanding of the Maya land ethos? In other words, I was interested in investigating the current state of a Yucatec Maya community's land-use knowledges and practices as part of a broader integrated, culturally informed environmental ethos. My research depended on in-depth semi-structured interviews with Yucatec Maya leaders, Elders and other community members, as well as experiential learning in their land-use and other community activities during my field research. Through a synthesis of my field data I found that the Yucatec Maya land ethos is informed by what I refer to as 'responsibility-based thinking'. I define responsibility-based thinking as an Indigenous cultural value that informs and mediates personal and collective conduct by instilling in an individual and, by extension, a community, a sense of duty or responsibility toward her/his human and other-than-human, including environmental, relations. My research findings indicate that a large number of present-day Yucatec Maya land-based and other cultural practices and social conventions are motivated by a responsibility-based outlook on interpersonal and environmental relationships. Their responsibility-based thinking informs their environmental ethos expressed and represented to me in Xuilub as learning to be "part of the land" (Chapter 6). Such focus on one's responsibilities to the land and all its human and other-than-human beings is at the core of the Maya way of thinking, land use patterns, and current social organization in Xuilub.

This research project contributes to broader postcolonial, Indigenous geographies, and IK research efforts that seek to better investigate the ways in which Indigenous groups of the Americas observe and practice distinct, spiritually influenced land management approaches, and how cultural practices and IKs continue to inform these 
groups' interactions with the land. In keeping with the objectives of postcolonial analysis and Indigenous geographies, this research aimes to give a voice to Indigenous peoplesin this case the Maya-and valorize their worldviews and knowledges, in an effort to challenge and renegotiate dominant ethnocentric policies that continue to marginalize these groups and their ways of knowing. I was keen on providing an in-depth analysisusing field data-of the ways in which different land-use practices (in particular milpa farming, apiculture, hunting, and cattle ranching) are part of the spiritually informed, integrated land-use strategy and vision of being part of the land. This approach allowed my analysis to use an Indigenous lens and look beyond romanticized and anachronistic Eurocentric depictions of how "traditional" Maya use their land. To my knowledge, this is the first study of its kind-representing the Maya environmental ethos within a responsibility-based paradigm and using an IK research approach to investigate Indigenous land-use activities as part of a broader culturally distinct environmental ethos - to be conducted in the Yucatan. In terms of practical applications, I believe that these insights could in the future: (1) help to provide a clearer understanding of presentday state of Yucatec Maya land-related knowledges and practices, which may be used to better elaborate and implement more sustainable and culturally respectful development and conservation initiatives; and (2) make contributions in the fields of postcolonial theory, Indigenous geographies, and IK research with regard to using more Indigenous perspectives in environmental research. This would also ensure that the practical and applicable value of IKs is better understood and valorized by the academe, and later more broadly by the general outside society, in an environmental planning context. 
In the following sections, I discuss some of my prior assumptions and positions vis-à-vis IK research prior to beginning this project, and give an outline of key themes that are present throughout my dissertation, and on which I elaborate in subsequent chapters. Next, I give a brief overview of the role of colonialism in reshaping IKs and provide the reader with a summary of the Yucatec Maya land-based knowledges and practices. Then, I highlight the contributions of postcolonial theory with regard to legitimizing and highlighting the importance (in the eyes of the academe) of the study of Indigenous (and other non-Western) knowledges and briefly discuss some of the key characteristics of IKs, as identified and articulated by Indigenous scholars. To conclude this chapter, I provide summaries of each remaining chapter to prepare the reader for the concepts and discussions that follow.

\subsection{The Researcher's Prior Assumptions and Positions}

Being from a family with a strong Indigenous academic/intellectual lineage, ever since I can remember I have known about the importance of responsibility in many Indigenous cultures around the world. From my early childhood days, my father (who is a retired Huron-Wendat academic historian) and I have had regular discussions about the role of Indigenous people as stewards of the Americas and of our responsibilities to the land, our peoples, and the rest of humanity (see 4.2 Positionality for more on my family and culture and its influence on my way of thinking). The notion that Indigenous peoples are not merely victims of colonialism, but have cultures and knowledge systems that contain underexplored and profoundly valuable ways of knowing, is something that has since birth been ingrained in my psyche. I was always taught that despite the atrocities and injustices that happened (and continue to happen) to us, we, Indigenous peoples, have 
a responsibility to share our cultural and spiritual wealth with the rest of humanity.

Throughout my life, I have been privileged to sit in on conversations between my father and hundreds of Indigenous scholars, Elders, and others who carry out their land-based traditions and practices, hailing from a multitude of different peoples from around the world. I was always able to discern a common way of thinking among all these people, whether they were Mohawk, Aymara, Dene, Navajo, Kogi, or anything in between. Therefore, prior to my academic journey (and this project with the Maya) I operated under the assumption that most (if not all) Indigenous cultures had a similarresponsibility-based - way of understanding and making sense of the world and in particular their relationships with the land.

I want to make it explicit that I am by no means the first scholar (Indigenous or otherwise) who has put forth the notion that Indigenous cultures are guided by a responsibility-based mindset and way of knowing ${ }^{2}$. In fact, my personal understanding of responsibility-based Indigenous thinking was only reinforced when, during my master's studies, I began to truly engage with the scholarly literature on IKs, written by both Indigenous and non-Indigenous authors. For example, although they use slightly different terms, authors like Deloria (1992), Cajete (2000), and Pierotti and Wildcat (2000) have been very influential in allowing me to better conceptualize the responsibility-based philosophy that is common to many Indigenous cultures. More recently, I have been exposed to a number of insightful and well-articulated accounts of the meaning of

\footnotetext{
${ }^{2}$ I am, however, unaware of other scholars who may have used the exact term that I present in this dissertation. I believe the term responsibility-based thinking is useful in helping scholars to understand and convey in their writings about what is, to me, the most essential characteristic of this complex cultural philosophy.
} 
responsibility in Indigenous cultures, and especially with regard to their relationships with the land. For instance, authors like McGregor, Bayha \& Simmons (2010) discuss their belief in the "responsibility to keep the land alive inherent in Indigenous research" (p. 103). In the context of water justice, McGregor (2013) also argues that long-term responsibility to the land and all creatures on it is a notion that is critical in Indigenous environmental thought:

In some respects, the waters we interact with in the present are the same waters our ancestors experienced, and the same ones that may be experienced by future generations, should we take care of the waters sufficiently to ensure their (and our) future viability. This understanding holds us, as the current generation, highly accountable, and obliges us to ensure that our grandchildren, great grandchildren, and so on, can engage with the waters as we have (p. 72).

The idea of intergenerational responsibility is one I share with McGregor (and other Indigenous thinkers). Contained in the above excerpt is the idea that it is the duty of the current generation to not only live by the example of past generations, but to provide a model for future generations. Although Indigenous cultures may evolve and change over time, we believe that it is our responsibility to at least carry on the essence of our responsibility-based thinking because we have a deep love for the land, and for all creatures who have, who currently do, and who will exist on it. McGregor refers to this notion as 'loving responsibility' (p. 73). This philosophical tradition provides an alternative (and thus a response) to modernity's problem of spatial alienation. Instead of fleeing from the dangers and challenges presented by the world, this philosophical tradition facilitates an understanding of the world that promotes and celebrates harmonious relations between the individual, his/her human society, and the land. The land is not viewed as something to be escaped from in the pursuit of a higher realm (such 
as Paradise or Heaven) - it is the highest realm, and learning to live on it and belong to it comes with a set of inexorable responsibilities (for humans and all other creatures). This consideration was inextricable from the decision-making process that was followed by my own people, the Huron-Wendat (Huron was the name given to us by the French; therefore, I henceforth use Wendat), before the imposition of non-Indigenous political systems on our homeland (known as "Wendake," located near present-day Georgian Bay in Ontario). Sioui elaborates on this notion:

Wendats, like many other North American [Indigenous cultures], not only saw humans as part of the animal world but also saw animals as being among the Godcreators. As with their government, in which all individuals were equal [including women, children, past and future generations] and represented, the Wendats had a council of animal-deities who decided and executed everything in the most purely democratic fashion (Sioui, 1999, p. 22).

On this idea of a community and society of all creatures, Mohawk biologist F. Henry

Lickers, offers us additional perspectives:

You can't ... take away the culture and take the animals and the environment out of it. The intrinsic value of the environment and the cultural beliefs of the Mohawk people are very, very much linked. And everything that the Mohawks do has to always look at this concept of responsibility. The non-Native society around us looks always to laws and rights, and they talk about fulfilling their rights or fulfilling their laws. Within the Mohawks, you'll hear always the talk that the responsibility is the most important thing for us - our responsibility to the world, our responsibility to the animals, our responsibilities to all of the things that surround us (Virtual Museum of Canada, 2012).

Such an understanding of Indigenous philosophies and IKs, from my cultural and family background and further reinforced in my academic research and reflection, has unquestionably influenced the kind of meanings and representations I expected to uncover during my research with the Yucatec Maya. Indeed, I was expecting to find evidence of some form of responsibility-based thinking in representations of land-use 
practices and other cultural activities in Xuilub. However, in my interview questions and interactions with the people of Xuilub, I was careful not to use the word "responsibility," (or related words like "duty"), in order to avoid influencing the way in which they expressed and represented the Mayan land ethos and IKs. Despite this, the vast majority of the people with whom I talked and worked on the land used this word and other similar concepts, as the reader will note throughout this dissertation. In fact, I was surprised at just how important the concept of responsibility is to the Maya of Xuilub, in terms of how often it was mentioned by people of all ages and occupations, both women and men. Though I believed there would be evidence of this concept as part of the Mayan land ethos, in actuality it turned out to be so central and important that I have since come to understand it as perhaps its defining principle (along with "being part of the land"). This discovery of the profound cultural significance of responsibility (to the land) in the present-day Maya culture is the reason why this is the main focus of my dissertation (and why it is included in its title).

Prior to my research in Xuilub, I had a good idea of the philosophical and abstract dimensions of responsibility and how it is understood in Indigenous cultures. What was missing in order to gain a more holistic understanding (i.e. philosophical/abstract and through lived experience and emotional connection) of responsibility-based thinking was to be able to witness how it is conceived and how it underpins all land-use practices (which are all spiritually informed) and day-to-day community life. Currently, there is also a paucity of empirical IK research that focuses on investigating responsibility-based thinking in present-day Indigenous groups and communities. Thus, this case study allowed me to make an empirical contribution to the IK research literature that has long 
been developing theoretical tools for understanding responsibility (on the land) as an important Indigenous cultural precept. The Yucatec Maya of Xuilub, who continue to depend on the land for survival and sustenance, were an ideal Indigenous community in which to empirically investigate my prior assumptions and understandings about Indigenous responsibility. This research helped me to further my own knowledge of Indigenous responsibility by leaps and bounds. Whereas prior to my work in Xuilub, responsibility was something abstract and philosophical, the people of the community showed me, through the ways in which they carry out their duties and relate with one another and with other creatures on their homeland, the "real-world" and lived meaning of this principle that I delineate in detail in Chapters 5 and 6. I see the examples and indepth discussions about what constitutes responsibility-based thinking and being part of the land (described in my research findings) as additional contributions to the evolution of the scholarly understandings and definitions of these important Indigenous principles. My representations could possibly be compared with the findings of other scholars who investigate Mayan IKs in other Maya regions and communities, and also different Indigenous cultures around the world. This newly gained (for me) and deeper understanding of responsibility have allowed me to articulate a detailed and a fully fleshed-out thesis about what it means to the Yucatec Maya. In sum, although there has been much discussion about the Indigenous notion of responsibility to the land, in my estimation, prior to this dissertation this term had not yet sufficiently been presented as a pillar of human-environment interactions and relationships in Indigenous cultures

Lastly, another notable assumption that I had prior to starting my research in the Yucatan was that the IKs-related information that I would acquire would be sufficiently 
accurate. I was aware that something is always lost in translation, in this case from Spanish to Mayan and Mayan to Spanish, during verbal interactions between the researcher and Indigenous people with whom s/he is doing the research. This is a reality of conducting research and engaging with Indigenous peoples when not being able to speak their language. I have no doubt that certain Maya concepts and words are impossible to translate into Spanish or English with complete accuracy. I elaborate on this point in Chapter 4.

\subsection{Colonialism and its Influence on Indigenous Peoples' (Land-Based) Knowledges in the Americas}

An increasing number of Indigenous groups across the world have begun to reclaim or reassert territorial sovereignty on their ancestral lands (Battiste, 2000). Many of these groups are at the same time contending with powerful government and corporate forces that are reshaping landscapes in ways that conflict with their own worldviews and land ethics (Curry, 2004; Mander and Tauli-Corpuz, 2006). Through the years conflict between Indigenous groups and governments has generally tended to revolve around issues relating to government and/or corporate interference on traditional Indigenous territories (Curry, 2004). Some scholars have observed that such contentions between Indigenous groups and governments over land use and management are the result of a clash between two competing worldviews, the place-specific and relational Indigenous approaches informed by IKs and the Western approaches to knowledge, which tend to be more reductionist (Kovach, 2010).

In the face of intensifying neoliberal economic pressures and constraints, many Latin American Indigenous groups and communities are responding by looking back to 
traditional land-use knowledges and practices in order to challenge oppressive land management regimes. Like most regions of the world outside of Western Europe, Latin America has a long and marked legacy of colonial power and influence that continues to direct the political, cultural, social and environmental trajectories of its twenty-three countries. Of the original European colonial powers that have colonized this continent, Spain has had a disproportionate influence. In fact, save for Brazil, Haiti and the small French islands of Saint Martin and Saint Barthélemy, all states that make up Latin America were once Spanish colonies, under the rule of the Spanish Crown. The original (Indigenous) inhabitants of what is now called Latin America have, through successive generations since their first encounters with the Spanish, generally had complicatedlargely conflictual - relations with the Crown as well as Spanish settlers and their descendants. The establishment of Spanish colonial governments rapidly overturned Indigenous peoples' traditional sociopolitical and territorial governance systems, which had for centuries been firmly in place. In the time that has since elapsed, colonial regimes have dramatically refashioned the Indigenous human-environment dynamic. The colonial order has often been met with varying forms of resistance by Indigenous people (Warren and Jackson, 2003). As can be discerned from a review of the literature, the bulk of the academic discussion surrounding Latin American Indigenous land use has to do with Indigenous resistance movements and struggles for territorial sovereignty and autonomy. On the other hand, I found comparatively limited sources which focus on understanding present-day Indigenous land-use practices and ethics as multifaceted, holistic systems combining spiritual beliefs and concrete land-use practices. 


\subsection{The Yucatec Maya Land-Based Culture and Identity}

Understanding the evolution of Yucatec Maya relationships with their traditional territory through time is crucial gaining a more complete picture of the conditions "on the ground" in Xuilub today. In the last few decades, Yucatan has been at the forefront of Mexico's tourism development initiatives. The region's tourism industry has increasingly depended (and capitalized) on the Western/"Northern" imaginary surrounding the Classic Maya civilization and its perceived mysticism. This was perhaps most recently evidenced by the (misguided) apocalyptic Maya Calendar craze in late 2012, an event that attracted thousands of international tourists to the area. Today, the tourism industry is the Yucatan's main economic pillar (Brown, 1999; 2013). Private and government interests have generally imposed tourism development projects and other Western land-use models, policies and regulations (most significantly monocultures like soy). Through their investments and official policies, both the state and federal governments have demonstrated that the tourism industry is a top priority in terms of land-use planning (Brown, 1999; 2013; Garcia-Frapolli et al., 2007). Yucatec Maya are in most cases afforded little or no political representation in regional land-use planning outside of their community-managed agricultural territories, or ejidos (Brown, 1999). The commercialization of the "Maya landscape" is thus reshaping and redefining the Maya people's relationships with the landscape and subsistence land-use practices (Brown, 2013).

Yucatec Maya land-based culture should not be romanticized and imagined as being frozen in time, nor is it useful to assume that all Maya subscribe to a single, cohesive set of beliefs and practices. As can be gathered from a scan of the literature, 
Yucatec Maya land-use patterns have been in constant evolution for as long as they have existed, and are continuing to adapt to new challenges and opportunities. Indeed, Indigenous peoples in Mexico and throughout the Americas have experienced over five centuries of land expropriation, the loss of access to natural resources and in many cases, barriers to use of their sacred sites (Kicza and Horn, 2016; Jackson, 1999; Gabbert, 2004). When the Spanish "conquered" the Yucatan, ancient Maya religious, political and social institutions were gradually replaced by colonial administration regimes (Patch, 1976). Over the centuries, the dispossession of the Yucatec Maya has included the takeover of sacred sites and other sites of religious significance (Evia Cervantes, 2002; Munro and Melo Zurita, 2011). A succession of both colonial and (later) republican governments have attempted to assert control over the Yucatan Peninsula (Antochiw, 1999; Patch, 1976). Traditional Maya sacred sites have thus been given new uses and meanings in mainstream Mexican society. While cenotes (sinkholes) and other physical features of the Yucatan landscape have for centuries - possibly even millennia - been considered sacred sites by the Maya, different non-Indigenous conceptualizations of the meaning and use of these sites have emerged and in many cases supplanted the traditional Maya worldview as the dominant social-environmental paradigm of the area (Antochiw, 1999; Brown, 2007). Indeed, different (some would say more utilitarian) understandings of place and human-environment relations have become entrenched in mainstream Yucatec and Mexican society (Brown, 2007; 2013; Munro and Melo Zurita, 2011). As a result, the use and meaning of Yucatec Maya places and landscape and its sacred sites have shifted in the collective psyche in response to a multitude of non-Maya religious, cultural and economic activities that have firmly taken root in the Mexican societal order 
over the course of the more than 500 years since the Spanish first set foot in the Yucatan. My field research has shed light on the ways in which Yucatec Maya communities and individuals continue to entertain spiritual and cultural relationships with the land. This current state of affairs in Yucatan is in line with what postcolonial scholars have been witnessing all over the Americas: Indigenous peoples are continuing to find ways to adapt and keep alive their cultural knowledges despite official state institutional and legal frameworks that aim to undermine and supplant traditional meanings and uses of the land (Battiste, 2000; Zimmerer, 2000; Sherman, 2008; Radcliffe, 2007). This notion has great relevance to the situation in Xuilub, where my research partners are very keen on preserving the culture that they love and value. In the next subsection, I provide a brief outline of the main contributions of these scholars and the influence of the postcolonial literature on my own research with the Maya.

\subsection{Postcolonial Theory and the Value of Non-Western Knowledges}

Postcolonial scholars have produced an abundant literature that addresses and critiques European colonialism's historical distortion of the Indigenous cultural presence in the Americas, a practice that effectively "justified" the colonial takeover of the continent (Battiste, 2000; Blunt and McEwan, 2003; Castree, 2004; De La Cadena and Starn, 2007; Johnson et al., 2007; Shaw, Herman, \& Dobbs, 2006; Tuhiwai Smith, 1999). Through the years, the primary effort of postcolonial theory has been to 'demonstrate how the production of Western knowledge is inseparable from the exercise of Western power and reassert the value of alternative experiences and ways of knowing' (McEwan, 2003, p. 350; also Said, 1978; Spivak, 1988). Postcolonialism has challenged and unpacked colonial Eurocentric approaches to knowledge, which rest on the idea that there 
exists a singular, monolithic approach and correct path toward 'progress' and 'development' (Clayton, 2003; Legg, 2007). The focus on economic utility attendant to such approaches continues to marginalize Indigenous cultural values and relationships with the land (Louis, 2007). Postcolonial scholars have demonstrated a keen interest in both deconstructing and critiquing Eurocentric (or Western) knowledges and revalorizing a diversity of non-dominant (local) histories, epistemologies and subjectivities that have remained shrouded by the colonial veil (Bhabha, 1994). Authors inspired by postcolonial theory have argued that their non-essentialist, or "grounded," analytical perspectives and research foci can assist non-Western (including Indigenous) peoples in setting out their own sociopolitical and territorial agendas (e.g. Howitt and Jackson, 1998; Larsen and Johnson, 2012).

Such theoretical openings allow Indigenous knowledges - in my research, specifically Maya knowledges - to be recognized and valued by the academe, on the same level as other cultural knowledges such as Western science. Thus, the concept of recognizing the value in other (Indigenous) knowledges, as a central concern of postcolonial scholarship, is central to my research on current land-based knowledges. Postcolonial scholarship has effectively legitimized the study of non-Western, namely Indigenous, knowledges in the academy. In the next subsection, I provide an outline of some key characteristics of IKs.

\subsection{Investigating Indigenous Knowledges (IKs)}

My aim is not to suggest that all Indigenous cultures of the Americas, along with their distinct environmental approaches, can be neatly organized under one label. Nevertheless, though the myriad American continental Indigenous cultures are 
prodigiously diverse in their spiritual beliefs and relationships with the natural environment, it can be argued that many of them are still rooted in a common ontological and epistemological standpoint, which Tewa scholar Gregory Cajete (2000) coins 'native science.' Native science, as described by Cajete, understands and represents the world in terms of relationships and networks between human and other-than-human beings as they play out in space (on the land). The emphasis in this philosophy is on responsibility and accountability to one's "relations" on the land. Several authors have noted that many, if not most, Indigenous cultures of the Americas to varying degrees share this understanding of land relations, one that is markedly different from the one that inspired and helped conceptualize colonial land-use regimes (for example: Berkes, 2008; Cajete, 2000; Deloria, 1992; Low and Lawrence-Zúñiga, 2003; Sioui, 1992).

Coulthard (2010) has written that most American Indigenous philosophies share the concept of 'land' as an ontological framework for understanding existence and interrelationships. Semantically, the concept of land is generally understood very differently between most Indigenous and European cultures. In the Déné language, for example, the definition of 'land' is not limited to the material, lifeless characteristics of space, but encompasses human and other-than-human beings, themselves understood through non-hierarchical, relational transactions (ibid.,p. 80). Most commonly in American Indigenous cultures, land is understood as the place, or the setting, in which networks of relations are in constant negotiation and interplay (Cajete, 2000; Louis, 2007; Sherman, 2008). These systems are thought to be self-intelligent and balance-seeking despite the perpetual disturbances that continually reconstitute them. Indigenous peoples who live by such beliefs and knowledges often generate critiques of dominant (but 
foreign) structures of spatial organization anchored in colonial discourses of progress and development (Deloria, 1992; Pierotti and Wildcat, 2001). To those groups and individuals, the meaning and representation of place fundamentally differs from colonial meanings of it as a container of information to be logically and hierarchically ordered and subdued for the benefit of human development. It is by engaging with these non-colonial and hybrid meanings of land (and land-as-place) that postcolonial and Indigenous geographies (including Indigenous and non-Indigenous thinkers) can collectively create variegated and fluid ontological spaces that will serve to further destabilize entrenched essentialized colonial representations of Indigenous peoples and their relationships with the land.

Indigenous peoples worldwide have a variety of traditional governance approaches that can potentially provide viable alternatives to narrower Western economic-centred visions of progress and development (Pierotti and Wildcat, 2000; Alfred and Contrassel, 2005). Today, many Indigenous groups continue to carry out their land-use practices according to their spiritually informed moral frameworks and IKs. In turn, these practices are quickly becoming strategically instrumental to their land-use struggles against powerful government and corporate forces operating simultaneously on the international, national, regional and local scales. The 'native science' common to many Indigenous cultures has been recognized by a number of authors as offering the world new philosophical windows from which to conceive more equitable environmental management approaches and strategies (Gadgil, Berkes \& Folke, 1993; Cajete, 2000; Shaw, Herman, \& Dobbs, 2006, 2006; G. E. Sioui, 1992; M. Sioui, 2014). There is growing recognition in geography and other fields that Indigenous philosophical 
traditions and environmental worldviews can possibly provide an alternative (and thus a response) to inequitable colonial territorial governance systems (Barker and Pickerill, 2012; Morgensen, 2011; Muir, Rose, \& Sullivan, 2010; Shaw, Herman, \& Dobbs, 2006; Wainwright and Bryan, 2009). Indeed, in my field research in the Maya ejido of Xuilub, a number of interviewees expressed a firm belief in the broader appeal and value of their land-based values. Also, from what I can gather from these discussions and my participation in various land use-related activities, such as milpa farming, apiculture and ceremonial visits to sacred sites, for the most part members of this Maya community share the place-based environmental worldview — or IKs - described in the above paragraphs. The world has much to learn from Indigenous environmental philosophies and knowledges and my research in Xuilub follows in the same postcolonial vein that seeks to demonstrate the value of learning from these different cultural perspectives and knowledges.

Now that I have contextualized my research project, I provide a chapter-bychapter overview of the remainder of this dissertation in the next subsection.

\subsection{Dissertation Overview}

\section{Chapter 2}

In chapter 2, I provide necessary background information to adequately contextualize my analysis. First, I discuss the impacts colonialism on Indigenous land use, as well as its influence on Western meanings about Indigenous rights. Next, I consider the history and trajectory of the Maya people and their culture, from first contact with the Spanish to the present. I then critically review past research on Maya land use to 
determine the current state and directions of this literature, as well as gaps in knowledge that my research has begun to address.

\section{Chapter 3}

I begin this chapter with a discussion on the postcolonial literature that addresses and critiques European colonialism's historical obfuscation of the Indigenous cultural presence in the Americas. I then discuss the work of Indigenous geographies scholars in continuing to unpack and critique colonial spatial organization discourses that have legitimized the territorial dispossession of Indigenous peoples. Next, I turn consider the Indigenous knowledges (IKs) literature and how Indigenous scholars have articulated their own understandings of IKs. As I point out, there is much value in critical postcolonial and Indigenous geographies research, and I expound how I borrowed some key ideas from each body of literature, and how I applied these ideas in my research. However, I also reflect on the ways in which my research with the Maya in Xuilub contributes to the evolution and advancement of those fields.

\section{Chapter 4}

The methodological approach used for my field research is presented in chapter 4 . My formal data collection methodology was predicated on a two-pronged approach: semi-structured interviews and experiential learning. In this chapter I discuss why I elected to use both Western academic and Indigenous methodologies in order to gather the type of data best suited to answer my research questions. Next, I delineate my approach to interviews and experiential learning in Maya land-use practices (namely milpa farming, apiculture, hunting, and cattle ranching), as well as taking part in the dayto-day activities of community members and community events. I also describe the "two- 
eyed seeing” (see Bartlett, Marshall \& Marshall, 2012) data analysis approach I used to synthesize and make sense of all my interview and experiential learning data and to determine how to analyze and present this information in this dissertation. Other considerations such as research contributions, ethics, and limitations are also included in this chapter.

\section{Chapter 5}

In this chapter, I weave interview and experiential learning data to demonstrate how responsibility-based thinking is present in the main land-use activities in Xuilub: milpa farming, apiculture, hunting, and cattle ranching. I also discuss the ways in which the community's present-day land-based culture and main land-use activities are informed and guided by ancient teachings, mythologies, and other culturally distinct beliefs, in addition to modern scientific knowledge in historically non-Maya practices like apiculture and cattle ranching. In each land-use activity practiced in Xuilub today, as I describe, no human or other-than-human being is considered to be outside of the web of relations that spiritually connects all these beings, each with its own responsibilities and duties to the land.

\section{Chapter 6}

In Chapter 6, I describe my understanding of the Maya responsibility to "be part of the land," as expressed to me in interviews and informal discussions with community members, and situate it in relation to the postcolonial, Indigenous geographies, and IK research literatures. I then demonstrate how spirituality, Maya culture, identity and social organization are also part of the Maya environmental ethos, and that land-use practices (described in Chapter 5) cannot be considered in isolation of them. I then explain how the 
Maya of today are able to see the land and all its beings as what I characterize as a "Great Circle of all Peoples," which includes human beings, animals, plants and other natural beings, as well as supernatural beings such as Maya gods and Catholic saints and past and future generations. In the latter part of the chapter, I argue that responsibility-based thinking and learning to be part of the land has the potential to be useful in advancing postcolonial, Indigenous geographies, and IK research discussions and debates on Indigenous environmental philosophies and geographies, as well as enhancing mainstream environmental thinking.

\section{Chapter 7}

In this chapter, I begin by reiterating key ideas behind my analysis of the Maya land ethic. I then offer some reflections on some directives that can be adopted by future scholars working with Indigenous groups and their IKs, and consider some implications of adopting a more responsibility-based approach to postcolonial and Indigenous geographies research. I conclude the chapter with a discussion about what I believe are some promising future research opportunities that stem from this project and my main findings. 


\section{Chapter 2: Colonialism and the Evolution of the Relationships Between the Yucatec Maya and their Land}

\section{Introduction}

In this chapter, I critically examine what previous scholars have written about Maya culture, IKs, and land-use practices as an ongoing discussion about scholarly understandings of Maya land use. I analyze what past researchers have focused on in terms of documenting land use, as well as the main approaches that have been taken by these researchers to increase our academic understanding about Maya land-related IKs. This background information and critical discussion is necessary to contextualize my research project on the Maya environmental ethos currently lived and practiced in Xuilub. I start with an overview of colonialism in Latin America, which has had profound impacts on Indigenous peoples and their land-use patterns and IKs through the centuries since first contact, followed by a discussion on the Western concept of rights and how they stem from these colonial legacies. Then, I provide a geographical profile of the Yucatan, to better understand the physical and climatic conditions in which the Maya environmental ethic and its attendant land-use practices have evolved, as well as a brief history of the Yucatec Maya from their first encounters with the Spanish to colonial times, post-independence Mexico, up to the present, which gives the reader an insight into the evolution of relationships between the Maya and settler governments on traditional Maya territories. 


\subsection{Colonialism and the Concept of Indigenous Rights and its Evolution}

The history of Indigenous struggles to preserve their distinct cultural knowledges and assert their autonomy on their traditional territories in the face of colonialism has shaped the current state of their relationships with their traditional territories and their land-use patterns (Blunt and McEwan, 2003; Alfred and Corntassel, 2005; Tuhiwai Smith, 1999; Yashar, 1999, etc.) Indigenous peoples throughout the Americas have experienced five centuries of territorial expropriation, the loss of access to natural resources and in many cases, barriers to the use of their sacred sites (Gabbert, 2004; Louis, 2007). Whether English, French, Spanish, Portuguese, or Dutch (and others), the colonial powers have dramatically impacted the livelihoods of the great majority of Indigenous people the world over. Indigenous peoples have almost invariably at some point in their post-contact histories been subjected, by different colonial powers, to racist or discriminatory policies and practices and undermining their territorial sovereignty. Like virtually all regions of the world, Latin America has a long legacy of colonial power and influence that continues to direct the political, cultural, social and environmental trajectories of its twenty-three countries (Yashar 1998; 2005). Colonial histories still influence present-day conflicts between Indigenous groups and governments has revolved around issues relating to land use and management on traditional Indigenous territories (Curry, 2004). Generally, the original (Indigenous) inhabitants of what is now called Latin America have, through successive generations since their first encounters with the Spanish, have had complicated—largely conflictual—relations with the Crown, subsequent republican governments, as well as Spanish settlers and their descendants (Warren and Jackson, 2003). Today, the processes of globalization and the liberalization 
of world markets continue to shift the values and governance strategies of governments around the world. In Latin America, in particular, extractive economies, industrial farming and monoculture crops, cattle ranching, and logging are all key factors that are redefining the ongoing dispossession of the Indigenous peoples and limiting them in the use of their ancestral territories (Yashar, 2005). Today, rights-based Indigenous resistance movements remain vibrant, and their contentions with states and corporate forces have repercussions extending beyond national borders onto the global stage (Yashar, 1998; 1999).

Until the arrival of Europeans to the shores of the American continent, the concept of "rights," in its Western democratic interpretation and meaning (which does not include other-than-human, including spiritual, beings) was foreign to Indigenous cultures. In contemporary Western societies, rights are seen as fundamental to civilization, progress, society, democracy, and culture. The Western notion of rights can be traced back to early Western societies such as the Ancient Greek, whose constitutions espoused the idea that certain designated segments of society (in this case, land-owning men) should be granted a number of privileges and protections as free citizens (Preus, 2005). The Western definition of rights and questions related to what kinds of rights should be granted to what classes of individuals or groups has evolved and changed ever since. Different Western societies through the ages have revisited and renegotiated the concept of rights and have adapted it to fit within their parameters (in most cases dictated by a monarch). For example, European monarchies had the notion of the monarch's Divine Right to Rule over the commoners (Wootton, 2003). It was not until the French Revolution (1789-1799) that monarchic systems began to die out around Europe. The 
French Revolution, which caused a dramatic shift toward (Western) democratic thinking, was informed by a (then-)new conception of rights in which the notion of liberty and equality among all men (women, of course, were not yet considered equals to men in Western societies) (Hunt, 1996) was considered paramount. The wholesale renegotiation of the concept of rights that took place during the shift from monarchic systems to the idea of republicanism demonstrates that Western interpretations of the concept of rights are transitory and subject to continual reinterpretation according to changing sociopolitical and economic conditions. Rights and rights-based societies and democracies are therefore subject to change according to the shifting priorities of the current group of human beings who hold power over others (i.e. politicians, private interests, etc.) (as documented by Hunt, 1996). What we, as a Western democratic society consider today to be absolute, immutable, and inalienable rights may very well be considered regressive, inequitable, foolish, or unjustified by the next generation of power holders - as the transition to Western democratic thinking outlined above exemplifies.

The Western concept of "Indigenous rights" has in recent decades grown in prominence, at least symbolically, in many political states around the world, namely in the Americas. This Western understanding of what kinds of rights should be granted to Indigenous peoples originated in Europe during the late Renaissance (Anaya, 2004). Upon reading colonial accounts of dealings with inhabitants of the New World, authors like Swiss philosopher Jean-Jacques Rousseau became conscious of the brutal treatment of Indigenous peoples in the name of acquiring land and resources for God and for the sovereign. Rousseau famously wrote texts praising the uncorrupted (but primitive) "Noble Savage." Rousseau's writings on the unjust treatment of Indigenous peoples 
(especially his Discourse on the Origin of Inequality, first published in 1755-see

Rousseau, 1999) present the Indigenous peoples as the hapless but morally upright victims of ruthless colonial powers that mercilessly sought to subjugate them. Rousseau and some of his contemporaries expressed their concern over the treatment of Indigenous peoples and the destruction of their societies at the hands of greedy European elites. These ideas resonated with other authors and thinkers of the time. Rousseau is thus credited with sparking the initial European consciousness of the plight of Indigenous peoples and, in turn, the socio-ethical foundation for discussions about their rights and the idea of redressing injustices done to them in the course of their colonial experience (Keal, 2003).

Although the notion of Indigenous rights has existed in the margins of Western thought for more than 200 years, until recently it had certainly not been on the political ordre du jour in Western political states. At present, Western rights and rights-based legal and institutional frameworks have become indispensable in protecting certain historically oppressed groups from other powerful (and in some cases predatory) groups. However, as postcolonial and Indigenous geographies scholars, we must not lose sight of another important reason why we do this research with Indigenous peoples and their IKs: to Indigenize our way of thinking and doing, because we believe doing so will yield lessons for our societies and could inspire us to live in a more equitable and respectful manner, especially in relation to the environment $—$ or the land, in Indigenous terms. I am not suggesting that we must do away with rights-based concepts, for, as mentioned above, they do in fact provide pathways to emancipation and to the correction of (neo)colonial injustices that continue to be the lot of Indigenous peoples throughout the 
world. However, I posit that as postcolonial and Indigenous geographies scholars, we must continue to broaden Western meanings and understandings of rights to further understand and include notions of responsibility and accountability to the land and to non-human creatures (e.g. animals, plants, spiritual beings, future/past generations) in our interactions with Her.

International environmental legal documents have already begun considering the Indigenous notion that the human and the environment are one, and that the exercise of rights is incomplete without exercise of responsibility. At present, the United Nations Declaration on the Rights of Indigenous Peoples (UNDRIP, 2007) has been signed by 145 states, including Canada and Mexico. Just a few decades ago, the UN would have more than likely been hard pressed to find more than a handful of signatory states. Similarly, the relatively new notion of the rights of the environment, which has in the last three decades been gaining political currency and clout in countries around the world like New Zealand, Bolivia, and Ecuador, would have no doubt been discarded as ludicrous one or two generations ago. I consider this evolution and broadening in terms of what Western states and societies consider as fundamental rights as a process of "Indigenization" of Western society. These relatively new rights-based documents like the UNDRIP are creating the legal and institutional grounds for Indigenous peoples to reassert their responsibility-based land stewardship agendas and strategies. As an example, let us consider Articles 5 and 11 of the UNDRIP:

\section{Article 5:}

Indigenous peoples have the right to maintain and strengthen their distinct political, legal, economic, social and cultural institutions, while retaining their right to participate fully, if they so choose, in the political, economic, social and cultural life of the State (p. 6). 
Article 11:

1. Indigenous peoples have the right to practise and revitalize their cultural traditions and customs. This includes the right to maintain, protect and develop the past, present and future manifestations of their cultures, such as archaeological and historical sites, artefacts, designs, ceremonies, technologies and visual and performing arts and literature.

2. States shall provide redress through effective mechanisms, which may include restitution, developed in conjunction with indigenous peoples, with respect to their cultural, intellectual, religious and spiritual property taken without their free, prior and informed consent or in violation of their laws, traditions and customs (UN General Assembly, 2007, p. 7).

Although the UNDRIP cannot be enforced at the national level of political states, the notion of the right for Indigenous peoples to practice their own cultural traditions (including IKs) on their territories allows for the exercise of Indigenous responsibilitybased relationships with the land. This is, to me, a recent promising development in recognizing the cultural importance of responsibility to the land in Indigenous cultures. In a similar fashion, the Universal Declaration on the Rights of Mother Earth, which was introduced at the World People's Conference on Climate Change and the Rights of Mother Earth in 2010 (Cochabamba, Boliva), includes language that speaks to a recognition that the human and the environment are one and that the land (and all creatures on it) has agency and that humans have responsibilities to it (Universal Declaration on the Rights of Mother Earth, 2010).

What is more, in recent decades various Indigenous groups have gained some form of territorial rights, autonomy and recognition by different nation-states. For example, in Panama there are several 'comarcas indígenas,' or administrative regions/territories managed by Indigenous groups. These Indigenous groups are politically independent and semi-autonomous. In Andean countries like Bolivia and 
Ecuador, there has also been a series of constitutional reforms to grant territorial autonomy to Indigenous groups (Gonzalez, 2015). Although not a recent development, in Mexico, the ejidal system of communal lands used for agriculture, explained in 2.3.2, has reinstated Indigenous groups like the Maya as stewards of the land on their ejidos. Thus, at present the question of the treatment of Indigenous peoples and the recognition of their territorial autonomy cannot be portrayed as invariably discriminatory or oppressive; there are some deviations from the norm like these and others. Moreover, if the current trend is maintained, it seems that the evolution of negotiations surrounding Indigenous rights and their implementation could soon provide even more opportunities for Indigenous groups to have their territorial autonomy officially recognize and protected. This would, in turn, afford these groups increasing opportunities to reassert their responsibility-based territorial governance approaches. Indeed, although these changes are welcome and necessary, these rights-based approaches and international legal documents are still in their infancy in terms of their understanding and articulation of Indigenous responsibilitybased thinking. Western political and legal institutions must continue to do away with a binary understanding of rights that tends to separate them from discussions about their corresponding duties and responsibilities. It is my hope that this dissertation will provide some useful insights for other postcolonial and Indigenous geographies scholars about how to refine, through a more Indigenous lens, responsibility-based approaches to relating with the land and more meaningfully affirm their value for the rest of humanity.

Though the main goal of my dissertation is to enhance our understanding of Indigenous responsibility-based ways of knowing, being, and doing — starting with the case study on the Mayan land ethos-I recognize the value of rights-based approaches as 
a way of protecting responsibility-based systems. To me, these two ways of thinking and acting can be complementary. I simply wish to point out to the reader that the focus in postcolonial and Indigenous geographies scholarship has thus far, in my opinion, been too heavy on the side of promoting rights-based agendas. With this research project, I aim to rebalance the current state of affairs in these disciplines.

\subsection{The Maya of the Yucatan Peninsula: Geographic and Historical Context}

The paragraphs that follow will begin by giving an overview of the geography and climate of the Yucatan and the history of the Yucatec Maya. Next, I provide a critical outline of previous observations and interpretations about Maya land-use patterns and practices (such as milpa farming, apiculture, hunting, and cattle ranching). Throughout this outline of previous research on the Yucatec Maya and their land-use patterns, I point out some current gaps in knowledge and how my addresses these. These discussions will serve to contextualize my research findings about the responsibility-based environmental ethos I observed in Xuilub, described at length in Chapter 5.

\subsubsection{The Geography and Climate of the Yucatan Peninsula}

Yucatec Maya spiritual beliefs, culture and land-based practices cannot be considered in isolation from the Yucatan Peninsula's geographical and climatic context, so a brief overview of the region's geography and climate is in order (Anderson, 2005). The Yucatan has rich biodiversity, and many plant and animal species are still managed by a large percentage of the Maya population. This is also a result of a warm, tropical climate with an abundance of rainfall (Dahlin, 1990). The Yucatan peninsula is located between the Gulf of Mexico (to the North) and the Caribbean Sea (to the South), covering an area of 
nearly $44,000 \mathrm{~km}^{2}$. Geopolitically, the Peninsula incorporates parts of the Mexican states of Yucatan, Quintana Roo, and parts of Campeche, in addition to northern Belize and part of Guatemala's El Petén Department. It is part of the greater Yucatan Platform, mostly composed of karst, limestone and soluble rocks (MacSwiney et al., 2007). In terms of its geohydrology, this area is not divided by drainage basins or rivers that flow to the Gulf of Mexico or the Caribbean Sea (Wilson, 1980). There is limited rainfall captured by the soil, so groundwater sources are especially important. The area's thousands of cenotes—or freshwater sinkholes - which are now world-famous tourist attractions, provide access into this system, which is the main source of drinking water in the Yucatan. For this reason, since ancient times cenotes have been of great cultural significance to the Yucatec Maya; they hold spiritual meanings and are frequently the sites of ceremonies and rituals (Evia Cervantes, 2002; Munro and Melo Zurita, 2011). Although there has been much investigation into ancient uses and meanings of cenotes by the Yucatec Maya, their presentday spiritual significance and role in ceremonies remains unclear.

The Yucatan Peninsula's vegetation is dominated by both short and tall dry tropical forests that are the home to thousands of species of plants and animals, a large number of which have for centuries been actively managed by the Yucatec Maya (Gomez-Pompa et al., 2003). From northwest to southeast, the Yucatan has a vegetation gradient that transitions from mangrove and dry deciduous shrub (on the northern coast on the Gulf of Mexico), semi-deciduous low-to-medium high forest (western interior, to moister mediumto-high broadleaf evergreen forest (nearer eastern coast on the Caribbean Sea) (Rico-Gray and Garcia-Franco, 1992). Land cover in the region has been greatly modified due to human use even prior to the arrival of the Spanish in the early $16^{\text {th }}$ century. Yucatan's forests have 
been greatly modified and cleared by agriculture and, more recently, cattle ranching. Much of the dry forest has been converted into secondary growth communities as a result of henequén plantations during Spanish colonial time, and from cattle grazing (GonzalezIturbe, Olmsted \& Tun-Dzul, 2002).

The region's climate is characterized as tropical (average yearly temperature of $25^{\circ} \mathrm{C}-27^{\circ} \mathrm{C}$ ) and humid year-round due to its proximity to the warm waters of the Caribbean Sea and the Gulf of Mexico (Curtis, Hodell \& Brenner, 1996). The annual average rainfall exceeds 100 centimetres, the majority of which occurs from May to August (the Yucatec Maya agricultural season). One climate scientist I interviewed in Valladolid told that the particularly marked changes in the local climate began about five years ago (before our interview in March 2016), and that the climate has been getting hotter and drier, with more unpredictable weather patterns. His testimony was congruent with my interview data relating to the impacts of climate change as they are manifested in Xuilub. For example, one milpero lamented, "dry seasons have been particularly dry and sometimes it rains when it's not supposed to rain. It's also getting hotter and drier earlier in the summer. As a result, harvests have been getting smaller." It is clear that as the effects and impacts of climate change in the Yucatan continue to become more severe, this factor will increasingly pose a challenge to the people of Xuilub in their milpa-based land-use patterns and activities. In my view, the question of how climate change is influencing and reshaping Maya land-use patterns and practices remains underexplored, even though it could potentially have a significant impact Yucatec Maya livelihoods. My research begins to look at how climate change is reshaping the relationships between the Maya and the land, but I believe that further research is needed. 


\subsubsection{The Historical Trajectory of the Yucatec Maya}

It is necessary to understand the general history of relations between the Maya and foreign colonial powers and subsequent republican governments in the Yucatan as this history in order to better contextualize and understand current Maya land-use patterns in Xuilub. The first Spanish explorers arrived in the Yucatan Peninsula in 1527. At that time, there were an estimated 300,000 Maya, belonging to a number of largely independent citystates (Gabbert, 2004, p. 9). At first the Spanish found little value in terms of natural resources as the Yucatan is for the most part devoid of precious metals like gold and silver. As a result, Spanish colonization in the Yucatan had "milder effects" on the Yucatec Maya than on the Aztec and other Indigenous groups located in more central areas of Mexico containing more sought-after resources (Stoner Chamberlain, 1966). While the conquest of the Aztec civilization lasted no more than two years, it took the Spanish nearly two centuries to formally conquer the Yucatec Maya (Clendinnen, 2003). The Maya system of independent city-states meant that Spanish conquistadors had to take over Maya polities on a one-by-one basis (Gabbert, 2004). The arrival of the Spanish to the Yucatan engendered a significant decrease in the Yucatec Maya population, which dropped from 300,000 before first contact to an estimated 70,000-140,000 Yucatec Maya in 1580. Diseases like smallpox, influenza, and measles are thought to have been the most significant factor in this massive population decrease (Stoner Chamberlain, 1966).

Because of the lack of precious metals in the area, the Spanish opted to implement an economy in the Yucatan centred on the establishment of haciendas, or private estates originated in land grants to conquistadors and other Spanish landowners and were reserved for agricultural production (Patch, 1976). Given its demand in other regions of the Spanish 
Empire, in the Yucatan sugarcane plantations came to be the staple of haciendas (Kirk, 1982). From the beginning of the seventeenth through the end of the eighteenth century, the hacienda economy of the Yucatan grew in response to the rapidly increasing populations of American Spanish colonies as a result of Spanish settlement and natural increase (Sosa, 1988). To meet the ever-growing demand for sugarcane, estate holders began to increase production and expanded their operations to bigger scales (Sosa, 1988; Gabbert, 2004). In the late-eighteenth century, the Yucatec Maya had found themselves dispossessed of their agricultural lands, which had all been claimed by Spanish estate holders. No longer able to carry out their subsistence practices, many Yucatec Maya farmers had no choice but to relocate to haciendas, where they became indentured plantation workers serving Spanish hacienda owners (Farriss, 1984). As hacienda workers, Yucatec Maya were forced to pay tributes to the landholders in addition to providing them with forced free labour. This rural economic development system carried on after Mexico gained its independence from Spain in 1821 (Patch, 1994).

After Mexico gained its independence, large-scale plantations had increasingly encroached on traditional Maya communal forests, which were frequently razed to create new pastures for cattle and new haciendas for the mass production of corn, sugar, cotton, and henequén (a cactus whose fiber is used to make rope) (Rivero, 1999). Maya farmers near Spanish settlements were pushed out of their traditionally managed forests and economically compelled to enter into a system of peonage as workers on these new, postindependence rural development enterprises (Faust and Bilsborrow, 2000) (n.b. Maya populations farther inland and away from the coast were generally under less direct control of the state in Spanish colonial times). Through the first half of the nineteenth century, the 
Yucatec Maya increasingly manifested their general discontent with the Mexican ruling order; this reached a boiling point in 1847 , the year that marked the start of the so-called Caste War (Rugeley, 1996; Reed, 2001). That year, with the help of the British in neighbouring Honduras, the Yucatec Maya organized an army that mounted an insurrection against the Mexican government, in the hope of creating an independent Maya state. Their objective was eventually realized with the foundation of the Chan Santa Cruz State, which was officially recognized by the British (Reed, 2001). Decades of fighting ensued, during which both sides claimed victories and experienced losses. In 1884, the Yucatec Maya signed a treaty with the Mexican government recognizing Mexican sovereignty over Chan Santa Cruz in exchange for Mexico's appointment of Maya leader Crescencio Poot as Governor of the state (Dumond, 1985). The changing political climate between Mexico and the United Kingdom eventually led the two countries to sign a treaty in 1893 recognizing the sovereignty of the Mexican government in the Yucatan. The Mexican army regained total military control of the area in 1901, thereby effectively ending the Caste War of the Yucatan.

The Mexican Revolution of 1910-1920, informed by the revolutionary dictates of "land and liberty," sparked the beginning of an agrarian land reform throughout Mexico, much to the benefit of the Yucatec Maya (Markiewicz, 1993). For instance, between 1915 and 1933 the Yucatan State government reallocated one fifth of privately owned farmland to (in most cases Indigenous) peasants (Gabbert, 2004). In 1934, Mexican President Lazaro Cardenas passed an agrarian code that redistributed additional privately owned land to peasant and Indigenous groups as plots reserved for communal agriculture known as ejidos (Benitez, 1985; Medin, 1997). To this day, many Yucatec Maya depend on the ejido system 
of rural land organization for their cultural and economic sustenance (Anderson and Medina Tzuc, 2005).

In the 1930s, the creation of Mexico's ejidal system, which redistributed privately owned agricultural land to peasant and Indigenous communities for communal use, helped marginalized groups like the Yucatec Maya to regain access to parts of their ancestral territories and have greater control over their management (Benitez, 1985). However, today the loss of lands, resources and sacred sites is occurring once again in part through recent changes in the Mexican constitution that allow for the privatization and sale of what were formally collectively managed ejidos (Smith et al., 2009). In other recent cases, Indigenous groups including the Yucatec Maya have been prevented from visiting or using sacred sites for cultural purposes. A large number of culturally significant sites - particularly cenoteshave become private property under individual or joint ownership frequently commercialized as "adventure tourism" areas (Evia Cervantes, 2002). Though this affects a number of Yucatec Maya communities in the Yucatan, Xuilub's cenotes have thus far not been sold to or commercialized by outside interests. Other cenotes that are under municipal jurisdiction have been adapted into public recreation centres and swimming areas.

Since the Mexican Revolution, Yucatec Maya communities (including Xuilub) are for the majority legally recognized ejidal communities with a comisario (leader), secretary and treasurer. Public officials serve for three-year periods and cannot be reelected once their term expires (Gomez-Hernandez, 2005). Ejidal communities fall under the federal jurisdiction and ejidal politicians are accountable to the federal and state governments and report to local government offices in cities like Mérida and Valladolid. The mandated duties of ejidal comisarios are of local, immediate nature and include 
representation of the village at the state or national levels, granting resource use permits to individuals and acting as mediators in local conflicts over resources. Until recently, ejido lands could not be sold, divided or alienated in any way. However, in 1993 the Mexican government passed Article 27 of the Mexican Constitution that provides "ejido grants" to their users, to "maintain, divide or sell [ejidos] as they [see] fit" (Anderson, 2005, p. 45). For the most part, Yucatec Maya ejido residents (including those in Xuilub) resisted the temptation to sell their communal lands to outside private interests or breakup their land into privatized parcels. Only one quarter of Yucatan State's ejidos have been "parcelled out," compared to one third of the rest of Mexico's ejido lands (Anderson, 2005, p. 45). So far, to my knowledge (based on interview data), there has been no sale of ejidal land to private interests in this community (n.b. individual ejidatarios wishing to sell their parcels must first go through a formal legal process to gain 'dominio pleno,' or full ownership of their piece of land).

It is surprising to me that there has not been much, if any, research about the significance or role of the ejido in maintaining the Maya land ethos and social order in communities like Xuilub. I was interested in determining if the ejido has a bearing on how this land ethos is maintained, and if it is useful for elected officials and community leaders in enforcing the social order. Specifically, I wanted to initiate discussions related to the following questions: How are individuals who contravene this Maya social order and environmental ethos on ejidal lands dealt with? What methods are used to maintain or enforce this social order? More broadly, it is still unclear how the ejido system interacts or meshes with the Maya environmental ethos and today, and how Maya people, 
as a culture, undertand ejidos (e.g. do they view this non-Maya territorial unit as 'home' or as a Maya cultural 'place'?).

\subsubsection{Demographic Profile of the Yucatec Maya}

The demographic snapshot that follows helps to give the reader some necessary information about the Maya presence in Yucatan, and the influence that the Maya culture and people still exert in the region. In 2010, there were approximately 537,000 native Maya speakers in Yucatan, 178,000 in Quintana Roo, and 72,000 in Campeche, representing roughly $30 \%, 16 \%$, and $12 \%$ of those states' total population, respectively (INEGI, 2010). Although a large number of Yucatec Maya have adopted the "mainstream" way of life and have jobs in cities, a significant segment of the population have continued to live according to certain distinctly Maya spiritual and cultural values, or land ethics (Anderson, 2005, Anderson and Medina Tzuc, 2005; Martinez-Balleste, Martorell, \& Caballero, 2008; Sweetwood et al., 2009; Toledo et al., 2003). It is clear that the Maya population is young and, thus, in terms of sheer numbers, the Maya population and presence is quite strong. As observed by the scholars just named and others, at present, many young Maya are leaving their communities and migrating to cities in order to pursue post-secondary education or professional training, as well as to seek employment. Although researchers have observed a definite trend in terms of Maya youths leaving their communities, attitudes about the teachings of their Elders and about the relevance/importance of maintaining Maya IKs and their distinct way of life have not been given sufficient academic attention. Now that the historical and demographic context has been laid out, in the remainder of this subsection I conduct a critical review on past research regarding Maya land-use patterns and IKs, which are the central focus of this dissertation and of my field research in Xuilub. 


\subsubsection{Past Understandings of the Relationships between the Yucatec Maya and their Traditional Territory}

Like all Indigenous peoples in Mexico and throughout the Americas, the Yucatec Maya have experienced five centuries of land expropriation, the loss of access to natural resources and in many cases, barriers to use of their sacred sites (Kicza and Horn, 2012; Howard Jackson, 1999; Gabbert, 2004). When the Spanish "conquered" the Yucatan, ancient Maya religious, political and social institutions were gradually replaced by colonial administration regimes (Patch, 1976). Over the centuries, the dispossession of the Yucatec Maya has included the takeover of sacred sites and other sites of religious significance (Evia Cervantes, 2002; Munro and Melo Zurita, 2011). A succession of colonial and republican governments have attempted to assert control over the Yucatan Peninsula and all its land and water resources, of which cenotes are especially important as they the region's main sources of drinking water (Antochiw, 1999; MacSwiney, 2007). Traditional Maya sacred sites have thus been given new uses and meanings in mainstream Mexican society. While cenotes and other physical features of the Yucatan landscape have for centuries-possibly even millennia - been considered sacred sites by the Maya, since the Spanish conquest, different conceptualizations of the meaning and use of these sites have emerged and in many cases supplanted the traditional Maya worldview as the dominant socialenvironmental paradigm of the area (Antochiw, 1999; Brown, 2007). Indeed, today neoliberal economic principles are having a significant influence on rural development policies in Yucatan, where tourism development and large-scale monoculture crops are increasingly replacing traditional Maya land-use activities (Brown, 2007; 2013; Munro and Melo Zurita, 2011). As a result, as reported by Mayanist scholars, the use and meaning of 
the traditional Maya landscape and its sacred sites have shifted in the collective psyche in response to a multitude of non-Maya religious, cultural and economic activities that have firmly taken root in the Mexican societal order over the course of 500 years since the Spanish first set out to colonize Yucatan. However, what has been absent in the literature are discussions about how the Maya 'sense of place' is articulated and represented today, as well as how non-Maya knowledges are used and incorporated into the broader Maya environmental ethos.

Communal agricultural land distribution programs are absent in many Latin American countries, making it difficult for Indigenous groups to carry out their traditional agricultural knowledges and practices. In Mexico, however, Indigenous groups benefit from the federal system of ejidos, or areas of communal land designated for agriculture (Smith et al., 2009). This gives groups like the Yucatec Maya relative freedom to assert their traditional land use practices and ensure their transmission to younger generations within ejidos. Prior to conducting my research in Xuilub, it was unclear to what extent ejidos are compatible with Maya land-use models and what kind of meanings they have with regard to sense of place, and if they are consciously used to reinforce traditions and social order in Xuilub. I was also curious to ascertain whether ejidos are seen as a meaningful territorial unit and if they are considered a microcosm of the greater Maya homeland, the Yucatan.

\subsubsection{Past Research on Maya Spirituality and Land-Based Culture}

Since early colonial times, the influence of the Catholic Church has pervaded the Yucatec Maya ways of life, and it remains an integral part of many Maya communities (Watanabe, 1990). Despite centuries of colonization, however, a large number of Yucatec 
Maya retain many distinct spiritual and ecological values and teachings that have some influence on communities' sociopolitical organization and individuals' land use practices (Barrera-Bassols and Toledo, 2005; Brown, 2007). What is currently known is that the Yucatec Maya manage about one thousand plant species and one hundred animal ones for food and fiber as well as spiritual and aesthetic purposes (Remmers and de Koeijer, 1992; Ramirez Barajas et al., 2001), and their management generally follows rules approved in ejidal public meetings. "Rules for forest, game, and milpa management are made in these assemblies, and then enforced or unenforced according to how much public sentiment is voiced" (Anderson, 2005, p. 115). Mayanist authors have written that the cultural use of this large number of plant and animal species rests on an intimate knowledge of the "management needs" of each species (Barrera-Bassols and Toledo, 2005; Gomez-Pompa et al., 2003; Diemont et al., 2011). Others have observed that Yucatec Maya landscape users and knowledge holders employ a multiple-use approach, in which individual species have more than one use. For example, a certain plant species can at once be managed for medicinal use (processing its leaves) and aesthetic properties (using its flowers for decorative purposes) (Toledo et al., 2003; Garcia-Frapolli et al., 2007). Thus, adherents of the multiple-use management approach have many incentives to look after resources with conservation and long-term sustainability as a principal motivator. Anderson (2005) has observed that the Yucatec Maya "love the flowers, birds, and wildlife of the forest" ( $p$. 120). There has been much written and discussed about Maya emotional connection to animals and plants, but I was not able to understand the deeper spiritual and cultural meaning and motivation behind this "connection" that has been documented. I was interested in finding out more about the spiritual motivation for this "love" for animals and 
plants as part of the larger Maya environmental ethos (i.e. how are animals and plants understood as part of the Maya land? Are they seen as part of Maya society and social structures and relationships with the land?).

In addition to spiritual and emotional dimensions of Maya land use, several studies suggest that Yucatec Maya resource users and managers are also acutely pragmatic in their land management objectives and practices (for example, Anderson, 2005; Brown, 2007; Martinez-Balleste et al., 2008 and many others). Another important consideration that has received little attention relates to the importance of the Maya landscape sense of place with regard to maintaining a Maya land-use system. In particular, it is unclear whether structures like pyramids built by the Ancient Maya, which are part of the Maya cultural landscape in the Yucatan (and in Xuilub), continue to have an influence on individuals' conceptions and meanings about the land. Also, I believe that the role (if any) of pyramids and other ancient structures in reinforcing the Maya social order and traditions merits further investigation. As a geographer, such considerations about the role of the landscape in shaping and influencing human beings' relationships with the land is of great interest to me, which is why such questions are addressed in Chapters 5 and 6, in which I present my research findings.

\subsection{Milpa Farming, Apiculture, Hunting, and Cattle Ranching: The Main Current Maya Land-Use Practices in the Yucatan}

In my review of the extant literature surrounding Maya land-use patterns and practices, I noticed that there has been little to no effort to understand these different land uses as part of an integrated environmental ethos. I have my own thoughts and speculations regarding this lacuna. I believe that this gap in our understanding is due to the vast majority of Mayanist 
scholars being non-Indigenous, and approaching academic investigations about Maya land use from Western-centric reductionist paradigms that tend to isolate different components or parts of a system from one another, in order to study these individually. Perspectives from Indigenous scholars about these topics have definitely been lacking. I believe that my own understanding of and insights on Maya land use as an Indigenous geographer from the "north," even though I am non Maya, allow me to put forth perspectives, angles and thoughts that are somewhat different but also complementary to past and current Mayanist research. Moreover, my approach of trying to understand Maya land-use patterns and activities as part of a broader spiritually informed cultural environmental ethos could prove useful to other (Indigenous and non-Indigenous scholars) in applying a more IK-focused approach and research questions when investigating these themes. That being said, it is certainly not my intention to "speak for the Maya," nor do I claim to completely understand or provide a perfect representation of Maya conceptions and understandings of their relationships with the land. Future research will benefit tremendously from accounts of Maya geographers and other scholars who are concerned with land-related questions and issues. To date, there has been a marked paucity in terms of research on these themes carried out by the Maya themselves. These insider perspectives are perhaps the most critical element that is lacking in the past and current research on Maya land use. However, I hope that my effort can initiate a broader movement that will eventually result in more Indigenous, and particularly Maya, authors investigating the Maya environmental ethos and its potential to enhance mainstream environmental thinking and policy. 
I following paragraphs I provide a critical overview of past research about the four main current Maya land-use practices in the Yucatan: milpa farming, apiculture, hunting, and cattle ranching. This review of past knowledge about these activities, as well as explanations of why my research in Xuilub fills some gaps that exist in the current literature, allows me to more fully flesh out my rationale (and convey to the reader the need) for carrying out this research.

\subsubsection{The Milpa}

Archaeological evidence indicates that agriculture in the Yucatan Peninsula has been practiced for at least 5000 years (Anderson, 2005). The milpa is the traditional Maya system of rotational agriculture, in which lands are cropped for a few seasons and abandoned for new clearings to ensure long-term soil regeneration and overall ecosystem vitality. Anderson considers that agriculture (and the milpa), to the Maya, is "not just a source of the staple food; it is a religious act and a moral duty" (ibid., p. 44). More recently, Shaw (2008) wrote that many Yucatec Maya still observe a number of agricultural rituals and ceremonies throughout the year. The Maya agricultural cycle in the Yucatan begins between April and May, depending on weather conditions, when religious offerings are made in the milpas before clearing the fields of brush and debris. As the crops begin to sprout in late July to August, offerings of corn and beans are made to the earth. The cycle concludes during the harvest in September, when thanks are given to the crops (de Frece and Pool, 2008). Present-day Yucatec Maya ejidal communities are still organized according to the milpa lifestyle, and agriculture remains central to community life in Xuilub, as well as social organization. As in the past, the crops most commonly grown in the milpa are corn, beans and squash. In addition to the main milpa crops, Rico-Gray et al. (1990) found documented 
other important plant and vegetable species such as tomatoes and chilies that were grown in small family gardens looked after by women. de la Cerda and Mukul (2008) more recently observed that some Maya look after more than dozens of species of vegetables and plants in their home gardens. There has been much research about the plant species that are grown in these home gardens in terms of their economic value to Maya households (e.g. de la Cerda and Mukul, 2008; Neulinger and Alayon-Gamboa, 2013), but little is currently known about how women see their work in their home gardens (solar) in terms of a spiritual or moral duty or responsibility, and whether their work and gender roles are considered with the same degree of respect, by both genders, as the milpa farming of the men. Small-scale cattle ranching, a non-traditional activity, is also practiced by some families in the community, indicating that Maya culture and land practices are not immutable; in fact, Maya farmers frequently incorporate these and other non-Indigenous agricultural practices into their land management strategies (as observed by Diemont et al., 2011). The addition, in recent decades, of "non-Maya" land-use activities like commercial apiculture and cattle ranching into community land-use practices suggests that the Yucatec Maya land ethos, as well as how it is currently understood and practiced by community members, is evolving. This evolution has yet to be documented and interpreted in a meaningful way in scholarly investigations. More generally, little (if any) research exists in terms of documenting how milpa farming, apiculture, hunting, and cattle ranching are understood and interpreted by present-day land-base Maya individuals themselves, who are increasingly introducing mainstream land use practices while maintaining certain core elements of the Maya environmental ethos. This 'systemic' and holistic (rather than reductionist) way of 
conceptualizing these Maya IKs could provide new perspectives and knowledge for the Mayanist body of research.

What is more, there are a number of other important questions related to the evolution of Maya land-use patterns and activities that have remained un(der)explored: Why do some young people leave the ejido while others stay? What are current attitudes of young people toward the traditional milpa culture? How do the Maya characterize their relationships with the land today? What are some distinguishing characteristics of this Maya environmental ethos? What are the current attitudes about gender roles in Maya culture? How are women understood to contribute to contribute to the Maya environmental ethos? Because these questions are not the focus of my dissertation, I am only able to report and offer some preliminary findings to other interested scholars in the hope that future research addressing these questions will be considered important.

\subsubsection{Apiculture}

Apiculture is also an important current land-based practice in Xuilub and across Yucatan and Quintana Roo. It is one of the main economic sustenance activities in Xuilub. A large number of families in the community own bees and produce honey. Many Apiculturists believe in spiritual rules or commandments set out by the Maya Bee God $A h$ Muzen-Cab (Anderson, 2005, p. 51). Apiculture has been practiced by the Maya since preColumbian times (Quezada-Euán, de Jesús May-Itzá, \& González-Acereto, 2001). Beekeeping remains a common Yucatec Maya practice, and it often helps families prosper due to its profitability and marketability. Previous studies like Echazarreta et al. (1997) and Villanueva, Roubik \& Colli-Ucán (2005) have focused on themes related to apiculture and its influence on biodiversity, and the economic dimensions of apiculture. Although a source 
of income, apiculture carries elements of a distinct Indigenous environmental worldview that is observable in concrete land use practices. However, Maya beekepers are also very keen on learning and incorporating cutting-edge scientific practices in beekeeping, such as using certain industrially manufactured vitamins and nutrients to keep the bees healthy. In Maya apiculture, there is no reticence to use Indigenous traditions as well as Western scientific knowledge to make sure the best possible methods are being employed. However, there is paucity with regard to investigations on Maya apiculture related to understanding the current spiritual meanings and dimensions of this practice as part of a broader Maya environmental ethos. In my view, a very important and insightful element of Maya apiculture, which distinguishes it from its Western practice, has been understudied: Maya syncretism. To date, scholarship on Maya syncretism has almost exclusively focused on the blending of ancient Maya and Catholic religious/spiritual beliefs, ceremonies, and practices. However, the concept of the Maya blending IKs and Western knowledges has not been to any meaningful extent been extended to studies about Maya land use. As a result, there has been very little focus on identifying the characteristics that make the Maya practice of apiculture different from its mainstream form. In my opinion, Mayanist scholars have not sufficiently investigated the spiritual meanings that are attributed to the practice of apiculture, as well as to the honeybees, that inform the way in which it is carried out in Maya communities. To me, through the merging of Western and Maya customs and knowledges (e.g. Western scientific knowledge about the honeybee's feeding patterns and the ancient Maya belief about the need to pray and to show respect to the Lord of the Bees), apiculture represents a merger of two different knowledge systems and approaches (Western and Maya) and their synthesis into one coherent land-use practice that is reflective 
of a broader Maya environmental ethos. My research sought to increase the academic understanding of how this syncretic approach is currently manifested in apiculture in Xuilub, as well as how this practice, along with milpa farming, hunting, and cattle ranching, is spiritually informed and is part of the Maya environmental ethos.

\subsubsection{Hunting}

Hunting (particularly deer and peccary) remains an important subsistence activity in Maya territories in Yucatan State (Léon and Montiel, 2008; Anderson and Medina Tzuc, 2005; Rodriguez et al., 2012). In Xuilub, hunting wild animals provides food and a variety of other goods for a large number of households (as found to be the case in different ejidos around the Yucatan by Léon and Montiel, 2008; Anderson and Medina Tzuc, 2005; Rodriguez et al., 2012). Hunters have been noted to hunt only what is necessary for their own household, and wild game meat usually serves to supplement to the milpa-based foods

like corn, beans, cassava, and squash. Anderson and Medina Tzuc (2005) identified some of the main Yucatec Maya hunting rules which they observed at the time: (1) Do not kill an animal unless you have good reason; (2) Do not take more food than you and your immediate family need; (3) Do not take many animals at one time; (4) Do not kill more than a small number of animals within a year; (5) Try to minimize the killing of animals in reproductive condition; (6) Do not leave a wounded animal to go off and die (p. 72). A number of decades ago, Barrera Vasquez (1970) found that many Maya hunters in the Yucatan feared that failure to abide by these sacred tenets would anger the yuntsiloob (Lords of the Forest), believed to enforce hunting rules. Maya hunters kill animals primarily to feed their households, but sometimes sell (or trade) surplus meat to their neighbours and in local markets in order to supplement their income from agriculture. Emery and Brown 
(2012) have written that the Maya hunting tradition follows precepts of Yucatec Maya spirituality and land-based knowledges instructing that animals and plants do not belong to human beings but to the yuntsiloob, who must be petitioned to grant hunters permission to kill the game animals. There is a strict limit on the number of game animals that can be killed in one year. Evia (2006) has observed that many of the older Maya hunters (and some of the younger ones) believe that killing more prey than is allowed will result in the Lord of the deer punishing the perpetrator with diseases. Thus, previous research on Yucatec Maya hunting has investigated some of the spiritual dimensions, and how these have had an influence on the establishment of Maya hunting "rules." What is less clear from this literature, however, is how Maya hunters perceive wild (game) animals: What is their perceived role within the Maya land ethos? How do Maya hunters currently understand their relationships with game animals? What do these hunters believe are their responsibility(ies) toward these animals? What do they believe are the responsibilities of game animals and their Lords toward human beings? My research with the Maya hunters of Xuilub yields some initial data on these questions, which I believe are useful in broadening the academic understanding of the practice of Maya hunting as an activity influenced and informed by a distinct non-hierarchical cultural environmental ethos according to which both humans and other-than-human beings (including animals) are understood as sentient and intelligent beings with agency.

\subsubsection{Cattle Ranching}

Cattle ranching in the Yucatan began soon after the establishment of large haciendas near Merida (Yucatan's capital city today) by the Spanish at the start of the seventeenth century (Farriss, 1984). Because of the lack of precious metals in the area, 
the Spanish opted to implement an economy in the Yucatan centred on the establishment of haciendas, or private estates originated in land grants to conquistadors and other Spanish landowners and were reserved for agricultural production and cattle ranching (Patch, 1976; Gabbert, 2000). From the beginning of the seventeenth through the end of the eighteenth century, the hacienda economy of the Yucatan grew in response to the rapidly increasing populations of New Spain colonies as a result of Spanish immigration and natural increase (Sosa, 1988; Meyers and Carlson, 2002). Small-scale cattle ranching in Yucatan has been practiced since the 1970s as a way to supplement milpa-related income. In past and more contemporary research, cattle ranching has been understood and represented only as a Western land-use activity that has been adopted by some Yucatec Maya communities as a source of income. Perhaps because this is the newest land-use activity in Yucatan's Maya communities, there are several important questions that have not yet been addressed in the previous research. I could not find any studies on the way in which Maya ranchers view their cattle and other domestic animals. Also, to my knowledge there have been no investigations into what elements (if any) make Maya cattle ranching distinct from non-Maya forms and operations. In my research with Xuilub's cattle ranchers, I was guided by the following questions: Do Maya cattle ranchers have any spiritual meanings associated to this practice and/or to the cattle? What is the current spiritual meaning and significance of cattle ranching in the context of the Maya environmental ethos? How do ranchers understand their relationships with their cattle? Do they have the same respect for the cattle as they do for wild animals? Do they "love" or have an emotional connection to their cattle? (How) have the Maya adapted this Western land-use activity into a "Maya" one?. As for all other Maya land-use practices 
mentioned heretofore, my intention and rationale for attempting to answer such questions was to investigate cattle ranching as it is currently practiced in a Maya ejido as an activity that is part of an integrated and spiritually informed Maya environmental ethos and landuse system. I believe this effort could assist other scholars in approaching the study of Maya environmental philosophies and knowledges from a less reductionist framework in which individual land-use activities are analyzed in a stand-alone fashion. Indigenous thinking and IKs, as discussed in detail in Chapter 3, should be approached from a more holistic and relational perspective, through which the world is understood in terms of relationships between different beings and activities on the land. In the next section, I provide an overview of the geography, history and current demographic outlook of Xuilub, which equips the reader with necessary background information about the community before sharing my understanding of the Maya environmental ethos in Chapters 5 and 6.

\subsubsection{The Main Present-Day Outside Influences on the Yucatec Maya Land Ethic and Land-Use Practices: A Look at the Tourism Industry}

Through their investments and official policies, in terms of land-use planning both the state and federal governments have demonstrated that the tourism industry is a top priority in Yucatan (Brown, 1999; 2013; Garcia-Frapolli et al., 2007). In 1992, the Mexican, Salvadorian, Guatemalan and Belizean governments signed an agreement to stimulate tourism growth in the Zona Maya ("Maya zone”), or historically Maya-occupied territories shared by those countries (Brown, 1999). In the years following the signing of this agreement, tourism infrastructures in Yucatan State have expanded at a rapid rate in order to accommodate the large influx of western — largely North American — tourists. This large- 
scale project by federal and state planners has involved the widespread commercialization of traditional Maya lands and sites of cultural and spiritual significance. Brown (1999) has investigated the ways in which traditional Yucatec Maya landscapes are being reshaped and commodified to cater to Western tourists. The author finds that the Yucatec Maya are afforded little or no political representation in tourism planning, while multinational tourism corporations continue to build resorts and hotels and charge admission to sacred and historically significant Maya cultural sites and places. Brown concludes that the tourism industry, backed by the federal and state governments, is removing the Yucatec Maya to create an illusory, anachronistic Maya world devoid of actual Maya people. This less obvious form of dispossession, argues the author, no less results in the growing inability of the Maya to carry out their land-based subsistence activities including agriculture and hunting. A study by Juarez (2002) notes that a very similar process, through which the Maya are left out of the planning and decision-making process on their lands, is equally prevalent in the neighbouring state of Quintana Roo. To summarize the role of the tourism industry in reshaping Yucatec Maya societal structures, I refer to the following passage by Brown: “[..] [T] he [Yucatec] Maya social, cultural, and political structures have been debilitated by the loss of its young men to the tourist area for work, including loss of Mayan language, dress, consumption habits, religious beliefs, customs and oral histories" (2013, p. 17; Torres and Momsen, 2005, p. 274, quoted in Brown, 2013). Such past and more current research has clearly demonstrated that the tourism industry is reshaping Maya socio-political structures. There are a number of studies, such as the ones mentioned above, which examine how the tourism industry has been exploiting Maya culture, and how this has had an impact on Maya communities' social and political structures, but I found that little was known about the 
impacts of this industry on the Maya land ethos and on the ability of Maya people to maintain their relationships with the land. My research in Xuilub opens an academic discussion related to this question that has been heretofore overlooked.

With the geographical, historical, cultural and context I have provided, as well as my critical review of the past research and literature surrounding Maya land-use patterns and practices that I have laid out in this chapter, the reader is now better prepared to consider my analysis of the Maya environmental ethos that I observed and documented in Xuilub. 


\section{Chapter 3 - Theoretical Framework: Postcolonial Theory, Indigenous Geographies, and the Study of Indigenous Knowledges (IKs)}

\section{Introduction}

Postcolonial scholarship currently takes many different forms and explores a wide variety of topics from colonized regions around the world, yet all of its variations have a common rationale and mission. The main theoretical frameworks that inform this research project are postcolonial theory, Indigenous geographies, and Indigenous knowledges (IKs) research. Postcolonial theory demonstrates how Western concepts related to time, space, science and progress, which are often accepted by the academic community as universal truths, can be deconstructed and challenged (McEwan, 2009). Postcolonial theory holds that there is no inherently objective, exclusively valid, or innately superior approach to geographic concepts or models of spatial organization and, by extension, land use (ibid.). Unpacking these taken-for-granted truths helps to legitimize the inclusion of other cultural knowledges as sources of inspiration for challenging social structures and policies reflective of colonial legacies. With goal similar to that of postcolonial theory, Indigenous geographies afford us new opportunities to engage with Indigenous land-based knowledges until recently not been given their due attention by the geographical discipline (Coombes et al., 2012), although cultural ecologists had already begun highlighting the importance of Indigenous land-use knowledges in the 1950s. Indigenous geographies are a relatively recent area of focus in 
human geography. In Indigenous geographies there is recognition that the colonial takeover of Indigenous territories was made possible by a discursive (and in some cases physical) erasure of the Indigenous presence that were (and still are) converted into spaces of Western meanings and uses. As put by Howitt, Muller \& Suchet-Pearson (2009), still today,

There is a dominant discourse that is theoretical, political, and administrative and represents and imagines Indigenous geographies in terms of absence, placing Indigenous peoples into an ahistorical past or into exotic (and distant, remote) places anywhere but the contemporary Eurocentric here-and-now (p. 359).

In order to contest these dominant colonial discourses, the main objective of Indigenous geographies is to attempt to understand and highlight Indigenous conceptualizations of their territories and meanings about place and land use and governance, which have for centuries since colonial occupation been shrouded by the Western geographical veil. This allows Indigenous geographers to unpack and challenge Western land-use and management approaches that were once viewed as "rational" and self-evident and to critically reassess these constructions and discourses that maintain colonial power relations between nation-states and Indigenous peoples. For postcolonial and Indigenous geographies scholars it is thus crucial to seek to understand IKs and determine how these ways of thinking can enhance and enrich mainstream environmental land-management policy.

IK research focuses on recognizing the importance of IKs and realizing their potential for expanding societal consciousness and governance practices, especially with regard to environmental management. IK investigations approach the research process from a perspective and approach that seek to gain a greater understanding of the present- 
day land-use philosophies and practices of Indigenous groups without the pretence of assuming an "objective" or "impartial" observer standpoint. As a result, special attention is paid to Indigenous meanings and representations related to 'place,' 'the earth/land,' and relationships with other human and other-than-human beings (including spiritual beings, past generations, and future generations) on the land. It has become my belief that for my own research project that seeks to document, interpret, and represent Maya landuse knowledges, combining the three fields of postcolonial theory, Indigenous geographies, and IK research is the most effective and comprehensive approach. As my brief characterizations about each field demonstrate, they all overlap to some degree. I am at once concerned with unpacking and challenging Western concepts and discourses (related to land use and management) (postcolonial theory), investigating how the Yucatec Maya occupy and use their traditional territory (Indigenous geographies), and understanding the philsosophical/spiritual motivations behind their relationships with the land and how their different land-use activities are all part of a broader integrated environmental ethos (the study of IKs).

What has been missing from postcolonial and Indigenous geographies investigations on the Yucatec Maya (and Indigenous people in general, to a certain extent) are place-based studies on the philosophical and spiritual underpinnings of IKs and concrete land-use practices by an Indigenous researcher. Although there is a vast literature on Yucatec Maya land-use practices from a Western scientific paradigm from the "objective" view of an "impartial observer," I have identified a strict paucity with regard to studies on Yucatec Maya IKs from researchers approaching their questions from an engaged and non-Western perspective. This engaged and "insider" 
characterization of Maya relationships with their territories ('the land') has to date been absent from investigations on Maya (and to my knowledge, any) land-based knowledges and practices. Furthermore, as I outline later in the chapter, I consider that the focus in postcolonial and Indigenous geographies investigations on Indigenous land-use philosophies and practices is on assisting these groups in their struggle to gain rights, or to help them to have their rights recognized by states and corporate actors. This is what I refer to as a 'rights-based' approach to research on Indigenous land use (e.g. the terminology used in Howitt, Muller \& Suchet-Pearson, 2009 and Coombes et al., 2012). I consider this rights-based perspective very useful in exposing the injustices and inequities that are ever-present in terms of challenges to Indigenous peoples' territorial autonomy and exercise of their land rights. However, I believe that helping Indigenous groups to articulate their own culturally distinct perspectives, vocabularies, and approaches to understanding the environment - and recognizing that the very concept of rights was historically foreign to many, if not all, Indigenous nations of the Americas prior to the arrival of the first Europeans to the North and South American shores (Alfred, 2009) — is much-needed and could provide useful alternatives to Western-centric rightsbased discourses. In my own research approach, I tried as much as possible to simply learn about how the people of Xuilub view their relationships with the environment and their cultural motivations that undergird their work on the land. With this aim in mind, I avoided bringing up or referencing any Western-centred terminologies and vocabularies, such as 'state,' 'corporate,' 'environmental management,' 'rights,' in order to understand how they speak about their relationships with the environment for themselves, and not in relation to Western concepts and frameworks. I was surprised to find that there was never 
any mention of those aforementioned terms. The themes that did surface time and again were those more closely related to concepts of 'the land as "she," 'responsibility,' 'duty,' 'respect,' and 'reciprocity,' as the reader will notice when reading interview excerpts throughout this dissertation.

These three bodies of knowledge and areas of scholarship, and their relevance to my research project, will be discussed in the following sections. In 3.1 I give an overview of postcolonial theory and how it applies to research on Indigenous land-based knowledges and practices in general and my own research specifically. Next, in 3.2 I discuss the study of Indigenous knowledges (IKs) and the ways in which these bodies of knowledge demonstrate (and celebrate) the value and potential of Indigenous ways of knowing and doing to rebalance human societies' relationships with the other-thanhuman sphere. I also consider how this body of knowledge has allowed me to approach my own research project from an "Indigenous" epistemological standpoint. Finally, in 3.3 I highlight some theoretical contribution(s) of my research to the fields of postcolonial and Indigenous geographies, namely my 'responsibility-based thinking' approach to understanding and representing the Maya environmental ethos of "being part of the land" (described in Chapter 6).

\subsection{An Overview of Postcolonial Theory and how it Relates to Research on Indigenous Land Use}

The origins of postcolonial consciousness and calls for 'decolonization' of the treatment of colonized peoples in colonial and post-colonial nation-states can be traced to early $20^{\text {th }}$ century 'third-world' literature, especially anti-colonial narratives produced by non-Western authors (Boehmer, 2005). The term 'postcolonialism' is highly contested 
and has generated much academic debate over recent years (Blunt and McEwan, 2002). Although scholars have generally had no qualms about recognizing the dramatic and global repercussions of European imperial expansion and colonialism, the meaning of the prefix 'post' is still the matter of debate and contention (Childs and Williams, 1997). To some, postcolonialism simply means 'after colonialism', implying that colonialism and its practices no longer exist or are no longer relevant in today's social, cultural and economic landscapes (McEwan, 2009). Adherents of this definition of postcolonialism refer to the decline and eventual failure of European colonialism after WWII (MooreGilbert et al, 1997). The period after WWII saw many European colonies in Africa and Asia gain formal or de facto independence from colonial powers like Great Britain, France, Belgium, Spain and Portugal ${ }^{1}$. However, although the post-war period effectively marked the end of the centuries-old exercise of formal colonialism, its legacies continue to heavily influence world geopolitics (Grosfoguel, 2002). In recent decades, the legacies of colonialism have become domains of postcolonial scholarship in the humanities and social sciences (Barnett, 2006).

One of the main contributions of postcolonial scholarship has been to bring into the historically narrow academic consciousness the damage to non-European societies caused by colonial practices in the race for territorial control in faraway lands by different European powers. Thanks to the work of postcolonial scholars through the decades, there now exists an abundant literature, including both Indigenous and non-Indigenous scholars (some of whom would not consider themselves postcolonial scholars per se), that

\footnotetext{
${ }^{1}$ Latin American countries generally gained their independence much earlier than WWII, from around 1800-1830. Mexico gained its independence from Spain in 1821.
} 
addresses and critiques European colonialism's historical obfuscation of the Indigenous cultural presence in the Americas, which "justified" the colonial takeover of the continent (Battiste, 2000; Blunt and McEwan, 2003; Castree, 2004; De La Cadena and Starn, 2007; Johnson et al., 2007; Shaw, Herman, \& Dobbs, 2006; Tuhiwai Smith, 1999). As postcolonial theory has shown, the mobilization of colonial discourses was aimed at placing colonized peoples in an inferior position and effacing Indigenous epistemological, ontological and intellectual traditions and cultural landscapes (Louis, 2007; McClintock, 1995; Robbins, 2011). The colonial aggression against Indigenous peoples was, then, also discursive, in addition to the physical violence discharged in order to physically take hold of Indigenous-occupied territories. This discursive violence delegitimized IKs and relationships with the natural environment, allowing Eurocentric land management paradigms, informed by rationalism and scientific traditions, to be uncritically applied on Indigenous places throughout the North and South American continents (as demonstrated by Louis, 2007; Pierotti and Wildcat, 2000; Tuhiwai Smith, 1999, and many others).

Feminist thinkers, whose work has informed postcolonial theory in its investigations into the gendered nature colonial practices and power relations, argue that knowledge is invariably 'situated' or contingent (Haraway, 1991; Rose, 1997). Situated knowledge results from a cultural group's or an individual's 'representation' of reality. Representation denotes partiality and subjectivity, and can be described as a "set of practices by which meanings are communicated" (Duncan, 2009, p. 703). Representations, while informed and produced by an independent reality, are never actually reality (Duncan, 2009). In the geographical context, colonial geographies were 
informed by knowledges that were firmly situated within Western scientific paradigm aspiring to find the most "objective" or "rational" land-use and territorial management strategies. Colonial geographies of Indigenous territories rested on a fallacious notion of the impartiality and objectivity of Western scientific ways of knowing. Guided by these insights, postcolonial theorists have problematized and challenged the colonial representational practice of speaking on the behalf of colonized groups about their cultural understandings — or in this sense their situated knowledges (e.g. Spivak, 1988, in her seminal article "Can the Subaltern Speak?"). By bringing to light the "crisis of representation' inherent to colonial discourses about the colonized, postcolonial scholars have done much to expose the ethnocentrism of colonial land management discourses, which have undergirded the exercise of Western power over other - often Indigenouscultural groups in the last few centuries (Barnett, 1997). In Mexico, as in most of Latin America, the first ethnographies and outsider representations of Indigenous cultures (like the Maya) and their spiritual beliefs, rituals, social organization, and customs were written by religious authorities, such as Catholic priests and friars (Anderson, 2005). These first colonial accounts of Indigenous life were used by colonial authorities to justify the takeover of their lands. They continue to have an influence on how they are viewed and represented in popular culture and the media as backward and primitive.

Authors like Chakrabarty $(1992 ; 2000)$ have put forth that postcolonial scholars are well positioned to play key roles in 'provincialising' Europe, by recognizing and demonstrating the 'situatedness' of Eurocentric knowledges, which are not inherently more universal, or a more faithful reflection of reality or Truth, than any other cultural discourse. It must be noted, however, that Chakrabarty's work engages with a vastly 
different context (India) and topic in terms of deconstructing colonial discourses. As a postcolonial historian, his approach has been to analyze textual colonial sources to unpack and deconstruct colonial representations about the colonized. Although my postcolonial approach deals with the lived experience of the Maya, I find Chakrabarty's ideas very relevant to my research and personal objective as a scholar to highlight the value of IKs to the outside society. Indeed, as he argues, by eschewing the colonial notion of hierarchies of knowledge, atop which are placed Eurocentric (scientific) knowledges, postcolonial theory has been able to open up to the hybridity and dynamism that imbue the local knowledges of colonized peoples such as the Yucatec Maya. Indeed, his postcolonial reflections, as well as a variety of other postcolonial voices, have engendered new conceptual and theoretical spaces in which the cultures of colonized peoples the world over can be (re)explored in terms of their present-day relevance rather than being relegated to the margins within hegemonic Western paradigms (Radcliffe, 2012; Zimmerer, 2012). Indigenous meanings and representations of terms like appropriate land use, progress, equity, reciprocity, communalism and relationality are beginning to be investigated, as they are increasingly being regarded by postcolonial scholars as potentially containing viable alternatives to neoliberalism and other 'linear' Eurocentric economic development models (Battiste, 2000; Pierotti and Wildcat, 2000; Shaw et al., 2006). My research uses this approach to find currency in the Maya environmental ethos, which calls for all to learn to be "part of the land," rather than to perceive themselves as being owners or dominators or managers of it. In the English language, the word "management" carries the sense of an inherent hierarchy in which humans are at the top of the natural order. Just as the manager of an office is at the top of 
the workplace hierarchy, so too are human mangers of the land who are "in charge of" controlling the territory and its natural resources. This is a view of human relationships with the environment that goes against Indigenous values. I consider that my research makes its most significant contribution to postcolonial scholarship by furthering the scholarly discussion surrounding Indigenous understandings of IKs and land-based relationships. As I have established in the previous pages, postcolonial scholarship has, since its inception, aimed to deconstruct colonial accounts of colonized peoples, colonial practices and power relations, and the impacts that these colonial logics and legacies continue to have on non-Western cultures around the world. There are volumes of works by authors driven by this objective from all regions of the planet; therefore, I do not see my research as offering any new insights into the deconstruction of colonial legacies.

\subsubsection{The Role of Postcolonial Theory in Contesting Colonial Geographies and the Exercise of Territorial Control over Indigenous Peoples}

Challenging the Western colonial conception of 'closed'—or static—space, authors like Massey propose that places, as our senses allow us to perceive them, are transitory collages of innumerable elements and circumstances, as well as their quasiinfinite relations with one another $(2005$, p. 107). With space and place as its central concerns, the discipline of geography enjoys a privileged position from which to challenge dominant approaches to spatial organization that have undermined colonized peoples. Postcolonial geographical research can therefore allow different cultures, and their respective epistemologies and knowledges, to learn from one another by sharing their spatial values (McEwan, 2009). 
Today, one of the main focuses of postcolonial scholarship is to challenge Western land management philosophies and to investigate their role in the exercise of colonial power. Although not a geographer by training, Anne McClintock has made significant contributions to the investigation of the spatial dimensions of classical colonial historicism. McClintock's book Imperial Leather (1995) provides many compelling accounts and examples of the imperial (and colonial) conception of spatial organization that seeks to 'domesticize' animals, women and colonized peoples. The author argues that colonial governance systems were predicated on the alienation of colonized peoples from their "economically unproductive" homelands. Different land types (e.g. forests, agricultural lands, cities, etc.) were ranked in order of importance according to their relevance to Western definitions of progress and development. As a result, cultures and societies that would value so-called under- or undeveloped spaces were considered primitive, with little, if anything, to contribute to the advanced, rational order. As mentioned by Shaw et al. (2006) the geographic discipline has contributed to the projects of imperialism and colonialism, especially through the use of mapping as tools for discounting the presence of the original inhabitants. In the following excerpt, Barnett describes the importance of spatial control, along with delegitimizing Indigenous conceptions of place and relationships with the land, to the exercise of colonial power:

Colonial discourse can be understood as revolving around a three-way relationship in which relations between European or western colonizers and non-western 'native' subjects is mediated by representations of land, space, and territory. Characteristically, this relationship involved representing non-western spaces as empty, or inhabited only by ghostly subjects, or untended, in ways that legitimized colonial and imperial intervention in the name of proper stewardship of people and land (2006, p. 153).

Imperial colonial powers have imagined space in terms of its instrumental value and its 
economic potential (Barrow, 2004). Non-Western societies that hold different understandings of and attribute different values to space have thus largely been dismissed as anti-progress and backward (Etherington, 2007). Harris (2004) observes that the colonial concept of Indigenous-occupied territories as terra nullius led to a "grounded" form of colonialism that resulted in "dispossessions and repossessions of land" by colonial authorities (p. 164). This is the case in the Yucatan, where the imposition of Spanish colonial values and land-use strategies like the establishment of large sugarcane and henequén plantations and haciendas (cattle ranches) supplanted what the colonial authorities deemed backward and primitive Maya land-use activities and spiritual beliefs that informed their relationships with the land (Fariss, 1984; Patch, 1994). The establishment of Spanish colonial governments rapidly overturned the traditional sociopolitical and territorial governance systems of the Maya, which had for centuries been firmly in place on their lands. Catholic religious authorities like Friar Diego de Landa (1524-1579) and their disparaging accounts of the apostasy of the Maya and what he saw as their primitive customs justified broader Spanish colonial efforts to take over their lands and put them to "productive" use as plantations and haciendas (Timmer, 1997). The continuation of such practices and prejudices against the Maya continues to this day, as they continue to be subjected with newer, more subtle forms of racism, such as receiving substandard education and treatment in state institutions, as argued by Vasquez Castillo (2013).

As previously stated, postcolonial theory is concerned with uncovering knowledges of the non-Western "other." In the context of Indigenous cultures, in order to uncover these knowledges, it is crucial to investigate oral traditions and histories (Berkes, 
Colding \& Folke, 2000; Berkes, 2008). For a variety of reasons, academia has been reluctant to seek to understand local ways of knowing and to incorporate relevant traditional knowledge concepts into studies on space, place and landscapes (Mason, 2000). However, of late, geographers like Gibson (2006) have conducted studies that rely on "traditional" - in most cases oral—knowledge. The nature of documenting and analyzing oral knowledge effectively allows Indigenous research subjects to speak for themselves (Louis, 2007), a call originally issued by Spivak (1988). By highlighting the use and importance of IKs, researchers are decolonizing geography. The horizons and scope of academia seem to be broadening, though slowly, and the value of IKs is beginning to be recognized by an increasing number of researchers and policymakers. This turn in the academic practice gives hope to scholars who are interested in reconciling the Western and Indigenous land ethics. Several geographers (for example: Aswani and Lauer, 2006; Briggs 2005; McGregor, 2004) have recognized the need for the discipline to harmonize these two approaches to knowledge through the creation of common channels of communication.

Postcolonial theory has expanded the realm of consideration of human geography, just like every other discipline in the humanities. Postcolonial geographers' (and others like Wenzel, Posey, Hunn, and Berkes) concentration on the local level and on lived cultural practices has done much to legitimize the study of local, non-Western knowledges, including those of Indigenous peoples (Cameron, de Leeuw, \& Greenwood, 2009). Virtually all of the world's Indigenous peoples have at various periods in time had to contend with colonial power. The recent emancipation of European colonies in Africa and Asia has in some cases attenuated the colonial power that had been imposed on these 
continents' populations. In contrast, this has generally not been the case for most Indigenous peoples. The majority of the world's Indigenous groups are ethnic minorities within political states and are still subjected to certain neocolonial practices by governments and private actors (Page, 2003).

In recent decades, the international turn to neoliberal economic policies has redefined the nature of colonial power (Escobar, 1995). Several nation-states in Latin America have in recent decades fallen under the influence of neoliberal policies in order to be more competitive in the global market place. The adoption of such policies threatens Indigenous groups who are struggling to maintain their land-based cultures in the face or corporate actors who are vying for control of their territories or resources (Yashar, 2005), as is the case with Yucatan's tourism industry encroaching on traditional Maya lands. This reality has led scholars like Cameron, de Leewu \& Greenwood (2009) and Shaw et al. (2006) to suggest that in today's neoliberal atmosphere Indigenous peoples are particularly in need of decolonized research approaches to assist them in rearticulating IKs and reasserting their distinct land management visions on their territories. According to these authors, geographers must be weary of imposing Western rationalism on their Indigenous research subjects. Instead, they argue, geographers must be open to incorporating different conceptions of society, culture and spatial organization into their research approaches.

The deconstruction of colonial geographies affords us new opportunities in engaging with Indigenous land ethics and geographies until recently disregarded by the academy. A number of critical geographers have tasked themselves with decentering the Occident's imagined position as the world's historical, cultural and intellectual zenith, 
answering the call issued by Said (1978). In this vein, postcolonial geographers have used the discipline's unique spatial consciousness to challenge dominant spatial organization patterns and tools, as well as current environmental management dogmas moored on a narrow economic development rationale (Clayton, 2003; Frantz and Howitz, 2012; Gregory, 1998; Massey, 2005). Land use and management approaches that were once viewed as "rational" and self-evident are now being critically reassessed as constructions and discourses that maintained colonial power relations and, as put by Gregory (1998), 'constitutive exclusions and erasures' (p 72).

Our discipline must continue to build on the successes of these theoretical and methodological paradigms as the burgeoning subfield of Indigenous geographies expands into the future. I believe that the discipline of geography is just beginning to understand the potential of decolonization approaches. I believe that the formation of more Indigenous scholars and geographers from around the world is needed in order to bring about this change. Lastly, the geographical observations and commentary on the use of Indigenous knowledge in decolonizing knowledge production and reproduction inform my own reflections on Yucatec Maya landscapes and how these fare in the face of colonial state development pressures.

\subsection{The Study of IKs}

In the last two to three decades, Indigenous Knowledges (IKs) have become a subject of intense academic debate about environmental management. Until recent decades, Western science did not recognize as being valid other methods of acquiring knowledge of our physical surroundings. Today, other forms of local, less formalized knowledge are gaining currency (Berkes, 2008). Indigenous peoples around the world 
have historically depended on their intimate relationship with their natural surroundings in order to survive and prosper. This environmental knowledge base, gained over the course of centuries, is transmitted orally and through practice and in situ teaching, as well as empirical observations. The emphasis in IK systems is on intergenerational knowledge transmission of both knowledge and skills, passed down from one generation to the next. The method of knowledge transmission in IKs differs greatly from Western academic methods, which rely on textual analysis and exegesis. In IK systems, oral histories, songs, and stories are highly valued by both knowledge holders and learners, as they allow for a highly engaging and iterative experience and dialogue between all those involved. Unlike Western science, developing intimate emotional connections with and a love for the land are an integral part of the learning process, and are encouraged by knowledge holders. In addition, as Cajete (1999) points out, IK systems (and most Indigenous languages) are verb-based, as opposed to noun-based, as is the case of the English language. As a result, explains Kovach (2015), this "accentuates an outcome orientation of the world" (p. 52). In other words, possessing IKs is meaningless if one does not act on these knowledges one has been taught, acquired, or otherwise gained. In contrast, Western science does not contain any ethically normative action-based framework that compels its knowledge holders to translate this way of knowing into a way of being or doing. The outcomeoriented nature of IKs means that it is incumbent upon the possessor of these knowledges to actively uphold her/his spiritual relationships and responsibilities with the land as a lifelong process (or journey).

Pierotti and Wildcat (2000, p. 1335) elaborate on the epistemological foundation of IKs: "[w]ithin an [IK]-based ethical system, nature exists on its own terms, and 
individual non-humans have their own reasons for existence, independent of human interpretation $[\ldots][$ IKs encompass $]$ both science and religion, in the sense that religion is the ritual representation of the community, and a device for sanctioning moral and ethical codes." IKs, therefore, cannot be considered in isolation from broader Indigenous ethical frameworks, which inform acquisition and transmission of these knowledges (Berkes, 2008). This intellectual tradition is fundamentally different from the western, rational vision of natural/resource management, which exempts the scientific method from ethical considerations and implications. Inherent to the science of western environmental management is the belief that an ecosystem can (and should) be managed by breaking it down into small, manageable components (i.e. individual resources, such as plant and animal species) (Pierotti and Wildcat, 2000, Berkes et al., 2000). Such a view is foreign to most traditional Indigenous peoples. First, the idea that the environment can be managed is not widespread in the indigenous world (Turner, Ignace \& Ignace, 2000). IKs also differ from Western environmental management in the ways it is used by its holders. Western resource management strategies are, generally speaking, conceived to effectively manage individual resources in the short term (Sallenave, 1994). It must be mentioned, however, that newer, more holistic approaches to land management, such as the implementation of watershed-scale management areas, instead of areas defined by arbitrary political boundaries with no ecological significance, are emerging (Sabatier $e t$ al., 2005; Sioui and McLeman, 2014).

Several authors have noted that in many cases Indigenous cultures, as well as their corresponding, context-specific knowledges, and their physical surroundings appear to be co-constitutive (Deloria, 1992; Berkes, 2008, for example). This is to say that while the 
physical environment has had a profound influence on the Indigenous cultures and their cosmologies, the same is true of the Indigenous cultural imprint on the landscape. Of course, one can say that all cultures and the physical environments from which they hail are co-constitutive. This notion was in fact a primary concern for highly influential cultural geographers like Sauer (1925) and and anthropologists like Steward (1972). However, scholars such as LaDuke (1999) argue that Western ("Imperialist") cultures have generally entertained more exploitative, human-centred relationships with their homelands, rather than the symbiotic dynamism that often characterizes Indigenous relationships with the landscape. Indeed, IKs are embedded in Indigenous cultures' relationships with the land. It is through relationships and interactions with the otherthan-human beings that co-exist with humans on the land that IKs are continually (re)created. This is why the notion of relationships is central and pervasive when trying to articulate the meaning and nature of IKs.

A great deal of ink has been spent on identifying the differences between the Western scientific and Indigenous approaches to knowledge (see Berkes, 2008 for a rich, detailed account). One key philosophical difference between the two ethical traditions has to do with the perception of humans' position in relation to time and place, which in turn influences their respective relationships with the land. It has been suggested by some scholars that Indigenous peoples across the Americas have a 'spatial' perception of their place in relation to the universe (Deloria, 1992; Pierotti and Wildcat, 2000). This is to say that they (traditionally, at least) look to their location in relation to their physical surroundings to gain a personal understanding of what constitutes appropriate human behaviour in relation to the land. Evidence of the Indigenous spatial worldview can be 
found in the common traditional practice in many Indigenous cultures of invoking the Four Directions, the sky and the earth when praying (ibid.). Other scholars have noted that settler societies look backward and forward in time to gain an understanding of their place in relation to history; this can be defined as a linear (or temporal) worldview (Johannes, 1989; Anderson, 1996). Indigenous knowledge is part of a relationship-based worldview of the land and all its constituting elements (Sioui, 1999; 2008). With Indigenous spirituality, one's life on earth is thought to be sacred (Deloria, 1992). In terms of the temporal dimensions of IKs, these have to do with following the cyclical (often seasonal) processes of the land ${ }^{2}$. This belief system holds no notion of mankind's ontological or ethical primacy over other elements of the environment. Rather, all elements of the ecosystem are thought to be part of a sacred circle (Pierotti and Wildcat, 2000). Instead of fleeing from the dangers and challenges presented by the physical environment, some scholars put forth that the Indigenous tradition facilitates an understanding of the world that promotes and celebrates harmonious relations between all beings (e.g. LaRochelle and Berkes (2003) in their case study on Raramuri IKs in Tarahumara, Mexico).

Unlike Western environmental management, IKs is not entirely analytical in its approach. It is closely linked to Indigenous spirituality and philosophy. Among many Indigenous groups, IKs serves to guide humans' interaction with the non-human world, as well as to regulate actions that can potentially affect future generations. Pierotti and

\footnotetext{
${ }^{2}$ Maya land-use practices and relationships with the land are in correspondance with the cycles and seasons of the land in Yucatan (e.g. the milpa cycle, apicultural flowering seasons, and the seasonal order of spiritual ceremonies that I observed in Xuilub and describe in Chapter 5).
} 
Wildcat (2000: 1335) offer a useful definition of IK: "[IK is] an intellectual foundation for an Indigenous theory and practice of politics and ethics, centered on natural places and connection to the natural world, which is capable of generating a conservation ethic on the part of those who follow its principles." In other words, for many traditional Indigenous groups, IK is a way of life, not simply a land use and management strategy (Berkes, 2008).

'Native science,' as coined by Cajete (2000) understands and represents the world in terms of relationships and networks between human and other-than-human beings as they play out in space (on the land). The emphasis in this land ethic is on responsibility and accountability to one's relations. Several authors have noted that many, if not most, Indigenous cultures of the Americas had fundamentally different understandings of and relationships with space than those that were advanced by Eurocentric and colonial land use regimes (for example: Berkes, 2008; Cajete, 2000; Deloria, 1992; Low and Lawrence-Zúñiga, 2003; Sioui, 1992; Tuan, 1977). Late Sioux philosopher Vine Deloria (1992) has argued that one of the key metaphysical distinctions between European and Indigenous worldviews relates to their spatial consciousness. Indigenous scholars have come to distinguish Eurocentric 'temporal' epistemologies from the more spatially oriented and focused modes of thought common to many Indigenous cultures across the Americas (Deloria, 1992; Pierotti and Wildcat, 2000). Coulthard (2010) has written that most American Indigenous philosophies share the concept of 'land' as an ontological framework for understanding existence and interrelationships. Budhwa and McCreary (2013) also add, "indigenous landscapes are composed of relationships with physical sites but also a set of cultural essences, intangible structures of belief, that tend to be difficult 
to bind to a particular location $[\ldots]$ The matrix within this physical and spiritual landscape defines Indigenous ways of being" (pp. 199-200). Semantically, the concept of land has marked differences between most Indigenous and European cultures. For example, in contrast to this Indigenous meaning of land as a living and sentient entity, Tuck and Yang (2012) describe the colonial process of transforming land (and Indigenous landscapes) into a lifeless and purely economic commodity: "In the process of settler colonialism, land is remade into property and human relationships to land are restricted to the relationship of the owner to his property" (p. 5). In the Déné language, on the other hand, the definition of 'land' is not limited to the material, 'lifeless' characteristics of space, but encompasses human and other-than-human beings, themselves understood through non-hierarchical, relational transactions and relationships (ibid.,p. 80). Most commonly in American Indigenous cultures, land is understood as the space, or the setting, in which networks of relations are in constant negotiation and interplay (Cajete, 2000; Louis, 2007; Sherman, 2008). These systems are thought to be self-intelligent and balance-seeking despite the perpetual disturbances that continually reconstitute them (Herman, 2008; Wildcat, 2009). Put simply, in the Indigenous way of thinking, land means everything, and is the inspiration for everything from philosophical and political models and structures, as well as sustenance-based practices (e.g. hunting, trapping, fishing, picking berries, etc.) and spiritual ceremonies. Zinga and Styres (2011) elaborate on this key notion about land as the pillar of Indigenous societies: "It is important to appreciate the fundamental being of Land and its role in the conceptualization of identity for Indigenous peoples. For us, this refers to land as a living entity providing the central underpinnings for all life, the understanding of interconnected 
relationships, and is underscored by her capitalization as a proper name" (p. 62).

Indigenous peoples who live by such beliefs and knowledges often generate critiques of dominant (but foreign) structures of spatial organization anchored to linear discourses of progress and development (Deloria, 1992; Pierotti and Wildcat, 2001). To those groups and individuals, the meaning and representation of 'place' fundamentally differs from colonial meanings of place as a container of information to be logically and hierarchically ordered and subdued for the benefit of human "development." Their profoundly different approach to relationships with the land is what many authors believe inspires Indigenous resistance to colonial discursive erasures of Indigenous relational spatial metaphysics and landscapes (Coulthard, 2010; Deloria, 1992; Pierotti and Wildcat, 2000; Sherman, 2008). Such thinkers and activists invoke these multidimensional representations of land and place as a particularly luxuriant source of inspiration for elaborating critiques and resistances aimed at colonial spatial/environmental agendas (Johnson, Howitt and Peters, 2007; Shaw et al., 2006). Indigenous struggles are often distinguished from Marxist analyses of other social movements in which social class is the main issue at stake: the colonial oppression of Indigenous peoples can be understood first and foremost as stemming from their territorial dispossession rather than from a 'theft of time' in the case of exploitative relations and uneven 'power geometries' between the élite and the masses (Coulthard, 2010, p. 81; Massey, 1994).

In terms of investigating Indigenous alternatives to colonial territorial governance systems, McGregor (2004) has argued that academics must seek answers in IKs and their current relevance in environmental management. Indigenous scholars intent on elucidating their peoples' relationships with the natural environment have stressed that it 
is necessary for Indigenous peoples to teach the academic collective about their own understandings of IKs, along with the fundamental principles of 'respect, coexistence, cooperation, honour, thanksgiving, reciprocity, balance and harmony'-all of which are congruent with a teachings contained in IKs (Sherman, 2008; Sioui, 2012). Perhaps the defining characteristic of the majority of IK systems across the Americas, is that they are almost invariably represented as a way of living, in addition to a way of knowing. Indeed, IKs are often understood and described by Indigenous scholars as a way of 'living well within one's place' (Sherman, 2008). Carrying oneself responsibly in natural environment, it is believed, leads to a freedom of consciousness and to a sense of solidarity with all of one's relations in space. In agreement with this view, Deloria (2001) has articulated his own understanding of IK as a way of knowing and living in a network of relations:

Because we gather knowledge from older beings who have wisdom of the world within their grasp, we must maintain a relationship with the rest of Creation [the network of relations to which we belong and must tend]. IK is not just about knowledge about relationships with Creation or the natural world; it is the relationship itself. It is about being in the relationships with Creation; it is about realizing one's vision and purpose and assuming responsibilities accordingly (p. 60, emphasis added).

Judging form Deloria's definition of IK, it is apparent that this way of knowing is in certain ways fundamentally different in its ontology, epistemology, and practice than Western "objective" science and ways of relating with the environment. Pierotti and Wildcat (2000) add,

Despite apparent differences, all Western attitudes toward nature come from the same European philosophical roots, i.e., Descartes, Bacon, and the Enlightenment (Smith 1996). In the writings of philosophers as different as Aristotle, Descartes, and Kant, it is assumed that humans are autonomous from, and in control of, the natural world (Mayr 1997). For example, John Locke (1952) argued that nature 
existed primarily for facilitating the comfort and convenience of humans (p. 1334).

Peloquin and Berkes (2009) highlight other important distinctions between the two knowledge systems in relation to land use and the management-by-compartmentalizing approach:

Western science-based societies have tended to simplify ecosystems in order to manage them, for example, by creating monocultures in place of traditional mixed systems such as agroforestry[...] Such a discontinuum makes reductionism possible, but reductionism has important shortcomings in a context of complexity of environmental systems [...] The environmental monitoring practices of some Indigenous and rural societies are significant in identifying ways to perceive the continuum of nature holistically, as opposed to trying to reduce complexity to a few measurable and controllable variables. Indigenous knowledge does not have the quantitative tools and approaches used by western science and technology, but some local and Indigenous systems seem to have developed ways to deal with complexity (p. 533).

Indigenous scholars generally believe that such a continuum and relationships with the natural environment can be more holistically understood and communicated in relational, rather than technical or quantitative, terms (Kuokkanen, 2011; Sherman, 2008). The orally transmitted nature of IK systems provides ample mechanisms for incorporating new knowledges, ideas and changing environmental conditions, which can then be taken into consideration in socio-environmental governance structures (Berkes, 2008; Berkes et al., 2000; Cajete, 2000). IKs are thus flexible and well suited to incorporating new knowledge about changing environmental conditions or socio-cultural realities.

These concepts contained in IKs have influenced my research in Xuilub, and helped me to understand how Maya IKs are translated into land-use practices and social organization and community governance structures. I believe that if I had not undertaken this research within these IK research parameters that broaden our understandings of 
Indigenous land-based knowledges, meanings, definitions, and practices, I would not have been able to adequately answer my research questions listed in Chapter 1. The IK research approach identified earlier in the chapter fills the lacunas in the Indigenous geographies field that generally approach Indigenous land-use questions from a more rights-based perspective and associated vocbulary. Postcolonial scholars continue to uncover the hidden colonial meanings that are embedded in dominant meanings of 'place,' 'nature,' and environment. These continue to affect how Indigenous land use is perceived (still largely in a negative light) by policymakers and planners. These efforts have motivated me to continue in a similar vein as that of Indigenous geographies in continuing to uncover the value of Indigenous land-use knowledges and strategies. The value of IK research for my research in Xuilub is that it allowed me to broaden my understanding of these knowledges and seek to uncover their use and relevance from an Indigenous responsibility-, rather than rights-, based paradigm. In so doing, in my estimation, I was able to approach my research questions from a more embedded (nonoutsider) and engaged position, and without having to use Western cultural references to 'rights' and 'state' when documenting and interpreting Maya cultural knowledges. I am not trying to convince the reader that my approach is universal, the most widely accepted, or the best possible way to engage with questions relating to Indigenous land use; this is my own interpretation and position. However, if we consider the concept of 'situated knowledge' described earlier, what I am presenting in this dissertation is my best attempt at understanding the Maya environmental ethos, and that attempt is, of course, deeply embedded in my own personal and cultural biases, just like any person's representation of reality. Notwithstanding, the postcolonial, Indigenous geographies and IK research lenses 
have all provided me with sometimes overlapping but also unique insights and theoretical frameworks that have allowed me to better contextualize present-day Maya IKs within their broader Indigenous and colonial epistemologies and histories.

\subsection{The Contribution of this Research to Postcolonial and Indigenous Geographies Scholarship}

Colonial discourses and representations had a profound impact on the spatial organization of land use in Indigenous territories across the Americas. However, the Yucatec Maya have challenged the imposition of foreign land use conceptualizations and models. The very founding of Xuilub is directly tied to colonial legacies, where in this case a group of wandering Maya established the community after the end of the Caste War against the colonial elites and landowners. A direct descendant of one of the founding members of Xuilub reflected on the ways in which he felt the impacts of colonialism still reverberate in the community:

Of course we feel it here too. After we were left homeless because of the Caste War, we wandered through the Yucatan and finally stopped here and established our village. We've always felt like outsiders because we had to basically flee from our original homes and go deeper into the forest where something like the Caste War could never happen to us again. So you can say that ever since our relations with governments have been quite a source of stress for us. We still have the memory of that dispossession and we fear that something like that can happen to us again. Even though we live in an ejido, which is supposed to be protected by law, we also fear that our members can sell their parcels of land to private interests. We're convinced that's what the government wants. They want us to sell to private land buyers...the tourism industry. It would make our land a lot more economically valuable and productive for Yucatan state and Mexico that way.

Yucatec Maya communities like Xuilub continue to maintain spiritual and cultural relationships with the land and use their sacred sites through increased use and practice of cultural activities within them. Despite the colonial history and legacies in the Yucatan, many land-based Maya are pressing forward, developing strategies to be able to continue 
carrying out their distinct way of life. This current state of affairs in Yucatan is in line with what postcolonial (and indigenous) scholars have been witnessing all over the Americas: Indigenous peoples are continuing to find ways to adapt and keep alive their cultural knowledges despite colonial legacies that have infringed upon Indigenous groups' land-use systems (Battiste, 2000; Zimmerer, 2000; Sherman, 2008; Radcliffe, 2012).

As shown in Chapter 2, there is a vast literature related to Maya religious beliefs and rituals, as well as the ways in which these people use individual resources or carry out agricultural or hunting practices. However, the analytical and theoretical angle in postcolonial studies on Indigenous land-use philosophies, knowledges, and approaches on the Maya has not been from a postcolonial and Indigenous geographies perspective. In many cases, Indigenous groups are commonly represented as victims of (neo)colonialism and outside encroachment on their traditional territories. I consider that the most valuable contribution of Indigenous perspectives on environmental management and social organization is our responsibility-based epistemological framework. Although responsibility-related terminology and concepts have been articulated and used by Indigenous scholars, this model for understanding the Indigenous environmental worldviews is still too seldom drawn on in the postcolonial and Indigenous geographies literatures. At present, most of the postcolonial scholarship has a marked 'rights' focus. Scholars in this field are mostly concerned with assisting Indigenous groups in gaining rights to reclaim lost lands, rights to political representation, and rights to be meaningfully consulted before development projects are approved on their territories. Research on Maya land use, specifically, has taken on different theoretical leanings over 
time. The first wave of research (from around the early 1900s to the 1960s) on Maya land use was almost exclusively ethnographic in nature, with investigations done with an ethnocentric "outsider view" of an educated and impartial Western-trained scholar studying the "native" Maya interactions with their environment (for example, Benedict and Steggerda's 1936 book The Food of the Present-Day Yucatec Maya and the article "Changing living patterns of the Yucatec Maya by Brainerd, 1956). This (neo)colonial attitude slowly began to evolve toward an appreciation of local Maya knowledges, but more from a technical and management point of view (like Ewell and Merrell-Sands' Milpa in Yucatan: A Long-Fallow Maize System and its Alternatives in the Maya Peasant Economy, 1987 and Rico-Gray and Garcia-Franco's 1992 article “The Maya and the Vegetation of the Yucatan Peninsula"). This attitude of appreciation for Maya IKs has continued to this day. Now the bulk of investigations on Maya land use are postcolonial in their epistemology and praxis. In this literature, the emphasis is on decolonization of official land management regimes that are redefining the territorial dispossession of the Maya at the hands of the tourism industry and the post-NAFTA (1994) push for monoculture plantations in the region (e.g. Brown 1999; 2005; 2013; Wainwright, 2008; Armstrong-Fumero, 2009, Leatherman and Goodman, 2005; etc.). The new wave of postcolonial scholarship that deals with Maya land use is certainly having a positive impact and exposing neocolonial government practices that place already vulnerable and under-resourced Indigenous groups like the Maya in an even more precarious position, and is assisting these groups in their struggles to gain or secure rights to their territories. I see my own contribution to Maya land-use scholarship as combining postcolonial, Indigenous geographies, and IK research theories and concepts into one coherent 
approach that does not place these knowledges into a rights-based framework from the outset. Rather, I sought to allow the people of Xuilub to express themselves according to their own culturally distinct philosophies and perceptions about their position vis-à-vis the land and other-than-human beings. Scanning the current postcolonial and Indigenous geographies literatures, one finds that discussions tend to be 'rights-based.' In concluding a synthesis of the disciplinary orientations and objectives of Indigenous geographies, Coombes et al. (2012) urge scholars of Indigenous geographies to do "more research into the consequences of formal arrangements for implementing Indigenous rights " (p. 818). In a similar line of thinking, Howitt, Muller \& Suchet-Pearson (2009) believe that:

For the discipline, engaging with the rights of Indigenous peoples to maintain their identity, maintain their autonomy, and benefit from the new United Nations Convention will reveal some of the hard edges of state administrative structures, private and other institutional frameworks that are too often taken for granted as being neutral or well intentioned (p. 362, my emphasis).

The general idea in both of these excerpts is that Indigenous geographies researchers should concentrate on investigations on the ways in which to assist Indigenous groups in their struggle for rights within formal state institutions and structures. Furthermore, my representation of responsibility-based ways of knowing, doing, and being that I use in this dissertation ("being part of the land"), I offer, is a simple and effective theoretical device for understanding the fundamental (to me) difference between Indigenous and Western approaches to knowledge. It is my hope that the reader (particularly Indigenous geographies and postcolonial scholars) will join me in using this term as a useful tool in continuing to decentralize Western concepts by introducing a new Indigenous socio-territorial paradigm and terms of reference with regard to environmental thinking and praxis. In the remainder of this chapter, I further 
define responsibility-based thinking and contextualize it within the Yucatec Maya reality, in Xuilub. Again, I wish to stress that this is my own representation of IKs and understanding of and belief in their broader relevance and value. I recognize that this view may not be shared by all Indigenous or non-Indigenous scholars who study Indigenous land-based knowledges. I offer this representation because I personally believe it could be useful in expanding our collective conceptions and representations of IKs.

As was intimated in the previous section, among many Indigenous groups, including the Yucatec Maya in Xuilub, IKs serve to guide human interactions with the land, as well as to regulate actions that can potentially affect future generations. For many Indigenous groups, IK is a way of life, not simply a land use and management strategy. The way that the Maya of Xuilub view and interact with their natural environment in the Yucatan corresponds to these broader continental patterns. My field research with the Maya of Xuilub demonstrates that the community's land-use attitudes are best understood under the responsibility-based thinking lens. I define responsibility-based thinking as an Indigenous cultural ethic that informs and mediates personal and collective conduct by instilling in an individual's and, by extension, a community's, a sense of duty or responsibility toward her/his human and other-than-human, including environmental, relations. One Elder taught me a Yucatec Maya phrase that elegantly encapsulates this mindset: In kuxtal he lùm ma, or "the land is my life, and I owe everything to her. So I have to make sure I carry out my duties to her." He then went on to explain what exactly he meant by the "land," which, as he pointed out, is not strictly limited to the inanimate physical landscape, but includes the spiritual and supernatural realms. When I asked him 
what his definition of "land" includes, in the same vein as most Indigenous cultures across the continent, he replied, "men, women, animals, Saints, alux (magical dwarf beings in Maya lore described in greater detail in Chapter 6), God, the unborn and the departed." The similarity of his definition to other Indigenous meanings of land is striking. To impress upon the reader the significance of this finding, it must be mentioned that the Maya of Xuilub have no knowledge, outside of Hollywood movies, of northern Indigenous cultures or their environmental philosophies. The current Maya land management system and social organization follows responsibility-based thinking, and life on earth is thought to be sacred, as there is no strict disconnect between one's earthly life and the afterlife and supernatural realm. According to this worldview, a person is responsible for his/her actions here on earth. Maya responsibility-based thinking holds no notion of humankind's primacy over other beings of the land. Rather, all elements of the ecosystem are thought to be part of a sacred circle of relationships between beings. For the people of Xuilub, place is experience and represented on two main scales: the ejido and the Yucatan as the homeland. In this case, the ejido of Xuilub as a place of meaning is created by the experiences of human ancestors, as well as relationships with all beings on the land (Barker and Pickerill, 2012 explores this concept of place as land-based relationships to Indigenous people). I found that sense of place in Xuilub is more directly related to immediate family ties, whereas the meaning of place on the Yucatan scale is tied to broader understandings of an Indigenous Maya culture and civilization. Perhaps what distinguishes the Maya sense of place is that notion of "beings" that interact with humans includes past and future generations (the ancestors and the unborn). In other words, the Maya sense of 'place' is synonymous with relationships amongst a community 
of beings that belongs to a certain territory(ies) - Xuilub and the Yucatan, in this case. This non-hierarchical and place-as-relationships view of relationships with the environment could possibly offer useful insights for the fields of postcolonial theory and Indigenous geographies. Scholars in both these areas of scholarship continue to seek inspiration from Indigenous groups in terms of making environmental thinking and management more holistic and equitable, not only for human beings but for other-thanhuman entities that also constitute the environment. This non-hierarchical understanding of place and the land as relationships, as taught to me by the Maya of Xuilub, stands in direct opposition of colonial definitions of land as a collection of resources to be exploited and with which to generate economic wealth. Part of this approach entails devising territorial management strategies in which land-use activities are carried out as a concrete and observable dimension part of broader ancient knowledge systems. There is often a conscious effort made by these groups to translate traditional teachings into concrete land-use practices, thereby recognizing the relevance of old knowledge that compels their adherents to entertain a profound, respectful relationship with their physical surroundings (Sherman, 2008). In some cases, this deep respect and admiration for the land compels Indigenous groups and individuals to resist what they consider irresponsible development or exploitation of natural resources by governments and/or corporations (see, for example, Desbiens, 2004; Scott, 2011; Sioui and McLeman, 2014). Landdependent Yucatec Maya possess a vast knowledge about the Yucatan landscape that could be useful to land use planning and natural conservation initiatives. However, so far, federal and state governments have rarely been receptive to including the Maya traditional knowledges, or engaging with them in sharing environmental management 
responsibilities. By failing to recognize and value the traditional knowledge of the Yucatec Maya, these governments could be missing an opportunity to conceive of and put into practice more holistic and sustainable land and water management strategies. However, the first step that was taken toward achieving this vision, and the main goal of this research project, was to document and interpret the present-day Maya land ethic and its influence on their relationships and interactions with the land.

Using postcolonial, Indigenous geographies and IK research approaches and theory, this project contributes to broader scholarly efforts that seek to better understand the similar challenges faced by Indigenous groups across the Americas in preserving cultural knowledge and traditional land-based activities in the face of changing political, cultural, social and environmental conditions and contexts. This research offers direct insights into the ways in which these Indigenous groups' land ethic is practiced, and gauges the similarities between the land-based worldviews and approaches to territorial management of these distinct Indigenous groups. Informed by robust theoretical frameworks, the IK-based lens used here generates new perspectives on how the Maya environmental ethos ("being part of the land," described in Chapter 6) can be part of broader efforts to ensure that their distinct cultural land-based knowledges not only remain in existence, but also influence their nations' (as well as global) future environmental policy. Through the approaches and schools of thought mentioned in this chapter, the intended key contributions to knowledge of my research are to help postcolonial scholars and geographers better understand how traditional Indigenous peoples' distinct epistemologies and land-based knowledges play out on their traditional territories in their day-to-day lives. Indigenous ways of knowing have historically been 
ignored in official environmental management policy discourse not only in Mexico but also in most other countries in the Americas, and remain largely excluded from official land-use plans and strategies (Battiste, 2000; Berkes, 2008). This project seeks to continue in the vein of postcolonial theory and Indigenous geographies in seeking to learn more about and valorize non-Western (and Indigenous) worldviews and the ways in which these can enhance Western society's approach to dealing with social and environmental issues.

\section{Conclusion}

I see my contribution to the postcolonial literature as providing a better understanding of how decolonization is not just about correcting past and present (neo)colonial wrongs, acknowledging and assisting Indigenous peoples' rights and struggles to have these rights recognized, and assisting Indigenous peoples in having their distinct perspectives and knowledges to be heard by the broader non-Indigenous collective. I want to instead highlight the insights that can be gained by overcoming and moving past colonial notions of territorial control and management, the dualism that exist in Western thinking between 'society' and 'nature,' and the belief in an "objective" science that is superior to Indigenous ways of knowing, being, and doing. I also believe it is important for postcolonial scholars to begin to see our relationship with the environment as a spiritual and moral one in which humans are not at the top of a hierarchy or in a position and role of absolute domination and control over it. In terms of Indigenous geographies, my research considers human-environment relationships in a less binary way. I use an Indigenous conception and definition of 'place-as-relationships' between all human and other-than-human entities that are in constant interplay on the 
land. In this sense, places are not just the setting for human experience(s), but humans are just one element of place. I offer an alternative spatial ontology that includes and valorizes identity, location, and belonging, which can be used by other Indigenous geographies scholars seeking to adopt more holistic and "Indigenous-centric" conceptual model for future investigations on Indigenous land-use patterns and practices. Lastly, with regard to IK research, I consider that my research adds an important dimension to understandings, definitions, and meanings of IKs. In addition to recognizing and explaining IKs as a way of living, in addition to a way of knowing, and acknowledging the agency of other-than-human actors, I frame my research within a responsibility-based lens that recognizes the significance to Indigenous concept of the concept of intrinsic and eternal responsibilities between all beings that constitute the land.

Throughout my research, the people of Xuilub expressed their firm belief in the presence and agency of other-than-human beings. A sense of responsibility, duty and reciprocity with these other-than-human actors currently shapes land-use patterns and practices in Xuilub in abstract and philosophical as well as concrete ways. Each human and other-than-human life form that shares the realm of existence has specific responsibilities and duties toward his/her or its relations. The milpero, for example, has well-defined duties toward the land, Catholic saints, Maya spiritual beings, and animals and plants that he must perform in order to ensure a good harvest. Prior to the hunt, the hunter must implore the Lords of the Forest, or yuntsiloob, through prayer and offerings, to provide him with game to bring home to his family. The Maya woman, who grows habanero chilies, beans, and oranges in her home garden, or solar, also expresses her responsibilities and duties that must be performed. In terms of my field research, 
responsibility-based thinking was evident in the more traditional land-use activities such as the ancient milpa system of farming, and hunting. It was also manifested by local apiculturists and cattle ranchers, who practice these historically non-Maya land-use activities. The responsibility-based vision springs from a cultural paradigm that understands that it is human beings who must "learn to live with the land," as told to me by one great-grandmother in Xuilub. This way of thinking instills in its adherents an inherent awareness that the other-than-human realm is capable of existing and thriving without humans.

Although several postcolonial and IK authors have mentioned Indigenous conceptions about responsibility and duty to the land, few, if any, have put forth the notion, explicitly, that perhaps this sense of responsibility to be part of the land could be considered one of the main drivers of Indigenous land-use systems and individual practices. From this duty to be part of the land stems the responsibility-based mindset that is reflected in land-based practices, spiritual beliefs, and community organization, as explained in this chapter and Chapters 5 and 6 . This proposed new way of thinking about Indigenous land-based cultures is perhaps the single most important contribution of this research to the postcolonial scholarship and could act as a useful theoretical device in furthering these fields' reflections, discussions and debates and findings on Indigenous environmental philosophies. Learning to be part of the land is about managing human beings' interactions with the environment instead of managing the environment. I reiterate that my view on the ways in which my 'responsibility-based' approach can enhance current postcolonial and Indigenous geographies conversations is based on my own 'situated knowledge.' This is my own interpretation, which I believe could be of 
benefit to others who are concerned with similar research themes and subjects as mine, but I am not suggesting this view should be adopted by all. In fact, the point of bringing attention to the idea of situated knowledges is to recognize that every individual's biases are what make her knowledges at once inherently unique (and useful) as well as flawed or incomplete. This is why Indigenous peoples value inclusivity and the "Circle" of relationships; everyone's voice and diverse knowledges are welcome because there is something valuable to learn from each person, each being, and every culture.

This chapter and the previous one have: (1) provided key background information about Yucatec Maya and a critical review of past research on their (spiritually informed) land-use patters in their homeland, and (2) laid out the theoretical framework that has guided my philosophy and approach related to my research in Xuilub. In the next chapter, I delineate my methodological approach to the field research (including data collection and data analysis) I carried out in Xuilub. 


\section{Chapter 4: Research Design and Methodology}

\section{Introduction}

In this chapter, I delineate my research design and methodology for my project in Xuilub. Specifically, I used a two-pronged data collection method, which consisted of experiential learning (which, I consider an Indigenous form of 'participant-observation') and semi-structured interviews. First, I discuss issues surrounding my positionality vis-àvis the research and the Xuilub community, and how this influenced the research process. I then delineate this research process and describe how I applied my methodological approach while being sensitive to the local Indigenous context (people and land) in Xuilub. I also discuss how I made sense of all the data that I collected, and how it was analyzed and interpreted, as well as how I dealt with ethical implications of this research. Lastly, I offer some thoughts about research contributions to the community, ethics, and some possible limitations of my research project and its methodology.

\subsection{Aim of the Study}

The study design and methodology for this project, which consisted of five trips to Xuilub from the spring of 2014 to the spring of 2016, was based on addressing the research questions laid out in Chapter 1. In order to address my research questions and objectives in the most efficient and comprehensive way possible, so as to collect formal data I elected to use methods of experiential learning and semi-structured interviews, situated within an Indigenous methodologies research philosophy that is predicated on building respectful and long-lasting relationships with the community. In addition, I 
sought to understand and make sense of more informal knowledges and information by using my own hermeneutic analytical approach in line with Indigenous methodologies and basic manual coding (my approach is described in 4.5.3 Data Analysis).

\subsection{Positionality}

\subsubsection{My Cultural Heritage and Family History and its Influence on my Thinking}

My family name_-Sioui_-means “rising sun” in my people’s Wendat language, which, although it is preserved in dictionaries, is not spoken anymore. My people's story began in Wendake, "the land of the Wendat" (or "Huronia," which came into colonial usage in the $19^{\text {th }}$ century), located near the present-day counties of Simcoe and Grey, southwest of Georgian Bay, Ontario. I am from the Turtle Clan and the Bear Nation, and am a descendent of Michel Sioui (Teashiandare, "the one who has two functions" 17661850), Chief of War and Diplomacy (Gariwha Doutagata) and Keeper of the Wampum of the Wendat. In 1825, he travelled to London as part of a delegation of four Wendat chiefs and diplomats to meet King George V of England and establish new formal diplomatic ties with the British Empire (see Figure 4.1). As a Headman of the Wendat of Lorette (near present-day Quebec City, where my community of Wendake is still situated), he saw diplomacy as the only way of ensuring the long-term survival of his people and his culture. The fact that I have written this doctoral dissertation is testament to the success of his strategy. The cultural precept of diplomacy and of building bridges and establishing relationships with other peoples and cultures has for centuries been ingrained in Wendat thought. It is this fervent sense of pride and responsibility to protect the Wendat intellectual and cultural traditions that inspired my father Dr. Georges Emery 
Sioui ${ }^{1}$ to lead three of his other brothers in a legal contention against the Government of Quebec to uphold the Wendat ancestral right to use their territory for cultural purposes, protected by the Murray Treaty of Longueuil (1760). In 1982, four of the five Sioui brothers, Georges, Régent, Konrad, and Hugues, were performing a traditional Wendat ceremony in Jacques-Cartier Provincial Park, when they were charged with violating section 9 of the Québec Parks Act, which prohibited cutting trees and making fires in undesignated areas. They took their case to the Quebec Court of Sessions of the Peace and were convicted of the charge against them. In 1984, they appealed the decision in the Superior Court of Quebec and were again unsuccessful. Then, in 1985, they won when a two-to-one majority of judges ruled that the Murray Treaty was a valid treaty protecting the Wendat's Indigenous rights over certain provincial laws and regulations. However, the Province of Quebec appealed the ruling and the case went to the Supreme Court of Canada. In 1990, the Supreme Court unanimously ruled in favour of the Sioui brothers in the R v. Sioui case. The Sioui case has changed the way in which Indigenous rights and treaties are interpreted in Canada and has since influenced a number of landmark Indigenous rights cases such as the $\mathrm{R} v$. Marshall case (1999). I use these examples to impress upon the reader that my pride in my Wendat culture and tradition, and imperative

\footnotetext{
${ }^{1}$ Dr. Sioui was Full Professor and Coordinator of the Aboriginal Studies Program at the University of Ottawa before he retired in 2016. My father is the first First Nations person in Canada to hold a PhD in history, and he has penned a number highly influential books in the Indigenous studies and philosophies fields, including For an Amerindian Autohistory and HuronWendat: The Heritage of the Circle, first published in French in 1989 and 1994, respectively. His works have been translated in a number of different languages. He is also a polyglot, published poet, and songwriter.
} 
to carry on these traditions, is not new; it comes from a long line of Sioui chiefs, intellectuals, and Indigenous leaders. I am simply fortunate enough to be an inheritor of this ancestral treasure and profoundly "Canadian” legacy.

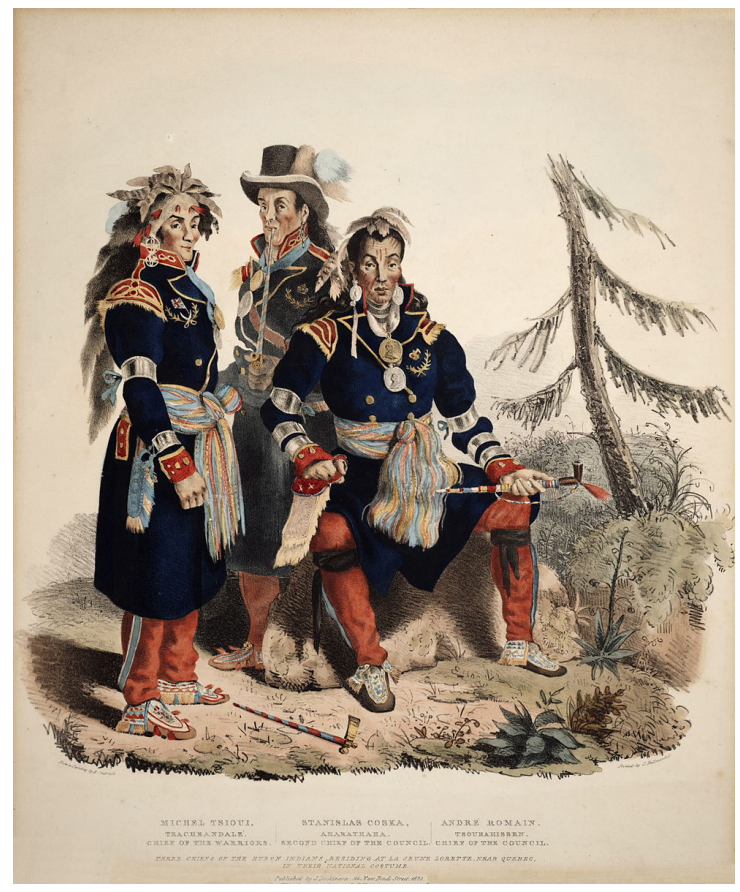

Figure 4.1. Portrait of Michel Sioui (left) and two other Wendat chiefs in London (1825) (original author: Edward Chatfield (retrieved from https://www.torontopubliclibrary.ca /detail.jsp? $R=D C$

To sum up my personal (Wendat) philosophy and what I feel is my missionsince birth — as a Wendat "Warrior of Words," as my father Georges says, I offer you this poem by him (Sioui, 2013, p. 85):

\section{We are the Wendat}

"The Hurons are the aristocracy,"

The French said.

We had built

And we maintained

The Heart-Country,

Wendake. 


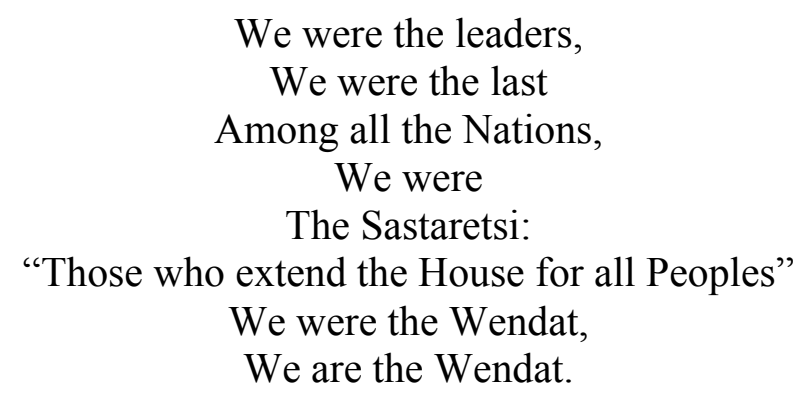

One of my given names is Sastaretsi, which, as expressed above, means I have the lifelong responsibility of "extending the rafters of the Longhouse," or of establishing relationships and common ground with others regardless of their culture and background. This duty was set out for me before I was even born, and I will continue to carry these traditions, voice, and mission of my ancestors until I cease to exist in this realm. I am ineffably proud of my ancestors for preserving their (cultural) intellectual tradition and heritage through colonization by the French (and Jesuit priests, the original French colonial agents), epidemics that left them decimated, and then a massive dispersal of their remaining populations from their homeland of Wendake to New France, Michigan, Ohio, and Kansas in the 1650s, following decades of warfare against the British. My ancestors were part of the group that relocated near what is today Quebec City and proudly carried, for generations, and ultimately bestowed upon me their name- Sioui, which I am equally honoured to bear. It is my duty to represent my Wendat ancestors' name and all the things it represents.

As Michel Sioui and my other Sioui and Wendat ancestors, I was raised in the spirit of justice, diplomacy, and ideas, and am thus keenly aware of the need for harmonizing relations between Indigenous and non-Indigenous communities through the creation of mutually usable channels of communication. In my opinion, the key to 
achieving this result is the erasure of the chasm that has historically separated the Indigenous and academic epistemologies and ways of knowing, doing and being. For a variety of reasons, until recently, Indigenous ways of knowing were more or less absent from official environmental management considerations in countries like Canada and are still excluded from Yucatan's official land use plans and strategies hinging on tourism and large-scale agribusiness. As a Wendat thinker and a geographer, I see my purpose as a cultural translator between two worlds that have historically been unable to meaningfully communicate. I believe this harmonization process will be mutually beneficial to the holders of both knowledge systems by assisting them to develop environmental management strategies that are more likely to promote responsible and respectful relationships with the environment in the long term. It is my hope that this effort will help the global society to deal more credibly and effectively with complex environmental management challenges. This personal position with regard to Indigenous knowledges and land-based practices has certainly informed my research from start to finish, and has influenced my interpretation of the Maya knowledges I present in this document.

It is this deeper motivation that initially sparked my interest in the field of environmental studies and management. With its acute spatial consciousness and humanenvironment interaction focus, the academic discipline of geography (and environmental studies) is in my view the best positioned of the social sciences to commence this harmonization process in tandem with IK approaches. My perspective is in line with the concept of "two-eyed seeing," an Indigenous research methodological approach that calls for using one "eye" to see with the strengths of IKs and the other to see with the strengths 
of Western knowledges (see Bartlett, Marshall \& Marshall, 2012). My growing interest in Indigenous environmental management paradigms compelled me to pursue my M.A. in geography. My two-year participatory research project sought to understand the traditional Algonquin spiritual ecology (mino pimàdiziwin) as it is currently practiced by members of a federally unrecognized ("Non-Status") Algonquin group in eastern Ontario, and compare it with land-use ethics underlying resource development strategies promoted by the Ontario government. Although I found that the two visions are fundamentally at odds, I identified some opportunities for future partnership and collaboration between the two parties.

In terms of the importance of Elders as holders and transmitters of IKs to the younger generations, which I discuss with regard to the case of the Yucatec Maya in this text, this is also a notion with which I have been familiar since I was a young child. I have many vivid memories of participating in various Indigenous cultural activities and ceremonies, such as hunting, trapping, smudges, sweat lodges, powwows and other dances, and traditional feasts like the potlatch. In each of these activities, it is Elders from the community who teach the younger ones how to perform or carry out these activities in a respectful manner that teaches us about our responsibility to and our relationships with land. I have long been keenly aware of the importance and special role of Elders in Indigenous cultures throughout the world. In my own Wendat family, our Elders-and especially the female ones (like my late grandmother Dr. Éléonore Tecumseh Sioui 
CC)— were and are greatly venerated and celebrated ${ }^{2}$, and they are people to whom we turn when we want to learn more about our history, the way of our ancestors, and how to relate with one another and with the land. The (cultural) importance of Elders has been well documented in countless studies on Indigenous groups around the world, and I go back to this concept and cite examples in later chapters.

As a result of this prior understanding of the special role of Elders in my and other Indigenous cultures, I began my research in Xuilub with the assumption that Elders in the community would be highly considered and respected by all. Again, in this case I found much empirical evidence (discussed in Chapters 5 and 6) to support my assumption. My understanding of the role of Elders has not changed as a result of this research. Rather, my experiences with Elders in Xuilub, and my witnessing their treatment by younger people, has reinforced the ideas that I already had.

\subsubsection{How My Culture and Background Have Informed My Research Methods}

Naturally, my cultural and family history, laid out in the previous section, influences the way in which I view and conduct research and relate with people both inside and outside my community. I was raised in an Indigenous tradition of respect for other peoples and a recognition of their position of authority on their homelands. Since I was a little boy, I was taught by my Wendat family to be humble and learn from other cultures about their philosophies and ways of knowing, doing, and behaving when I am a guest, as I was to the Yucatec Maya of Xuilub who hosted me and treated me like a family member during my five trips to the area as part of my field research. I always seek

\footnotetext{
${ }^{2}$ This is true of all Iroquoian cultures, where women have always occupied positions of authority in our societies.
} 
to learn from Elders in any Indigenous community I visit, as I respect them greatly and know they are the ones who carry their culture's traditions and knowledges. Furthermore, Elders have had many more years than others to learn how to live according to the realities and conditions in their homelands. In my research in Xuilub, I assisted Elders in whichever way I could in order to show my respect and appreciation for them.

Nevertheless, although I share certain elements of a common way of thinking with the Maya, I do not claim to be a member of their community or have an "insider perspective" of their culture or IKs. Prior to beginning my field research, I definitely had some concerns about how to navigate being an "outsider" to the community. For example, I recall introducing myself and sharing my proposed research plan to with Xuilub ejidal council during my first trip to the community in the spring of 2014 with my doctoral advisor Dr. Smith. After some nervous first moments and introductions with Maya leaders and Elders, and hearing the way in which they spoke and welcomed me to their community, I immediately felt more at ease. I then felt comfortable opening up and sharing with them my own cultural background as an Indigenous person. I could see they were surprised to hear I was Indigenous as, for the readers who have never seen me, my appearance would not be considered as typically "Indigenous" by any means. However, once these people heard my story (translated from Spanish into Mayan by Demetrio Dzib Canche, my local research partner), I was able to see smiles on their faces and a few of their heads nodding. I was driven to tears while talking to the audience. I could see my own Wendat ancestors in their faces and mannerisms. Seeing me having trouble articulating my thoughts while fighting back tears, one elderly man stood up to comfort me and said, "you are one of us and you'll always be treated like a relative here." That 
day was the first time I was able to experience what other thinkers and scholars meant when they talked about Indigeneity. The people in attendance had no prior cognizance of my Wendat people, or of any "northern" Indigenous people, for that matter. Yet by hearing the way in which I expressed myself and told them about wanting to learn from them how to relate with their mother, the Earth, in their homeland, I sensed that they understood who I was and where I was coming from, spiritually and emotionally.

The goal of the above story is not to argue that questions of my outsider status and relative privilege as a university-educated citizen of one of the world's most prosperous countries are irrelevant. It simply serves to illustrate how that moment and my initial spiritual connection with the Maya people and their land allowed me to really believe that there was perhaps hope for me to become something more than an outsider, with a continued effort to build a strong relationship with them. I am, of course, aware that there remain questions about my privilege and status, as well as a language gap, that influences the nature of my relationships with the community and its members. I recognize that I will never be fully "Maya" or a member of Xuilub, but that is not to say I cannot continue to build strong — even familial— ties with the land and its people. That is the only way I know how to relate with other Indigenous peoples and their traditional territories. I believe that, as Wilson (2008) offers, "the source of a good research project is the heart/mind of the researcher," and "a good heart guarantees a good motive, and good motives benefit everyone involved" (p. 60). Having a good heart and mind can, in my view, go a long way with regard to breaking down some barriers that come with being an outsider to a community. In my case, I am grateful for my position as an Indigenous academic, but I do not take it for granted. I fully intend to continue to use this status and 
privilege for the benefit of communities like Xuilub in any way that they believe is appropriate.

Despite the best intentions of the researcher, however, the question of language is of critical importance to the research. Language is often one of the main limitations that even Indigenous scholars face in working in other Indigenous contexts and with Indigenous cultures that are not their own (Lambert, 2014 addresses this problem). Indigenous languages are often considered extensions of Indigenous worldviews and ways of knowing, being, and doing, and each one carries unique cultural information that is specific to a certain place - in this case, the Yucatan. For this project, I did my best to convey key ideas and concepts in Spanish. Many of the people in the community do not speak Spanish, so my words had to be translated to them into Mayan by Demetrio. Also, in many cases my interviews and discussions with individuals had to be translated from Demetrio's Spanish into English when I was transcribing them for future analysis and interpretation. As a result, I must admit and warn the reader that what my understandings and representations of the Mayan land ethos and IKs, and the terms and vocabulary that I use to describe them, are unlikely to be perfect or complete, as this project involved countless translations between these three languages. This obvious limitation notwithstanding, I believe I put forth my best effort to make sure my representations are as accurate as possible, by sharing them with the community on numerous occasions (town hall meetings, interviews, and informal discussions with community members) and noting and incorporating all suggestions. Moreover, as a person from a culture whose language is no longer spoken, I have had a lifetime of experience in dealing with this issue in my interactions with people from a wide variety of Indigenous groups. Clearly, 
the linguistic issue is a significant limitation, but "even if you don't speak the language, you can understand the Indian heart and soul in what they're saying," as I was once told by a Cree Elder from Saskatchewan when I asked him for advice on dealing with this problem. I lived by this advice in Xuilub and trusted that my Wendat "heart and soul" would guide me in my interactions with my Maya "family."

\subsection{The Research Process in Xuilub}

\subsubsection{Indigenous Methods}

As is the case with Indigenous groups elsewhere, the Yucatec Maya have, over the last five centuries, experienced strained relations with governments, states, and other outside interests (Alfred, 2009; Yashar 2005). There has generally long been a history of academic exploitation and appropriation of their land-based knowledges. In order to prevent this, I incorporated Indigenous research methodologies (such as the ones outlined above) in my methodological approach. Also, given that I am an Indigenous researcher, I was particularly dedicated to making sure that I established and maintained respectful research partnerships with the community and its members, as well as the land on which the research took place, by making offerings of tobacco and sweet grass from Canada to the Yucatec land each trip upon arriving in Xuilub (Louis, 2007 stresses that research relationships with Indigenous groups should extend beyond the human community-the researcher must also establish relationships with the Indigenous land on which the research takes place). Indigenous and non-Indigenous geographers and other postcolonial scholars have stressed the importance of developing Indigenous research methodologies in order to respectfully engage with Indigenous communities and individuals in the study of culturally sensitive knowledges. 
There are particular challenges and considerations associated with conducting field research in Indigenous communities. Castellanos (2004) writes that, more frequently than in most other groups, Indigenous communities that are the subjects of academic research are often concerned about the appropriation of their IK by western researchers. As a result, many Indigenous communities around the world have grown wary or distrustful of academic researchers, who in many cases are seen by Indigenous research subjects as "parachuting" into a community, collecting the necessary information to meet their own objectives and leave, never to be heard of or seen again (Tuhiwai Smith, 1999) Therefore, it is crucial that the researcher recognize and highlight in her research methods the importance of respectful relations and relational accountability to Indigenous people (Wilson, 2001; 2003; 2008; Louis, 2007).

This requires that the researcher seek to build meaningful—and lastingrelationships with the community and local research partners ${ }^{3}$. In this light, Rundstrom and Deur (1999) have set out some general principles for academic researchers to follow that are informed by an Indigenous outlook on relational (as opposed to extractive) research:

(1) Relational accountability: the interrelatedness and interdependence of all life, including parts of the research process, and the accountability of the researcher to each thread in the interconnected web; (2) Respectful representation: a thoughtful and humble consideration of how a researcher represents self and all parts of the research; (3) Reciprocal appropriation: recognition that "all research is appropriation" and benefits must be fairly shared; (4) Rights and regulation: an understanding that Indigenous peoples have control over research protocols and control their own knowledge (qu. in Louis, 2007, p. 133).

\footnotetext{
${ }^{3}$ I use the term 'research partner' instead of 'participant,' as I consider the people of Xuilub who have shared their knowledges with me to be partners in this joint research project with the community.
} 
Also, in order to produce culturally respectful research, the researcher must be willing to modify her research, in order to better accommodate the interests and goals of the group. This can be problematic if the researcher arrives in the community with a rigid research plan. Menzies elaborates on this idea: "It is important that the researcher be prepared and willing to modify the plan to accommodate the needs and protocols of the [community]" (2001, p. 22). The researcher must thus be well attuned and responsive to the needs and requests of the collective, to make sure the community understands that the study will not result in a one-way appropriation of IKs by the academe, and that the research will aim to produce recommendations that will be of practical use to the community. Moreover, the findings/results of the research should be made available to the community for discussion, debate and review whenever possible (ibid.). This means that the researcher must make a meaningful effort to periodically share and discuss her findings and make modifications to her research upon request from community members. The involvement of the community at all stages of the research process is essential to the project's academic integrity and credibility in the eyes of the aboriginal community.

\subsubsection{The Research Process: How I Applied Indigenous Methodologies in Xuilub}

In order to make sure that Indigenous methods principles were not only followed, but also adapted to the specific context, needs and objectives of the Yucatec Maya, I had discussions with Maya individuals, prior to conducting interviews or any official field research, during which I asked them to share their thoughts on what they consider to be culturally appropriate research methods and protocols as outlined above. At every step of 
my project, I sought to engage in meaningful consultation with community members, and provided opportunities for research partners to offer me guidance and advice.

My first trip to Xuilub came before my dissertation project proposal defence. Thus, I needed to present to my PhD committee a proposed project that would, in their eyes, lead to the writing of a dissertation that would be defendable and in accordance with the rigors and standards of academia. However, it was always a priority for me to make sure I was following Indigenous methodologies. The researcher's commitment to co-designing the research project with the community is one of the key components of Indigenous methodologies. Therefore, at my dissertation project defence, I made sure to explain to the committee members that the research question(s) that, although I thought the research question(s), research methodology, and overall project I was defending that day was respectful and useful to the community, an important principle in Indigenous research is to have consultations with community members to possibly modify some elements of the research project according to the needs and interests of the community. Thus, as I stressed to the committee, I could not guarantee that the community would accept the project or the research question as it was presented on that day. Thankfully, my committee was sensitive and understanding of the need to follow Indigenous research methodologies, and all were in agreement that my proposed project was not set in stone and were willing to allow me to change certain questions and elements of the proposed project.

When I got to the community and started having conversations with members, as well as later hosting formal town hall-style meetings to present my vision for this research project, my ideas and proposed project were welcomed. A number of different 
community members of all ages and occupations, both women and men, told me they were happy I was approaching this research with a more holistic philosophy, but recommended I make a slight change to my research focus. In retrospect, after re-reading my original project proposal, I can see that the focus of the research changed slightly. Whereas my original proposed idea focused more on milpa farming and less on other land-use activities in the area, a certain community members told me the believe that although milpa farming is central in Maya culture, I should not neglect other land-use activities being done in the community. I should especially not, as one woman told me, neglect the importance of social organization in the community, which should be stressed in order to show the young people a good example. My first town hall meeting, one milpero mentioned that previous academic researchers who had done work in the community wanted to focus only on what they saw as one small part of their culture (e.g. only honeybees, deer hunting, a certain medicinal plant species, etc.) in isolation from their broader spiritually informed Maya worldview. I received very positive feedback from many community members who believed my approach of interviewing Elders and milperos, solar gardeners, apiculturists, hunters, and cattle ranchers had value, as they wanted these knowledges, and especially the words of the Elders, to be documented and preserved and immortalized for the benefit of the younger generations of today and future generations. Thus, I believe I did my best to include the community from the outset of this project, and am gratified that there was general consensus as to the value of our joint effort, with community members' roles as consultants, contributors and local research partners, and my role as learner, researcher, and writer. 
As a final note on the Xuilub community's input into this research project, though I made an effort throughout my field research to include input from community members, I cannot say this project and its methods were truly co-designed with the Xuilub community. Due to the narrow scope and very specific objectives that have to be me as part of a PhD research project in a Western academic institution, the prospect of codesigning the research with a community is fraught with challenges and risk to the student/researcher.

In the following paragraphs, I provide further stories and examples of how my research process applied some of the key principles of Indigenous methods in four key dimensions.

\subsubsection{Developing Relationships}

In order to develop meaningful relationships with the people of Xuilub and their land, in my first two trips to the community I shared stories with them about our respective cultures and how we know what we know, and our views on relating with the land, our Mother. Many of them were amused and amazed by my stories of the Canadian winter and the cold, ice, and snow that are part of us as Wendat (and other northern) peoples. We also shared stories about our land-related IKs, and I had many a conversation about our respective hunting/trapping methods, animals, and medicinal plants. I shared my knowledge of traditional plants that was taught to me by my grandmother, who was a traditional healer. I also approached different Elders in the community and invited them to chat over refreshments. I asked them if they needed help with anything in their homes or in their work (e.g. milpa, cattle ranch, etc.) and made myself available to assist them in any way, as that is the way of my culture that I have 
learned. I also bonded with Xuilub kids through our shared love of baseball, which is the most popular sport in the Yucatan. Together, we played many baseball games over the course of my five trips, and I believe this helped me to relate with them and to gain their trust and friendship. Also, with regard to developing a strong bond with the community's youths, in the summer of 2016, following a request I got from one mother, every evening for two weeks I taught English to two groups of students, one with elementary schoolchildren and the other with high school students (see Figure 4.2). Many of their parents personally thanked me for taking the time to teach their kids something that they believed would be very useful to them in the future.

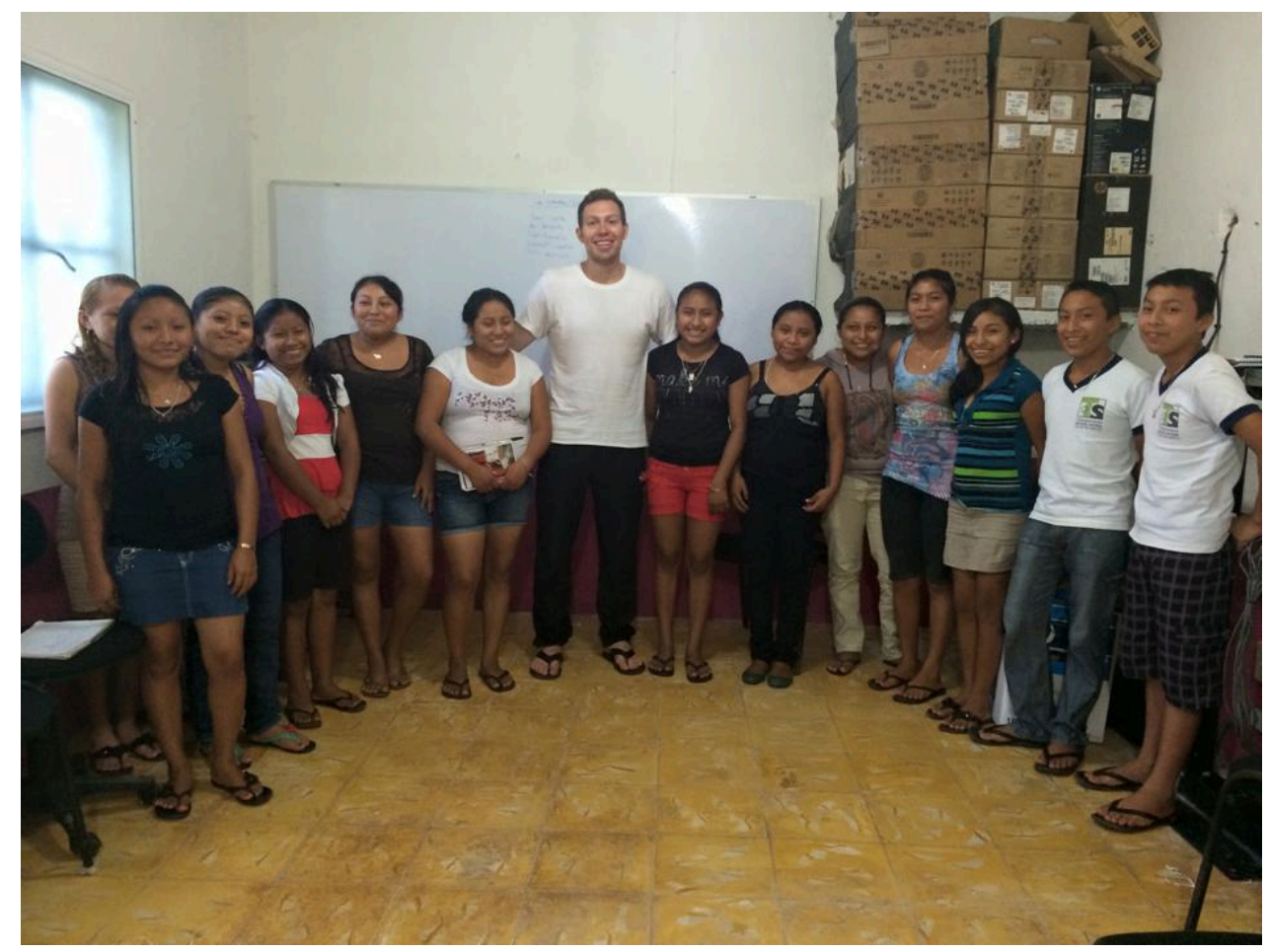

Figure 4.2. The author posing with his some of his English students in the computer and media facility in Xuilub. 


\subsubsection{Working Together}

At my first "town hall" meeting in Xuilub, I shared my plan of working with everyone in the community, and announced, "I'm here to learn from all of you and I want to help in any way that you consider useful.” I was glad that right away, milperos, apiculturists, hunters, and cattle ranchers expressed their willingness to take me up on my offer and show me how they did their work. I ended up going out on the land with a number of the people who were at that meeting. I believe my announcement and genuine willingness to learn and help went a long way in showing them that I was/am committed to respectfully engaging and relating with the community and the land, and that it is a long-term engagement. I also went around the ejido with Demetrio to introduce myself door to door and to have informal discussions with ejidatarios and inform them of my purpose and share with them my personal background. I engaged these people in discussions about my research and personal intentions, and told them to let me know, at any point during my research, if they had any thoughts or concerns. Before any interview or work on the land with an individual or group, I made sure to ask if I could write notes, take audio recordings, and to include/use some parts of our informal discussions in my dissertation, and all of them gave me their oral consent (see Appendix C). My informal discussions and interactions with the people of Xuilub were an integral part of my research process and the evolution of my understanding of the Mayan land ethos. Even though I did not devise a formal strategy to synthesize and interpret the knowledges I gained from my informal interactions and discussions with my research partners (such as the one for semi-structured interviews and experiential learning), the insights I gained as a result of these were critical to my hermeneutic analysis method (delineated in 4.5.3). 
Also, prior to taking photos of any individuals or the land, I asked for permission and informed them that the photos may appear in my dissertation and any subsequent publications.

\subsubsection{Seeking Feedback}

In order to seek meaningful feedback from the community, I made sure to organize at least one town hall meeting during every trip to Xuilub. At each meeting, I expressed my current state of understanding with regard to the Mayan land ethos and IKs and asked for clarifications when something was unclear or was difficult for a non-Maya person to grasp. I also asked them at each meeting to share with me ideas about what they considered appropriate research protocols to follow in their community and on their land. Some directives that I adopted as a result of these discussions include: (1) not naming my community research partners and knowledge holders or making it so that they can be easily identified in my writing; (2) treating the land as they do/would; (3) providing updates about my progress during each visit (which I did); and (4) promising I would come back to the Xuilub once the research is finished in order to present my research findings and hold open discussions with community members in terms of how best to apply/mobilize our research (which I am still very intent on doing, and I elaborate on this in 4.6 later in this chapter).

4.3.2.4 Maintaining my Relationships in Xuilub: How I Worked Toward My Long-Term Accountability to the Community and the Land

The involvement of the Xuilub community at all stages of the research process was essential to my project's academic integrity and credibility in the eyes of the Yucatec Maya. At every step of my project, I sought to meaningfully engage in community 
consultation with its individuals, and provide opportunities for them to offer me guidance and advice. This was done by corresponding on a bi-weekly basis with Demetrio by email and telephone conversations in order to receive feedback and comments from partners in my research, as well as other interested community members. During these biweekly progress reports, I discussed with him what I was currently working on and how my project was evolving.

Having now completed my field research with the community, I consider myself to be friends with Demetrio, as well as with his extended family. As an example of my close bonds with his family, during my second trip to the community (December 2014January 2015), I was invited, along with my parents (who were vacationing in Valladolid), to participate in the noche buena (Christmas Eve) and New Year's Eve celebrations hosted by the comisario's family. This special event made our bonds of friendship even stronger and, I believe, helped to solidify my research partnership with the community. Since I started my research in 2014, I have kept in close contact with some of the Xuilub community's leadership and other families and have become involved with the community beyond my the "researcher" capacity. On many occasions I have been invited inside the homes of Xuilub members and consider many of them friends. Because of my close relationship with the community, I believe that many Xuilub members have come to trust that my research will benefit the community once it is ready to be shared.

The above discussions highlight some of the ways in which I have applied and am committed to using Indigenous research methods in Xuilub, centred on the building of respectful research relationships - and familial bonds — with the Maya of Xuilub. For me, 
this research process is nothing out of the ordinary; it is how I have learned to relate with other Indigenous people across Turtle Island. The cultural values of relationships, respect, reciprocity, and love for the land, which, as I found out, were very strong in Xuilub, are the same values that I live by. I treated my Maya hosts in the same way my Wendat ancestors would have treated a Maya guest. As a people of diplomats and traders, the Wendat knew the importance of respecting other peoples' cultures, especially when they were guests on their homelands. That is how they understood and practiced responsibility and accountability, and in turn that is how I implemented these principles in my research with the Maya of Xuilub.

\subsection{Preliminary Planning Considerations for my Research in Xuilub: The Geography and History of the Community}

With an area of approximately $32 \mathrm{ha}$, Xuilub is located in the eastern part of Yucatan state approximately $40 \mathrm{~km}$ southeast of Valladolid (see Figures 4.3 and 4.4). It is roughly two to three kilometres northwest of the Yucatan-Quintana Roo state border. At the centre of the ejido is the 'comisariado,' or the main administrative building. Most houses are located within a radius of one kilometre of the community's main cenote, which is the "heart" of the community. There is a Catholic chapel next to the comisariado that is also central to community life and events.

With this basic geographical information about Xuilub to help situate the reader, I now provide a (very) brief history of Xuilub and its members, as well as some basic demographic statistics of the community. This basic information provides necessary context for my research findings presented in Chapters 5 and 6. 


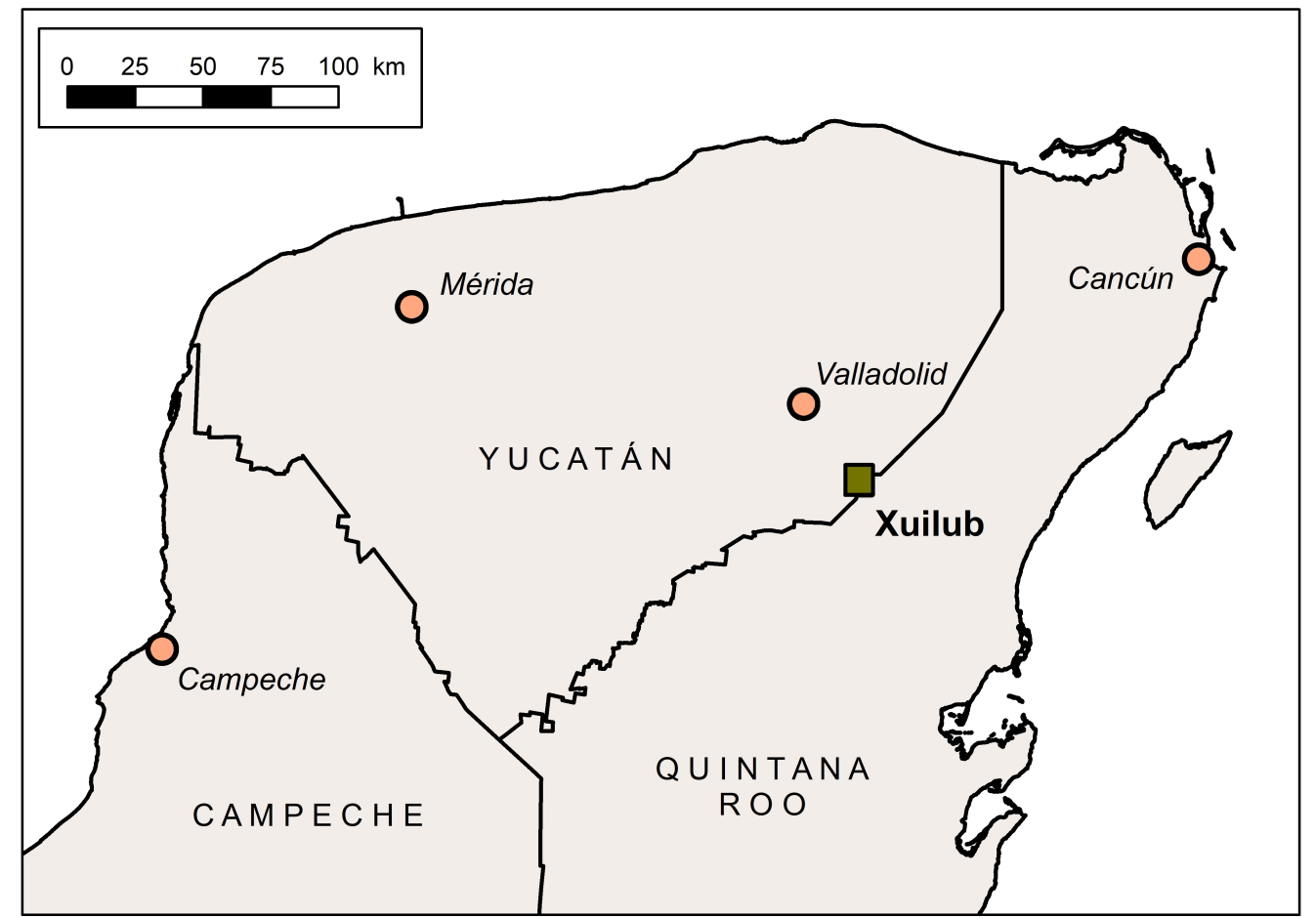

Figure 4.3. Map of the location of Xuilub in relation to the Yucatan (map by author and D. Smith)

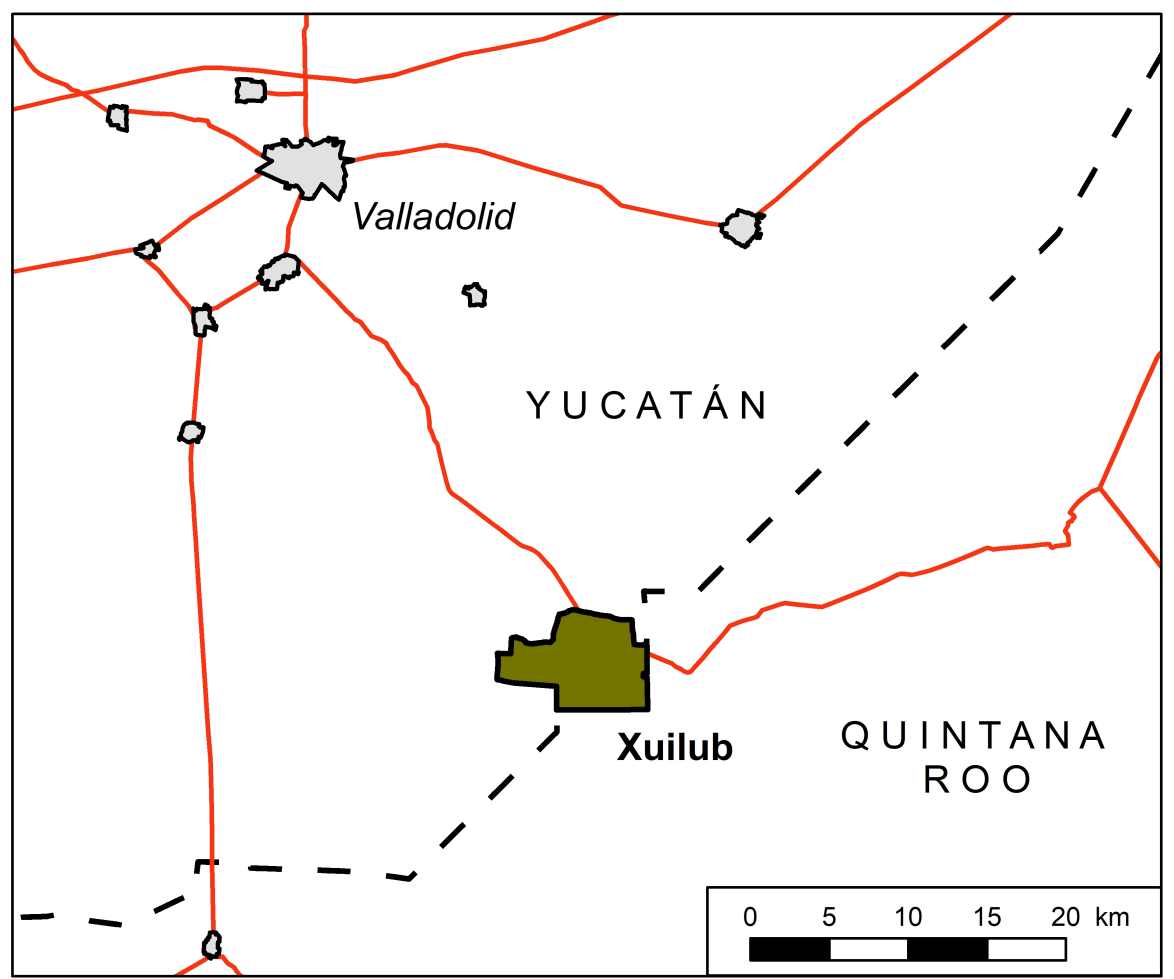

Figure 4.4. Map of the boundaries of Xuilub and Xuilub's position in relation to Valladolid (map by author and D. Smith). 


\subsubsection{Xuilub: Past and Present}

As mentioned in previous chapter, the Caste War took a large toll on the Yucatec Maya. Maya farmers were forced to flee their agricultural lands in order to survive; many of them went into hiding in the forests and subsisted for years mostly on wild roots and plants (Reed, 2001). As a result of the War, traditional Maya livelihoods and cultural and economic systems were temporarily abandoned. Although the end of the conflict marked a new period of freedom for the Yucatec Maya, most families were living in squalor as they were unable to secure stable sources of income as they had in past times (Rugeley, 1996). However, groups of survivors of the Caste War established a number of Maya communities throughout the Yucatan Peninsula. Of those pioneers, three brothers, Buenaventura Dzib, Teodoro Dzib, and Alfonso Dzib, officially established the community of Xuilub approximately 150 years ago, after roaming the Yucatan for years trying to find a new home. According to the Elders and community leaders I interviewed, the Dzib brothers, still reeling from the conflict, made their way deep into the thick forest along with other families of survivors, and stopped at a cenote to rest and replenish their water supplies. Buenaventura Dzib, the eldest of the brothers, noticed that the cenote was replete with catfish. Aware of his group's exhaustion and poor health, the leader Buenaventura decided that his people would travel no more, considering that this was an ideal location to establish a permanent community, as it was nestled in lush vegetation, ripe with edible plants, fruits and game animals. The elder brother named Xuilub after his discovery of catfish - Xuilub literally means "here, there are catfish." Over the years, the pioneers of Xuilub slowly cleared the heavily forested land and converted it into milpas and land upon which to build their homesteads and gardens. Xuilub's present-day 
residents are for the most part direct descendants of the pioneers that established this community over a century and a half ago. In fact, to this day, there are many people in the community who belong to extended Dzib family.

According to the most recent and (and most accurate, in Demetrio's estimation) census of the community done by the local medical clinic in 2015 (which I examined in March 2016), Xuilub counted 707 ejidatarios (shareholders or members of the ejido), of which 362 were male and 345 were female. Youths make up a large portion of Xuilub residents, evidenced by the community's median age of 23 , about 4 years younger than that of the population of Mexico ${ }^{4}$. Adults under 40 also make up a significant proportion of Xuilub's population (78\%). $89 \%$ of community members speak Mayan, and 27\% speak only Maya and do not have a working knowledge of Spanish (i.e. elderly people). I was told by Demetrio that the $11 \%$ of non-Mayan speakers is made up of mostly spouses of Xuilub natives born outside of the community. In order to live in Xuilub, these 'outsiders' have to be voted in by the ejidal council. The main occupations for men (over the age of 18) in Xuilub is milpa farming and construction work, as well as apiculture to a lesser extent. Most women are listed as homemakers, although a large number of them keep home gardens and in some cases sell or trade their products with other women from neighbouring ejidos, or in markets in Valladolid. Unfortunately, there is very little current official government data about outmigration patterns and demographic changes in the region's ejidos including Xuilub.

\footnotetext{
${ }^{4}$ Indigenous populations around the world tend to be young. In Canada, for example, the media age of the Indigenous population is 27, compared to 40 for the national average. This is in part due to health disparities (earlier death) and a high birth rate (see Adelson, 2005 and Guimond, Kerr \& Beaujot, 2004).
} 


\subsection{My Field Research in Xuilub}

My fieldwork in Xuilub consisted of five trips (one preliminary "introductory" trip and four subsequent official research trips) from May 2014 to March 2016. The following is a breakdown of the dates and number of days spent in the community during each trip:

Trip 1 (May 2014): 7 days

Trip 2 (December 2014-January 2015): 10 days

Trip 3 (July-August 2015): 31 days

Trip 4 (October-November 2015): 10 days

Trip 5 (March 2016): 10 days

Total number of days spent in the community: 68

I visited the community at different times of the year in order to cover all of the seasons or stages of the agricultural, apicultural, hunting, and cattle ranching cycles.

Prior to conducting formal research, I accompanied my doctoral advisor Dr. Derek Smith to the community in May of 2014. Dr. Smith already had a multi-year relationship with the community and its leadership, and had successfully carried out a participatory mapping project with several community members. The community had received tangible benefits from Dr. Smith's project, including the delivery of the finished community maps (created using data related to the location of culturally significant sites, produced by community members and Dr. Smith as head cartographer). Dr. Smith advised me to travel with him to the community to meet community members and present my research plan to them and to get some form of approval from the community leadership, namely the comisario. The small village of Xuilub was suggested by my doctoral supervisor Dr. Smith as a research base for my project due to its proximity to Valladolid (one of the major cities in Yucatan State), other land-based Yucatec Maya 
communities and sites of cultural significance, in addition to its amenities (e.g. accommodation options, Internet access, etc.). The comisario of the community at the time expressed to me his full support and trust, given his respect for Dr. Smith, whom he believed would be a good mentor for me.

It is during that trip that I met Demetrio Dzib Canche, a man from the community, then in his mid-20s who was Dr. Smith's main local research partner at the time. After discussing with Demetrio about my research plan and goals, he told me he was confident that with his help my research project could be successfully carried out. I was quite pleased to have found someone from the community whom I thought would become a great partner and friend. Demetrio has indeed been instrumental to my project's success. He has served as a research partner, translator (from Maya to Spanish and from Spanish to Maya), and my local guide in each of my five trips to Xuilub. Quite certainly, I would not have been able to see the project through without his help. Demetrio's contributions were crucial to this research project. His upbringing, as he has told me, was very much land-centered, and he is a native Maya speaker, although he is also fully fluent in Spanish. His family currently practices apiculture, and one of his grandfathers is an Elder and milpero who, despite his old age, continues to work the land every day. Demetrio has told me that he is actutely familiar with the teachings of the old people, and has learned to work the milpa the traditional way. Moreover, at the time of my field research, Demetrio was the director of the computer and media centre in Xuilub, where he regularly taught classes to youths on information technology. Hailing from an influential and wellrespected family in the community, he has long been well connected with the majority of his fellow community members. Two years prior to working with me on this research 
project, Demetrio completed a bachelor's degree at the Universidad de Oriente (UNO), and is thus accustomed to different forms of academic work. For these reasons, I could not have asked for not only a more competent local research partner, but also a person from the community more respectful of the Maya culture and land-use traditions. Although his contributions to the project were manifold, the two most important ones are the following: through his connections with a great number of members of the Xuilub community, he knew exactly which women and men, from Elders and milperos, apiculturists, hunters, and apiculturists to seek out as potential participants in this project (this is work that he did independently while I was in Ottawa); his work as a translator was invaluable, as a person who was able to translate very complex Maya knowledges and land-related stories from interviewees into Spanish while expressing the essence of those knowledges in a way that I could understand as a non-Maya researcher.

Demetrio's hard work in seeking out and approaching potential participants and translating the Maya IKs of a variety of different people in the community made my work much easier. I want to reiterate that Demetrio's work was integral to this research project and dissertation. I want the reader to appreciate Demetrio's work and to make sure I give him the credit he is due. Thanks to his contributions, I was able to gain a great deal of rich cultural knowledge and information about Maya culture and land-use philosophies and practices that were expressed by different interviewees and other community members in Spanish. This made it possible for me to have access to a bigger bank of cultural information, from which to then interpret and synthesize all of this knowledge, develop my own original ideas related to my understanding of the Maya land ethos, and ultimately articulate these ideas and arguments in this dissertation. Nevertheless, given 
how this research was conducted, and the fact that I did all the analysis and interpretation and writing of the dissertation, it is appropriate that I am the sole author of this dissertation. At the same time, I want to underline the fact that Demetrio was more than simply an assistant.

\subsubsection{Recruitment of Research Partners}

In terms of my experiential learning and interviews, it is Demetrio and I who identified research partners for both interviews and experiential learning. We sought out individuals who practiced milpa farming, apiculture, home gardening, hunting, cattle ranching, and those who were knowledgeable about ceremonies and spirituality. Demetrio was instrumental to the recruitment process as he knew beforehand all of the individuals in the community who are considered knowledge holders. As a first step, we sought out these knowledge holders, who are in most cases Elders, to ask for assistance in recruiting research partners for this research project. These knowledge holders then directed us to different "experts" the abovementioned land-use practices. Each one of these research partners was either read or given a consent form to read and sign (see Appendix B - Written Consent Form) that had to be approved prior to beginning interviews or the activity in question with me. In the community, the term "expert" refers to individuals considered by their fellow community members to be highly experienced, knowledgeable, and wise in their respective work. This recruitment method is known as 'purposive sampling.' Purposive sampling is non-probability method of sampling in which the researcher (and/or local research partners like Demetrio) relies on her judgement for finding research partners and interviewees according to certain characteristics, such as experience, knowledge of customs or traditions, or embededness 
and importance within a given community (Etikan, Musa \& Alkasim, 2016). This method is highly useful when working with Indigenous groups, in which seeking certain individuals like Elders or healers is required, as they are generally the ones who are the knowledge holders and are responsible for storing cultural knowledges and IKs and passing them down to younger generations. What is more, purposive sampling has been shown to hold up against random sampling. According to Tongco (2007), "the inherent bias of the method contributes to its efficiency, and the method stays robust even when tested against random probability sampling” (p. 147). All research partners and informants were residents of Xuilub involved in agriculture, apiculture, cattle ranching, and other local land use activities. In terms of research partner inclusion criteria, I was looking for both men and women (as both men and women in the community carry out land-use activities) from any age group. With the preliminary research planning and recruitment methods for this project now elucidated, we turn to the research methods.

\subsubsection{Methods}

\subsubsection{Experiential Learning}

To gain primary Maya knowledges about the interaction and relationship—or connection - with the land of the Yucatec Maya, I used an experiential learning method close to what traditional ethnographers would call 'participant observation.' This method was developed in the ethnographical and cultural anthropological fields in the early $20^{\text {th }}$ century (Atkinson and Hammersley, 1994). Participant observation aims to "generate practical and theoretical truths about human life grounded in the realities of daily existence" (Jorgensen 1989, p. 14). Such research requires the participant (researcher) to use a range of methods, such as informal discussions and observation (and documentation 
by recording notes in an audio recorder or field notebook), of direct engagement in the life of the community. The data obtained is then analyzed and interpreted by the researcher. This data yielded by this method is mainly qualitative, although quantitative data and statistical analysis can sometimes play a supplementary role (Atkinson and Hammersley, 1994; Taylor, Bodgan \& DeVault, 2015). However, quantitative analysis was not used for this research project, given the unquantifiable nature of Maya environmental ethos. I used this approach when I participate in quotidian land-use activities, ceremonies, and community life during my field research process in order to collect primary data about individuals' interactions and relationships with and on the land and human and other-than-human beings, and to gain an insight into the social organization of Xuilub. However, what distinguishes my experiential learning approach from traditional ethnographic participant observation relates to my long-term engagement to build relationships with the people and land of Xuilub, and to acknowledge my emotional and spiritual connection with them. This is generally not done in the strict participant observation approach, which counts on the researcher's relative "disconnectedness" from the land and its people in order to produce more "objective" research.

As is the case with any Indigenous culture, the documentation and interpretation of the Yucatec Maya land ethic and its manifestation in the form of concrete land use practices requires a "hands-on," or experiential, participatory research approach (Huntington, 1998). In order to seek to gain a deeper understanding of IKs, it is necessary for the researcher to engage in daily, especially land-based, activities of the communities and their members (Berkes, 2008). A key purpose of this research was to examine in 
which ways the Yucatec Maya relate with their traditional territory. The Maya value oral transmission of cultural information (Cajete, 2000; Kovach, 2010). To gain insights into an epistemology that is mainly passed on orally through the generations, it is necessary for the researcher to engage in participatory experiences and daily activities of the community in which that epistemology is put into action. Based on my research objectives and rationale, I elected to use this experiential learning approach to data collection. I have been strongly influenced by anthropologist Hugh Brody's methods in this regard. In his book Maps and Dreams (1983), Brody establishes an approach to experiential learning in Indigenous communities predicated on the researcher's active experiential learning in both the day-to-day and specifically cultural activities (subsistence and livelihood activities, feasts, gatherings, etc.) of the Indigenous community. Brody spent eighteen months living with the Beaver Dènè of northeastern British Columbia. There he lived as an unofficial member of the community, participating in important community events as much as in everyday activities. By using this research approach, Brody was able to establish respectful relationships with Beaver Dènè and gain a heightened (and more engaged, on a personal and emotional level) understanding of their IKs. This knowledge helped Brody more fully understand the spiritual and cultural motivations behind the community's interactions and relationships with the land. Brody's method is in contrast with the Boasian approach of "salvage anthropology." The Boasian method entails collecting as much information as possible about a society through field interviews and passive observation and documentation of Indigenous cultural practices as a disconnected and "objective" observer (Harris, 2001). Although I did not live Yucatec Maya for extended periods of time, I applied the basics 
of Brody's method during my trips to Xuilub during the "data collection" (in reality, I would characterize this as "experiential learning”) period from 2014-2016.

I used this approach when I participate in quotidian community activities, meetings and land use practices during my field research process in order to learn about individuals' interaction and relationship with the land. During my time spent on the land with community members, I used a field notebook to record my observations. I noted down individual members' thoughts and impressions while participating in their day-today activities. I also informally asked community members to discuss their own personal relationship with the land, and how it relates to Yucatec Maya spirituality and land ethic. Demetrio accompanied me in each of these activities and, in some cases, acted as my translator when I could not communicate with a non-Spanish speaker. In all my interactions with Xuilub community members as an experiential learner, I used an audio recorder as well as a notebook to record informal conversations and my personal observations during or after the activity. Research partners were informed that I would be manually recording my observations in my field notebook during time spent on the land with them, and I always asked the research partner before using my audio recorder. I acted as an experiential learner in the following land-use and general community activities:

Milpa farming

Over my five trips to Xuilub, I participated in work on seven different milpas (usually one- or two-day outings) that were looked after by seven different milperos in the community. Because my trips were organized according to different stages in the milpa cycle, I was able to participate in all the different types of milpa work: fallowing, 
planting, and harvesting. Participating at different times of the year and milpa cycle allowed me to gain a more complete understanding of the work that has to be done yearround.

\section{Apiculture}

In terms of experiential learning in apiculture, I did work with three different families in the community My outings with them ranging from one to three days at a time. In this case, too, given that I visited at different times in the year (from flowering season to harvest season), I was able to perform all the different tasks related to this activity: cleaning/clearing the apiaries, inspecting the hives to determine the health of the bees, transfering certain hives from one apiary to another according to the availability of blooming flowers, and harvesting and selling the honey.

\section{Hunting}

Due to the use of firearms in hunting (and the risks associated with their use), and not being able to get a Carleton University Research Ethics Board clearance for this activity, I was not able to participate in actual hunts. However, I had a number of informal discussions with two hunters, during which they taught me how to prepare for the hunt and then clean out a deer and peccary, butcher the animals, and decide how to divide the meat among the hunters and their families.

\section{Cattle Ranching}

I engaged in experiential learning with two different cattle ranchers from Xuilub. I spent periods of one or two days working with them on their ranches looking after the cattle and feeding them, as well as inspecting them for disease and injuries. I also observed their interactions with the cattle in order to get a sense of how these animals are 
perceived and treated, and to ascertain whether they are considered with the same respect as wild animals.

\section{Ceremonies}

I participated in a number of ceremonies with a variety of individuals, including the Cha-Chac ceremony conducted before the sowing of milpas in the community. In this ceremony, prayers and food offerings are made to Cha-Chac, the Maya god of rain, to ask for a good growing season and an abundant harvest (see Chapter 5 for more a more detailed explanation and discussion of this, most important, Maya ceremony).

\section{Miscellaneous}

I was also an experiential learner in a number of different community and family activities, such as: various festivals and dances, birthday celebrations, family gatherings, a high school graduation, Christmas and New Year's celebrations, etc.

\subsubsection{Semi-Structured Interviews}

I used the semi-structured interview method as I judged it to be the style most appropriate to this research project with Indigenous research partners and dealing with complex and abstract subjects related to Maya spirituality and environmental philosophies. In contrast to the structured interview, this method allows research partners to help guide the interview and discuss themes not included in the original topics thought of in advance by the interviewer (Lindlof and Taylor, 2002). Thus, semi-directive interviews allow interviewees to have a meaningful input into the interview process, making this research component more respectful, inclusive and reciprocal (in accordance with Louis' (2007) third principle mentioned previously). Louise Barriball and While (1994) describe some of the benefits of the semi-structured interview in terms of finding 
a balance between structure (in this case to address my research questions) and freedom for interviewees to touch on other themes that were not originally included in the interview questions:

Semi-structured interviews were selected as the means of data collection because of two primary considerations. First, they are well suited for the exploration of the perceptions and opinions of respondents regarding complex and sometimes sensitive issues and enable probing for more information and clarification of answers. Second, the varied professional, educational and personal histories of the sample group precluded the use of a standardized interview schedule (p. 330).

My semi-structured interviews proved highly useful to me in gaining an in-depth understanding of Maya IKs and practices as part of a greater ethical system—as a Maya land ethos, in my terms. Interviewees had enough time to go into detail in terms of translating abstract Maya spiritual teachings and knowledges into language that I could understand, and to explain to me the relationship between Maya spirituality and presentday land-use patterns and social organization in Xuilub.

I sought to interview both women and men who were part of the community and who used the land in some way. Research partners were interviewed about their personal opinions and views relating to Maya spirituality and land-based knowledges and practices, as well as the interviewees' personal outlook on the future of Maya land-based culture and knowledges (see Interview Questions in Appendix A). The interviews, which lasted between one and two hours, took place in the homes of the community members. Electronic recording equipment was used in the interviews. Information I gathered relating to the interviewees' understanding of Yucatec Maya IKs, as well as their personal understanding of appropriate land use, was to a large extent consistent, and it was possible to find meaningful parallels between their various statements (see 4.5.3 Data 
Analysis). These discussions allowed me to understand the processes by which abstract notions of Maya spirituality and land-based knowledges are currently understood and expressed by Maya individuals who use the land.

In all, I conducted 55 interviews with community members of all age groups (from teens to elderly individuals), 33 of which were with men and the remaining 22 with women. I told Demetrio to recruit interviewees from who performed different types of land-based work or activities in the community (i.e. home gardening, milpa farming, apiculture, hunting, cattle ranching, Maya spiritual ceremonies, etc.). When Demetrio and I discussed the topic of interviewing women, we decided that it was best for me to be in the company of the interviewee and another woman (in most cases a relative). Demetrio told me that having another woman present would create a more comfortable atmosphere for the women being interviewed, who otherwise may feel uneasy. Also, I learned that it is expected that the researcher offer refreshments to Elderly research partners as a token of respect, as Elders are highly regarded and respected in the community. Special attention was paid to making Elders feel comfortable during the interview process.

\subsubsection{Data Analysis (or Making Sense of my Learning Journey in Xuilub) ${ }^{5}$}

My data analysis rested on two main methods: (1) hermeneutic analysis in line with the Indigenous research philosophy and methods (used for interpreting and understanding all of the knowledges I obtained through informal methods - -i.e. everyday conversations and being part of the quotidian life of the community and its members);

\footnotetext{
${ }^{5}$ Although IKs and cultural information are not merely lifeless "data," I still use this term in this context to avoid confusion and elucidate this process clearly for all (Indigenous and nonIndigenous) readers.
} 
and (2) basic manual coding (which was used to create categories to sort the large quantities of information that were generated by my semi-structured interviews and experiential learning in outings on the land, ceremonies, and other cultural activities. I decided that both of these components was necessary in order to conduct an analysis that is respectful of holistic IK traditions and ways of being and doing, while simultaneously organizing my more formal data in a way that was conducive to performing an analysis that stands up to the standards of Western academic research. In keeping with my own personal objective of bringing two knowledge systems closer together, and to find a common ground for Western and Indigenous research methods, I believe that the these two methods are complementary and in line with the "two-eyed seeing" philosophy previously described. I delineate each method individually below.

\subsubsection{Hermeneutic Analysis}

The philosophy and rationale of the hermaneutic analysis is in line with some key Indigenous methodological objectives, namely personal reflection and interpretation (informed by relationships with the community and research partners) as a way of finding meaning about knowledge gained in Indigenous communities (an approach suggested by Kovach, 2010). My analysis of the data was thus highly dependent upon my personal reflection and interpretation of the data according to my own personal cultural knowledges, education, and experiences (in accordance with the philosophy of hermeneutic analysis outlined Paterson and Higgs, 2005; Kafle, 2011). Kafle (2011) states that:

In using this approach we accept the difficulty of bracketing. To overcome this difficulty we acknowledge our implicit assumptions and attempt to make them explicit. In addition, we accept the notion that there may be many possible 
perspectives on a phenomenon, like when we turn a prism, one part becomes hidden and another part opens. Hermeneutic avoids method for method's sake and does not have a step by step method or analytic requirements. The only guidelines are the recommendation for a dynamic interplay among six research activities: commitment to an abiding concern, oriented stance toward the question, investigating the experience as it is lived, describing the phenomenon through writing and rewriting, and consideration of parts as a whole (p. 191).

In a line of thinking as the above directives outlined by Kafle, I did not depend on a fixed or rigid data analysis method, but rather I opted for a critical iterative process with regard to the analysis of my research data.

I understand hermeneutic interpretation as being generally in line, and thus possibly a bridge between, Western and Indigenous ways of knowing and interpreting information and knowledge. Indeed, hermeneutic analysis resonates well with Indigenous worldviews and perspectives on learning and making sense of information. The hermeneutic method depends less on a formal or strictly scientific and so-called dissociated approach of the researcher with regard to the subject of analysis. It depends on the researcher's personal interpretations and careful and critical reflections about what she witnessed, heard, and experienced and connected with emotionally in her learning journey. In practice, the hermeneutic approach is also largely in line with Indigenous holistic ways of knowing and what understandings of what counts as knowledge. Hermeneutic analysis is concerned with experiencing and internalizing knowledge in ways that diverge from Western empiricism. Stories, lived experience, emotional connections and experiential (and land-based) learning are all considered valid ways of acquiring information - just as they are in IKs and Indigenous methodologies.

Dwayne Donald, a Cree education researcher, shares a viewpoint similar to mine, which, due to its close relevance to my research, I present here as an extended excerpt: 
Hermeneutics is a form of radical thinking suspicious of prescribed solutions that seeks to engage with difficulty and ambiguity - 'the fix we are in' - by remaining right in the midst of tensionalities rather than searching to rise above or move beyond them (Caputo 1987, 3). It is this desire to remain amidst the messiness and difficulties of a situation or context that creates opportunities for new knowledge and understanding to arise. Rather than working to remove ambiguity, hermeneutics works to interpret and give voice to the difficulty and ambiguousness of life itself. The hermeneutic call to immerse oneself in the complexities and ambiguities of a given situation or context of engagement requires attentiveness to the significance of history, culture, tradition, and philosophy in producing standpoints of interpretation. It is a provocative call to come to better understand the 'fix we are in' that eschews foreclosure and conclusion. Hermeneutic imagination helps us make sense of ambiguity because interpreting culture demands a creative ability to speak across disciplines, cultures, and boundaries. There are no direct methodologies that can describe how this moving across can occur; we must rely on our own skills of interpretive imagination and creativity. This means that hermeneutical consciousness is always and everywhere a historical consciousness, a way of thinking and acting that is acutely aware of the storied nature of human experience. Researchers are required to work to create meaning through their interpretations rather than simply reporting their findings. To require such meaningful interpretations places added emphasis on the importance of the skilled weaver of the textual braid who employs certain sensibilities in order to make meaning tangible and palpable (2012, p. 545-546, my emphasis).

In a hermeneutic research approach (adapted to Indigenous methodologies) closely akin to Donald's, I treated the data analysis as a process of interpretation using my creativity, imagination, and my own Wendat perspectives about research. I also used my background knowledge on the Yucatec Maya history, colonial legacies, and my prior understanding of Maya IKs based on a review of the extant literature. The first step in the analysis of my data, therefore, primarily took place in my own mind. All the knowledge that I gained in each trip to the area, and the experiences that I live and shared with community members, were distilling in my mind while I was deeply engaged in finding my own meaning and interpretation of his information. During the field research stage, my time spent away from the community (while in Ottawa) allowed me to take a step back and reflect on my own understanding of the Maya land ethos and its broader 
meaning and significance. Thus, the ideas/themes/elements of the data that I counted as important and worthy of analysis are based on these personal reflections and hermeneutic analytical process. In retrospect, I consider this data analysis method to have been the most important in terms of shaping my understanding and main arguments about the ('responsibility-based,' as I have come to understand) Maya land ethos that informs relationships with the land and social organization in Xuilub. In the hope that my mixture of a hermeneutic and Indigenous approach to research and making sense of what I learned in the field may be useful to other scholars in similar situation to mine looking to find a source of inspiration for their process of analysis and interpretation, I outline some basic steps and methods I personally used:

1. I engaged in as many day-to-day activities, informal interactions and discussions, as well as various learning experiences in the community as possible (while being careful to maintain a respectful relationship with my research partners, and to not be overbearing). 2. At the end of each day in the community, I recorded voice memos (about 10-15 minutes each) about my impressions, feelings, and thoughts of what I had seen, heard, experienced and/or done that day.

3. When I was back in Canada, I re-listened to each daily reflection from the trip and jotted down further notes about my current thoughts on those reflections (after having had a few days to let my lived experiences and newly gained knowledge from the community settle in my mind).

4. At the end of my (formal) field research, I transcribed all the daily reflections and retranscribed my additional notes. I consulted these transcripts periodically throughout the rest of my PhD process, whenever I felt I needed to reconnect with my original thoughts 
and feelings about the research and the knowledge I gained in the field. I paid special attention to the emotions evoked by these thoughts, and how these influenced my interpretation and understanding the Mayan land ethos.I constantly went back to the transcripts as I was reflecting on my research and writing my dissertation. The subjects/contents of the transcripts were not organized in any logical fashion as I wanted to respect my personal Indigenous learning journey process, which cannot be dissected, or any ideas or elements considered in isolation from one another. The researcher's emotional connections with my host community and their homeland must be accepted as they are - as part of an integrated whole that cannot be abstracted from the learner/researcher.

\subsubsection{Basic Manual Coding}

In addition to hermeneutic analysis, however, I used a very basic manual coding system (without the use of coding software) in order to allow me to sift through all the rich and diverse IKs I documented and to allow for greater ease of reference. I discussed my intention to use a coding strategy at two town hall meetings that I organized in the community over two successive trips to the area. I described to the people in assistance my proposed coding system (see below) and asked if anyone had any feedback, questions, or concerns about my approach not being reflective of Mayan was of knowing. I received no objections or negative feedback. At both meetings, the general consensus from the community was that it made sense to for me to follow a basic coding process for data from my semi-structured interviews and experiential learning in the context of writing a book or a dissertation. Two ejidal council members explained to me that they believed that if they were faced with a similar task, where information necessarily has to 
be organized systematically in order to produce a detailed and fully fleshed out analysis about a culture that is not their own, they would adopt a very similar approach to making sense of the information.

All interviews, recorded conversations, audio field notes, and handwritten field notes were transcribed by me into separate Microsoft Word documents. All Spanish data was translated by me into English in order to make my analysis as consistent and effective as possible. Upon completing my field research, I translated (Spanish to English) and transcribed all fifty-five interviews as separate Microsoft Word documents. The field and interview data collected was reviewed for general trends in individuals' understanding of Maya IKs and land-use practices and how these knowledges influence their own personal relationship with the land. Following a discussion with community meeting attendees, I decided not to use coding software to analyze the interviewees' responses, as the majority of those present told me they felt uncomfortable with regard to the possibility of Maya land-related knowledges being reduced, filtered and dissected using this western academic method. As a result, I determined the process of "manually" sifting through and making sense of the data was more appropriate and better-suited to make sense of the spiritual and deeply personal dimensions of the data collected, and to commit to using Indigenous research methodologies.

I standardized my analysis by using a coding methodology that allowed me to break down interview data (which, as mentioned above, was recorded on an audio recording device and transcribed) and experiential learning-related data recorded manually in a notebook. Upon an initial review of all the Word documents and data contained in them, I decided to organize the data into segments or passages that would be 
placed in one of the following broad categories (which I felt captured all of the main themes and general content of my research in Xuilub): 'milpa', 'apiculture', 'hunting', 'cattle ranching', 'Maya spirituality', 'Catholic religion', 'social organization.' Then, after scanning all the data within each of these broad themes, I was able to further classify and organize the content into subthemes for each broad category, as follows: Milpa: milpa work, medicinal plants, milpa-based foods, milpa-related ceremonies and rituals, cenotes

Apiculture: apicultural work, CDI Maya apiculture funding program, flowers, spiritual "owners" of the bees

Hunting: hunting practices, wild animals, community hunting rules, spiritual "owners" of the animals

Cattle ranching: cattle ranching practices, predators, food for cattle, cenotes (water for cattle)

Maya spirituality: syncretism, ceremonies, prayer, mythical/supernatural beings, ancestors, future generations

Catholic religion: God, saints, Virgin of Guadalupe, prayer, ceremonies

Social organization: Maya identity, Maya concept of 'place,' gender roles, Elders (and infants), respect

Although I organized the data according to the main categories and their corresponding subthemes as shown above, I also allowed for sufficient flexibility to allow new concepts and ideas not originally considered to be logically and systematically organized and classified as needed. This prevented new insights and information from being overlooked in a rigid coding methodology.

I scanned all of the data in each of these main categories and subthemes a number of times, recording all my reflections and observations about individual passages and excerpts as well as broader meanings and themes that this data evoked. This process of 
interpreting and making sense of the data lasted approximately one month. When I felt I had sufficiently pored through all the data and was satisfied with my written observations about individual data sets (i.e. categories and/or subthemes) as well as general observations about the entirety of the data, I began a process or reviewing all my notes and scanning them in order to uncover one or two central ideas. My analysis yielded one main thread or concept that was present throughout all main categories and subthemes: responsibility. This was the singular thread that was consistent throughout all my interview data, whatever their category. Also evident was the idea of Maya people as being part of a web of relationships between human and other-than-human beings in 'place,' which refers to both the immediate community of Xuilub, as well as a shared meaning of the broader Maya homeland of the Yucatan. Those are the main themes that emerged from my data analysis and my own interpretations as an Indigenous geographer doing research in a community that is not my own, and is in fact quite far removed from my geographic and cultural context. After having identified these key themes that defined my research findings, I began to structure Chapters 5 and 6 according to the main categories and subthemes above. These became the basis for these chapters' sections and subsections, as the reader will note.

\subsubsection{Representation}

In terms of representation, I wish to make it clear that the information that I present in Chapters 5 and 6 , based on the data collected during my fieldwork, is my own interpretation of the Maya land ethos and IKs. I do not claim to be presenting the absolute truth or to be speaking for the Maya people and their own understanding of their relationships with the land. Although I am an Indigenous person, I am not Maya and was 
not born and raised in Xuilub. Indeed, even though I have tried my best to use Indigenous methodologies and consult with the community and have welcomed all feedback and advice, the fact remains that I am a privileged outsider-researcher who is still, at least to some degree, writing about the "other," and am cognizant of all the risks to the community this represents (see Robbins, 2012 for a detailed discussion on tis theme). As a result, I want it to be known to the reader that I am presenting just one possible interpretation of the Maya environmental ethos and land-based culture. There are still structural inequalities and colonial legacies that make it possible for me, a Canadian Indigenous researcher, to pursue a doctoral degree and conduct an international research project, while it is outside the realm of possibility for the vast majority of people in Xuilub to do the same - or even to do research in their own community. Despite my best attempts to give a voice to the Maya of Xuilub, and to faithfully represent to my academic audience their IKs, there remain such structural inequalities that prevent more Latin American Indigenous peoples from sharing their "insider" perspectives about their cultures and enriching the current academic conversation dominated by academics who are not from these Indigenous communities. The complete solution in terms of redressing colonial legacies that have since resulted in these inequalities will, I believe, only be found when more Indigenous peoples are able to write about their own IKs in their own terms and according to their distinct worldviews.

\subsection{Research Contributions to the Xuilub Community}

I consider that the first step toward ensuring my research will make a meaningful contribution to the Xuilub community was made when I shared my research progress and preliminary findings at town hall meetings during each trip to the area. At each of these 
meetings, I informed the community of the current state of my knowledge and progress in my doctoral program. These opportunities to update and to reconnect with the community about our project have established my commitment to making a lasting contribution and partnership with Xuilub. I told the community that I would gift them with a copy of my dissertation as soon as I get the chance to return to Xuilub after my $\mathrm{PhD}$ defence. Once back, I told them, I want to, specifically: (1) share my $\mathrm{PhD}$ findings with the community in plain language; and then (2) engage with as many people as possible and have discussions to determine how my research will be the most useful to the community people of Xuilub.

During that trip, I also aim to gauge the current state of their relations with the Yucatan state and Mexican governments, and to identify any new land-related issues that have emerged since the end of my formal field research. I plan on reconnecting with my contacts at the Universidad de Oriente (UNO) in Valladolid and to also give them a copy of my dissertation and present them with a document outlining the Xuilub community recommendations regarding how best to mobilize my research. I believe that Xuilub will benefit from having a document (this dissertation) that fleshes out their land ethos in great detail, and which covers most key dimensions of the current Mayan culture and IKs as lived and represented in the community. I envision this document being useful to the leadership in their future negotiations and dealings with the state and federal governments, private interest, and NGOs as it will allow them to show to outside policymakers, developers and planners, in the form of a treatise, a thorough and welldocumented account of their way of thinking and relating with their homeland, the Yucatan, of which they have for millennia been the stewards. I equally see the potential 
for this dissertation in assisting them in any legal matters related to the protection of their (and other Maya) lands in the Yucatan against private sector encroachment, in particular tourism development and industrial agricultural projects.

I hope this dissertation will help the Xuilub community and the Yucatec Maya more generally in demonstrating the value in their IKs and distinct ways of relating with their lands, and that one day others who live on it will be more willing to learn from them about how to be part of the land. It is my sincere belief that having their land ethos in writing can allow well-meaning politicians, policymakers, business leaders, NGOs, and international tourists to, for the first time, begin to more fully and meaningfully understand Indigenous liefeways and their value for the rest of humanity, starting with the (non-Indigenous) Yucatec and Mexican societies.

It is my wish that land-use planners in Yucatan (and Mexico) will one day base all their land-use strategies, plans, decisions, and projects on a responsibility-based approach similar to the one that I found in Xuilub. Only then will they learn to conceive of land-use and development strategies that are "part of the land," or are tailored to the Yucatan and reflect the values of a people — the Maya — who have for thousands of years, through trial and error, perfected the spiritual art and science of learning to be part of the Yucatan. Although at this juncture I have no concrete and/or specific suggestions as to specific policies that should be amended, discarded, or adopted (this would constitute a separate dissertation), such is the philosophy and mindset that is needed in order to initiate the shift for which I hope. Once this philosophy becomes business as usual, specific laws, policies, and regulations can be developed under the authority and guidance of the Maya people themselves, who are the original stewards of the Yucatan. 
Finally, in terms of ensuring long-term accountability to the people and land of Xuilub, I consider my relationship with the community to be lifelong. I have developed familial bonds with many people and I feel a strong sense of attachment to them. In fact, for the last three or four years I have regularly communicated with many of these people (especially the younger ones) on Facebook. I have already included the community in my future research funding plans with different funding agencies. Also, I have committed to assisting Demetrio in writing a comprehensive oral history of Xuilub by interviewing and discussing with Elders in the community who helped us in this research project. Moreover, as mentioned previously, I am treated like a son and brother by a number of people in Xuilub. In my culture, symbolic adoption into our community is recognized as de facto membership. Historically, when someone from outside a Wendat community was symbolically adopted, he or she was considered fully Wendat and forever a relative. I consider that the Xuilub community has symbolically adopted me. In my culture, being symbolically adopted comes with responsibilities and duties to one's adoptive community, in my case, Xuilub. I feel a sense of accountability to the people and the land that I have had the privilege to begin to learn to be a part of; the way I see it, I am accountable to Xuilub for life - it is my second home and culture. This is how I was raised to interact and relate with my relatives from across Turtle Island, and I would expect the same from a Maya person who is adopted into my culture.

\section{$\underline{4.7}$ Research Ethics}

Given that the formal field research methods involved interviews and community engagement (research involving human subjects), I applied for and was granted an ethics approval for my research project in the spring of 2015. There are no formal Mexican or 
Yucatec Maya ethics board or governing body that reviews academic research projects on Indigenous research subjects. However, my home institution (Carleton University) requires an ethics approval by its ethics board in order to assess the ethical aspects of my research project involving human subjects. The submission of my ethics application required that I submit the General Ethics Protocol Form to the Carleton University Research Ethics Board (CUREB) for approval, which was granted to me in April of 2015. In this form, information related to project registration, a research project description, methods for the recruitment of research partners, consent, confidentiality and data collection, storage and dissemination must be provided. The review process for ethics applications lasted approximately one month. Once my project was approved by the CUREB, I began my formal interviews and experiential learning.

Outside of the formal CUREB process, I applied a more personal ethical framework to my research. In Xuilub, many members cannot read and write in Spanish and many others are wary of contracts or written agreements, as is often the case in Indigenous communities throughout the world. Community members expressed to me orally their trust and willingness to participate in my research project, and community leaders told me that it was best for me to seek oral consent of individual members prior to engaging in experiential learning in their daily land-related activities or engaging them in informal interviews/conversations about their land use and management.

Prior to interviews I made sure to advise partners that they could withdraw at any point and were in no way obligated to participate in interviews or have me accompany them on the land during their subsistence-based activities. I let all research partners know that if they wished to end an interview, or if they wanted to end our work on the land 
together, I would respect his/her decision, and that this would have no bearing on my research relationships with the community or its individuals. Furthermore, research partners' names and identities were (and are) kept anonymous in any field or interview data obtained. I used pseudonyms for each research partner prior to conducting interviews and encrypted research photos and audio data from interviews. All my research data was stored on my Apple Macbook laptop computer. I am the only person with access to this computer and the data that it contains. The computer is passwordprotected. I used FileVault software to encrypt the data, in order to further ensure its safekeeping. I kept the data indefinitely for possible future study on this topic only (journal articles or other publications, for example), under the same safekeeping conditions. I informed the research partners that the data will be used solely for future research and analysis on this topic, and not for any other purposes and that the risk of a data breach is minimal. What is more, as no personal information on any of the research partners was stored (and pseudonyms were used in audio recordings), a breach would not compromise the safety of any individual. I was the only person who assigned pseudonyms to each research partner, therefore no other person would be able to associate a pseudonym to a specific research partner's identity. Along with the CUREB approval, these steps were taken to make sure I was maintaining a respectful relationship with the people of Xuilub, their IKs, and the land. 


\section{Chapter 5: Responsibility-Based Thinking in Land-Use Practices}

\section{Introduction: Responsibility-Based Thinking in Xuilub}

As discussed in chapter 2, IKs understand and represent the world in terms of relationships and networks between human and other-than-human beings as they play out in space and place, or on the land, in Indigenous terminology. The emphasis in this environmental ethos is on responsibility and accountability to one's relations. To groups and individuals who adhere to such environmental paradigms, the meaning and representation of "place" fundamentally differs from (neo)colonial meanings of place as a container of resources to be logically and hierarchically ordered and subdued for the benefit of human development. This latter notion, which has roots in the Western society/nature dichotomy, continues to influence mainstream environmental policy the world over. In contrast, the terms "nature" and "society" cannot be translated into the majority of Indigenous languages in the Americas (Davidson-Hunt and Berkes, 2003). The place-based land-use approaches common to many Indigenous cultures have increasingly been recognized by geographers and other scholars as offering the world new philosophical windows from which to conceive more equitable socio-spatial orders and environmental ethics, as demonstrated in Chapter 3. Indeed, there is growing recognition in geography and other fields that Indigenous philosophical traditions and spatial worldviews can enhance less holistic Western territorial governance systems. Indigenous scholars have stressed that it is necessary for Indigenous peoples to teach the academic collective about their own understandings of Indigenous knowledges (or IKs). 
During my field research in Xuilub, I learned that the community's land-use and management attitudes are best understood using a conceptual lens that is best described as responsibility-based thinking. I define responsibility-based thinking as an Indigenous cultural ethic that informs and mediates personal and collective conduct by instilling in an individual a sense of duty or responsibility toward her/his human and other-thanhuman, relations. This mindset inspires and informs a responsibility-, rather than a Western democratic rights-based, way of thinking (as described in Chapter 1). The current Maya land management system and social organization follows responsibilitybased thinking, and life on earth is thought to be sacred, as there is no strict disconnection between one's earthly life and the afterlife and supernatural realm. According to this ontology, a person is responsible for his/her actions here on earth. Maya responsibilitybased thinking holds no notion of humankind's primacy over other beings of the land. Rather, all elements of the ecosystem are thought to be part of a sacred circle of life. Again, such a mindset inspires and informs a responsibility-, rather than rights-based, thinking. Moreover, as has been documented by Berkes (2008), Pierotti and Wildcat (2000) and many others, the spiritual practices of many Indigenous groups are part of their land-use paradigm.

Throughout my research, the people of Xuilub expressed their firm belief in the power of other-than-human entities and of their self-awareness and purpose. A sense of responsibility, duty and reciprocity with these other-than-human actors currently shapes land-use patterns and practices in Xuilub in abstract and philosophical as well as concrete ways. Each human and other-than-human life form that shares the realm of existence has specific responsibilities or duties toward his/her or its relations. The milpero, for 
example, has well-defined duties toward the land, Catholic saints, Maya spiritual beings, and animals and plants that he must perform in order to ensure a bountiful harvest that yields enough food for his family. In terms of my field research, responsibility-based thinking was evident in the more traditional land-use activities such as milpa farming and hunting. However, as I will delineate in the latter part of this chapter, it was also manifested by local apiculturists and cattle ranchers, who practice these historically nonMaya land-use activities.

In the preceding paragraphs, I have defined responsibility-based thinking as an Indigenous land-based ethos and praxis. I have presented my argument that the presentday land-use patterns and practices of the Maya of Xuilub can best be understood within the responsibility-based paradigm. In the remainder of this chapter, I turn to individual land-use activities that are practiced and performed by the Maya of Xuilub, to demonstrate how responsibility-based thinking influences and informs each of these activities. The purpose of the following analysis is to demonstrate that the current community organization and individual land-based practices in Xuilub are part of a broader, comprehensive ethos and way of knowing, doing, and being that is undergirded by the individual's sense of responsibility and duty to all of his/her relations, be they human, other-than-human or supernatural. The goal of this chapter is to present my research findings and what I have learned about spiritually informed land-use in Xuilub in an "ethnographic," manner, and not in relation to disciplinary conversations in postcolonial theory, Indigenous geographies, or IK research. This is done in order to give the reader sufficient evidence in this chapter to support my argument that responsibilitybased thinking is the defining characteristic of the Maya land ethos, and that it transcends 
the different meanings associated with the main land-use activities in the community. The broader significance of these findings and a critical discussion regarding the intended contributions of my research in Xuilub to the aforementioned disciplines are reserved for Chapter 6.

\subsection{The Milpa: The Linchpin of Maya Land-Based Culture}

Over the years, much ethnographic research has been done on the Maya milpa system of agriculture. A variety of accounts have described in great detail how milpa work is conducted and how certain Maya spiritual beliefs have an influence on milparelated beliefs and ceremonies (e.g. the Maya god of rain, Cha-chac, and the ceremony performed every year in his name). Given this, the goal of my research was not to fill a gap in knowledge with regard to how milpa work (or any other Maya land-use activity) is carried out, or to contribute to the ethnographic body of work on Maya land-use practices and livelihoods. Past and current ethnographic research on the Maya is rarely concerned with discovering key principles of this culture's land-use philosophy that could potentially have broader, more mainstream value and could help expand Western perspectives about the environment. However, this was one of my main objectives in carrying out this project. To guide my analysis on milpa-related practices, I draw on the postcolonial (and Indigenous geographies) notion of seeking to understand different (nonWestern) ways of envisioning 'place,' 'the environment' (or the land) and the role of human beings within the environment. These efforts to understand Indigenous environmental concepts are not undertaken out of simple academic curiosity but these efforts are, as suggested by Coombes et al. (2012, 2012b), done to meaningfully engage with underexplored land-use-related concepts that can (and do) increase human 
understanding and can help us to deal more effectively with environmental concerns and issues. It is the belief of myself and many other postcolonial and Indigenous IK scholars (such as Pierotti and Wildcat, 2000; Cajete, 2000) that Indigenous peoples and their ways of knowing and doing contain concepts that are highly valuable and that their study should be prioritized by environmental planners and managers around the world. This idea (and mission) certainly influences the way in which I interpret and present my observations on milpa work, apiculture, hunting, and cattle ranching. Of course, nonIndigenous people also practice agriculture, apiculture, hunting, and cattle ranching, but the Maya way of practicing these activities, as part of an integrated environmental ethos and way of life, is what remains understudied. With the above in mind, I have synthesized and reflected on the field data collected for this project and, to me, the milpabased lifestyle of the Maya exemplifies their responsibility-based environmental ethos.

The Maya observe a number of agricultural ceremonies over the course of the year. The agricultural season in Xuilub begins between April and May, depending on weather conditions, when religious offerings are made to Cha-chac, the Maya god of rain, in the milpas before clearing the fields of brush. As the crops begin to sprout in late July to August, offerings of maize and beans are made to the earth. In addition to the main food crops (maize, beans, squash, etc.), some medicinal plant species are planted in some milpas and are harvested periodically during the growing season. The agricultural season concludes during the harvest in September, when thanks are given to the crops. Life in Xuilub is still structured according to the milpa lifestyle. Spiritual, cultural and social customs related to agriculture have remained central to community and family life. 
Present-day Yucatec Maya ejidal communities like Xuilub are still very much organized according to the milpa lifestyle. One of Xuilub's oldest milperos shared his thoughts on the milpa lifestyle (see Figure 5.1): "Being Maya is about hard work. Milpa farming is arduous labour, day in and day out; it never stops. It's our duty [to all beings on their land, the Yucatan] as Maya. My Maya culture is the knowledge I have about la tumba ("slashing") and the harvesting of maize, beans and squash. To me, that is what it means to be Maya - to work the land." Milpa farming, therefore, is as much a subsistence activity as it is part of the Maya identity and their values of responsibility, reciprocity and hard work. Milpa farming is perhaps the single most significant Maya land-use practice that most middle-aged to elderly men wish to transmit to their sons and grandsons. Five milperos whom I interviewed even told me they would be willing to share some of their milpa farming knowledges with anyone from outside the community, even outside Mexico, who wishes to learn. As young boys start going out on the milpa with their fathers or other older male relatives, they begin learning the skills that are required to tend to their own milpa. Typically, once a young man is around twenty years old, he is deemed old and experienced enough to have his own milpa, which will sustain his family, and to duly carry out milpa-related labour. As repeated many times by different milperos, the milpa is a long-term engagement. The young man starts out planting primarily maize, beans and squash but once he is able to successfully manage those three crops successfully, he can start adding sweet potato, cassava, pumpkins and any other crop. The young man's need to gradually prove his worthiness to his seniors as a milpero is reflective of a responsibility-based mindset as practiced on the milpa. One milpero said that the milpa lifestyle is paramount in Maya culture, and therefore must be preserved by 
any means possible. "We must always keep sowing maize, beans and squash," he continued, "because without them — without the milpa — we have nothing to eat." Through my experiential learning on the milpa, as well as interviews and informal discussions with milperos, I have come to comprehend that milpa farming is not just a source of staple foods; it is a spiritual act and a moral duty. Almost all Xuilub community members observe a number of agricultural ceremonies throughout the year. Another middle-aged milpero interviewee told me that the special role of the Maya people with regard to sharing their knowledges with the world, is their milpa culture and lifestyle: the appropriate way in which to work the land and to grow the maize and other milpa crops. He believes sharing these knowledges with the outside world is a very noble and important duty because "the whole world needs to know how to work the land; it is she who feeds every person on this planet." The milperos of Xuilub have reiterated to me their belief that the earth is what sustains all of the world's peoples. "The earth is life," offered one milpero interviewee in his concluding statement. 


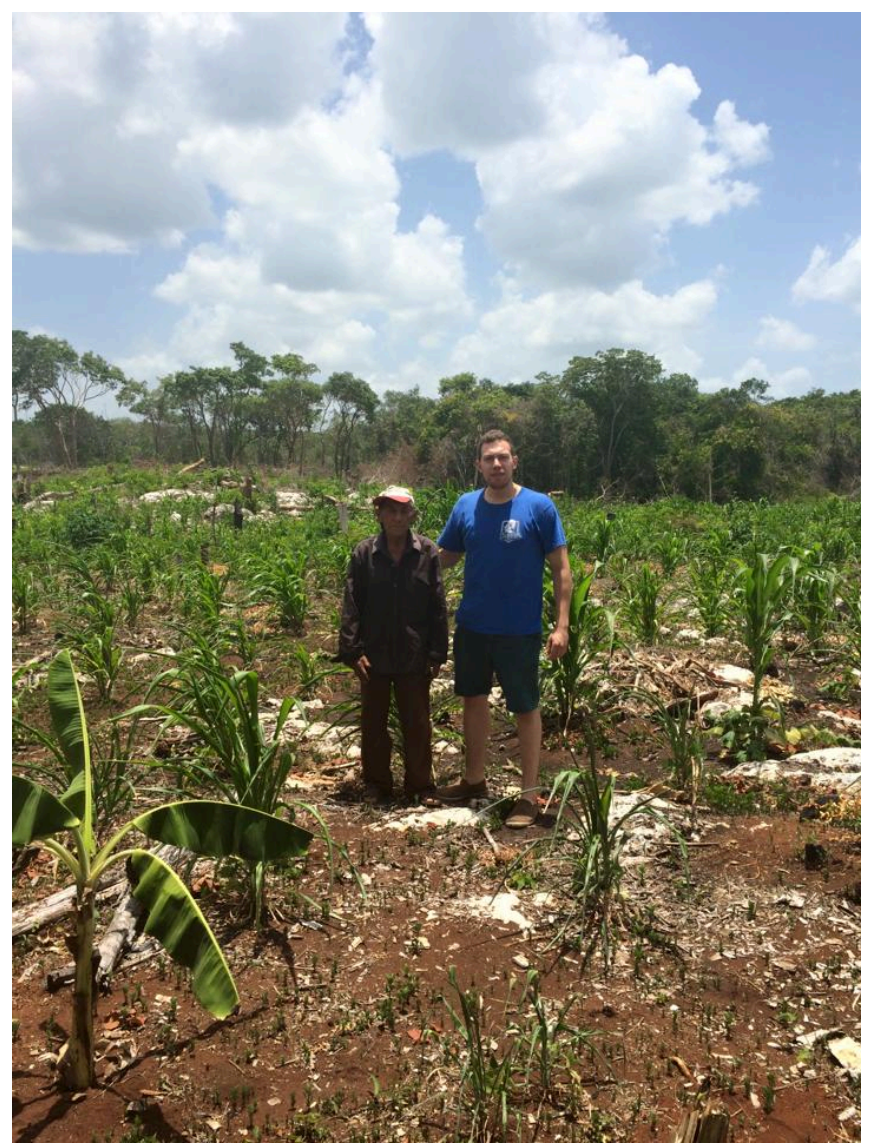

Figure 5.1. The author standing with Mayan Elder and milpero on his milpa.

My interpretation of the overarching theme that can be synthesized from my male interviewees is that the milpa is the lifeblood of Xuilub and its members. All men in their late teens and older have at least a basic knowledge of how to carry out milpa-related work. "We all know how to fell, clear the milpa and sow our crops in the traditional way," affirmed one milpero. "The traditional way of sowing our seeds in the milpa is to make a triangle when planting maize, beans and squash. When you go out to sow your seeds, you hold those three different ones in your hand and place them in the soil in one by one, so they form a triangle." This triangle method of planting maize, beans and squash seeds was mentioned by four interviewees. When I asked them whether it is the only way to plant their seeds, all of them responded that they do not know whether other 
communities' milperos do it this way, but that it is the only way they learned from their fathers and/or grandfathers. This has been the way of the milpa for centuries and even millennia and it still is the norm in Xuilub. It is necessary to keep in mind, however, that a growing number of young men in the community are seeking employment outside of Xuilub, in nearby towns and cities like Valladolid, mainly as construction workers and taxi drivers. Thus, one cannot say that this way of life is universal in Xuilub or in the Yucatan as it was in the past. Also, from what I observed, milpa farming is a strictly male endeavour in the community, so it is important to note that the "milpa-as-lifeblood" of the community characterization applies only to these men. Women, as mentioned in Chapter 6, believe their work as caregivers and gardeners is as important as that of men. In particular, they see their home gardens as complementary to milpas. They consider that the plants (jasmine flowers, peppers, oranges, etc.) they grow in their home gardens add "beauty and colour to the Maya diet, whereas the corn, beans and squash that are harvested in the fields provide sustenance but little variety," as expressed by one mother and home gardener. This example relates to the idea articulated by postcolonial feminist scholars that women may have different understandings of their cultural knowledges than men. It is important to seek to gain the perspective of women when investigating cultural meanings and representations, because too often (typically) male scholars present maledominated perspectives and conversations, and there is a tendency to downplay the role of women in community life (as pointed out by Radcliffe, 1997; Panelli, 2008; Barker and Pickerill, 2012). I have attempted to use a more gender-balanced approach to investigating the Maya environmental ethos than what is currently common in investigations on Maya land use. 


\subsubsection{Medicinal Plants}

I came to understand that growing and using medicinal plants is also part of the responsibility-based approach in Xuilub. One Elder explained to me that for countless generations, her ancestors grew and made use of these plants in order to prevent and cure a variety of different ailments and diseases. According to her, the old people had a responsibility to know how to grow these plants and use them properly in different ways according to each condition: "The old people continue to show us the way. It is our responsibility to our own people here in the community to know at least the basics about medicinal plants. It's everyone's responsibility to know how to heal one another, to look after each other's health. Can you imagine a community that can't heal itself?" She later complained that the younger generations are losing some of this ancient knowledge about the land (due to pursing their postsecondary education and employment opportunities outside of the community, chiefly in the tourism industry in the Mayan Riviera) and worried that it would die out along with her generation of Elders. All interviewees agree that modern medicine is a blessing to the community, and that it prevents and cures many diseases and allows people to live longer and healthier lives. Nevertheless, one middleaged hunter feels,

there is nothing that can substitute the knowledge of our plants, of our land here. The medicinal plants that we take don't cause addiction and side effects. If I have the choice between prescription drugs and medicinal plants, I take the plants; it's the way of our ancestors and it's much better for the body.

Knowledge about medicinal plants, given that they are part of the land, has been identified as a crucial part of IKs. Before the advent of modern medicine, Indigenous communities like the Maya needed to maximize their chances of surviving injuries and 
diseases, and this, of course, depended on an intimate knowledge of medicinal plants. As part of a survival-based culture, there is a responsibility, as an individual and as a community, to "know the plants, and to know the medicines of the land. They're part of us as Maya people," explained one curandero. Ankli, Sticher \& Heinrich (1999) investigated the cultural significance of medicinal plants in three communities in the southeast part of the state, and found that medicinal plants were commonly used to supplement Western medicine. I found their observation to hold true in Xuilub as well. Medicinal plants are used by more than half of interviewees as a supplement to pharmaceutical drugs and remedies. Although Xuilub has a small clinic equipped with basic drugs and medicine, and staffed by a medical doctor (part-time) and a team of nurses who work in shifts, most interviewees have used medicinal plants to cure or relieve various ailments at least once. Some plants are brewed as teas to treat the flu, migraines, stomach aches and diarrhoea, while others are grinded and pressed and their essence rubbed on cuts and wounds. One plant is even used as first aid against snake, scorpion, or tarantula bites, as well as less dangerous rashes caused by bites of small insects while working on the milpa. Although most snake species in the region are not deadly, the wool (Bothrops asper or pit viper) is feared for its highly venomous - and often deadly — bite. Milperos of Xuilub have, on many occasions, warned me about the wool, explaining that it prefers to live near human settlements, especially on milpas. This snake spends the daylight hours nestled in tall grasses and shrubs in milpas looking for insects and small mammals on which to feed. Nearly all milperos whom I interviewed recounted a story or two about an incident involving a wool. Some have had close runins, where they narrowly avoided being bitten while working the milpa. However, others 
have had the misfortune of receiving a bite from this snake. Until the fall of 2016, the $40 \mathrm{~km}$ road that connects Xuilub to Valladolid was mired by deep potholes. Vehicles had to navigate slowly through this obstacle course for an hour-and-a-half in order to reach the city. For a victim of snakebite, this was far too long a wait for medical care. Thankfully, the population of Xuilub has always had access to curanderos, or local healers, who have a vast knowledge of local medicinal plants and traditional Maya medicine. Such healers are still called upon in some cases when a community member suffers a snake bite from a wool. I was able to meet Xuilub's most respected curandero, who invited me into his home and showed me an array of medicinal brews that he keeps at the ready for different afflictions (see Figure 5.2). The curandero told me he came from a long line of traditional healers and that he had learned everything he knew from his father and grandfather. To summarize the importance (and duty) of preserving the knowledge of traditional Maya medicine, I end this subsection with an exerpt from his interview:

Of course, modern medicine has been a blessing. It is necessary nowadays with all the different kinds of diseases and problems that didn't exist a couple of generations ago. But, for people like me-healers - it is our duty to learn and pass on this tradition, the tradition of our ancestors. They knew how to use what nature provides for Maya to be healthy. Everyone has to do their part for the people and for the land, and as a healer, this is mine.

The curandero's statement explains exactly why he views it as incumbent upon himself to carry on ancient Maya knowledge of Yucatan's medicinal plants. I understand the notion of "duty" (or responsibility) to his people, the Maya, and to his community in Xuilub, as he puts it, as a representation of responsibility-based thinking with regard to knowledge about medicinal plants: he views it as his own personal responsibility to 
maintain the Maya relationship with plants on the land and use his expertise for the benefit and welfare of those around him. His statement is, in my view, the essence of responsibility-based thinking in terms of maintaining relationships with different beings - on the land.

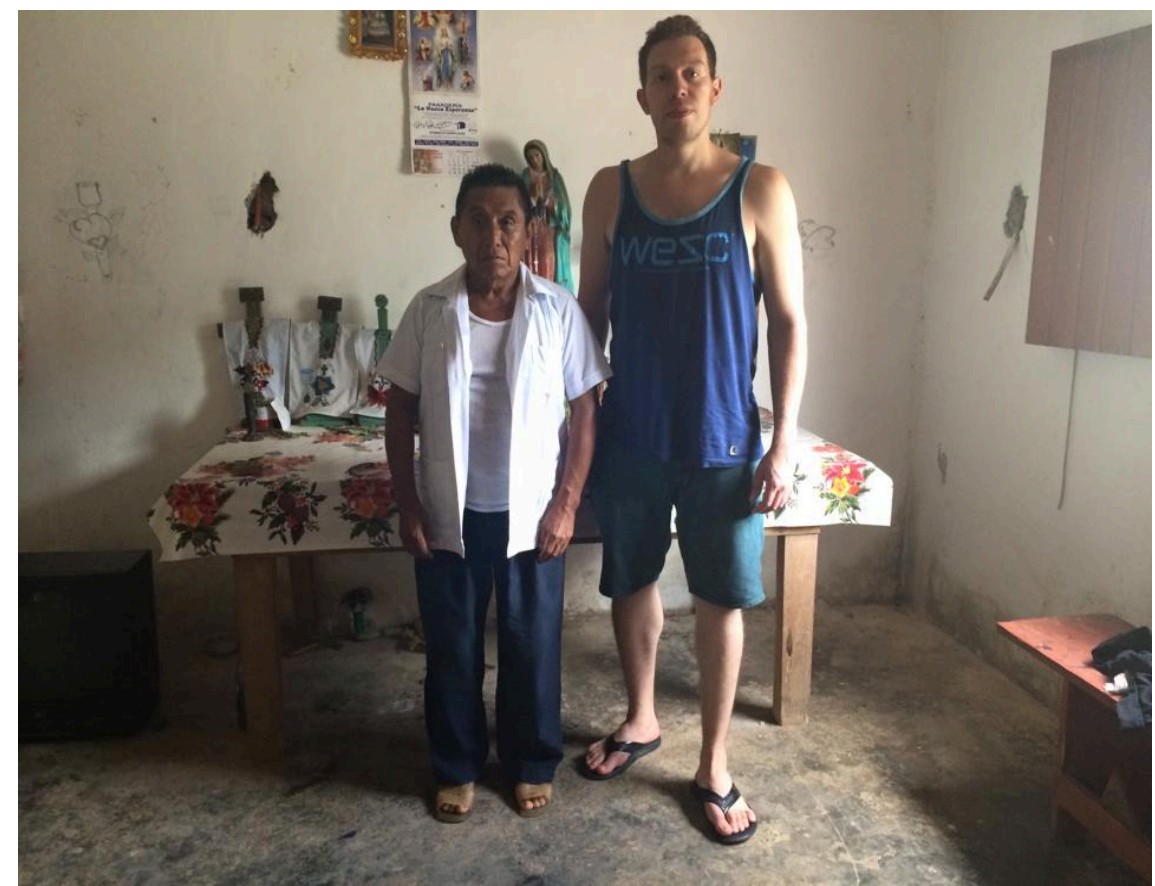

Figure 5.2. The author standing with Xuilub's most highly esteemed men and curandero.

\subsubsection{Milpa-Based Foods}

Foods that are considered "traditional" by interviewees typically include maize ("elote"), and different varieties of squash and beans as principal ingredients. Vegetables grown in Maya home gardens (solar - see Figure 5.3), chief of which are tomatoes and different varieties of mild and hot peppers, are also considered traditional. Traditional Maya staples remain the foundation of most Xuilub families' diets. Virtually all women in the community go to the community corn mill every day to make the corn dough that is then kneaded into flat discs and cooked on the comal stove to make tortillas, served with breakfast, lunch, dinner, and any snack in between (see Figure 5.4). This activity, 
which has been practiced by Indigenous women in Mesoamerica for thousands of years, is known locally as mix tamal, and was identified by all my female interviewees as the most important female-specific Maya tradition done in the home. "If it wasn't for our daily task of mix tamal, who would sustain our children, our husbands who work the lands...our community? To me, it's as important as any kind of work done by a man," said one Maya woman with a grin. This statement demonstrates that women have their own view about their responsibilities as women, and the role they play and the responsibilities they must carry out for their community and for their land. Women, too, believe they must maintain their relationships with the land and all its beings, in this case the plants they grow in their home gardens. It was very interesting for me to hear women like the interviewee quoted above discuss their understanding of responsibility and duty, as prior to this interview (my first with a woman in Xuilub), I was uncertain whether a similar sense of responsibility was held by women in the community, or if it was solely a male state of mind. In fact, I was concerned that perhaps my own male gaze was painting an unfaithful picture of the female Maya outlook on life and land. In subsequent interviews with women, it was interesting to observe very similar statements about their responsibility and that they have an "equally important role, but are more in touch with the land, because we, like the land, are mothers," as said by a young mother. For breakfast, milperos, apiculturists, hunters and others engaged in land-use activities prepare a beverage called atole, made by mixing corn flour into water and adding salt or sweetening it with sugar or honey. This cheap but nutritious and caloriedense beverage is consumed as needed from the time work starts (5:00-7:00am, depending on the activity) until the lunch break (around 1:00pm). "Atole really sticks to 
your ribs. One big cup usually makes me go until lunchtime," remarked one apiculturist before taking me to inspect his beehives at dawn.

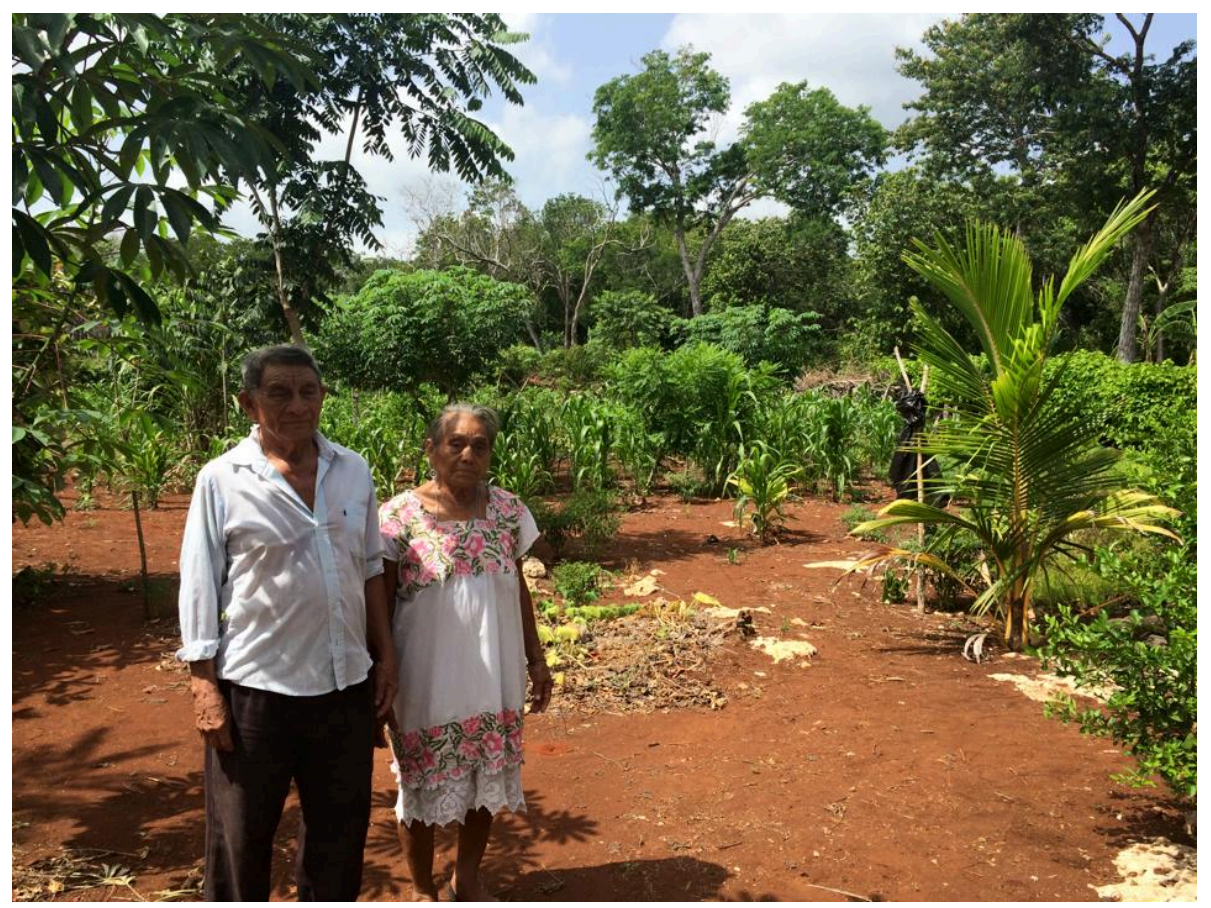

Figure 5.3. Elderly couple showing the author their solar.

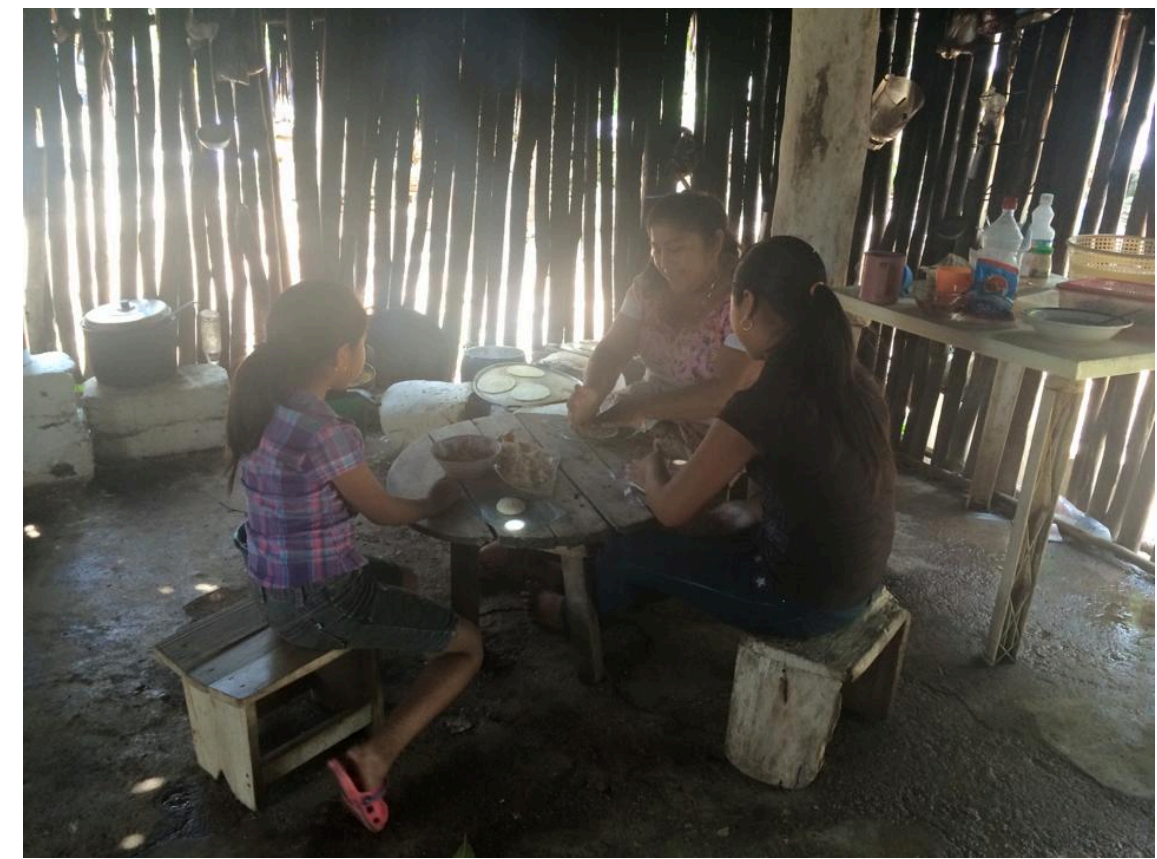

Figure 5.4. Mother and her two daughters making tortillas by hand on the comal stove. 
Not only are traditional ingredients and foods highly nutritious and filled with essential micronutrients, but they can be consumed without any extra cost other than the human labour it takes to work the land. One interviewee who was well over eighty years old blamed non-traditional foods for modern health problems that are afflicting his people in the community.

All these cancers, obesity, diabetes that are affecting people here, even the young!...it's because they drink Coca-Cola all day and eat junk foods. Look at me. I still get up every day at 4:00am to tend to my milpa and fetch water for my cattle. I've never had a cold in my life. I had my first Coca-Cola when I was fifty-five! I was raised on atole, beans and squash; that's why I'm strong and healthy to this day. To this day our traditional foods keep us strong and healthy. They're not like today's modern foods that are not from the milpa that people have started eating.

A number of interviewees agreed with this statement and expressed their belief that an important part of being Maya is to eat Maya foods from the milpa. "In order to keep being Maya, we must make sure that the younger generations keep eating the Maya foods from the land," warned one young milpero. The responsibility to make sure that milpabased foods remain the foundation of the Maya diet in years to come is a thought that was shared by four of my milpero interviewees.

Clearly, food (nourishment) is vital to any culture. The Yucatec Maya of Xuilub view milpa-based foods as what allows "us to be Maya and to perform our work on the land," said one milpero. Within the broader responsibility-based environmental ethos I observed in Xuilub, food is seen as more than a source of sustenance or as fuel. I am not trying to argue that other (Indigenous and non-Indigenous) cultures view food as less important than do the Maya, as, to be sure, food (and preparing food) has cultural meaning for all cultures around the world. However, my argument here (based on my own interpretations of my field and interview data) is that for the Maya, food has a 
spiritual significance, too, as it is seen as what links the human being to the land: it is a physical symbol of the relationship between the Maya and their territory. Food is fuel, to be sure, but it is fuel that allows the Maya land user to carry out her/his relationships to the land. It is, in fact, sacred fuel, as I understand it.

\subsubsection{Milpa-Related Ceremonies}

Milpas, on which grows the food that has sustained the Maya for centuries, do not stand alone. They are connected to the broader Yucatan landscape, and especially cenotes, which provide the freshwater that is needed to grow crops on the milpa. The Maya people of Yucatan have for centuries depended on cenotes for sustenance and cultural activities. In fact, the cultural survival of the pre-contact Maya people depended on the methodically planned use of fresh water. There is a rich mythology and milparelated cermonies associated to these unique landforms (Munro and Melo Zurita, 2011). In Xuilub cenotes (see Figure 5.5) hold spiritual meanings and are frequently the sites of milpa-related ceremonies. Today, many of Xuilub's members maintain spiritual connections to cenotes because several ceremonies are centred on cenotes (and generally water). One men told me that cenote water is believed to be "clean and pure, with spiritual qualities and dimensions, especially in the ones that aren't open because it is forever unexposed to light.” As was the case centuries (and possibly millennia) ago, cenote water is still used in ceremonies at the beginning of the agricultural season to implore Cha-chac to be merciful and provide the Maya with enough rain to ensure a successful harvest. Ancient Maya ceremonies like the Cha-chac rain ceremony have survived colonial invasion and rule and are still being carried out to this day. Like their ancestors, the Maya of Xuilub venerate the rain god Cha-chac, whose pity is needed in 
order to have bountiful harvests. Some of my milpero interviewees recounted to me some the more memorable annual Cha-chac ceremonies where they witnessed what they believed to be proofs of or manifestations of Cha-chac. Indeed, it is said, when particularly expert menes (plural of men) perform the Cha-chac ceremony, it is not uncommon for rain clouds to start forming and concentrating over the area in an otherwise clear and sunny sky. What demonstrates a particularly successful or effective ceremony, I was told, is a sudden downpour during or shortly after the men's prayers. "That's how one can tell whether the men dutifully carried out his tasks and responsibilities to his people," said one milpero. The statement by this milpero points to the importance of the values of reciprocity and relationships with Maya gods like Cha$c h a c$. There is a spiritual responsibility to maintain these relationships with the gods. The role of the men, specifically, within the integrated responsibility-based environmental ethos, is to act as an advocate and representative of the community, or as an intermediary between the spiritual realm and the land, where human beings exist. His role is one of great importance to the community, as the entire Xuilub community depends on him to make sure the human-god relationship is dutifully maintained through ceremony and prayer. The people of Xuilub depend on this person for their milpa-based livelihoods. Menes who fail to deliver on their promise of good harvests can be replaced by the community (they simply do not get called on again to perform ceremonies, said one milpero). 


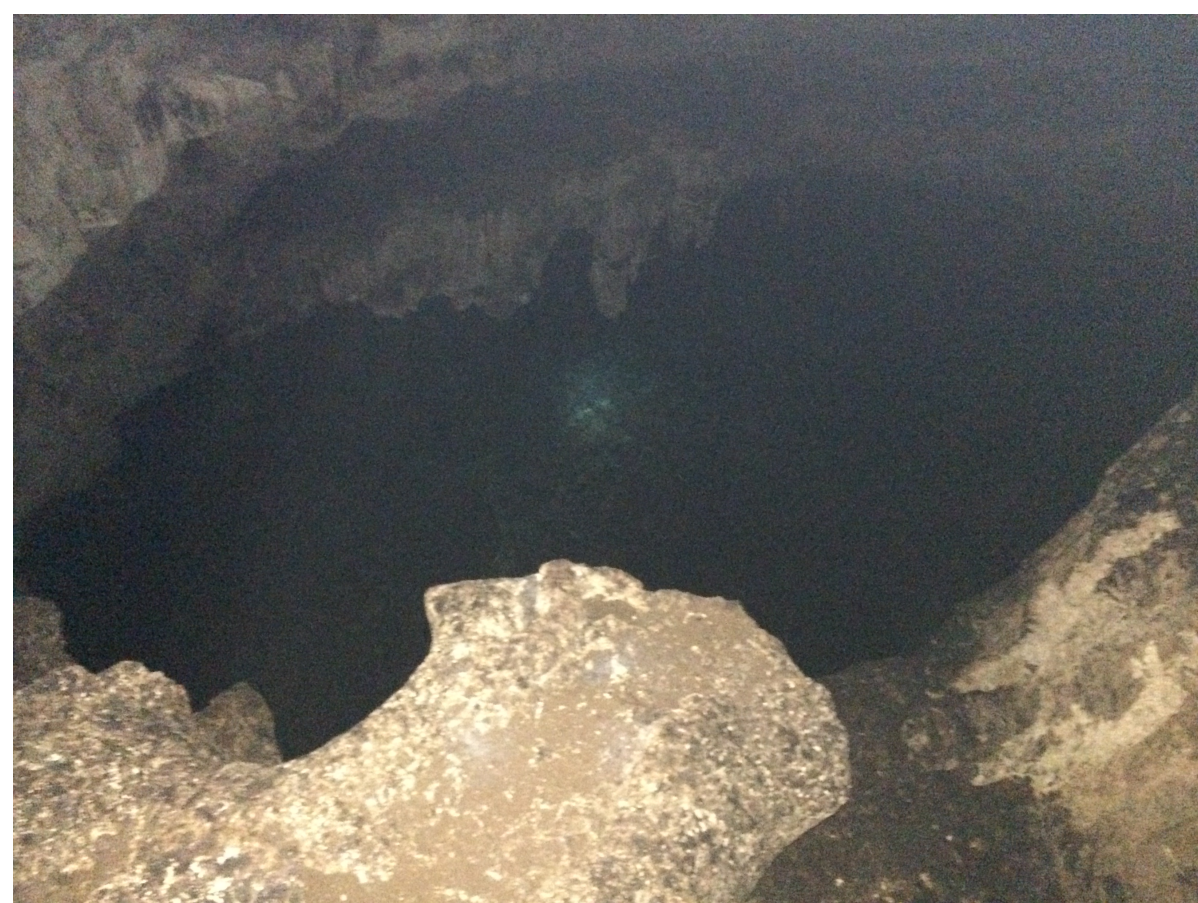

Figure 5.5. Looking down into the mouth of a cenote (and the freshwater at the bottom) in Xuilub.

On my third trip to the area in July of 2015, I was fortunate enough to witness a Cha-chac ceremony performed by one of Xuilub's most highly esteemed menes. In Xuilub, the ceremony begins before the sun rises, when the men leads a group of the community's men and children to the site of a sacred balché tree atop a cenote. The group then builds an altar with branches and leaves. The balché (Lonchocarpus violaceus) has since pre-contact times been regarded by the Maya as one of the most sacred tree species in the Yucatan. The group of men then sit and follow the men in prayer and song, while he faces the altar and recites Catholic prayers in Maya. The wine is a beverage consisting of pieces of the tree's bark and roots fermented in water from the cenote that has been spiritually purified by the men. The Cha-chac ceremony unites men and boys of all ages in prayer, and all individuals have an age-specific role and responsibility in preparing the ceremony, setting up the altar and petitioning Cha-chac 
and praying for rain and a bountiful harvest. Each person in attendance has a responsibility to perform his work and prayers and to contribute to the common effort. Young boys have an important role in the Cha-chac ceremony. They are told to mimic the frog's rain-time croak, and break out in calls of "Blek! Blek!” In the weeks prior to the Cha-chac ceremony, the officiating men must prepare balché "wine." Throughout the day, the men and a few of his assistants prepare dozens of stuffed tortilla-like breads. Interviewees all believe that once they fulfill their spiritual duty to Cha-chac, $\mathrm{He}$ is responsible for ensuring a favourable growing season and harvest. Again, this motivation for the Cha-chac ceremony rests on the values of responsibility and reciprocity between all human and other-than-human actors and beings of the Yucatan.

Just as milpas are connected to cenotes, they are also closely connected to the soil in which the crops are grown. Sahcab, a local type of soil composed primarily of gravel, white sand derived from a type of limestone, and organic matter, has religious and spiritual significance for Xuilub's milperos. With few exceptions, milpero research partners in this research project have described the cultural importance of sahcab. During the milpa planting season, it is customary for milperos to symbolically offer some of the last harvest's corn and a piece of to Cha-chac by planting it in a patch of sahcab. This offering of maize is an act of gratitude that symbolizes the sharing of the Maya dietary staple with the god who sustains the Maya people. Without Cha-chac's blessing, it is believed, the milpas would not yield the corn that is so essential to Maya livelihoods. One interviewee said he believed that "the land, the milpa, would simply not bear enough corn to feed my family," if he neglected to perform the maize offering. He continued, "it's a ceremony we do here before beginning to work the land. We offer the corn to the earth in 
order to be able to work it without any problems, without encountering any bad luck or accidents, and also to be blessed with a favourable harvest. We ask for permission to use the earth, and to be blessed with enough food to continue working it." I asked, "why is it important for you and others in Xuilub to perform this ceremony? What would happen if you didn't?" He replied:

It would affect everything. That's the tradition of the old people, the ones who built the pyramids over there [he pointed to a local pyramid in the forest near his milpa]. When they had their milpas, they would plant the maize, to give to the god of the harvest. To give the god thanks for having blessed them with the fruits of the land. If we stop carrying out this tradition, it could cause the land to become infertile and could cause us illness as well. We also need to pay our respect and make offerings to the old people of the pyramids. We also have to keep quiet at night and let them rest. They start to whistle at us if they are annoyed. If they notice that we haven't prayed for them in a while, they start to send wild animals like jaguars and snakes that come into our homes and don't want to leave. If that happens, then you know it's too late. We don't want that to happen to us so we pray for them and pay our respect.

In this example, the "old people" and the things they have built on the land - pyramids, sacred sites, etc. - serve to remind the present-day Maya of Xuilub that they are rooted in a landscape in which their ancestors also shared the same responsibilities toward all beings on the land. Those who are now departed, then, also become part of the web of relationships and responsibilities in the Xuilub and in the Yucatan. The responsibility to honour the traditions of the old people is met with the old people's responsibility to offer guidance to the Maya of today. The pyramids they have built are an additional visual reminder on the land that helps to maintain the Maya social order and respect for the land of which they can literally see they have been a part since time immemorial. In this sense, the Yucatec Maya are lucky to have a constant visual reminder of where they come from and a constant source of ancient inspiration that guides their way of life and 
environmental ethos - the pyramids and the old people are also (quite visibly) part of the land and of all the relationships between beings. The two common themes throughout the aforementioned milpa-related ceremonies and in the testimonies of adherents are responsibility and reciprocity between humans and supernatural beings, all of them connected by the land - in this case the milpa. In this system, as I understand, humans must do their part to appease supernatural beings. Likewise, supernatural beings must uphold their duty to give the Maya sustenance. The land, on the other hand, acts as the stage on which relations and responsibilities are performed and reinforced. "Nothing and no one can exist without the land," offered one milpero, reflecting on his understanding of the Maya land ethos. I then asked him, "can you give me some examples of milpa work or tasks that you relate to this broader vision that you've just explained?" First, he told me that an example of this is the Maya way of planting maize and beans in the same hole and squashes being planted in between these rows of maize and beans:

You see, these three crops have responsibilities to each other as well. They help each other to grow. One of them, maize, provides shade and coolness for the others, because they grow faster and taller and their leaves are broader. The other two provide nourishment for the maize and allow it to grow faster and stronger. One cannot exist and thrive without the other, and that's why they also carry out their own respective work and duties, their responsibilities - just as I do, day in and day out. All of us, the maize, beans, squashes and I, we all have work to do to allow each other to exist in a happy and healthy community here. The land does not belong to me, just as it doesn't belong to those three crops. We each fulfill our duties to her; we all depend on her-for soil, for water, for everything.

Next, he mentioned that even the "hardest part of milpa work," weeding throughout the agricultural season, is done out of a sense of responsibility to his non-human relations, in this case specifically the maize, beans, and squash:

Weeding is not something I can say I particularly love doing. It's very difficult and taxing work, especially in the hot sun. In fact, it's my least favourite part of my 
work on the milpa. But I do it because it's what is right. It's what I must do. My crops need me to do it. They count on me. I want to give them a beautiful place to grow and live - a beautiful home. If I do that, then they are generous and good to me. They grow tall and big and juicy and they are in turn happy to feed me and my family. I do my part and they do theirs. That's how we must do things here.

I consider that this man's description of those two examples of milpa-related tasks exemplifies how responsibility-based thinking, beyond discussions of abstract philosophical concepts, is put into practice on the land in a very concrete and observable manner. The milpero's close contact with the land and his crops gives him a daily reminder of his responsibilities to his relationships and of his responsibilities. In the milpero-crop relationship, it is understood that both humans and their crops have a responsibility to one another. The human must dutifully perform his arduous work and provide a "beautiful home" for the crops and, in turn, the crops must be good to the milpero by fulfilling their responsibility to be abundant and provide nourishment for his family: this relationship and responsibilities are indeed a two-way street.

\subsubsection{Working on the Milpa with a Maya Elder}

I was fortunate enough to be able to go on over 10 day trips on milpas with five milperos around Xuilub. To complement my analysis on the importance of responsibilitybased thinking in milpa-related activities, I will now share one of my experiences as an experiential learner during one day of work on the milpa with one of Xuilub's oldest milperos. What I did with this man represents a typical day of doing work on a milpa with any of Xuilub's milperos. It should be noted that he often stopped during work to make an observation or explain something to me, so in this and other cases, my presence may have had an effect on how the work was carried out. However, this snapshot of the milpa work I did during my field research is particularly significant because the man is 
regarded by his fellow milperos as being the most knowledgeable, wise and experienced one in the community. On March 5, 2016, Demetrio and I accompanied a Maya Elder to work on his milpa (see Figures 5.6 and 5.7). The man, whom I had interviewed a few days prior, had agreed to have us help him in his work on his milpa and harvest some cassava. Demetrio and I arrived at the man's milpa on our bikes around 8:15am. It is located roughly three kilometres due west of Xuilub, next to the Yucatan-Quintana Roo border. The man greeted us and began naming and pointing to some crops that were growing on his milpa: maize, jasmine flowers, sugarcane, sweet potato, beans, Mexican yam bean, breadnut, squash, cassava, lentils, balché, thatch straw, papaya, and more. He then handed us machetes and demonstrated how to bend down, hold and position the machete to cut down unwanted shrubs, trees, grasses and other plants. I felt very impressed by the way all of the different crops, plants and flowers appeared to be growing symbiotically, in my interpretation. "Some plants are taller than others and provide shade for the smaller plants, who can't grow under direct sunlight, but who provide nutrients that the taller plants need to grow," he said. I asked the man how often he works on his milpa. "Every single day of the year, even on Christmas and New Year's," he chuckled, "there's always work that has to be done!" Indeed, this does seem to be true. There are rarely any days of respite, especially during the agricultural cycle. 


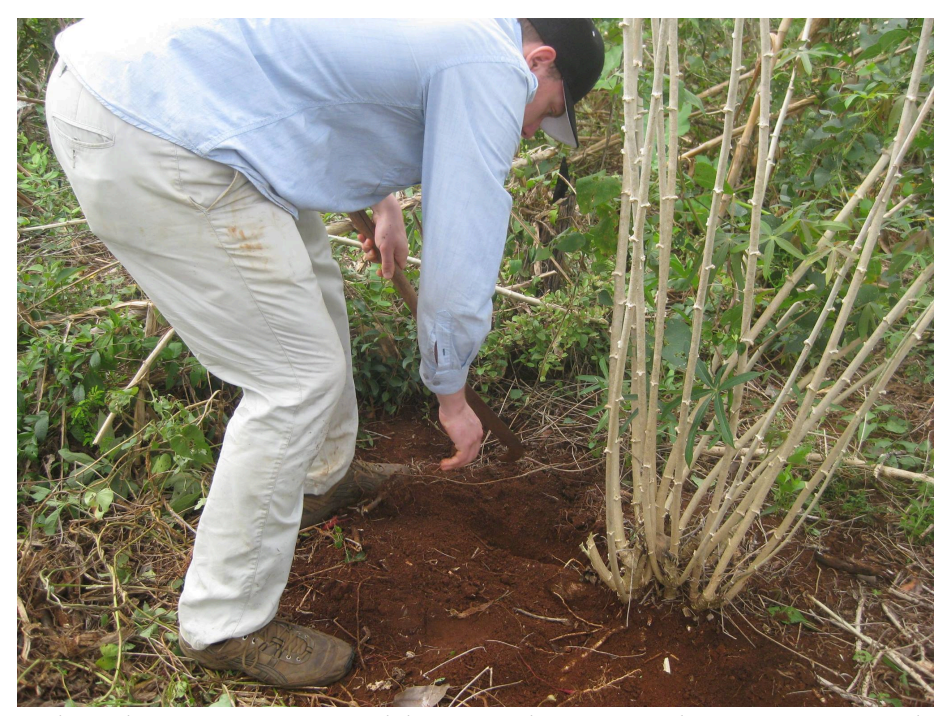

Figure 5.6. The author being instructed by a milpero on how to properly harvest a cassava root.

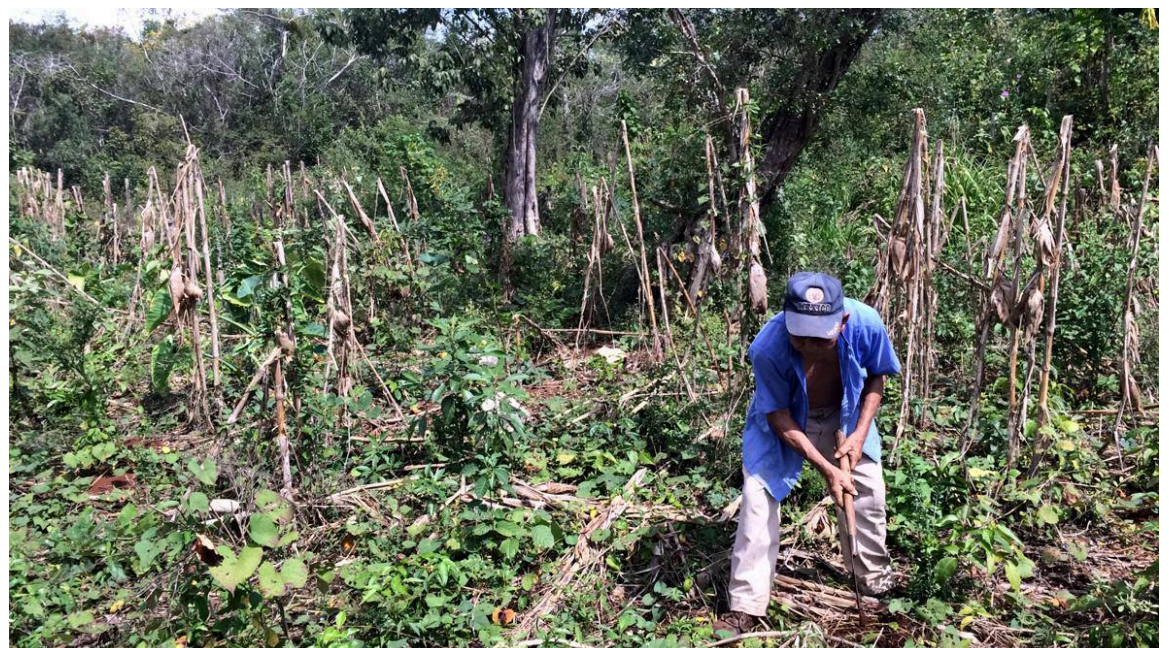

Figure 5.7. Milpero in the process of harvesting some root vegetables on his milpa for the evening's supper.

I observed the man's interactions with the crops and other plants growing on his milpa. His movements were very methodical and deliberate. His deep knowledge of his surroundings was quite striking. He knew exactly where to find the cassavas and Mexican yam beans by following their roots along the soil. As he deftly unearthed the tubers, he smiled and said to me in Spanish, 'Isn't this beautiful? It's the most beautiful thing on 
earth to be able to work the land the Maya way." He was overtly proud of showing this outsider from somewhere up north the beauty of the land and of his land-based Maya tradition. He commented his every move and why he was doing things a certain way: "I love my land; it gives me everything I need to live. For that, you have to respect her." It was clear that the elderly milpero felt a deep emotional connection with his milpa that is absent in contemporary agribusiness. "In kuxtal he lùm ma," he later said while taking a moment to stand straight and rest. Demetrio then looked at me and translated the old man's words: "The land is everything. She sustains us, and we have a duty to sustain her as well ${ }^{1}$." Those words have resonated in my mind ever since, as they perfectly encapsulate Maya responsibility-based thinking as it is put into practice on the land. This cultural dictate visibly translates into action on the milpa: "This is how we [Maya] work on the land; we owe respect and duties to everything that exists on it, and this is how we must continue to do things as Indigenous people in our home, the Yucatan." When I asked him what he meant by "everything" on the land, he explained that it means all of the beings, both spiritual and non-spiritual (i.e. humans, animals, plants, cenotes, etc.). The milpero's sense of duty and responsibility is to all his spiritual and non-spiritual relations on the land: fellow humans, animals, plants, Maya gods and supernatural beings, as well as the Christian God and Catholic saints. All these beings are thought to co-exist and co-relate in the earthly realm, and the land is the medium through which these

\footnotetext{
${ }^{1}$ Specifically, the agricultural practices that, according to this milpero, sustain the land are the: "cutting and burning of brush and weeds before planting the crops in early summer, the constant inspection of the crops once they are planted (to see if they are healthy and free of disease, and the harvesting of the maize at the end of the growing cycle. The maize and other crops we grow here love to feel our hands working the land...they feel our love for them. And also, we love to feel the soil through our hands. This contact with the earth in our work is a bond with everything that's underneath it."
} 
relations infinitely play out. He later elaborated on the relationship between milpa work and more general relations with the land, saying he had a responsibility and duty to maintain his crops and that, in his mind, "failing to do so means unsuccessful harvests and an inability to provide for my family. It's crucial for any Maya person—not just milperos - to fulfill their responsibilities to the land. We depend on it and it depends on us as Maya."

\subsection{Maya Apiculture}

To me, apiculture represents a merger of two different knowledge systems and approaches (Western and Maya) and their synthesis into a concrete land-use practice. Although chiefly economic, Maya apiculture carries elements of a distinct Indigenous environmental worldview that is observable in associated land-use practices that are informed by spiritual beliefs. However, Maya apiculturists are also very keen on learning and incorporating scientific practices in beekeeping (acquired from government apicultural scientists and technicians), such as using certain industrially manufactured vitamins and nutrients to keep the bees healthy, and acquiring information on their feeding and breeding patterns. The feeling of duty to practice apiculture as part of being Maya was less apparent in my interviews, as opposed to nearly all milperos in the community believing it is a Maya duty to know how to work the land. However, Maya apiculturists have told me that even though this activity is not as central as milpa farming to the Maya way of life, the honeybees that are kept and taken care of are as much a part of the land as any other being, human or other-than-human. Even though apiculture as a source of livelihood is relatively new in the Xuilub (n.b. it has been practiced in the Yucatan since before the arrival of the Spanish), having been practiced in that way for 
around forty years, according to one of the first apiculturists in Xuilub, interviewees believe it has taken on a Maya dimension and has become a truly Maya practice. "The way we do apiculture is different from non-Maya people. We see the bees as our relatives, as our family members," said one apiculturist. He continued, "we do it the Maya way here in Xuilub. We pray to the bees' Lords and we carry out our work so that the bees can live happily and healthily among us. And they treat us well by making honey that we can sell." What is clear is that although the milpa is at the centre of the Maya lifestyle in Xuilub, the spiritually informed form of apiculture practiced there is thought of by the community as a distinctly Maya land-use activity. Today, apiculture is one of the main economic sustenance activities in Xuilub. A large number of families care for bees and sell their honey. These families benefit from funding from the local chapter of the CDI (Centro del desarollo para los pueblos indigenas), a federal government agency that provides support for Indigenous business initiatives. The CDI has invested heavily in Maya apiculture projects throughout the Yucatan peninsula. The CDI is a federally funded agency whose mission is to "guide, coordinate, promote, support, foster, monitor, and assess programmes, projects, strategies, and public actions to attain integral and sustainable development and full enjoyment of the rights of indigenous peoples and communities," in accordance with Article 2 of Mexican Constitution (Political Constitution of the United Mexican States, 1917). The CDI has chapters in twenty-four of the thirty-one Mexican states, and has in place programmes that fund local cultural and language programmes, in addition to economic development projects. In Yucatan, the CDI has its state headquarters in Mérida but has a satellite office in Valladolid. I was able to interview one of the CDI's agents in Valladolid who is responsible for overseeing a 
variety of different projects in Xuilub and other ejidos in the vicinity of Valladolid. In Xuilub, the main programmes are: road construction and maintenance; electrification and lighting of the community (especially roads and the village core); building and delivering single-family concrete homes to those who are in need; and funding apiculture and smallscale cattle ranching ventures. Many of interviewees praised the work and the mission of the CDI and believe the Agency is acting in good faith to assist Indigenous peoples across Mexico in maintaining their cultural knoweldges as well as their economic vitality while offering critically needed financial assistance and knowledge transfer. One apiculturist family I interviewed affirmed that the CDI's support was critical to the establishment and growth of their business, which is their main source of income. The CDI, the father told me, "paid for all our initial beehives (wooden boxes with two layers of "frames" in which the bees fill the cells with honey). They also sent professional apiculturists to train us on how to choose and clear an apiary in the forest, care for the bees, clean the hives, and harvest the honey." Most of Xuilub's apiculturists depend on funding and scientific and technical training from the $\mathrm{CDI}$ in order to maximize their honey production. This training is provided by its Programa para el Mejoramiento de la Producción y Productividad Indígena (PROIN), or Programme for the Increase of Indigenous Production and Productivity, which is responsible for sending qualified personnel to ejidos to teach apiculturists about best practices, as well as providing all necessary equipment and garments (e.g. beehives, cinderblocks, metal smokers, sugar, knives, gloves, honey extractors, antibiotics, vitamins, minerals, etc.). These programs and efforts by CDI are no doubt having a positive impact on the Xuilub community. Their assistance in apicultural projects is, from what I understand, indispensable to 
Xuilub's apiculturists. Nonetheless, from my in-depth interview with one CDI official in Valladolid who oversees these projects in Xuilub, I am under the impression that aside from providing financial assistance to Indigenous groups, there is little effort or real interest in understanding their distinct environmental ethos. Said the official, "we have to help Indigenous people to participate in the Mexican economy. We need to give them a chance to be productive members of Mexican society - to generate wealth for our country." When I asked him if he thought the people of Xuilub, and the Yucatec Maya by extension, had any valuable knowledge for the rest of the Yucatec and Mexican society to learn from, and if he thought that perhaps Western land management models could benefit from incorporating more IKs, he responded,

Listen, their cultures are very quaint and pretty, and they're part of Mexico's history, and history here in Yucatan. They played an important role in shaping Yucatec society. But now things have changed. We are part of a global economy. Society has evolved. I think that our role at CDI is to assist these people economically. We have the scientific knowledge and expertise and the resources to allow them to gain some economic vitality and generate wealth, be it through apiculture or delivering prefabricated houses in their communities. They really appreciate us! So I think it's more a question of helping these people to understand how to contribute to the economy than of government structures to learn to be more like them. Their stories, folklore, and spiritual beliefs are all very nice to hear, but what they need is to learn more about science and economy.

I believe that most postcolonial scholars and Indigenous geographers would have a problem with the CDI official's position, to say the least. Given that (as discussed in Chapter 3) one of the main aims of both of these fields of study is to allow non-Western (and Indigenous) peoples to challenge dominant Western discourses and concepts (related to the meaning of place, progress, the environment, etc.), it is disconcerting to hear a government employee and representative display such a narrow vision that downplays the importance of IKs. The economic imperative in "assisting" Indigenous groups to 
participate in the regional, national, and global economies, whether they are willing or unwilling participants, is one of the main criticisms of such current state-sanctioned aid or assistance programs around the world. In this case, there is no strategy to meaningfully engage with Xuilub or other Indigenous communities and to seek to understand their worldviews and relationships with the land. Nor is there any evidence of a commitment to periodically provide these people with opportunities to give feedback or create an ongoing dialogue. A truly postcolonial approach and mindset would be to, prior to implementing financial assistance and scientific/technical training programs, allow the Xuilub community to give their input and to teach these government officials about alternative ways of understanding the environment, thereby challenging dominant Western discourses. I believe that CDI is missing out on an opportunity to learn from the responsibility-based thinking lived and practiced in Xuilub and to develop more socially and environmentally equitable environmental management models that could present a response to neoliberal economic models like monoculture crops and tourism development in the Yucatan that threaten biodiversity and Indigenous cultural survival (as argued by Wainwright, 2008). I would suggest that perhaps the responsibility-based model that exists in Xuilub is better suited to respond to the needs of local people in the Yucatan than the global neoliberal model that is applied more or less uniformly around the world, with no consideration of local context or conditions. The Maya model, in contrast, is entirely "Yucatan-centric," and depends on an intimate knowledge of the local environment and of the land and the relationships on it.

Although Xuilub apiculturists depend on the CDI's assistance to get their ventures off the ground, Maya apiculture is imbued with cultural meanings and spiritual beliefs. 
For instance, all of my apiculturist interviewees believe there are supernatural powers that determine the health of the bees and the bountifulness of the harvest. As a result, it is common practice to say prayers to the bees, who are seen as intelligent beings that are part of Maya society and the land, each day prior to working with them. Failure to do so, explains one apiculturist, "leads to their populations declining and getting sick-they get frustrated with us. You really have to love them and treat them as your own kids, as your own family...because they really are part of our family, and the honey they produce lets us have money to feed our own human family." Apiculture as practiced in Xuilub, therefore, represents a merger of scientific knowledge about bees and local traditions and spiritual beliefs about the land and relationships between all beings (in this case humans and bees). Also, very importantly, this Maya attitude about apiculture demonstrates a belief in the duty of apiculturists in the community to maintain (almost familial, in the words of the apiculturist above) relationships with the honeybees and their "land," or the apiaries and surrounding forests. The bees, in turn, are understood to have the responsibility to apiculturists to produce enough honey for a successful harvest for the individuals and families that take care of them.

Xuilub apiculturists have an extensive and detailed knowledge of the species of trees on which (their) honeybees (Apis mellifera) feed, based on "both CDI scientists and their own IKs of the forest from "years of observation and trial and error," as explained by one apiculturist. Honeybees in the Yucatan feed primarily on orchids and a variety of flowers that bloom on wild native tree species in the region. However, the tajonal (Viguiera dentata) and tzitzilche (Gymnopodium floribundum) trees are the most important. Honeybees play a crucial role in preserving the Yucatan's forests, as they 
pollinate a number of tree and other plant species (Echazarreta et al., 1997; VillanuevaGutiérrez et al., 2009). Apiculturists are aware of this and have a great incentive to protect native trees and plants, and to ensure that their immediate area not be deforested. Thus, the Maya tradition of beekeeping and honey production has a very positive impact on forest conservation in the Yucatan. As described by apiculturists in Xuilub, there are two main flowering seasons in the Xuilub area. The first usually starts between January and February, and the second between April and June (this is close to broad patterns in the Yucatan observed by Villanueva-Gutiérrez et al., 2009). The harvest season runs in close conjunction with the flowering season, and usually lasts from January to late June. In the weeks prior to this time, Xuilub's apiculturists drive or walk around the ejidal territory to determine which bushes and groves are flowering, in an attempt to anticipate the feeding patterns and movements of the bees. Maya apiculturists know exactly which of their apiaries (an opening in the forest where a collection of beehives are kept) will yield the most honey according to their distance to the most fruitful groves and bushes. The number of beehives in each apiary ranges from approximately twenty to fifty, according to one apiculturist. Families that practice apiculture typically look after two to eight apiaries often located within a few hundred metres or one another. During the flowering seasons, hives are frequently moved around from apiary to apiary. This is because one apiary may have a greater abundance of flowers (on which the bees feed) than another one just few hundred metres away (mostly due to the availability of sunlight and the distribution of the foliage, as explained by one apiculturist). Once harvested, raw honey produced by Xuilub apiculturists (and stored in fifty-US gallon metal drums- $-n . b$. apiculturists use the imperial measurements system when talking about the 
quantity/volume of honey) is generally sold to private honey redistributors in Valladolid, who in turn bottle the honey and sell it to local shops as well as international honey exporters. Although the flowering and harvesting season only runs from January to June, there is work to be done year-round. The main tasks of apiculturists involve: checking in on the beehives every week to two weeks and inspecting them for disease, parasites, and honey quality/yield quantity, as well as clearing the apiaries of growing brush and weeds;

moving beehives from apiary to apiary during the flowering season; harvesting about five to seven times during the from January to June; and providing enough sugar water for the bees to feed on from July to November or December when there are very few flowers in bloom.

In the remainder of this section on apiculture, I will share my experience of working with one particular family for three consecutive days, to illustrate how responsibility-based thinking and the Maya sense of duty to relationships on the land are put into practice by apiculturists in Xuilub on a day-to-day basis. During those three days, we carried out most of the main tasks related to apiculture described above: the yearly clearing of the apiaries of weeds and brush, the hauling of beehives from one apiary to another, and a trip to Valladolid to sell the product to honey buyers.

\subsubsection{Apiculture with a Family from Xuilub}

One morning in March 2016, I accompanied a family of apiculturists, composed of a married couple and their three children, for three days of work at three different apiaries. The family was selected because other apiculturists I interviewed told me that they were the most experienced and knowledgeable and that their honey harvests were often the most successful in Xuilub. I took part in three other daylong outings with three 
different families where I participated in either the clearing of the apiaries, inspecting the beehives, or harvesting the honey. However, this three-day outing was particularly meaningful because I was able to witness all the main types of work and tasks associated with beekeeping, as well as selling the honey in a honey market in Valladolid as a final step. On the first day, we left in the family truck at 7:00am and got to the first apiary shortly afterwards. The main task was to clear the apiary of any weeds and unwanted grasses that had been growing for a few months, in preparation for the translocation of beehives from one of the family's other (rented) apiaries about 20km from Xuilub in the state of Quintana Roo. As we used our machetes to remove shrubs and weeds, I chatted with one of the sons of the man who had invited me. I asked him if he had been helping his family out since he was a child. He nodded and said he felt it was his responsibility to help his father and his family. He continued, "my dad comes from poverty and has had to work hard all his life to earn and save what little he has today. He now owns about fifty hectares of land in different spots around Valladolid thanks to the honey." Clearing the apiary is hard work, and is certainly one of the most taxing tasks related to beekeeping. We spent three or four hours mostly bent over, swinging our machetes, aiming to cut plants as close to the root as possible. Once we were finished clearing the apiary, we gathered all the chopped weeds and made a dozen or so small piles. The family then lit each pile, one by one, and we all left after the small fires started to die down. The bees "need a very clean environment free of weeds and brushes where parasites and pests can breed and attack the bee colonies," explained the father while looking at the flames. My interpretation of this work that I did with the family is an example of responsibility-based thinking in practice. In my estimation, these tasks that were performed carried an 
underlying sense of responsibility to maintain and uphold the apiculturists' relationship to the bees.

Next, we drove to the second apiary. The father told me we had to find and cut two trees that were each approximately $4.5 \mathrm{~m}$ in length. These two trees would be laid down in the centre of the apiary as a base on which to place cinderblocks. The beehives would then, at a later date, be placed on top of the cinderblocks, which act as a barrier to ants, beetles, and other insects that invade the hives looking for honey. I accompanied the father on his search for the two trees while other family members stayed at the apiary to remove weeds and cut small shrubs with an axe. In all the work that had to be done, the family operated as a team, with each person, no matter the age or size, doing his/her part to help out the family. Once we laid down the base for the beehives and finished clearing the apiary, the father looked around and nodded, waving at us to get back in the truck and drive to the third and last apiary. Once we finished our work there around 1:30pm, the father wiped the sweat off his forehead and said, "alright, it's getting hot, let's go back home and have some refreshments." I was impressed by the unity demonstrated by the family. "Everyone in the family has a role and a part to play in this kind of work," observed the mother, sweating, while taking off her beekeeping suit.

Now that the apiaries had been cleared, on the second day of work the next task was to move the beehives from one apiary to another one about two kilometres away (see Figures 5.8 and 5.9). We left the family's home at 8:00am in the truck. That day, the whole family was ready to participate. Before I got into the truck, the father asked me if I had recently been in contact with a deceased person, or if I had given first aid to someone at the scene of a car accident. When I affirmed that I had not, the father replied "Good. 
You see, bees are very sensitive to injury, illness or death. Last year my wife had been to a funeral and came to help me at one of my apiaries. Soon after, the bees in that apiary started to die off and the bee population took a sharp decline. We had to ask one of the menes to recite some prayers and make some offerings of sahcab in order to restore the population." My interviews with other apiculturists show that this is perhaps a widely held belief. The father's statement indicates that even though it is a post-contact land-use activity, its Maya iteration is imbued with spiritual meaning. Just like all other land-use and community activities, Maya beekeepers follow an order of ceremonies and responsibilities to the bees, the trees, and the flowers. The man went on to say, "before moving the bees into their apiaries each season, I say a prayer to God and to the the bees' "owner" to keep the apiaries free of pests and to keep the bee populations healthy and productive. It's a matter of reciprocity. If we carry out our duties to the bees [apicultural practices], they will carry out their duty to us, which is to produce a lot of honey."

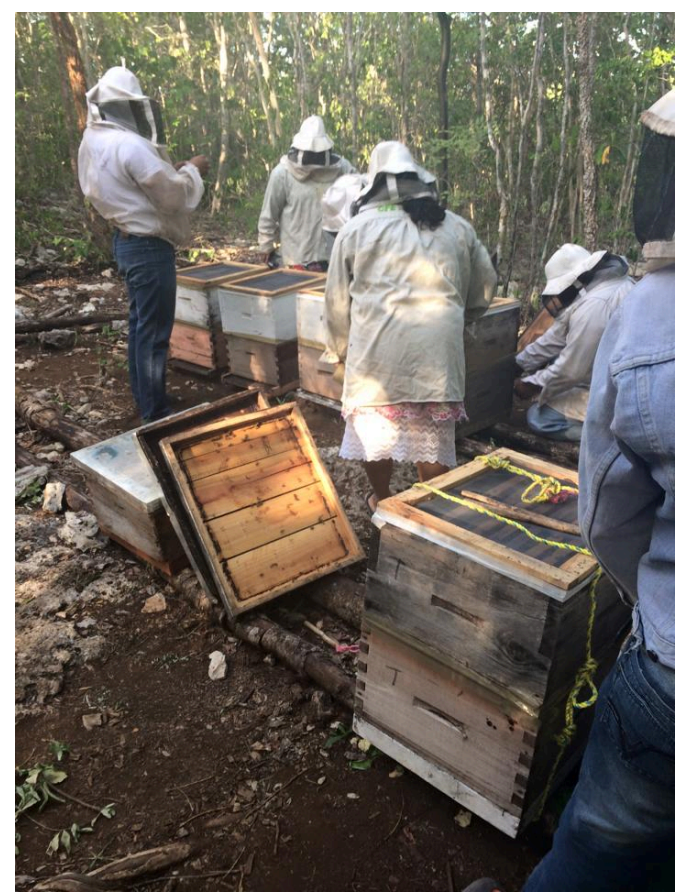

Figure 5.8. Family of apiculturists preparing the beehives to be moved to another apiary. 


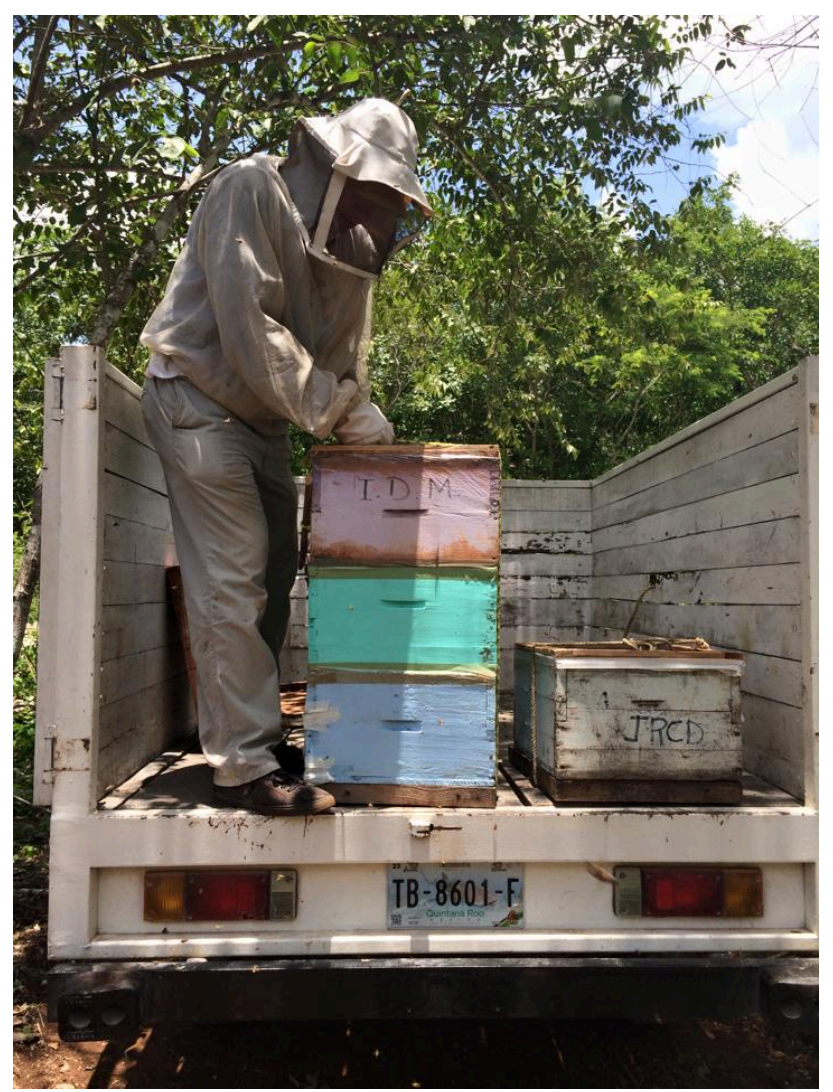

Figure 5.9. The author loading beehives onto the truck.

When we got to the other apiaries we began to board up the openings of the beehives to prevent the bees from escaping. While one person placed a small board across the slit of each beehive, two others used metal smokers resembling teakettles to blow smoke at the bees, which, I was told, calms the bees and minimizes the occurrence of bee stings. Next, we stacked two to three beehives at a time and tied a rope around each stack and strapped them to our backs like backpacks. We carried each stack to the truck. There was little time for chitchat as we carried out our work, and we paused only to take sips of atole and fresh water. When all thirty-five beehives were neatly placed and secured in the back of the truck, we drove back to the family's three freshly cleared apiaries (the ones we cleared the day before) and unloaded and distributed the stacks 
evenly on top of the bases consisting of two trees and cinderblocks that we had laid out the previous day. The stacks of beehives were very heavy and the July sun beamed down on us with intense heat. The ordeal took five hours, with very few breaks. (Unlike me, the family did not wear any protective gloves to handle the beehives, but their many years of experience allowed them to avoid getting stung by the bees.)

On the third day, the family invited me to accompany them on their trip to Valladolid to sell a few barrels of honey that had been harvested over the last few months. Before leaving their home, the father told me that we would be picking up people around Xuilub and taking them with us to the city. "Many people here don't have access to a car or truck. So each time we go to Valladolid, we let everyone know in case they need a ride. We feel we have to do our part to help other members of the community." On the way to Valladolid, we stopped to pick up elderly people and families from neighbouring ejidos. This is a common practice in Xuilub. It seems as though wealthier individuals feel a responsibility to help less fortunate community members in need. I consider this simple act of solidarity between community members as a manifestation of the responsibility-based mindset. As I have learned, it is manifested not only in land-use practices, but in most facets of community life.

When we got to the city, we parked on a little street not far from the downtown district, which has a handful of shops that buy honey from the region's Maya apiculturists (see Figure 5.10). We unloaded two metal 50-US gallon drums of honey. In each shop there is a scale where the honey is weighed and inspected with a magnifying glass to determine its quality. Depending on its quality, honey is bought from producers at a price ranging from twenty to thirty Mexican pesos (approximately $\$ 1.50-2.50 \mathrm{CAD}$ at the time) 
per litre, depending on its quality. The father and mother negotiated the sale of their honey at a price of twenty-eight pesos per litre. Each shop has a facility that stores empty honey barrels belonging to the honey producers. The family then left the two full containers and collected a few empty ones that they had left the last harvest. They were satisfied with the price that they had negotiated. The father and mother left the shop smiling and invited me to supper at a nearby restaurant with them. While we were eating and talking about the day's work, the father offered an insightful comment that captures the responsibility-based mindset as it applies to apiculture in Xuilub:

You see, this is how the work must be done. When we fulfill our responsibilities and work as a family, our responsibility to one another...but not only within the family, but to the bees and the apiaries where they live, their home, we all benefit. They were happy with us, how we treated them, the respect we showed for them and the gods they pray to, and now we're happy because we have a bit of money that will help us these next few months. That's how we work and live together, us and the bees, us and the spirits and the gods. We're all here to help one another and we all must keep our promise to one another. That's how we learned to live responsibly from the old people, and that's how we live today.

My three-day apicultural experience with the family gave me an insight into all the different kinds of work and tasks that go into caring for the bees (and their "home"), harvesting the honey, and selling the honey as a source of income. The individual landuse practices described in the following slides should be considered as part of the syncretic, integrated land ethic that I have just described - and not in isolation from one another or from the spiritual and religious and epistemological dimensions of Maya culture. In the land-based Maya culture, no person, thing, or activity falls outside of the web of relations and an individual's and a community's responsibility to these relations. 


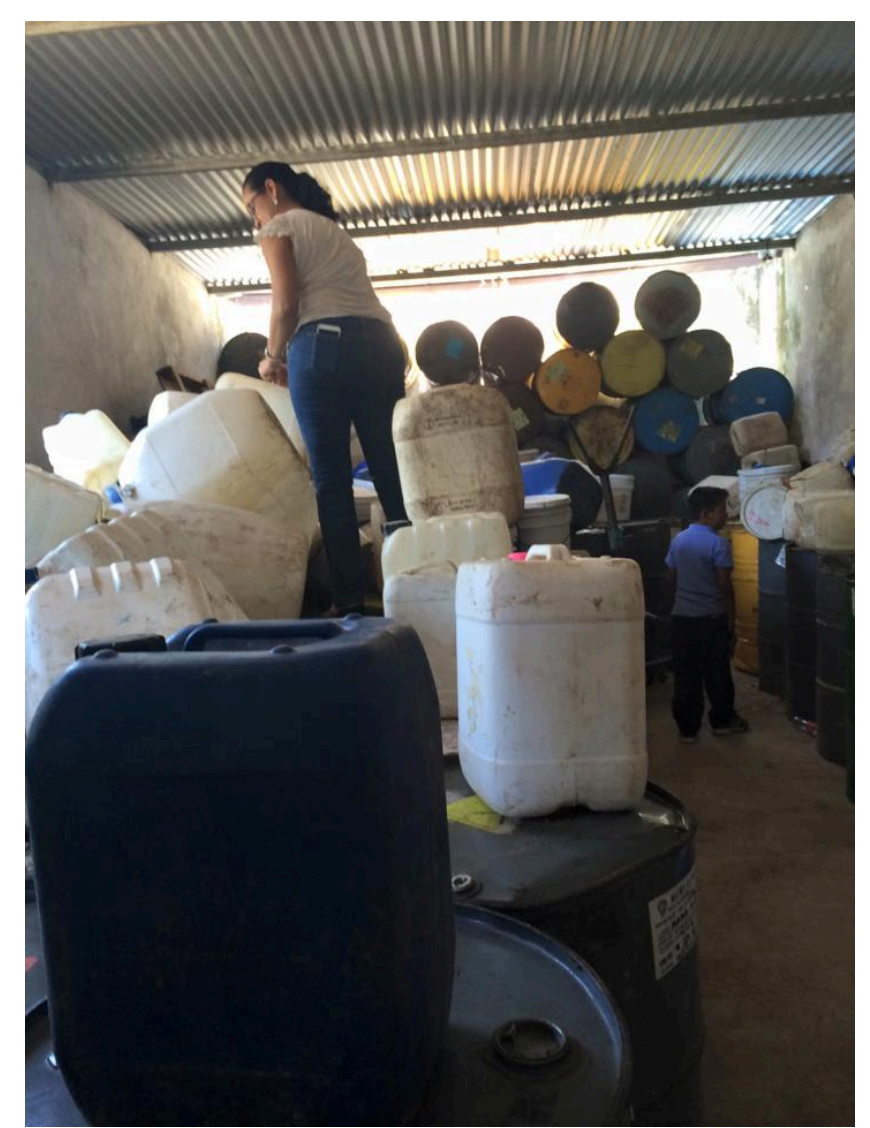

Figure 5.10. Honey merchant in Valladolid inspecting the quality of the honey.

\subsection{Hunting and Maya Relationships with Wild Animals}

In Xuilub, human interactions with wild animals (aside from insects) are mostly restricted to subsistence hunting. In addition to foods provided by the milpa, about half of all adult men in the community hunt and consume Yucatan brown brocket deer (Mazama pandora), collared peccaries (Pecari tajacu), and wild turkeys (Meleagris ocellata). As I learned (in my field research), the community's hunters - the majority of whom are also milperos - typically go hunting on the weekends in small groups of three to six men and boys. One young hunter explained to me that most of the hunting that is done in the community is not recreational. Indeed, for many families in Xuilub subsistence hunting provides an important supplement of food and is a much cheaper alternative to buying 
chicken or pork from their neighbours or from a butcher in Valladolid. He went on to say that in his estimation, most people he knows hunt about once a week or every two weeks. This rough estimation was corroborated by two other hunters whom I interviewed at a later date. In my interviews with Xuilub's hunters, it was clear that all these men had respect and compassion for the animals they killed. One hunter told me he believed animals had intelligence and free will. "I highly respect and regard wild animals," said one hunter. He continued,

They aren't domesticated; they have no owner and they can survive independently without us. They survive on the land and they eat from the land. They live their own lives independently and proudly. They have their own gods to which they pray and who are responsible for their wellbeing, just as we humans do. They also respect their ancestors like we do.

The statement from this hunter demonstrates a deep level of respect for wild animals, which he considers as free-thinking and as having agency, just as humans do. From my interviews and informal conversations with hunters over the course of two years and at different times in the year, I understand this to be a sentiment shared by the majority of them. I asked a group of hunters who had come back with a deer whether they knew of anyone in the community who did not have the same respect for the animals as they and the others I interviewed did, and they told me they were not aware of anyone. The impression I was left with is that a hunter who does not demonstrate the same responsibility-based mindset and ethic toward his animal relations in his hunting practices would unlikely be willing to make this known to his peers. In my view, this is due to the very strong feelings expressed to me about the respect hunters should show animals and the belief in reciprocity between human hunters, the animals, and their spiritual owners. 
According to the hunters interviewed, the Secretaria de Medio Ambiente y Recursos Naturales (SEMARTNAT), or Mexico's Secretariat of the Environment and Natural Resources, has little impact on regulating community hunting practices, since its wildlife officers rarely come to Xuilub to check for hunting permits. One hunter said that hunters in Xuilub “don't really need SEMARNAT because we maintain an internal system of hunting regulations. I asked hunters what internal mechanisms were in place in the community to prevent overhunting. The answers I received were generally much in line with notions of responsibility and following Maya traditions. Two interviewees boasted the freedom that they had as hunters to use their judgement when it comes to where and when to kill a game animal:

Hunters know instinctively about when and where to hunt. We base our actions on animal behavior. When we go hunting too often in a certain area, the animals will get scared and start to leave because they grow accustomed to the sound of gunshots. And when we avoid a certain area for a while, the animals start to come back to feed and then we can go hunting there again. We only hunt within the Xuilub territory, so when they leave, there is nothing to hunt. But the eventually come back when they've been away for a while, and that's when we know we can hunt.

The hunters of Xuilub use this simple but, they believe, effective system to know when it is appropriate to hunt. They base their hunting patterns on animal movements to and from the community's forested areas and do not chase after game. Rather, they let the game come to them. It should be known that some game animals have been overhunted and even extirpated from certain regions in the Yucatan (Léon and Montiel, 2008; SantosFita, Naranjo \& Rangel-Salazar, 2012). When I brought this up with hunters in Xuilub, they said deer and peccary populations are at a stable level, and they believe the human population density in the area is low enough to ensure the long-term viability of hunting 
as a land-use practice. Unfortunately, I could not find any population statistics for game animals in the Valladolid area (where Xuilub is located) to confirm these observations made by local hunters, which could be biased.

Another hunter described that group hunting with family members and friends is a very agreeable and bonding experience. It is an opportunity to spend quality time with people with whom they are close and to strengthen bonds between families in the community. When an animal is killed, the meat is divided between all in the hunting party. One elderly hunter, who mentioned he is his hunting group's leader, explained that this camaraderie and sharing between hunters made him have very positive feelings about the forest — and the land — and what she kindly provides to humans. From my time spent with hunters in Xuilub, it appears that Maya hunting practices are mediated by a responsibility to follow longstanding traditions to ensure wild animals, seen as sentient and highly intelligent, are treated with respect. The hunters whom I interviewed all stressed that wild animals are part of the land, along with all other human and other-thanhuman beings. Wild animals are thought to have their own will and independent thinking, and are in no way considered subordinate to humans. Just as humans, "they pray to their gods, and they try to live in the best way that they can. They want happiness for themselves and their families, just like we do," reflected one elderly hunter, "so they are our brothers and sisters and they deserve the same respect as we do. Failing to show respect will anger their gods, and once they are angered, the animals disappear for good." According to him, showing respect means praying to the Lords of the animals and telling them how beneficial the meat will be to their families, and making sure not to hunt more animals than they need for subsistence purposes. In turn, the animals and their gods also 
have a responsibility to be generous and provide meat for the hunters and their community. Reciprocity, respect, responsibility and coexistence continually emerged as the fundamental principles of the Maya practice of hunting.

\subsection{Cattle Ranching}

At the time I completed my field research, there were five people in the community whose primary occupation was cattle ranching. Out of all the land-use practices I investigated, ranching is the only one that was not practiced prior to the arrival of the Spanish. Nevertheless, the ranchers I interviewed and worked with all told me they view the way they practice this activity as "Maya." They believe that the cattle are their "relatives" who have spiritual Lords or owners who allow them to sacrifice their lives for the ranchers who look after them. As with all human and other-than-human beings in the Yucatan, there is a relationship between ranchers and their cattle that is one of reciprocity, responsibility, and respect. Ranching is thus also seen as part of a broader relationship with the land. The ranchers whom I talked to and worked with did not seem to be wealthier than the average person in Xuilub, and if they were, none of them talked about being well-off. I was able to interview three of these cattle ranchers, as well as to accompany one cattle rancher in his work. All three Maya cattle ranchers whom I interviewed believe that ranching is not only an important economic activity in the community, but also a lifestyle that taught them a great deal about human-animal relationships and respect for the land. Cattle ranching in the community can be described as small-scale, as Xuilub's cattle ranchers usually keep less than 25 head of zebu (B.t. indicus) cattle. Cattle ranchers buy zebu calves at livestock auctions in Valladolid and Tizimin (at twenty-eight kilometres from Valladolid, Williams et al., 2017 describe it as 
the centre of Yucatan's livestock production) and raise them until the age of three to four, when they are sold to meat merchants who come to the community to buy cattle and take them to a feedlot to prepare them for slaughter.

Cattle ranchers in the community tend to their cattle twice a day, year-round. Early in the morning, the ranchers cycle or walk to their cattle pasture to open the enclosure and let the cattle out to drink water and either feed on hay during the dry summer months, or graze in the pasture in the wetter fall-spring months. The rancher then returns in the evening, before sunset, to round up his cattle and lead them back to the enclosure, where they spend the night. This is done to protect the cattle from jaguars (Panthera onca) and pumas (Felis concolor), which are more likely to target lone cattle at twilight or at night. One cattle rancher explained to me that cattle bulls encircle and protect cows and calves when they are herded together. Although one cattle rancher told me this is a big concern for him, I was not aware of any reports of predatory felids in the area during my field research. He did mention that in such cases where a predator threatens his cattle, he needs to kill them to protect the herd: "it's a real pity to have to shoot such a beautiful animal, and it angers their Lord, and it's not good because the jaguars are our relatives. Some menes can even transform into them. But sometimes I have no choice." This statement is demonstrative of the idea that responsibility-based thinking does not mean one cannot make decisions in one's own interest (in this example, protecting one's cattle). Even though, as this hunter expresses, killing a jaguar is seen as something that should be avoided, when there is no other choice, it is something that has to be done. The responsibility to protect the cattle takes primacy over the responsibility 
toward the big cat. This seems to be a trend around the Yucatan. Reyna-Hurtado et al.

(2015) note that ranchers and jaguars occasionally:

engage in conflict when felids prey on livestock such as cattle or sheep. This problem is most acute when there is no cattle management and stock range freely. Several strategies to reduce predator-livestock conflicts are underway, including a predator compensation fund for dead animals to discourage ranchers from killing jaguars (Fondo de Aseguramiento run by SEGARPA)[Secretariat of Agriculture, Livestock, Rural Development, Fisheries and Food] (p. 241).

It should be noted that all of the ranchers I interviewed keep their cattle in an enclosure and thus the risk of cattle-felid encounters on their ranches is reduced. It is uncertain to me whether this is done with mostly economic intentions or whether this practice is also part of the broader responsibility-based environmental ethos, and if they see protecting their cattle in this way as a responsibility that they have toward their animals.

During the milpa season, from May to September, the cattle can graze freely on the grasses that grow on the pasture. However, from October to May, due to a lack of rain there is not enough grass growing in the pasture to sufficiently feed the cattle. Ranchers must therefore cut and pile and store grass during the harvest season to be used to feed their cattle from October to May. Every cattle pasture is located in close proximity to a cenote. Each day cattle ranchers pump cenote water, either manually or mechanically, for the cattle to drink. The water flows through a pipe that leads to a long water trough where the cattle drink. Thus, cenotes and the fresh water contained in them are crucial to cattle ranching. One cattle rancher mentioned that there is a sacred bond between cenotes, the cattle and the rancher. "Cenotes are what maintains the bond between Maya ranchers and their cattle. Both the cattle and humans depend on drinking water, and in that we are the same; we are connected." Insights by ranchers such as these about the spiritual dimension 
of cattle ranching (and relationships between humans, the cattle and the land) are, to me, what distinguish Maya cattle ranching from more large-scale and industrial forms. In my interviews and experiential learning, I was impressed by the cattle ranchers' insistence on the need to respect and "love" the animals as both humans and animals are of equal importance as beings that exist and depend on the land and its life-giving properties such as cenote water. One elderly rancher reflected on the importance of respectfully managing his pasture: "the land gives everything to me and my cattle. It gives me my cattle and my life and sustenance, and, of course, I depend on these animals for my survival."

\subsubsection{A Day on a Maya Cattle Ranch}

In early March of 2016, I was invited to see how work is done on a cattle ranch by a rancher whom I had interviewed a few days prior. I met with the man at his home at 7:00am and we cycled to his pasture, located $3 \mathrm{~km}$ east of the centre of Xuilub (see Figure 5.11). When we got there, he told me that we would first start gathering wooden boards and cutting down small trees to repair his cattle enclosure. Armed with machetes, the essential Maya tool used for all land-related activities, we began to cut down small trees in the early morning cool. We then placed the boards and pieces of wood along the enclosure to reinforce it. When he was satisfied with our work (after roughly an hour) he told me that it was time let his zebu cattle out of the enclosure (see Figure 5.12). We opened the gate and the cattle all marched to the water trough. He instructed me to spin a wheel located at the opening of the cenote to pump water into the trough. The cattle drank until their thirst was quenched and left the trough, on by one, to graze on the pasture. The man looked at his cattle and then turned to me, beaming: "Aren't they 
beautiful? I'm very proud of my cattle and I take great care of them." He walked into the pasture and began talking to his cattle and rubbing their heads affectionately. $\mathrm{He}$ inspected them as they walked by, paying special attention to their legs and hooves. "I'm making sure they're healthy and injury-free," he said. It was evident from his actions and words that he had deep respect for his cattle. He talked to and treated them like humans, telling me that each one has its own personality. "This one is the grumpy one. That one is a sweetheart. And that one, over there, is the main protector of the herd." He paused, "you see, they have a conscience and lives just like us humans. They are protected by the Virgin of Guadalupe, our ancestors, and other gods, just like us. I pray to those gods to protect my herd, to help them be as healthy as possible. Each year, I plant a corn husk there as an offering and say my prayers for them." "What would happen if you stopped doing that?" I asked. "If I stop, they will be vulnerable to disease and death, if the forest gods and the old people feel I haven't shown them enough respect through offerings and prayers," he replied. Once the cattle were all at a distance from us and grazing, the man said that it was time to harvest some of the tall grasses that were growing in his small milpa, across the main footpath that leads to the cattle pasture (see Figure 5.13). "These grasses will be used to feed the cattle from May to August during the period of dry weather, when there's not much grass growing. Then, I'll mix in molasses," he observed. After using our machetes to cut down the tall grasses for about two hours, the man looked up at the sun. "That's enough for today. I'll come back after supper to lead the cattle back into their enclosure for the night." 


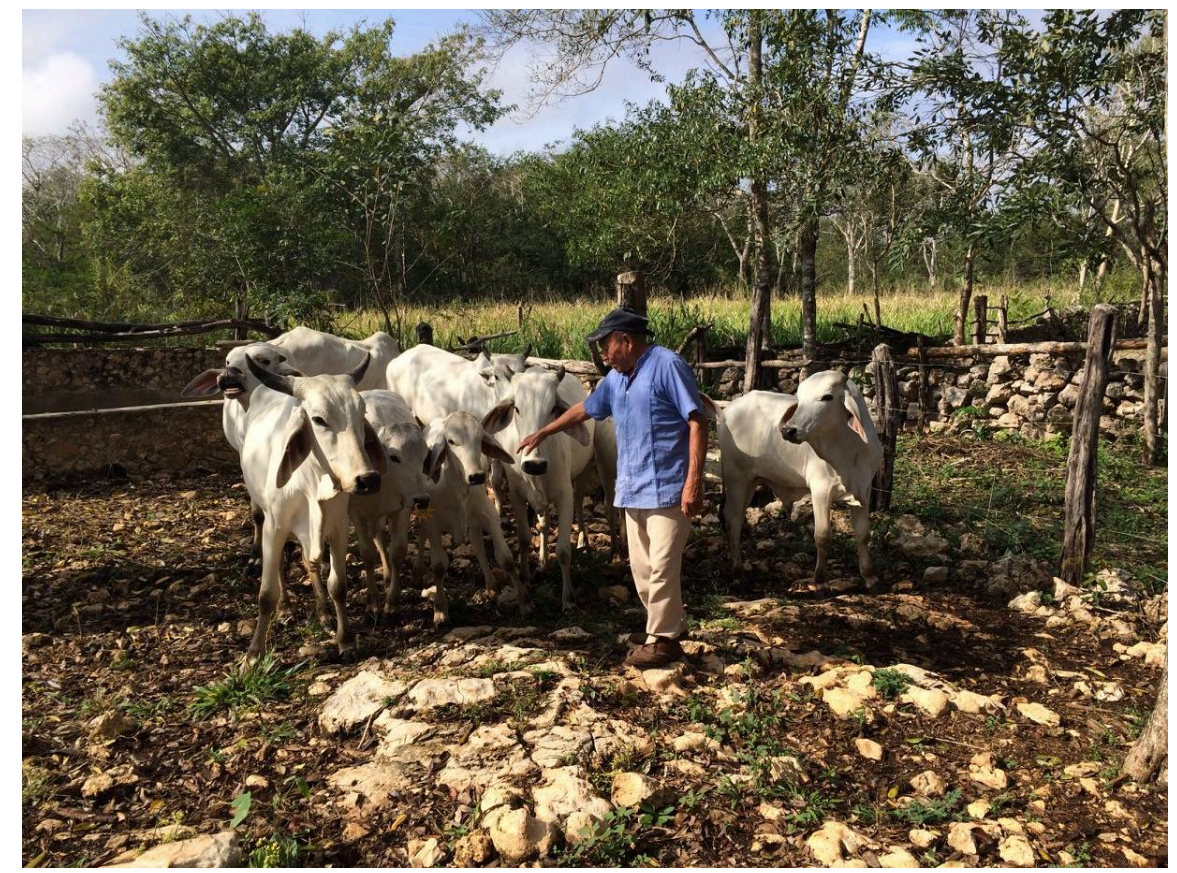

Figure 5.11. Cattle rancher greeting his cattle in the morning.

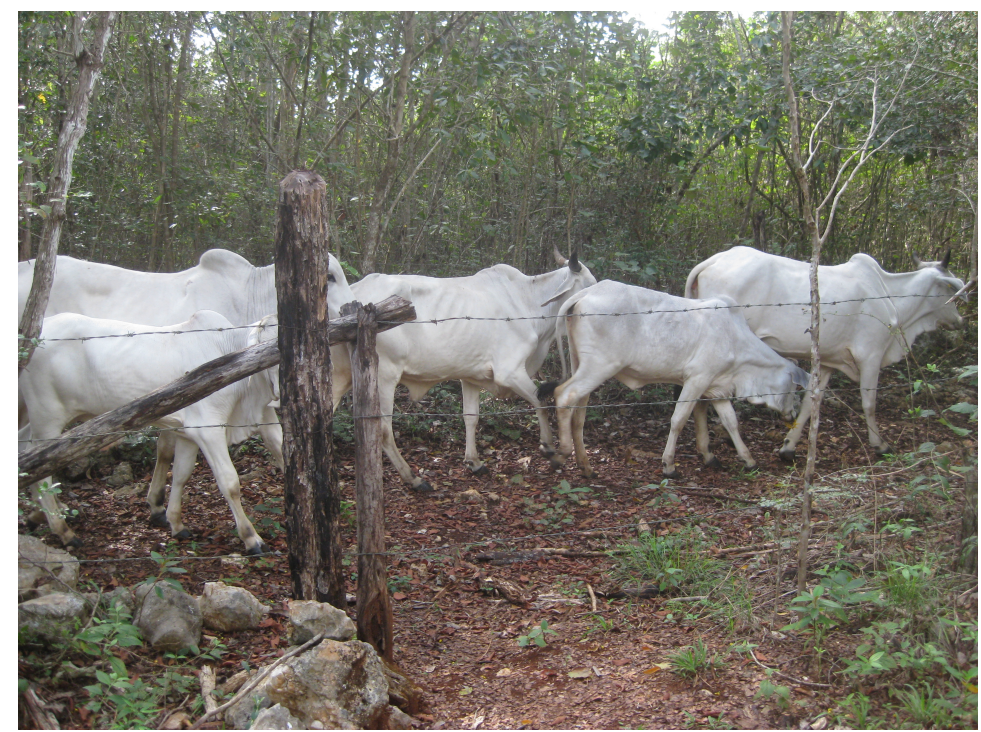

Figure 5.12. Cattle waiting for their enclosure to be opened in order to graze. 


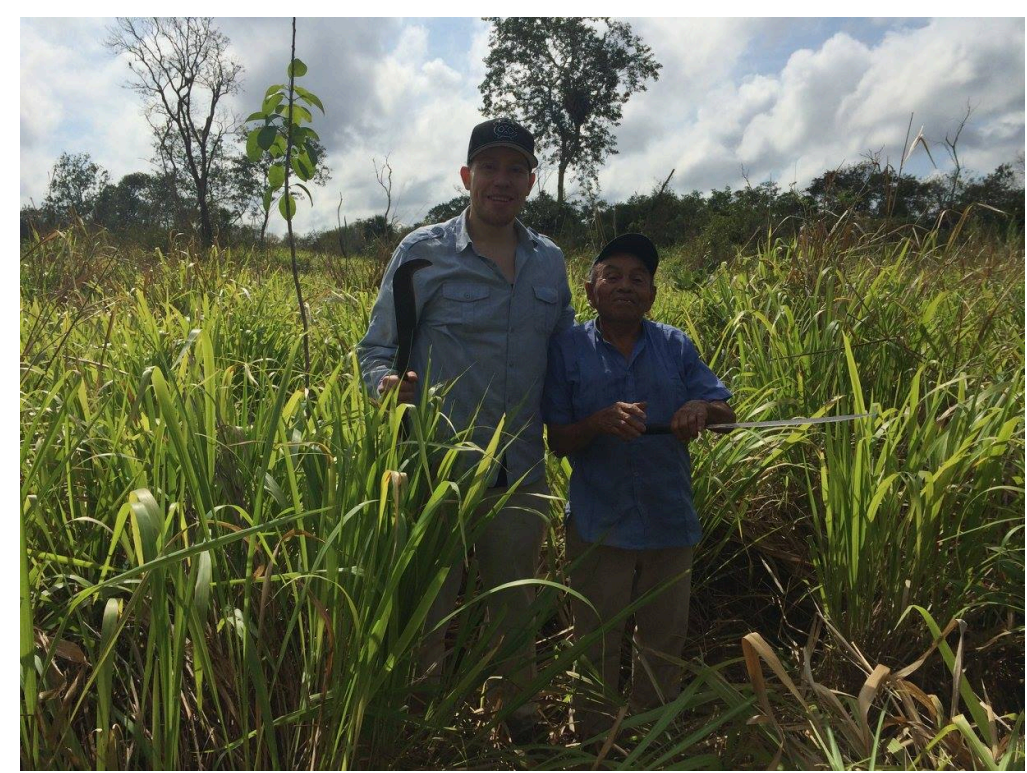

Figure 5.13. The author and a cattle rancher getting ready to cut some grass to feed the cattle.

As with other Maya land-use activities, cattle ranching cannot be considered in isolation from the milpa, or from the forest. Some of the grasses on which the cattle feed grow on the milpa, and the wood used to build and repair the cattle enclosures comes from the forest, and finally water comes from cenotes. Thus, each one of the main components of the Maya landscape (milpas, forests, cenotes) exists symbiotically with the others - and, importantly, "our individual homes and the collective ejido are considered part of the land as well," stressed the elderly milpero. As in all other land-use activities practiced in Xuilub, in Maya cattle ranching humans, animals, plants, Maya gods, Catholic saints and the departed (Maya ancestors) are considered to be codependent and to be actors and equals on the land.

\section{Conclusion}

In the Maya responsibility-based land-use paradigm, there is no clear boundary between agricultural lands or forests, soils, freshwater sources (cenotes), or even 
residential areas, each one usually falling on a gradient from "wild" or "natural" to "human habitat" in Western environmental thinking. The milpero, hunter, apiculturist, and cattle rancher each depend on a vast knowledge base that includes a multitude of elements and relations, including the sky (weather patterns), the earth (the milpa, the forest, the apiary and the cattle pasture), as well as the soil and the subterranean (cenotes). The Maya gods, Catholic God and saints, the Lords or Owners of the animals, as well as ancestors and future generations are also all in the minds of Maya land users, and their wellbeing is taken into consideration when making decisions about land use and when practicing land-use activities. However, as shown by the example of the rancher sometimes needing to shoot jaguars, responsibility-based thinking does not mean becoming animal rights activists or living like a secluded Buddhist monk, or putting human needs and wellbeing under all other beings'. Rather, it is a nuanced and complex approach and way of life, or a conversation and dialogue between humans and all other beings on the land. Much like a Western democracy (like Mexico or Canada, etc.) must take into consideration the wellbeing and interests of different groups and individuals and make decisions that are thought to be of benefit to the society as a whole, my interpretation is that the Maya of Xuilub, too, operate in this way, but with wellbeing and interests of all the other dimensions and beings mentioned in this chapter that also need to be considered. This understanding of responsibility-based thinking in Xuilub leads me to view the relationships between human and all other-than-human beings on the land as "The Great Circle of all Peoples of the Yucatan." The word "Great" refers to the fact that the Circle is not limited just human beings; rather, in it participate all beings. Perhaps this is the notion that is missing from Western (exclusively human) democracy, and it is a 
principle that we, as academics and policymakers can, I argue, learn and greatly benefit from considering. One milpero was describing his belief that all beings must have a say in the decision-making process, both on the individual and community scales. To make sure I was understanding his explanation, I interrupted him, asking "like a democracy?" And he immediately confirmed, "Yes, that's right! Just like a democracy!" On that thought he continued,

We must make decisions with the interest of all beings in mind and in our hearts. Of all those who share this land here in Xuilub. We must try our best to be fair and find a balance, but we any other being are not always perfect... sometimes we may do something that interferes with the life of another being, like if we step on an insect in the milpa, by accident. Being always perfect would be impossible. But we all try our best, all beings. We fail sometimes but we are guided by the bond that we have with one another, and by our duties to one another.

Just as most people believe that the exercise of Western (human-only) democracy involves some give and take and occasional mishaps and misunderstandings, from my observations and discussions in Xuilub, I would argue that the Maya land user who participates in the Great Circle of Peoples of the Yucatan believes in the democratic order, and that it is the best way in which to organize society and to make important decisions. There is a common sentiment in Xuilub that this responsibility-based approach and the values of duty, reciprocity, and respect are the best values by which to live by in order to create and maintain a society that is equitable and just for all beings. Moreover, the Maya land user depends on a truly multifaceted and integrated knowledge base and land-use system that involves as much trial-and-error and empirical observation science as it does a spiritually derived epistemology and moral compass. In all land-use practices Maya responsibility-based thinking is manifested in the words and actions of milperos, apiculturists, hunters, cattle ranchers, and home gardeners. "Reckless" harvesting 
practices, one milpero told me, "extinguish our precious resources, which we are supposed to take care of. Everyone here must do his and her part to keep our land healthy." In this vein, a cattle rancher offered as a final statement for our interview about the Maya land ethic, "our ethic of respect for the land, to me, has to do with respecting life, no matter what kind of plant or tree or animal species that lives here and not use anything unless it is really needed. We all live together here on our land" (emphasis added).

The responsibility-based thinking cultural principle that I is lived and represented in Xuilub and that I have presented in this chapter has the potential to broaden the disciplinary perspectives of Indigenous geographies. Yet, there is very little discussion about the potential for IKs to enhance Western societies and broaden their perspectives on the environment. It seems that the distinct knowledges of Indigenous peoples are not given an opportunity to show their true potential and value for the global society. As a child, I was taught by my Elders that the true Indigenous way is to think of everyone and everything as being part of a circle of relations. And, as a consequence, my (and my people's) knowledge is for the benefit of the entire circle, just as someone else's (from another culture) knowledge should benefit the entire circle as well. In this spirit of sharing and respect for one another, for me it is imperative to share IKs and demonstrate their relevance and value outside of Indigenous societies like that of the Maya in Xuilub. What is more, postcolonial scholars have called for all academics and policymakers to allow non-Western and Indigenous peoples to articulate their own concepts related to place, nature, history, and the environment (among others). In line with this, my approach to conducting research in Xuilub was to have the people articulate their understanding of 
Maya IKs without me using Western rights-based terminology and reference points in my questions and interactions with them. The interview responses and conversations I had with land users thus, to me, appear to be different from the those presented in most Indigenous geographies case studies, which are almost invariably framed within rightsbased parameters. Although most Indigenous groups across the Americas are now familiar with and have even learned to use Wester rights-based concepts and frameworks (such as the ones outlined in 2.1) to their benefit, I feel it is important to seek to understand IKs according to the words and feelings of Indigenous people, and not in relation to state institutions and structures that were, until first contact with Europeans, foreign to them and their lands. By learning from the way the people of Xuilub elucidate their relationships with their ancestral land, the Yucatan, in their own Indigenous words and way of seeing the world, I believe the results of this exercise that I presented in this chapter can broaden the disciplinary considerations of Indigenous geographies. As postcolonial scholars have pointed out, we all need to do more to understand nonWestern ways of thinking for their own sake - and not in relation to Western referents and (rights-based) discourses. In responsibility-based terms, this is our duty and responsibility and that is how I believe we will be truly able to meaningfully contest and replace constricted and economic-centred ways of relating with and using our environment. I ask the reader to take note of this final reflection in Chapter 5 as we turn to Chapter 6: Being Part of the Land, in which I situate the meanings of the Maya land ethos within the current postcolonial, Indigenous geographies, and IK literatures and disciplinary conversations, and the contributions of my research findings to these bodies of knowledge are highlighted. 


\section{Chapter 6: Being Part of the Land}

\section{Introduction: Being Part of the Great Circle of Peoples of the Yucatan}

The central argument of my dissertation is that the Maya environmental ethos should be understood as responsibility-based and allowing land users in Xuilub to see themselves as "being part of the land," and being part of what I characterize (and delineate in this chapter) as the "Great Circle of all (human and other-than-human) Peoples of the Yucatan" (which includes humans, animals, plants, supernatural beings, the Catholic God and saints, Mayan gods and spiritual beings, future generations and the departed, etc.). Postcolonial (including Indigenous geographies) researchers tend to look at Indigenous interactions with the land as a form of resistance to (neo)colonial authority and governance mechanisms by states and corporate interests. For example, in his book Human Rights in the Maya Region, informed by such a rights- and resistance-based perspective, Stavenhagen (2008) writes that it is crucial for postcolonial Mayanist scholars to investigate the following questions, summarizing some of the current main themes in postcolonial Mayanist research:

What is the relationship between globalized discourses such as human rights and local cultures? How are human rights working within the neoliberal state? In what ways do local appropriations of human rights discourse and the spaces opened by human rights discourse and its practices offer new possibilities for struggle, particularly for antiracist, anti-neoliberal, or other countersystemic struggles? (p.2).

This rights-based focus on Maya land use investigations is, to be sure, useful in assisting Indigenous rights-based struggles in the Yucatan. However, I argue that more research into Maya responsibility-based thinking (from a non-Western perspective, and without 
the use of Western terms like 'rights' and 'nation-state,' for example) can allow this group to articulate their environmental ethos in their own terms, knowledges, and according to their own cultural understandings and values. In my view Indigenous meanings, and cultural interpretations of the landscape (or the land) are a promising topic for more theoretical discussion in Indigenous geographies, which as it stands are mostly concerned about exploring Indigenous rights-related themes and assist these groups in gaining/reasserting their rights. My research in Xuilub considers these Indigenous meanings about place and the land through a non-Western (and non-rights-based) lens, and attempts to initiate a theoretical discussion on the links between such meanings to Maya conceptualizations of place-as-relationships in the Maya homeland. The argument in this dissertation is that Indigenous interactions with the land should be understood as informed by the understanding that there exists a Great Circle of all Peoples on the land. This is my own understanding and representation of this ethos, although I have had public consultations with Maya land users to make certain they agreed with my characterization of their environmental ethos. Through interpretation, reflection, and synthesis of all the data collected during my interviews, informal conversations, observations, and work with land users, and my lasting impressions of the meaning of this research, I provide a synthesis of my interpretation of "being part of the Great Circle of Peoples of the Yucatan (the land)," as an environmental ethos, in the remainder of this section:

The Great Circle of Peoples of the Yucatan is a way of seeing the position of human beings as part of a constellation of human and other-than-human entities that are connected to and relate with one another on the land. In some ways, it can be likened to 
the Western concept of a "democracy," because environmental and socio-political management decisions are made in consideration of the interests and wellbeing of both human and other-than-human beings. All of these entities are part of the land, which acts as the stage on which an infinity of relationships between beings are constantly being carried out and reinforced. All beings have responsibilities to other beings. In this Great Circle of Peoples of the Yucatan, all physical elements and spiritual dimensions (according to Maya spiritual beliefs) belong to the land, much like citizens in a Western democracy belong to and participate in a political state. The Maya people, the Maya departed and future generations, Maya gods and spiritual beings and creatures (e.g. the alux and Lords of the animals), the Catholic God and saints, animals (domesticated and non-domesticated), all plants (including the three Maya staples: maize, beans, squash, as well as trees, medicinal plants, etc.) are all considered active actors and participants in this Great Circle. Even if their voices and opinions cannot physically be heard or communicated to the Maya people, living by the cultural edicts of responsibility, reciprocity, coexistence, and respect is thought to allow human beings to, in the words of one grandmother and gardener, "at least strive to achieve some form of fairness and balance between all of us creatures." I told this woman that another Xuilub resident had agreed with my characterization of the Maya land-based ethos or way of being as the "Great Circle of the Yucatan," and she told me that representation was accurate according to her. In Xuilub, the land (something that is concrete and tangible) is society (something that is a philosophical construction and intangible), unlike Western meanings of society, with sense of collective belonging to intangible human philosophical constructions such as a nation-state. 
Although the milpa (growing food) and other subsistence-based land-use activities are an important dimension of being part of the land, this concept carries a deeper spiritual meaning and a responsibility-based bond with Creation. In addition to providing food and income, and thus ensuring survival, working the milpa, taking care of the bees, hunting, and cattle ranching are seen as ways of maintaining sacred spiritual relationships with the Maya homeland and carrying out responsibilities to other-thanhuman beings that are part of the Great Circle of the land. Land-use knowledges in Xuilub are indeed more than a way of knowing; they are equally a way of being. My understanding of the deeper meaning of these land-use practices is that they allow Maya land users to maintain their responsibility to perpetuate Maya traditions based on a spiritually informed environmental ethos. I find that the IK research-based approach to understanding Maya relationships with the Yucatan is lacking, and can provide novel perspectives on these issues, which are still viewed by postcolonial and Indigenous geographies scholars almost solely through the lens of Indigenous rights-based struggles and resistance to government and corporate interests. For instance, Juarez (2002), states that "if academics, policy analysts, and corporate developers want to alleviate the severe social and ethnic stratification found in one of Mexico's wealthiest states, they would do well to listen to Maya interpretations of their changing environment" (p. 120). The author argues that Mayas' interpretations of their relationships with the land should be studied for their use with regard to remediating social injustice and inequality that make the Maya vulnerable in Quintana Roo. Though Juarez's' objective is to be commended, I believe that the goal of understanding the Maya environmental ethos according to Maya 
concepts and vocabularies could allow postcolonial and Indigenous geographies scholars to develop and promulgate a less Eurocentric attitude.

Though there are, as pointed out in Chapter 5, obvious examples of "non-Maya" knowledges (and practices) being used by different people in Xuilub (e.g. Catholic beliefs, cattle ranching), I would argue that these knowledges are integrated within the Maya environmental ethos and are given Maya meanings and purposes. The postcolonial literature about Maya syncretism has only considered in terms of its religious dimensions, but I put forth that this concept can be extended to the broader environmental ethos and land-use practices. Watanabe (1990) considers that "when Christian evangelization banished the old gods from public purview, the Yucatec Maya of necessity turned to the tutelary Catholic saints allowed them by the missionaries in order to sustain the community rituals that they considered so basic to their survival" (p. 132). According to his understanding, syncretism was adopted more out of necessity than free will, and this definition appeals to a romanticized understanding of Maya culture as fixed in time, with immutable cultural traditions. During my research, I understood syncretism in the community as the product of a broader cultural ethos that is dynamic and adaptable. There is willingness among the people of Xuilub to seek to broaden the Maya cultural knowledge base, for, as one milpero sees it, "the land and everything else changes all the time. As a result, we need to adapt to change by trying to gain as much information and knowledge — be it from our own culture or from others — as possible." What is more, to me syncretism in Xuilub is not limited to religious or spiritual beliefs, but applies to landuse practices as well. I found evidence of syncretism in apiculture and cattle ranching, most notably, in terms of the combining of Western and Indigenous knowledges in those 
two "introduced" activities. Consequently, as postcolonial scholars and Indigenous geographers, we must be careful about determining what exactly are "authentic or inauthentic" Maya land-use practices or spiritual beliefs and judging present-day Maya culture against Western understandings of a singular romanticized Maya culture of yesteryear. The past and current Mayanist literature investigates the ways in which the Catholic faith has been adopted by the Maya people and combined with ancient Maya spiritual beliefs but very little has been said about their syncretic approach to incorporating Western science and other knowledges into their environmental ethos. Because the Maya of Xuilub have a syncretic outlook on spirituality and the incorporation of Western science and other knowledges into their land-use activities, representing Indigenous interactions with the land as inevitably in opposition with Western approaches is problematic and can fail to adequately reflect the more nuanced realities of the ways in which the Maya ethos was represented to and observed by me in Xuilub. Much of the current IK research literature tends to highlight the distinctions between IKs and Western ways of knowing like science, as discussed in Chapter 3. These distinctions are indeed very useful for understanding the different ontologies and objectives of these knowledge systems. I would suggest, however, that it is equally important to be cognizant of the possible areas where the two are compatible. The Maya environmental ethos in Xuilub has shown me that it is too simplistic to present the IKs and Western knowledges as invariably incompatible, as this group clearly uses and incorporates Western knowledges and belief systems into its own Indigenous ways of being, knowing, and doing. It is therefore not necessarily the case that IKs and Western knowledges are incompatible and irreconcilable in all regards. This research contributes 
to broadening our understandings of how IKs and Western knowledges can in fact be complementary, not only in theory, but in a "real-world" and lived example.

Within this Maya ethos, women and men have their respective and equally valuable roles that are defined according to tradition and spirituality. Both men and women see the role of women as equally important to that of men. Elders (both male and female) occupy a particularly significant role as mentors and knowledge holders for the younger generations. They are revered and loved by their community. In Xuilub, social order is maintained with the direction of Elders and a respect and love of the Old People, or the departed, and imprinted on the Maya landscape, in the form of pyramids and other ancient structures found throughout the ejido. These structures built by their ancestors, which are also very physically part of the land, are a constant visual reminder of the Maya responsibility to be part of the land. In terms of Indigenous geographies, common meanings and conceptualizations of 'sense of place' are often limited to the human experience in making sense of one's physical surroundings, as in Cresswell's (2009) definition:

Place is a meaningful site that combines location, locale, and sense of place. Location refers to an absolute point in space with a specific set of coordinates and measurable distances from other locations. Location refers to the 'where' of place. Locale refers to the material setting for social relations - the way a place looks. Locale includes the buildings, streets, parks, and other visible and tangible aspects of a place. Sense of place refers to the more nebulous meanings associated with a place: the feelings and emotions a place evokes. These meanings can be individual and based on personal biography or they can be shared (p. 1).

Cresswell's multilayered definition of place is at present generally accepted in the geographic discipline. In the above and other similar definitions by different geographers, human beings are the only ones who "make" place and their sense of place; place is a 
humanistic concept. Indigenous meanings of place, however, are ontologically different in that they consider other-than-human beings as co-creators of place and sense of place. My research in Xuilub demonstrates that it is through relationships on the land between human and other-than-human beings that place is constructed and given meaning.

The ejido system seems to help the Maya people in this regard. Having a defined territory on which they benefit from relative territorial autonomy as an Indigenous group, and have considerable freedom in their land-use practices, helps the leadership to reinforce cultural norms and responsibilities to the land. Those who are not willing to live by these rules and regulations are free to leave the ejido and live elsewhere. In this regard, the ejido, a state institution and non-Maya land organization system, is used by the Maya of Xuilub to the benefit of their culture and traditions. However, as more and more young people, who are exposed to non-Maya lifeways and technologies, leave the community for employment or post-secondary education, some individuals' ideals and values are changing. This ethos is in constant evolution, and I do not consider my interpretation of it based on my research conducted from 2014 to 2016 as a universal and timeless truth. As all Indigenous cultures and their IK systems, the Maya environmental ethos is in constant evolution and flux, and it, too, is at risk of attrition from internal and external factors.

The Maya environmental ethos will be explored and elucidated throughout this chapter, and will consider what I believe are its most important spiritual elements and dimensions. While land-use practices constitute the observable dimension of Maya responsibility-based thinking and of being part of the land, spirituality, culture, and identity are equally as important and complementary. These non-material dimensions of 
the Maya environmental ethos contain the epistemological and moral framework that informs the Maya land-use system as a whole. Then, I explore how responsibility-based thinking and learning to be part of the land as an integrated land ethos are different from mainstream environmental approaches and strategies that are commonly employed in Western democratic societies like Mexico. I also point out how my research (and different research findings) contribute to furthering reflections, discussions and debates on Indigenous peoples' relationships with their environments, and how it advances knowledge in the postcolonial, Indigenous geographies and IK research fields.

\subsection{The Spiritual Dimensions of Maya Relationships with the Land}

This section pertains to spiritual and religious beliefs in Xuilub. I use interview data and personal observations to demonstrate how Maya religious syncretism is a key dimension of the integrated Maya environmental ethos that inspires the people of Xuilub to live as being part of the land. My research contributes to the IK literature in one key area. This body of research tends to focus on delineating the vast ontological differences between Western and Indigenous knowledges (e.g. Deloria, 1992; Cajete, 2000; Pierotti and Wildcat, 2000; Wildcat, 2000). However, as I have come to find in my research with the Maya, IKs and Western knowledges and spiritual beliefs are not invariably irreconcilable. They are not always in diametric opposition to one another. The IK literature has provided many insights into examining the spiritual dimensions of Indigenous relationships with the land, but much of the discussions and debates deal with contrasting the two bodies of and approaches to knowledge, and of the dangers of allowing Western science and other knowledges to erode IKs in Indigenous communities. On this idea, Mazzocchi (2006) writes: 
Scientific knowledge has long held a central role and attained a dominant position in our developed societies, but we cannot ignore the fact that other valid knowledge systems exist. The imposition of Western scientific ideas and methods not only causes disruption to existing social and economic relationships, but also might spoil the local knowledge (p. 465).

Though this is certainly a cause for concern, the Maya syncretic approach seems to allow people in Xuilub to avoid the problem—-by incorporating Western knowledges into the Maya environmental ethos. My research makes a contribution with regard to how Western and Indigenous ways of knowing are, in practice, blended by Indigenous groups. In the Maya environmental ethos, Western science and environmental management approaches that are founded on a mostly utilitarian and reductionist philosophy are abstracted from these values and are used as tools that are incorporated within the broader responsibility-based Maya ethos. As I discuss in the following paragraphs, Maya spirituality and supernatural and spiritual beings are important actors in the Great Circle of the Yucatan. Land-use practices and activities, as well as social organization, cannot be properly understood in isolation of Maya spirituality. In Xuilub, Western (Catholic) religious beliefs (God, Catholic saints, etc.) have been made to be Maya. In terms of land-use, Western scientific knowledge has also been incorporated into present-day landuse practices such as apiculture and cattle ranching - this activity was not practiced prior to the arrival of the Spanish. In both spiritual beliefs and land-use practices, Western knowledges have been judged valuable and relevant to the Maya way of life. However, it is important for the reader to understand that non-Maya knowledges are adapted and used as part of the broader environmental ethic of being part of the land, of the Great Circle of the Yucatan. They have become part of Maya spirituality and land use —indeed, they have also become part of the land. The same spiritually informed moral and ethical 
responsibility-based framework, which reinforces the values of responsibility, reciprocity, coexistence, and respect guides the community and individuals on how to use these non-Maya knowledges in a Maya way. As one Elder explained, "as Maya people, we were moulded from corn, the Earth and the landscape around us. We are related to every creature on the land. We are related to our ancestors and our unborn children. We all belong to the same land." In this Mayan cosmology, the land is understood as web of relations in which humans are considered to be neither superior nor inferior to other beings, but equal. There is recognition that 'land' is a concept and term interchangeable with 'society' — a Great Circle encompassing all human and other-than-human beings.

\subsubsection{Spirituality and Religious Syncretism in Xuilub}

My field research has yielded data and information that have allowed me to understand that the religious and spiritual beliefs and practices of the Mayas of Xuilub are the key to understanding how responsibility-based thinking is translated from abstract concepts into concrete land-use practices in the community-in other words, how these spiritual beliefs teach the Xuilub Maya how to be "part of the land." The current Maya spiritual and religious belief system in practice in Xuilub is highly syncretic and almost seamlessly mixes Catholic and ancient Maya beliefs and teachings

into a coherent and integrated whole. Since the arrival of the Spanish to the shores of the Yucatan in the mid-sixteenth century, Catholicism has had a great influence on Maya spiritual beliefs and practices, which, as I have discussed, profoundly inform and shape current land-use patterns and practices in Xuilub (Watanabe, 1990; Early, 2006). However, the Maya have integrated Catholic teachings into their environmental worldview and ethos. One way to put it is that they have, in other words, integrated 
Catholicism into the Maya environmental ethic in such a way that it now is also "part of the land." In the postcolonial and IK literatures, Western religions are almost invariably represented as repressive and as tools of colonial power over Indigenous peoples and their cosmovisions. For instance, feminist postcolonial scholars Pui-Lan and Donaldson (2015) write that:

While many countries occupied and dominated foreign territories, only the group of nations claiming Christian identity implemented a global colonial system upon which the sun never set. The social transformation resulting from the decision to encroach on a foreign terrain reflects the determination of the colonizers to alter radically a regions politics in favor of the colonists - and the introduction of Christianity functioned as a powerful tool of such transformation. An all-toocommon paradigm for this process excluded the lands Indigenous inhabitants from these new arrangements (p. 6).

Postcolonial scholars like Donaldson and Pui-Lan continue to level incisive and poignant critiques of Western religions in the service of colonialism, and unpack the ways in which Christianity has allowed European empires to dispossess Indigenous peoples in the Americas and discount their cultural presence (Harris, 2004). However, Indigenous spiritual/religious syncretism, such as the one that exists at present in Xuilub, is underexplored in much of the postcolonial and Indigenous geographies literatures. In particular, there lacks research into how Maya religious syncretism influences land use in Maya communities. In Xuilub, Catholic saints have very significant religious/spiritual importance in everyday life in the community, as it does everywhere in the Yucatan, and Catholic saints have an influence on Maya relationships with the land (Jimenez Castillo, 1990; Cook \& Offit, 2009). Mayanist scholars have produced a rich literature on Maya religious syncretism, the amalgamation of pre-contact Maya religious and spiritual beliefs with Catholicism into a coherent religious belief system (Watanabe, 1990). In the 
Maya syncretic religious belief system, ancient Maya gods, spirits and supernatural creatures exist in the same dimension as the Christian God, Jesus Christ and Catholic saints. From interviews and informal discussions with community members throughout my field research stage, it has become clearer to me that although the vast majority of these people self-identify as Catholic, the form of Catholicism that is commonly practiced differs greatly from more formal forms of Roman Catholicism practiced in non-Indigenous societies. For example, one mother I interviewed explained her belief that a crucifix at a chapel in the nearby ejido of Xocen had magically relocated to Spain to punish the people of that ejido for their lack of piousness. She mentioned that one of the menes in Xocen had used black magic to transform the local priest into a snake, and that, to her, this is what drove the power of the Virgen of Guadalupe to remove the cross from the site and relocate it to Spain. Again, in this example, a catholic figure (the Virgin of Guadalupe) is, according to a Maya person, interacting with the magic and power of a local shaman. It was interesting for me to observe that there seems to be no perceived disconnect between the two religions traditions in Xuilub. Catholic and ancient Maya religious beliefs are commonly juxtaposed and melded into one.

\subsubsection{Daily Prayer as a Requirement for Being Part of the Land}

Catholic prayers are performed on a daily basis, and during community ceremonies, rituals and feasts, by land users as well as spiritual and religious leaders in the community (Jimenez Castillo, 1990). One elderly milpero from the community commented that there is a general sentiment among land-dependent Yucatec Maya that prayer is part of the day-to-day tasks that must be performed — an integral part of working the land. Just as neglecting to regularly and properly clear the milpa of any undesirable 
weeds and brush will lead to a poor harvest, so does neglecting to fulfill the religious duty to implore the Catholic God and patron saints for favourable weather patterns and bountiful crops. In the responsibility-based Maya land ethic, concrete and mundane landuse chores are part of the same system that actively and routinely solicits assistance from the deities. A great variety of patron saints are implored on a regular basis by interviewees. Catholic iconography and depictions of various saints - along with the ubiquitous image of the Virgin de Guadalupe —adorn makeshift mantles and altars in homes throughout the community. Thick layers of melted wax encrust wooden nightstands and dressers in Maya homes, as used candles are promptly replaced with new ones. Daily prayer is not optional; it is a demonstration of humility before the Divine and a daily portal and connection to the superhuman realm. This manifestation of responsibility-based thinking and the Maya precept of reciprocity demonstrate that this way of being is not limited to "traditional" or ancient Maya spirituality. The Mayas of Xuilub, and more broadly of the Yucatan, have (and continue to) adapted Catholic rituals and given them meaning and a purpose within their responsibility-based system of belief and action. As a result, Catholic beliefs and practices are today as integral to Maya social organization as pre-contact epistemologies and spiritual belief systems, and one cannot be considered in isolation from the other. Both are part of the greater integrated Maya landbased social ethos of being part of the land.

The Maya of today combine ancient teachings, mythologies, and other culturally distinct beliefs with western (modern) scientific knowledge in the use and management of various resources. Thus, syncretism is not limited to the spiritual or religious beliefs and customs of the Maya but rather defines a broader 'responsibility-based' land-based 
epistemology and praxis. Given that Maya spirituality is part of the broader worldview of "being part of the land," it is necessary to understand contemporary Maya spiritual and religious beliefs (and syncretism), as they are inseparable from the practice of landrelated activities and other facets of Maya society and culture. Indeed, as described in Chapter 5, all land-related activities and practices in Xuilub are intertwined with spiritual beliefs and superstitions.

All interviewees, both male and female, expressed that they believe in both ancient Maya spiritual precepts as well as Catholic doctrine. Although these Maya consider themselves Catholic, they still observe ancient Maya traditions and ceremonies, and believe in some of the same gods that were venerated by their ancestors. In my field research, I was able to hear about, witness and reflect on a number of syncretic Maya religious practices. The present-day Maya ontology understands that humans, otherthan-human beings (e.g. animals, plants and other "inanimate objects" like water bodies and rocks, etc.), as well as gods and spirits, are capable of simultaneously existing in the human and superhuman dimensions. All these actors are considered as having agency and as being part of the same Great Circle previously descirbed. Indeed, each of these beings inherently carries a useful function or role, but more importantly a responsibility to its relations as a member of this Great Circle - a web of infinite relations. The Mayas of Xuilub who adhere to this vision feel compelled to apply this ethic in all aspects of their lives, especially in their work on the land, as the land (which includes the Maya home, the milpa, forests, cenotes, other water sources, and cattle pastures) is the space in which all these relationships and interactions take place. One Maya Elder described how she personally understood and applied Maya syncretic spirituality in her daily life: "The 
land here is home to us, home to animals, gods, the old people. To keep living here in peace with all these beings, we must live in a certain way, with respect. We must ensure that the peace is kept between all beings on our territory." According to this interviewee, as she went on to say, humans co-exist with Maya gods, Catholic saints, alux (forest dwarves), luum (Lords of the forest), animals, and so-called inanimate beings.

To further illustrate this key concept of co-existence and relationships between all beings on the land, let us consider the example of the Maya belief in the dangers of "black magic." This very real concern in Xuilub reinforces the belief in the importance of performing spiritual and religious duties to all their relations, be they human, nonhuman or supernatural. Throughout my field research, Xuilub residents have frequently told me about their fear of black magic. In fact, several interviewees told me stories about presumed evil menes, or shamans, who used black magic to transform into jaguars or venomous snakes and attack and kill their rivals or enemies. These kinds of stories and beliefs are not unique to Xuilub; they have been documented across the Yucatan (e.g. Kunow, 2003; Boccara, 2017). Others told me that new community members (including newborn babies) needed to be "introduced" to the feared alux, which usually involves a ceremony performed by a men, in which offerings are made to these small magical beings. The alux are forest-dwelling anthropomorphic, knee-tall dwarves whose faces and bodies are covered in dark hair (see Villanueva, 2014). These beings are believed to have special powers that can be used to cause illness and even death in humans. The alux

\footnotetext{
${ }^{1}$ I learned that the people of Xuilub believe in their own (Maya) form of what can be described as "black magic." From my understanding, based on interview data, Maya black magic refers to "evil" menes using spells and incantations to cause illness, injury and even death to their enemies and their close ones.
} 
subsist on forest game, which they hunt collectively, as told by Balam and Quintal Avilés (2016). In different Maya communities throughout the Yucatan, it is thought that seeing a live alux forebears illness, which only an expert men can prevent or cure (Estévez, 2002). One young man recounted the story of when his wife (from Valladolid) first moved to Xuilub and was afflicted by the alux's incantations. A few weeks into her transition to rural life, her husband left for Valladolid for a temporary carpentry contract. Soon after, the woman is said to have begun having vivid, terrifying nightmares every night. She eventually started hearing voices calling to her at night. When she opened the door or a window to catch the troublemakers, there would be no one or nothing in sight. What is more, the woman inexplicably fell ill, and suffered from high fever. Fearing for her life, she told her husband by phone about her torments. He returned to Xuilub immediately, for he knew the alux were behind this. He solicited the help of one of the community's foremost menes, who conducted a ceremony at which he made offerings to the alux and asked that they cease their harassment of the woman. The men also told the woman to recite a number of "Nuestro Padre" prayers (or The Lord's Prayer) each day for one week. According to her husband, the woman soon was completely cured and the nightmares and mysterious voices stopped. In this case, praying to both ancient Maya spirits and to the Christian God and Catholic saints was seen as a complete solution to the problem. Thus, both Catholic and ancient Maya spiritual beliefs were called on and, in the minds of the young couple, the woman's life was saved from the alux. Not only was this ancient ceremony believed to relieve the woman's afflictions; her husband also believed that it would lead to better agricultural yields. In fact, during our interview, the man stated that since the offering has been made to the alux, he feels that they are 
protecting both his family and his milpa crops. When I asked him why he believed this was the case, he pointed out that the alux are also responsible for performing "good deeds" such as preventing insect plagues and ensuring bountiful harvests—-but only if they feel respected by means of offerings and ceremonies done in their name. In this human-alux relationship, which is but one out of a virtually infinite number in the Great Circle of the Yucatan, humans have a responsibility to acknowledge and make an offering to the alux - to avoid sickness and possibly death. On the other hand, it is believed that once this ceremony is performed, the alux have a responsibility to ward off pests and disease and keep the milpa healthy. This example illustrates the degree to which every aspect of life in the Great Circle is integrated and inseparable one from the others: in the mind of the husband, the young woman's health problems and afflictions are connected to the alux, who, in turn, are in part responsible for ensuring a good harvest. Implicit in this way of thinking is the concept of reciprocity between all relations on the land (as described by Indigenous scholars like Deloria, Cajete, Wildcat and others). When humans duly carry out their responsibilities and tasks, there is an understanding that supernatural beings must do likewise in order to maintain order in this Great Maya Circle that is much broader than Western definitions of society that are often limited to the human experience.

The above example is reflective of a more profound essence of Maya landbased thinking that I have observed in my interactions with Maya land users and managers: the land is the space in which human, other-than-human, and supernatural beings are in constant interplay. Humans do not benefit from a position of moral or ontological supremacy; they, like all other beings, must learn to be part of the Yucatan. 
Unlike monotheistic paradigms in which God, prophets and saints inhabit an ethereal realm, observing humans and animals on an imperfect Earth from a distance, in Maya cosmology, Earth, or the land, is a hub - a meso-realm, an in-between world where humans, other-than-human beings, saints, spirits and Maya gods are in constant interaction and dialogue in the Great Circle of the Yucatan. In the Maya responsibilitybased epistemology, the spiritual realm is intertwined with and inseparable from the physical world, or the land.

\subsection{Maya Meanings and Representations of Place, Identity, and Social Organization}

In this section, I will reflect on my observations of Maya culture, identity and social organization in Xuilub, and how each of these help teach or guide individuals on how to be part of the land. My analysis will focus on Maya understandings and meanings of 'place,' celebrations and representations of Maya culture in the form of feasts and celebrations, gender roles, the importance of Elders, and 'respeto' (respect) as a guiding principle in the social organization of Xuilub. The Yucatec Maya have tried to impress upon me the importance of maintaining their distinct (Indigenous) identity, which is, as one mother and gardener told me, what makes the people proud to belong to the community. The Maya identity in Xuilub is inextricably linked to 'place'-the Maya homeland of the Yucatan and the more immediate community of Xuilub. The Maya land ethos is associated with place and identity. The Maya meaning of place encompasses and is co-created by human and other-than-human beings, and diverges from Western meanings of place as something created by just human experiences within a geographical 
area, as Tuan's (1977) definition. Campbell (2016) summarizes humanistic meanings of place in the geographical discipline:

Place is imbued with meaning and, according to Tuan, how we create a 'sense of place' deserves focused study. Another humanist, Edward Relph, urges scholars to seek a more human-centred and empathetic understanding of 'the lived experience of place'. Relph stresses that there can only be a 'sense of place' when the bond between people and place is 'deep-rooted'.

This humanistic understanding of place is limited to the experience, emotions, and feelings about a physical locale by human beings. In contrast, the Maya meaning of place-as-relationships understands other-than-human beings as co-creators of place on the land, in the Yucatan.

\subsubsection{Maya Identity and Understanding of 'Place-as-Relationships' on the Land}

In the Indigenous geographies literature, the notion of 'place-as-relationships' on the land has been thus far underexplored. Maya interactions with the land correspond with meanings about place and identity (and society), and the role of humans within a society of beings on the land has in my view been neglected or perhaps not yet fully understood by Indigenous geographies scholars, who generally employ more humanistic definitions. My research with the Maya of Xuilub has yielded new insights into Indigenous meanings of place that can help the field to evolve in the ways in which it currently conceptualizes 'place' as a strictly human domain and experience. The Catholic god and saints, Maya gods and spiritual beings are also responsible in helping the Maya to maintain their social order; it is their responsibility to humans.

What is more, many Mayas have integrated into the broader Mexican society and no longer live according to the "traditional" Maya way of life. This is certainly the case in Xuilub, where a significant percentage of the members work outside of the community 
and participate in the broader Yucatec and Mexican societies and economies.

Nevertheless, several authors have written that in the everyday, "lived" reality, a large number of Maya communities and individuals do differentiate themselves from mainstream Mexican society by their spiritual beliefs, socio-spatial organization, land use practices and a shared belief of belonging to a distinct Indigenous community (for example Anderson, 2005; Ankli, Sticher \& Heinrich, 1999; Castellanos, 2010; Armstrong-Fumero, 2009 and many others). The social order that exists in Xuilub is not thought to be in perfect equilibrium or unfaltering: "There are and there will be mistakes along the way. There have always been mistakes. Nothing is perfect. We are not perfect. But we try our best to maintain our responsibilities," said one milpero. Individuals who contravene this social order and environmental ethos are given opportunities to learn and conduct themselves in a more responsible and respectful manner in the future because "they belong to the land, too, and this is their home, just as much as it is ours," reflected one grandmother. Nevertheless, those who do not learn or who time and again refuse to live by the values of responsibility, coexistence, respect, and reciprocity can be (and in some case are) asked to leave Xuilub. There is a local security and community regulations enforcement team, made of Xuilub community members, that is tasked with maintaining peace and security in the community. The then-comisario (March 2016) told me that one individual had recently been expelled from the community for cutting down trees to make and sell charcoal for industrial purposes in Valladolid. "We gave him many chances to clean up his act, but he did not want to change," he said. This statement demonstrates that although the Maya environmental ethos I have outlined here is 
generally considered an ideal, or at least something to work toward, it is understood that it is not perfect in practice.

Numerous authors like Anderson (2005), Brown (2007), Re Cruz (1996) and Gabbert (2004) have argued that the Yucatec Maya express a common profound spiritual attachment and sense of duty to their traditional landscape, the Yucatan Peninsula, and an understanding that they are "home." This is definitely the general sentiment that I gathered from my field research in the community. However, what is missing from Indigenous geographies understandings of the meaning of place to the Maya is the dimension of place-as-relationships between human and other-than-human beings. To the Maya, the sense of place is not created by only human experiences, feelings, and meanings. Sense of place is co-constituted by human and other-than human creatures and their experiences, feelings, meanings, and relationships within that place (physical location). As summed up by one very vocal and proud female interviewee, the people of Xuilub "feel that we are home here. The ones who came before us—our ancestors-were here many, many generations ago. They built all the things that you can see around the landscape: pyramids [see Figure 6.1], temples, and all those things. This is my home.” For the people of Xuilub, place is experience and represented on two main scales: the ejido, a "non-Maya" way of organizing the land that has been adopted by the Maya and incorporated into their land ethos, and the Yucatan as the ancestral homeland. In this case, the ejido of Xuilub as a place of meaning is created by the experiences of human ancestors, as well as relationships with all beings on the land. This notion of how a sense of place is constructed in non-Maya unit of land - the ejido-is also something that is lacking from Indigenous geographies studies about the Yucatec Maya. It is personally 
interesting for me to understand how Western knowledges and places like the ejido are given Indigenous meanings and become part of an Indigenous environmental ethos, and I believe that more research is needed to explore this dynamic in Maya communities to build on my initial understandings and reflections. I found that that sense of place in Xuilub is more directly related to immediate family ties, whereas the meaning of place on the Yucatan scale is tied to broader understandings of an Indigenous Maya culture and civilization. Perhaps what distinguishes the Maya sense of place is that the notion of "beings" that interact with humans includes past and future generations (the departed and the unborn). In other words, the Maya sense of place is synonymous with the Great Circle of the Yucatan, with the community of beings on the land belongs to a certain placeXuilub and the Yucatan. This meaning of place is different from more human-centred definitions, by geographers like Cresswell (2014), of place as location (i.e. geographical location/coordinates), locale (physical shape or structure of the place), and sense of place (the sense of attachment or belonging of human beings, but not other-than-human beings, to that place). One local curandero shared with me his belief that each human population —or people — comes from its own geographical area. According to this curandero, each population, like the Maya, is perfectly adapted to the physical environment from which it originates. Thus, it is impossible to consider different landscapes around the world independently from the people that, at least in small measure, moulded them into their current form. 


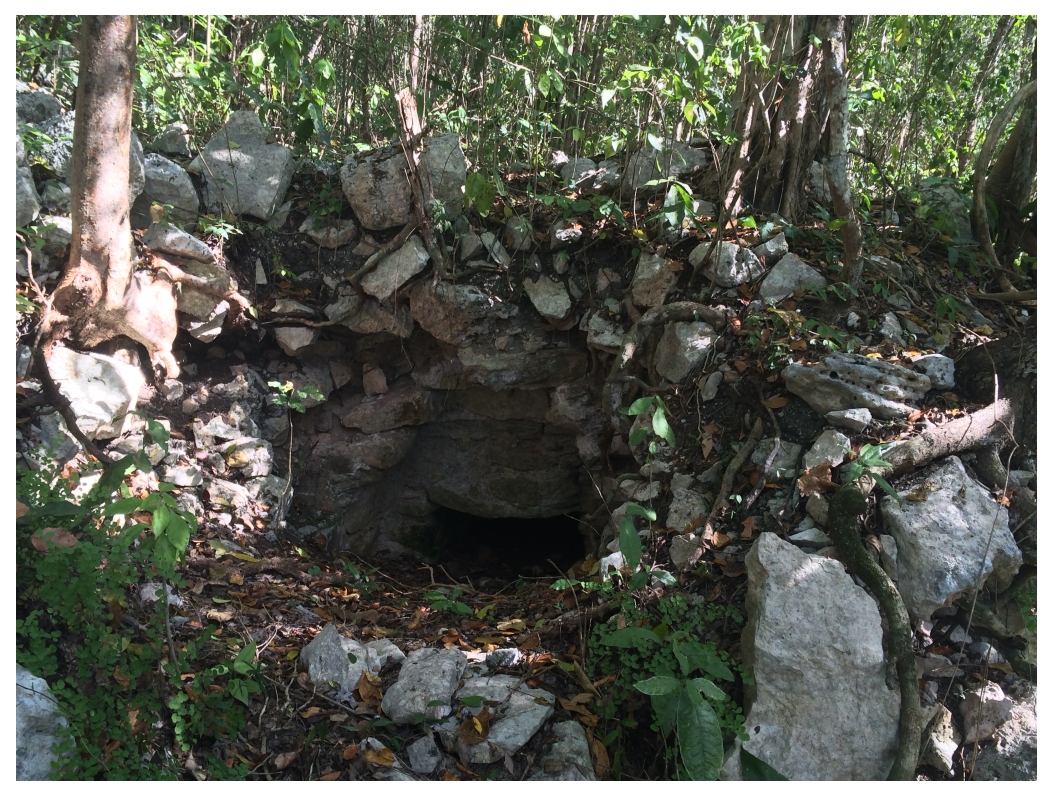

Figure 6.1. Entrance of an ancient pyramid located in Xuilub.

Also, the ejido has undoubtedly been a significant factor in the maintenance of the Maya cultural identity and environmental ethos and its associated land-use practices like milpa farming, apiculture, hunting, and cattle ranching. The ejido system was introduced in the early $20^{\text {th }}$ century by the Mexican government as a land redistribution strategy to benefit peasants and Indigenous groups who had lost their ancestral territories to wealthy landowners. Although not a "traditional" Maya land-use strategy, the ejido has not created a dissonance with Maya cultural values. It meshes well with the communal Maya responsibility-based way of working together in an atmosphere of reciprocity, coexistence, and respect, and being responsible at the community level. The Mayas of Xuilub believe that human societies are best organized in networks of small communities: “we live better here in our small Maya communities. It's easier to teach our children how to live properly on the land. People in big cities tend to lose their way," said one Maya hunter when asked about the social organization of Xuilub. The members of the Xuilub community depend on acquiring an intimate knowledge of the land and its various 
processes, and must remain attuned to biogeographical change, which is, according to one Maya mother, "more easy to do in small communities like ours." In Xuilub, there are sanctions for not respecting community regulations and rules, and elected authorities have a considerable amount of power in terms of ejecting people from the community who contravene these rules. Likely aware of this state of affairs, and of a necessity to conform to the broader Maya ethos when living in Xuilub, those who are not willing to live according to the rules often leave the community: "Drunks and lazy people unwilling to work and respect our way of life here and our responsibilities and tasks are free to leave our community. We encourage them to do so, and I think they understand that it is best for us and them, too," explained the then-comisario. I did not spend a great amount of time investigating this phenomenon or the significance of the ejido system in maintaining the Maya environmental ethos and social order, but I do believe it is an interesting dynamic that merits further investigation. A greater understanding of this would contribute to knowledge about Maya land use patterns. The postcolonial and Indigenous geographies literatures on Maya land use lack a greater understanding of the role of the ejido in allowing Indigenous groups like the Maya to maintain their cultures and land-use traditions through mechanisms of social order like the expulsion of individuals who do not follow this ethos from the community territory.

\subsubsection{What it Means to be Part of the Great Circle of the Yucatan}

When asked to explain what he felt about the place of the Maya people in their homeland, and what it meant to be part of the Yucatan, one Elder said "all peoples come from their own specific place on the planet and are most well adapted to that place. It's the same for us Mayas and the Yucatan." "Can someone like me, who's not from the 
Yucatan, learn to be part of it like you Mayas, if he or she is genuinely willing to?," I asked. He replied that “yes, it's our responsibility as Mayas in our homeland is also to teach others the proper way to live here. So I know I, and all of the people I know here in the community, are glad to teach you or anyone who wants to learn." According to this Elder, his sense of responsibility to be part of the land and to teach others to be part of the land and help individuals to maintain Maya identity, traditions, spirituality and religion, and land-based practices and gives her/him a life's purpose. Land-based activities and social structures of the Yucatec Maya have evolved on the land, in the Yucatan, for thousands of years. In present-day Xuilub, environmental governance and social organization are informed by ancient spiritual principles based on relationships and responsibilities. Environmental governance is about maintaining duties and responsibilities to the land, and to one another, and not about managing resources per se. Instead of asking himself/herself "What are my rights to the land and how much can I take?," the Maya women and men who I have interviewed and worked with in their landbased practices ask "What are my responsibilities to the land and my relationships with other beings on it?" This is what I and others like Sherman (2008) consider an "Indigenous" way of seeing the world and relationships with the land, and how we have learned to think. I was amazed to find a culture and its people with the same way of thinking thousands of kilometres away, and who have little to no knowledge of Indigenous cultures north of the Rio Grande. This observation gave ("real-life") tangible meaning to Cajete's (2000) concept of a common 'native science' shared by Indigenous groups across the Americas. I believe that this idea merits further examination, though I provide some of my own reflections in Chapter 7. 


\subsubsection{Gender and the Special Role of Elders (and Infants) in Xuilub}

As part of the Maya cultural identity, gender and age roles are an important aspect of land-use patterns and practices, as well as social organization. Postcolonial and Indigenous geographers have long found it important to conduct gendered analyses of non-Western cultures that were subjected to colonial rule and oppression (Rasan \& Park, 2000). In the context of Canadian Indigenous cultures, female scholars have argued that Indigenous understandings of gender and gender roles could offer new windows from which to critique hegemonic Western gender definitions and meanings. Postcolonial scholars, however, seldom explore the Indigenous idea of complementarity and reciprocity between genders. Within an Indigenous context, the focus of (feminist) postcolonial research has largely been on Indigenous women's rights framed within broader Western rights-based frameworks and discussions. I would certainly not argue against the value of assisting Indigenous women the world over in their struggle for rights and recognition after centuries of patriarchal Western socioeconomic systems that have been imposed on their groups. Kuokkanen (2012) summarizes some of these key issues in postcolonial feminist investigations on Indigenous women's rights:

The conception of indigenous peoples' rights as human rights on the one hand, and as both individual and collective rights on the other, exposes the double-standard in the domestic politicized rhetoric that opposes indigenous women's rights as individualistic and hence, in conflict with collective rights. If we conceive both indigenous peoples' rights and indigenous women's rights as human rights which exist in a continuum - rather than separating them into different categories such as sex or gender equality rights - it is also possible to develop a framework to address violence against women (p. 249).

The author's rights-based understanding of Indigenous women's struggles is a necessary effective approach to assisting Indigenous women in fighting against gendered violence 
and systemic and institutional discrimination, which is perhaps even more difficult to bear for Indigenous women than it is for Indigenous men. Postcolonial feminist scholars are thus undertaking much-needed research that does much good for Indigenous women. However, I believe that allowing Indigenous people (and women in particular) to articulate their own view on gender relations and roles could also provide new perspectives for feminist postcolonial scholars who investigate these questions. From what has been expressed and shown to me by both women and men in Xuilub, the Great Circle of the Yucatan would not be possible without recognizing the complementarity between the roles of men and women — and by a profound cultural respect and love for women and their contributions to the social order. Also, non-Western and Indigenous feminist scholars have criticized certain currents of Western feminism that they believe delegitimize so-called traditional women's roles such as motherhood and household tasks (Chilisa, 2011). In Xuilub, as I have come to understand, the role of women as mothers and as "masters in the home" (personal communication with a male Elder) is generally considered to be as important as the role of men as providers and protectors. Men and women, as was told to me by both male and female interviewees, occupy complementary roles, and one "cannot exist without the other" (female interviewee). The gendered social roles in Maya society define the type of work that is performed and an individual's specific spiritual and religious practices in the home and in community celebrations and special events.

Gender roles in Xuilub are well defined and generally well respected and upheld. The Maya household is operated as a (nuclear) family unit. In most cases, a newlywed couple will build its own palapa (Spanish word of Tagalog origin for palm thatch hut; 
see Figure 6.2) or occupy a cement house built by the CDI. Typically, the couple will soon begin to have children. In my interviews with community members, many of the interviewees mentioned that having many children is a blessing as they can eventually start helping the mother and father in their respective work and duties. Maya work and social activities and roles in the household are generally markedly gendered. Maya boys and men are expected to work in the milpa, hunt, and tend to cattle while girls and women collect water, take corn kernels to the mill daily to grind into corn dough to make fresh tortillas, look after the children, cook, and keep their family's living space clean. As I gathered from my interviews with Maya women of Xuilub, the Western concept of feminism is foreign and irrelevant to them. All of the Maya women I interviewed affirmed that the work they do is at least of equal importance to that of the men. Some of them believe their work to be even more important because without mothers and homemakers, there simply is no society, no Maya culture. "Who would raise these milpa farmers? Who would feed and raise those who earn the money and provide for their families without us?," commented one middle-aged woman. Some of the men shared the same opinion, saying that without women, there would be no Xuilub, no Mayas. The women and men whom I interviewed about this subject believe their respective gender roles are complementary, and that their respective work is equally important in different ways. "Men and women need one another, and one could not live without the other", said one milpa farmer. The strict gender roles that I observed in Xuilub are reflected in land-use activities practiced by community members. Men are invariably the ones who engage in milpa farming, hunting and cattle ranching. Apiculture is the only land-use practice in Xuilub in which both men and women (of the 
same household) participate together in the cleaning of the apiary, the routine tending to the hives, as well as the harvesting of honey. Women are responsible for child rearing, housekeeping and cooking, but also often take care of the solar in which they grow a variety of chilies, avocados, oranges and other fruit, and in some cases flowers. These tasks are "to be done by women," explained one woman tending to her solar. She continued her reflection on my question about what she saw as the role of women in the community and as caretakers or custodians of the land: "I think that women are just as much in contatct with the land as men, just in different but equally important ways. Naturally, as mothers, we have a close connection to the land and to life, because the land gives all of us, humans, animals, plants—everything—life.” Complementary gender roles, just as all other facets of Maya life in Xuilub explored in this dissertation, are considered to be organized according to the respective aptitudes and strengths of women and men. Being part of the land, said one father and apiculturist, "requires all of us here in Xuilub, to respect our different kinds of work and roles. That's how we have lived here for many, many generations and it's the only way we know." 


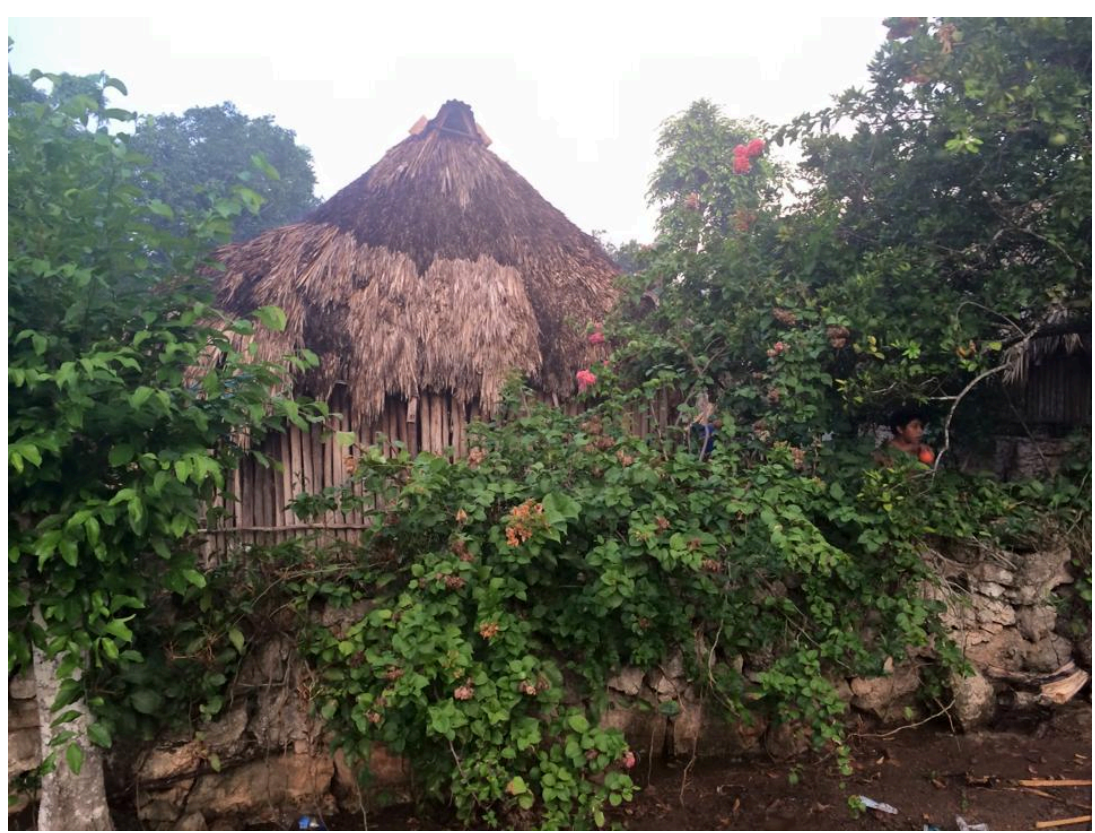

Figure 6.2. Typical Mayan palapa.in Xuilub

IK research has long investigated and described the importance of Elders in

maintaining Indigenous traditions as the IK holders of their peoples. On the significance of Elders in Indigenous cultures, Kulchyski, McCaskill \& Newhouse (1999) write that:

In traditional Aboriginal societies Elders were and still are evolved beings who possess significant knowledge of the sacred and secular ways of their people, and who act as role models, often assuming leadership positions in their communities. They are highly respective by the people. They are teachers, healers, and experts in survival, guiding indivudals' behaviour towards an understanding of the natural ways of Mother Earth. The Elders teach a world-view based on the knowledge that all things in life are related in a sacred manner and are governed by natural or cosmic laws (p. xvi).

As stated in Chapter 1, prior to beginning my field research I suspected that Elders in Xuilub occupy a special place in the community. However, I made another finding that added to my understanding of Indigenous perceptions about Elders that may also be useful for other IK scholars. In my interviews with Elders and younger people in Xuilub, I discovered that Elders are seen as being very close to babies and infants in their understanding of the human life cycle. The Maya of Xuilub have told me that they view 
each human life as a cycle — or circle — that begins (at birth) and ends (with death) at the same place - at the top of the cycle. Babies and infants are, naturally, considered to be at the top (or beginning) of this cycle, but Elders who are in their last years or months are also considered to be at the top. Therefore, as explained to me by one female Elder (see Figure 6.3),

Elders and babies/infants are close to one another - they have a special bond. They are both closer to the spirit world than people of other ages. Our ancestors and our unborn live in this spirit world. This world is in contact with ours here on the land. That is why both Elders and our youngest are treated with special love and respect. They are a living link with our ancestors and our unborn. They teach us the most important lessons. When you think about it, babies have to be fed and taken care of. They are not able to care for themselves. The same is true for Elders. We must feed them and take care of them, too. Elders and babies take care of us spiritually and emotionally, and we take care of them physically. They are at the same place in their life cycles.

To me, this statement is eye-opening for IK scholars because the significance of Elders as knowledge holders is universally accepted and understood in this field. However, the Yucatec Mayas' understanding of babies and infants as also having a special role as "knowledge holders," in terms of the valuable life lessons that they offer to people of the community. As far as I know, this concept has not been investigated by IK scholars doing research on the Yucatec Maya — and has received very little attention in other Indigenous contexts. To me, the special role of babies and infants in Indigenous cultures warrants further investigation and research. Although my research scope was limited and I could not devote much time to studying this, I believe more research could uncover important data about the role of babies and infants as regards Maya social organization. This would be a novel area of research in IK scholarship. 


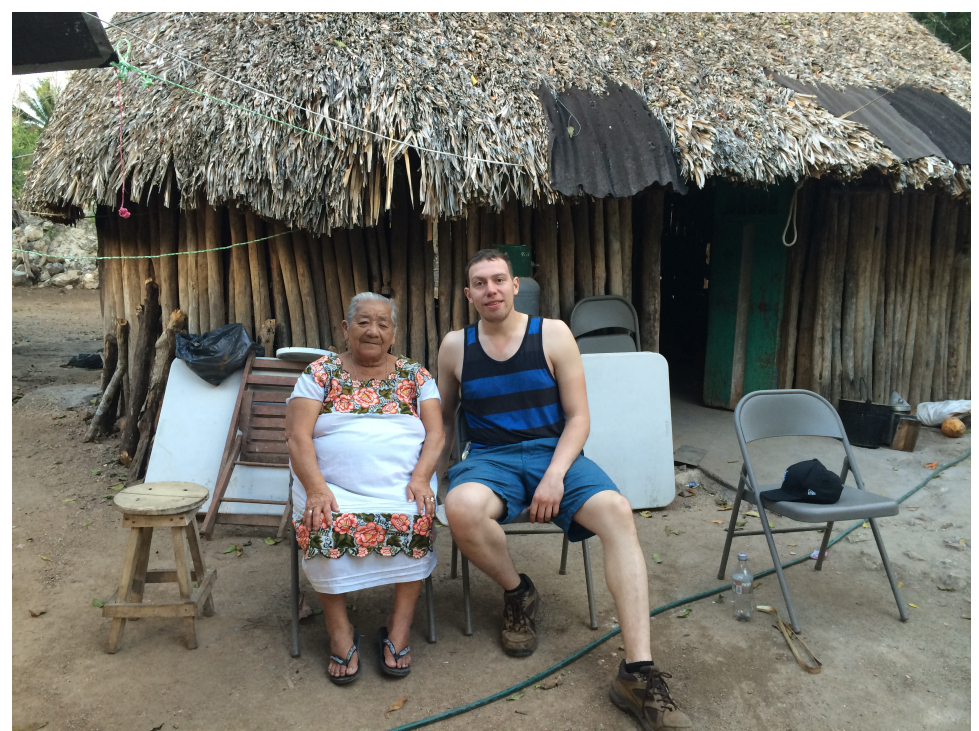

Figure 6.3 The author posing with an Elder (and great-grandmother).

In terms of the role of Elders in the community, I discussed with one Maya Elder the relationship between youth and Elders. According to him, there has "always" been a strict order between children, youths and their parents and (great-)grandparents. Maya children "are taught respect for their elders from a very young age. The respect we teach our children includes a sense of responsibility to help us in our Maya work and to listen carefully to what we teach them without argument or rebellious behaviour." Many interviewees talked to me about the responsibility of each individual to carry out daily tasks and observe certain religious and spiritual rituals according to her/his age, gender, physical condition and mental disposition and capacity. As in many Indigenous cultures, Elders are held in high regard in Xuilub. In Indigenous cultures, Elders are seen as being the carriers and transmitters of IKs, upon which these cultures and societies are built and according to which they are structured (Simpson, 2002). As described in Chapter 3, IKs are generally orally transmitted ways of knowing, being and doing (Pierotti and Wildcat, 2000), and the matters pertaining to the Yucatec Maya land ethos and land-based 
practices are no exception. In Xuilub, as a show of respect elderly men and women are referred to by younger members of the community as "uncle" and "aunt." On numerous occasions, I noticed that community members commonly deferred to Elders when I asked them questions on almost any topic. It is clear to me that this protocol is not simply an act of deference to someone that is more knowledgeable because of advanced age, but is a show of deep respect. This observation is similar to Ortega Canto's (2006), who investigates the influence of and respect for Elders in Yucatec Maya family life. In almost all of the households in which I conducted interviews, Elderly couples or widows and widowers lived with and were taken care of by their children, grandchildren and, not uncommonly, great-grandchildren. All of the men and women I interviewed told me they learned all they know about Maya culture and land use from their parents and grandparents. Interviewees expressed a profound respect for their Elders, for without them, they recognize that they would lack these essential spiritual and sustenance-based knowledges. All Elders I interviewed and had informal discussions with believe it is important for youths in Xuilub to have knowledge about Maya spiritual beliefs and ceremonies and land-use practices like milpa farming and home gardening. I asked a group of Xuilub teenage boys and girls, gathered around one of the convenience stores in Xuilub, if they believed the teachings of their (great-) grandparents were important to learn, even today with the advent of new technologies like the Internet and social media and the wealth of information that is available at their fingertips (most of them have a smartphone). One girl, who was a high school student, spoke up, saying 
Even though we have smartphones and Internet at the school here, I believe the teachings of our grandparents are very important to all of us. They teach us how to be Maya. Without them, we wouldn't know much about our culture. They give us a sense of direction. I'd say all my friends and people I know in school really respect their grandparents and value what they say-their teachings about the land and about our culture.

All of the twelve teenagers nodded their heads. I got the impression from this conversation and from my chats with various Xuilub youths, while playing baseball or other games with them, that they have a profound sense of respect and admiration for their elders and the knowledge that they hold.

In my interactions with Maya families, I observed that grandparents generally live with or very near nuclear families. During my interviews in the homes of Xuilub community members, it was common to see grandparents resting on hammocks while the younger family members performed household chores or were out working on the land. In several instances, these Elders were interacting and/or playing with babies and young children and teaching them about the land and the lessons that can be learned from stories about the different beings that are part of it. Carey (2001) also found that in the Kaqchickel Maya communities of central Guatemala Elders serve as teachers and mentors for the youth and are considered by younger people to hold invaluable information and knowledge about the environment, and actively take on the role of knowledge holders and educators. Indeed, in my own field research I noticed grandparents in serious conversation with children old enough to speak. I recall pausing during one interview to ask one mother what her mother and her daughter were discussing. She replied that her mother was teaching her daughter about which (poisonous) plants to avoid and which insects to look out for when playing with her 
friends in the tall grass. What has been clear throughout my research is that grandparents play an important (and complementary) role in educating children and youths, and are held in high esteem by all family members. Their main (voluntary) role is to impart their wisdom on the youth. I found that in most cases, they are shown much appreciation and affection by their sons and daughters and (great-)grandchildren, who look after and care for them. I was also told that widows and widowers with no close family members in the community are taken care of, financially and emotionally, by neighbours and friends. "We wouldn't let anyone, especially a widow, starve by our side here in the community. We owe the elderly a good life and dignity. They have taught us all we know," said one man in his mid-twenties.

\subsubsection{Social Organization in Xuilub: "Convivir con respeto" (to Co-Exist with Respect)}

Postcolonial scholars interested in decolonizing colonial systems of social order and community organization imposed on Indigenous groups (e.g. the reserve system in Canada) have thus far approached these discussions form a markedly Western rightsbased mindset and mission, like Wainwright's (2008) Decolonizing Development: Colonial Power and the Maya, or from a political ecology ${ }^{2}$ theoretical framework, as in Anderson's (2005) Political Ecology in a Yucatec Maya Community. Current disciplinary discussions in postcolonial theory and Indigenous geographies approach to Indigenous community life and organization with a focus on either understanding the outside socioeconomic influences on Maya relationships with the environment, or on assisting

\footnotetext{
${ }^{2}$ Political ecology is the study of environmental issues and questions as a result of various political, social, and economic factors.
} 
the Maya in asserting their Indigenous rights to use their lands and their resources, as (see, for example, Faust, Anderson \& Frazier, 2004). What I found to be absent in postcolonial and Indigenous geographies-related discussions about community life and organization is an attempt to understand social bonds and relationships in Maya communities through Maya cultural concepts and their environmental ethos. As in all aspects of my research in Xuilub, when it came to questions about Maya social and community organization, I avoided Western (and rights-based) terms and concepts so as to avoid influencing and misrepresenting Maya understandings and meanings about this subject. Upon analyzing my research data, I found that none of my interactions or interviews contained the notion of rights or any similar or related concepts. Instead, the common key theme in this data was the idea of carrying out responsibilities to one another in the community and living together in a spirit of respect, reciprocity and coexistence (the three words that were consistently used by interviewees and those with whom I had informal discussions, regardless of their age and/or gender). During my fourth trip to Xuilub (July-August 2015), I was able to interview the new comisario and his chief of community security about Maya concepts related to social order and community organization. The knowledge I gained from those two men gave me valuable insights into the present-day Maya social ethic. The key idea that was expressed by the comisario is "convivir," a Spanish word that refers to individuals learning to work around their differences and disagreements and live with one another in a respectful and peaceful manner. This concept, I was taught, is the foundation of the Maya social ethic in Xuilub. All members are free to live their lives exempt of interference from the community leadership so long as they treat others with the same respect and 
understanding. "Respeto," or respect, is, naturally, a corollary of convivir. Both men were intent on impressing upon me the importance of respect as a fundamental value in terms of Maya social organization. I was asked what I intended to accomplish with my research in their community. When I explained that my purpose is to learn about Maya relations with the land, and how I believe Indigenous land-related knowledges should be valorized and drawn on by Western societies to create more environmentally and socially sustainable and equitable policies and programs, in a spirit of mutual respect and learning, the men nodded and said to me, "that is how our community operates-with respect for one another and outsiders." The comisario added, "if that is how you also think, as I believe you do based on your comments, you are welcome to live with us and carry out your work." In a not-so-subtle yet respectful way, the comisario impressed upon me my own responsibility to the community as an outsider/researcher. I understood that I was welcome, and would be treated with warmth and respect so long as I shared this philosophy of non-intrusiveness and respectful coexistence.

I learned more about the Maya meaning of long-lasting, even lifelong, bonds during an interview with a family who told me about another Western researcher who had lived for more than a year in the community in the 1990s. Under the guidance of the locals, the researcher built his own palapa and cleared and planted his own milpa and "lived as a Maya," during his stay. The family mentioned that he was always respectful and polite, and fully participated in the social life of the community. His "going native" experience allowed him to gain a good understanding of nearly all facets of Maya life and culture, and his accounts were published as a book in Spanish (which is, admittedly, a very interesting and comprehensive account of Yucatec Maya land-based livelihoods in 
the early 1990s). However, visibly upset, the woman of the household remarked that upon finishing his manuscript, he left and never came back or contacted anyone in the community, including the many friends he had made and mentors who volunteered hundreds to thousands of hours of their time teaching him the Mayan language and landbased practices. When I asked other community members about the researcher's sudden departure and lack of communication, I got the sense that many who had met and interacted with him felt bitter, perhaps even betrayed. During each of my research trips, in the days leading up to my return to Canada, I was jokingly asked by interviewees and others, “you're not going to forget about us, are you? When are you coming back?” As I write this, youths I keep in contact with through Facebook still regularly ask me when I plan on returning. It is difficult for me to give them a determinate answer as of now, although I am committed to maintaining not only my research partnership with Xuilub, but the friendships I have built with so many of its members. The conditions and limits of so-called "research partnerships," as we understand them in the academy, have no significance in Xuilub. This is not unique to Xuilub or the Yucatec Maya, and the literature on Indigenous research methods the world over calls for researchers to develop respectful and warm relationships with their study communities, as discussed at length in Chapter 4. What I have come to learn is that the Maya expect long-term bonding and reciprocity with their non-Maya friends. To the Maya, it is almost unfathomable for an individual to spend time in the community and to break bread with its members, only to subsequently cut ties. As with other guests, it is expected that I keep in touch and return in the future. 
On my second research trip from December 2014 to January 2015, I accompanied my research assistant and different local guides to various culturally significant and sacred sites around the community. We visited ancient pyramids, cenotes, and abandoned homesteads of yesteryear. One local guide led us through winding trails in the forest to an unremarkable disused cattle ranching well (which invariably use cenote water) about two or three kilometres from the community core. He stopped there and began speaking to my assistant in Maya, pointing every few seconds to the inside of the well. My assistant explained to me that in the 1970s an American exploratory cave diving team had undertaken an expedition in the cenote without permission from the community, and had found and stolen artifacts and human remains. The team was confronted by a local cattle rancher who discovered them while he was fetching water for his cattle. According to the guide's account, the Americans bribed the rancher with an insignificant amount of American dollars for his silence. The rancher kept hush about his discovery for a few days, and the American explorers were able to make off with their Maya wares, never to be seen gain. Eventually, other community members saw evidence of the Americans' expedition in the form of tools and empty cans of food. The rancher was soon pressed by the community leadership about his knowledge of the event. Although he initially denied having seen anything, upon being pressed by the community leadership he later admitted to accepting the Americans' bribe. The guide excitedly described the rancher's reprimand by the comisario. "At first, they considered banishing him from the community for his disloyal act," he recounted, "but the comisario took pity on him because he had a young family and they allowed him to remain living here if he agreed to a few weeks of community chores and odd jobs." When I asked why the then-leaders of Xuilub would 
consider giving a person who had sold them out a second chance, the comisario replied, "because he is part of our community — part of us. Sometimes, for different reasons, people stray from the path our forefathers have set out. They don't do things as they should be done. But we are all from Xuilub, from the land and everything around here," he said pointing to the trees and the surrounding landscape. "He belongs to us, so we have to give him a second chance." This excerpt is very telling and directly relates to the central argument/theme of this chapter: the Yucatec Maya environmental ethos's central principle is to learn to be part of the land. Being part of the land is a lifelong process and habit, and it is accepted that no one will be perfect, but with help from others - and with a spirit of co-existence and mutual support — the people of Xuilub believe they are on the right path.

As another example, during one of my research trips in the summer of 2015 , at a salsa concert during a feria in the nearby ejido of Chemax, I was once again reminded of the Maya notion of respeto for the culture, traditions and foremothers and forefathers. As I stood in the crowd enjoying the flashy musical and dance performance, a visibly intoxicated Maya man approached me with a hostile gait. He stopped a few inches from me and asked me why I, a gringo, was there and what I was doing in his community. "What are your intentions?," he pressed. Wanting to avoid conflict and confrontation at all costs, I nervously explained that I am a researcher from Canada, and that I was staying with a family from Xuilub. I stressed my recognition of being on Maya territory and that I had no intention of taking any artifacts or sacred objects back to Canada with me, or otherwise desecrating or desacralizing any part of the Maya landscape. The man sneeringly listened to my declaration with an air of incredulousness. Luckily, my research 
assistant appeared and interrupted me, then turned to the man and exchanged a few comments with him. Within less than a minute, the man looked to me, smiled, and extended his hand. As I shook it, he smiled and said, "I see you're in good hands. Welcome to our Maya homeland, friend. Let me know if there is anything I can do to help." I was quite surprised by the man's sudden change of temperament and asked my research assistant about what they had said to one another. He explained to me that the members of Maya ejidos in the area had, through countless instances of disrespect and cultural theft from outsiders, grown very wary and mistrustful of outsiders - not only gringos but equally non-Maya Yucatecans and other Mexicans. All the man needed, he continued, was to be reassured that I was paying the Maya people and landscape the respect that was due. Again, the importance of paying respect to and to learn to be part of the land and its beings was made very clear to me in this instance. This interaction taught me that I, too, had to learn to be part of the land as an outsider/researcher, and that this was expected of all who seek to establish a partnership with a Yucatec Maya community. This is a finding that is in line with Wilson (2008) and Cameron, de Leeuw \& Greenwood (2009) and the relationship-based research approach that these scholars believes is needed when working with Indigenous groups. Louis (2007) and Zinga and Styres (2011) mention the importance for researchers of establishing relationships with the land, but my research in Xuilub has allowed me to understand this concept in a different way that could be useful for other postcolonial, Indigenous geographies and IK researchers. Indeed, the Maya have taught me that the researcher has to, like the Maya people themselves, not only establish relationships with the land upon which the research takes place, but to learn from the local Indigenous people to also be part of the land. 


\subsection{The Broader Value of Learning to be Part of the Land}

The Maya concept of being part of the land is a place- and context-specific philosophy. In most mainstream frameworks, Mexican, Canadian (or any other) society is abstracted from the Great Society of the land, which includes not only human but also other-than-human beings, as conceptualized by many Indigenous groups. Responsibilitybased thinking understands the world in a radically different way: the only material thing to which human beings can belong is the land herself. All other immaterial things to which we supposedly belong - human societies and the economy, for instance - are philosophical constructions. This section will consider what the postcolonial and Indigenous geographies fields can learn from the Yucatec Maya, who operate according to responsibility-based thinking and who are guided by the principle of learning to be part of the land.

\subsubsection{The Limits of Current Mainstream Approaches to Environmental Management}

As mentioned in Chapter 3, the bulk of the postcolonial and Indigenous geographies literatures focuses on approaches to correcting colonial injustices and assist Indigenous groups in their resistance to governments and corporate interests. Although the approach to Indigenous territorial governance has allowed many dispossessed groups to reclaim territories and the resources found within them, they often do so at the expense of their invaluable and distinct (responsibility-based) Indigenous philosophies, such as the Maya one, which I sought to highlight and represent in this dissertation. In other words, they have had to frame their resistances within mainstream discourses and terminologies that have in many cases been introduced into their way of thinking by 
Western democracies that have arisen since independent nation-states have formed on their ancestral territories (Alfred, 2005; Wainwright, 2008; Li, 2010). Employing such approaches stifles Indigenous peoples in the exercise of their responsibility and duty to be part of their lands. It should be noted that in recent decades a variety of different comanagement agreements have been brokered between Indigenous peoples and different nation-states (Armitage et al., 2011). In the Canadian Arctic, for example, four Inuit land claims agreements have been reached with the federal government. Each land claim agreement establishes a co-management strategy for natural resources, in which both scientific and Inuit knowledge are combined to develop environmental monitoring mechanisms and strategies (Armitage et al., 2011). However, these co-management agreements seek to find ways in which to incorporate IKs into Western rights-based frameworks, but not, simultaneously, the other way around. The starting point for discussions and negotiations for co-management is within Western legalistic and legislative parameters. Absent has been a meaningful effort to go into such discussions with Indigenous groups from an Indigenous environmental ethos. I believe that policymakers and planners would benefit from shifting co-management approaches to Indigenous understandings of appropriate relationships with the land and land-use activities on their ancestral territories. Despite the rising influence of the co-management school in both Indigenous geographies and environmental policy, critics argue that there is a tendency in the co-management school to work from an (albeit mostly unacknowledged) platform of Eurocentric perception of the environment as land-to-bemanaged, circumscribed by dominant philosophical and legal frameworks (Bebbington, 2009; Sillitoe, 1998). I believe that co-management systems tend to preclude Indigenous 
worldviews and concerns and keep the development-focused terms of reference off the negotiation table, thereby perpetuating colonial legacies of territorial domination and discursive obfuscation. Indigenous participants in co-management are thus often left with little choice but to once again submit to dominant cultures and land-use approaches and leave behind their responsibility-based environmental ethos. This research has sought to bring to light the present-day relevance of investigating the responsibility-based environmental ethos that I found in Xuilub. I propose that the responsibility-based attitudes relating to the land could influence non-Indigenous societies to make sounder environmental planning decisions that take into consideration the interests and wellbeing of all orders of beings.

Martínez Coria \& Haro Encinas (2015) outline some of the terminology and frameworks that inform the discourse surrounding Indigenous territorial governance and access to resources. They find that although they benefit from constitutional rights as Indigenous peoples, many Indigenous groups in Mexico face continued territorial dispossession as a result of the encroachment of private interests, such as Yucatan's tourism industry. The authors conclude that there are marked limitations in Mexican law in recognizing Indigenous territorial rights. Although included in the amended Mexican Constitution (1992), Indigenous rights and autonomy are found to be constantly under threat in the face of economic development and neoliberal policies espoused by the Mexican government. In the same vein, de la Peña (2006) examines the ways in which the Mexican legislation and policy that have undermined Indigenous struggles for selfdetermination and autonomy in order to grant concessions to multinational corporations and other Big Business interests. What is clear to many Indigenous (and non-Indigenous) 
thinkers and people in Xuilub, Yucatan, Mexico, and around the world, is the need for a different environmental framework that understands and incorporates elements of the place- and relationship-based worldview that has been unpacked and presented in this dissertation. In investigating the case of a Canadian-owned mine operating in an Indigenous area of Guatemala, Fulmer, Godoy \& Neff (2008) highlight some key ideas that illustrate the main limitations of non-Indigenous approaches to relating with and managing the environment. Although the constitutions of a number of countries in the Americas recognize Indigenous territorial (and resource) rights, and contain legislative and legal frameworks surrounding these, in practice they often fall short of honouring those rights, as these authors have found. The duty of governments and private industry to consult with Indigenous groups in cases of potential adverse environmental impacts and interference with Indigenous livelihoods on Indigenous territories is often secured by national legislative frameworks. This is the case in Mexico and in the Yucatan. In fact, the Pac-Chén and the Cancabchén Maya communities have been recent victims in land management frameworks that favour economic interests over Indigenous cultural preservation and subsistence autonomy (Gómez González, 2016). In those two communities, apiculture is the subsistence land-based activity and a large percentage of their members earn a living by selling honey products. However, in 2015 an amicus curiae legal body that is based in Ottawa, Lima, Bogota, and Mexico City highlighted one example in Yucatan in which the Mexican federal government has been resisting, through different legal approaches and mechanisms, to uphold their Indigenous constitutional rights: 
Since 2005, the Mexican federal government has authorized the release of genetically modified soybeans at the pre-commercial stage. On 25 February 2011, the "Monsanto Comercial S.A. de C.V." corporation requested permission to plant 30,000 hectares of genetically modified soybeans in the State of Campeche, Quintana Roo and Yucatán. Even though there was never a consultation process carried out by the government with the affected indigenous communities, the federal government provided Monsanto with a licence to go forward with the planting on 17 June 2011 (“Case of Indigenous Communities,” p. 2).

GMOs introduced in ancestral Maya territories pose a great threat to the Mexican tropical forests. The Maya groups in Pac-Chén and Cancabchén are highly dependent on the health of these forests because many families in these communities depend on apiculture as a main source of income. Most notably there is a high risk of these industrially produced seeds being carried by the wind and ending up on Maya milpas. Thus, even though the Mexican Constitution and international law is clear on the duty of governments and private interests to consult with Indigenous groups in case of potential environmental risks in their traditional territories, in practice this is far from guaranteed. This reality was also observed by Sioui and McLeman (2014) in their study on one eastern Ontario Algonquin group's struggle against uranium mining and other government and private sector threats to their homeland.

One of the main economic strategies in (non-Indigenous) Yucatan is to continue to foster growth in its rural industries such as tourism and monoculture crops. Growth in these industries is seen as the key to reinvigorating stagnant rural economies. The neoliberal economic ideal of 'limitless' growth is, to many Indigenous thinkers, reckless and dangerous, as it fails to consider the limits of the environment (see Comeliau, 2000 for a discussion on the neoliberal assumption of limitless economic growth). Such an ideological foundation for society presents challenges to the Mayas' spiritual 
responsibility as stewards of the land for all Mexicans. The current rural development vision “delegitimizes and trivializes indigenous peoples' claim of spiritual and social responsibility to the land in order to promote a Eurocentric vision of limitless economic growth based on unchecked resource extraction" (interview with a Yucatec Maya doctoral student attending a Canadian university). Such systems focus on technocratic fixes, or tinkering with the terms of reference of a project, or negotiating what percentage of the profits of an extractive enterprise (if any) go to the affected Indigenous group (Fulmer, Godoy \& Neff, 2008). However, meaningful questions such as who decides what counts as progress or development, and whether or not there are alternatives to resource-intensive and highly destructive land-use models are almost invariably left off the negotiation table. Even though local Indigenous participation in such projects is entrenched in International Indigenous law, it is not enforced. In fact, although through the United Nations International Labour Organization's (ILO) convention 169, signatory nations like Mexico have a duty to consult with Indigenous people is protected, Indigenous people have no right to veto exploitation on their lands. This is an example of one of the most important international policy documents about Indigenous cultures and land use that focuses on rights as opposed to responsibility and stewardship. Although they can try to persuade companies to adapt their techniques to minimize environmental damage, and to restore the environment afterwards, they have no real decision-making power or authority. Legal approaches to Indigenous territorial rights are mostly a "posthoc remedy as opposed to forward-looking governance" (ibid, p. 113). Laws can be strengthened, refined, and clarified but the fundamental question at stake remains: who decides what development projects proceed, how they proceed, and who benefits. In 
practice, it is clear that the scales of justice seldom tilt in favour of Indigenous groups over corporate interests, demonstrating what are, in my opinion, some clear weaknesses of the rights-based approach.

\subsubsection{Implications of Responsibility-Based Thinking and Being Part of the Land for Mainstream Environmental Stewardship}

IKs have been perpetuated through the generations, and are at present reflected in the land-use practices of groups like the Yucatec Maya in Xuilub. However, according to interviewees, the term 'environmental management' is an oxymoron: "How can we consider ourselves land managers when we depend on her everyday for food, shelter, and our survival? It's really the other way around: she manages us," affirmed one hunter when I asked him what he believed were the best practices in terms of managing animal populations in the area. The current Mexican environmental strategy, which divides ecosystems into various resources suitable for exploitation, such as forests, minerals, soils is a concept that can be difficult to reconcile with the Maya worldview that, according to the interviewees perceive the environment as an interconnected web of relations, and consider humans to be just one element of the land. In Maya thought, there is recognition that what the Western mind would call "democratic processes" includes human and nonhuman beings. In Xuilub, the environmental decision-making process is not limited to humans; management decisions are made in consideration of the non-human beings' interests. This guiding principle is contained in environmental visions expressed by other Indigenous cultures across the Americas. For example, it is captured in the Algonquin term mino-pimàdiziwin, which means to learn to live in balance with the land and with other physical and spiritual beings (M. Sioui, 2012; Sioui and McLeman, 2014). 
Interestingly, essentially the same idea is contained in the Quechua phrase sumak kawsay (Acosta, 2013).

It is precisely because of this inclusion of non-human beings in the Maya conception of society that the average person in Xuilub considers inappropriate the predominant environmental management-by-compartmentalizing (the land into independent resources) (Zoomers, 2000) approach. They believe that because they are part of the land, any actions that degrade the integrity or health of the ecosystem ultimately affect the health of human beings. In view of this ethical principle, economic activities that depend heavily on resource extraction (such as uranium mining) are strongly opposed. Many interviewees believe that all human beings are subject to the "laws of the land." Various Xuilub Elders have expressed to me the need for humans to stay attuned to the ever-changing reality of the earth. This consciousness of the necessity for humans to observe and respect the land and the attendant capacity to see life in its oneness and in relationships with the land are what Sioui $(1992 ; 1999 ; 2008)$ calls "circular thinking." According to this way of thinking, the sense of wellness, happiness, security, proportion and balance experienced by human beings depends on the quality of the relationships that they are able to develop and maintain in relation to other beings on the land, with which they share life, time and (re)create 'place' as a location of shared meaning and experiences, in the same vein as Tuan's (1977) definition. It is this knowledge and belief system that guides the people of Xuilub in their actions relating to land use and environmental management.

As identified in Chapter 3, one of the key contributions of postcolonial thought is that as critical scholars we cannot take Western ways of knowing (namely science and 
'reason') for granted as the single beacon that illuminates and guides humanity (Alfred, 2005; Ashcroft, Griffiths \& Tiffin (2000); Bhabha, 1994; Harris, 2004; Legg, 2007; etc.). Useful knowledge is found in different ways of knowing, doing, and being. Also, as the feminist school of thought has brought to light there is no single way of knowing that is inherently more objective or unbiased than the other, and to presume such a status is, I believe, misguided at best (Hawaray, 1991; Rose, 1997). This idea should be applied in the field of environmental management. Indeed, gaining knowledge from a multitude of different cultural (in this case Indigenous) perspectives, each with its distinct way of knowing, can assist us in negotiating the atmosphere of uncertainty that characterizes our changing environment on a planetary scale. I put forth that an ideology that does not allow an individual to understand that she is merely part of a Great Circle of all Peoples on the land, such as the one outlined in this present document, can never be 'responsibility-based.' The responsibility-based approach ascribes a responsibility (and a role) to each Indigenous and non-Indigenous individual to (re)learn how to "be part of the land." By learning to feel a responsibility to one's environment and an understanding that we, humans, are just one of a multitude of different participants and actors in the Great Circle (of the land), we may be more apt to make more holistic and thoughtful environmental decisions. My analysis of responsibility-based thinking and of the Indigenous perception of a responsibility to be part of to the land, as an integrated, spiritually informed environmental ethos, could help to create new avenues in terms of mainstream environmental governance and policy. Adopting the responsibility-based thinking conceptual framework into outlets that environmental planners and policymakers read could also assist Indigenous groups in articulating to policymakers and 
planners their own culturally distinct environmental management strategies. This would also legitimize these views in the academe without having to use a solely Western paradigm, along with a corresponding terminology that was absent in the Americas prior to the arrival of the Europeans to their shores.

As previously mentioned, in the IK literature there is a tendency to focus perhaps too much on the differences and "incompatibility" between Western and Indigenous knowledge systems. On the other hand, my research demonstrates that there are certain areas of common ground between the two ways of knowing (example). The field of Indigenous geographies can be credited for attempting to demonstrate some commonalities between the two, and how mainstream environmental management approaches can benefit from the incorporation of IKs (i.e. the idea of 'co-management' between governments and Indigenous groups). In this sense, my research attempts to bridge IK research and Indigenous geographies, as I recognize that as an Indigenous geographer, I can perhaps present a more persuasive argument as to why this should be done. As an example of such common ground between IKs and Western knowledges, from the evidence presented in this chapter, it seems reasonable to suggest that Indigenous groups like the Yucatec Maya are (and have for a very long time been) familiar with notions very similar to 'ethical extensionism,' which is increasingly being thought of as a forward-looking environmental ethics and management concept (Negra and Manning, 1997; Cafaro, 2001; Chan, 2011). We can define the philosophical concept of ethical extensionism as the idea of extending moral standing (and in some cases rights) to non-human entities (animals, plants, landforms, ecosystems, etc.) that were traditionally not thought of as not possessing such moral standing (Des Jardins, 2006; 
Chan, 2011). Recently in New Zealand, for example, the Maori won a landmark court case that will see the Whanganui River, which has great cultural significance to this group, recognized as having the same legal rights as a person (Hutchison, 2014). Long before its advent in the field of environmental ethics and management, ethical extensionism has been part of the philosophical traditions of many Indigenous cultures across the Americas, and this research is testament to this notion. As another example, at a United Nations conference in Geneva in 1977, traditional Indigenous delegates presented their understanding of this concept:

The peoples who live on this planet must do away with the narrow concept of human liberation and start to see that liberation must be extended to the whole of the Natural World. What is needed is the liberation of all things that maintain lifeair, water, trees - all the things that maintain the sacred web of life (spiritual leaders of the Haudenosaunee quoted in Sioui, 1992, p. 31).

This statement stresses the perceived need for humanity to broaden the limits of moral consideration to other-than-human beings. One Maya milpero summarized his thoughts on the extension of rights to the land:

Instead of taking and taking, we need to learn that we must give back. In that way, we don't end up abusing the land [...] We have no right to hurt her because she is a living being and has a right to exist unharmed. Those teachings need to be understood and taught to the greater society.

From what I have seen, heard, and done in my five trips to Xuilub, we, as researchers, have only begun scratching the surface in terms of the revolutionary potential of Indigenous knowledges with regard to transforming current mainstream environmental approaches. There remains much to find out in future through about their potential to, in the words of the Haudenosaunee leaders quoted above, "liberate" us from regressive and narrow environmental management frameworks in which human beings obstinately find 
themselves at the top of a socio-environmental hierarchy. Responsibility-based thinking and the Maya precept of being part of the land (as a Great Circle of beings) teach us to think beyond short-sighted and narrow approaches to environmental management-bycompartmentalizing. Being part of the land, as an environmental ethos, shows the academic, political and activist communities a new and potentially more effective way to frame and discuss environmental issues, beyond the limited scope of human or environmental rights perspectives (as I describe in 4.6 Research Contributions to the Community). Moreover, this way of thinking forces us to (re)consider our position and relationship (as humans) vis-à-vis the environment, and prioritizes a more holistic way of thinking that places relationships within ecological systems at the forefront of environmental thinking, and therein, I would submit, lies its great value and potential to positively influence Western society. 


\section{Chapter 7: Conclusions and Lasting Thoughts}

\section{Introduction}

In this dissertation, I have presented my understanding of the Maya land ethos. I have explained that this land ethos compels each individual who subscribes to it to learn to be "part of the land." This is an iterative process that never quite reaches a final state. Learning to be part of the land is best understood as a lifelong journey guided by a responsibility-based mindset and way of understanding life. To reiterate, I see responsibility-based thinking as a personal responsibility to be aware of one's responsibilities to the land, and to all of the beings (human and other-than-human) that (co-)exist on it. This research highlights some important considerations of which postcolonial and Indigenous geographies scholars should be mindful in doing future research with Indigenous communities and their respective IK systems.

As I have demonstrated throughout this document, my work is firmly situated in the postcolonial, Indigenous geographies, and IK research literatures. In line with the main objective of these scholarly fields, one of my main goals was (and is) to try to give a voice to Indigenous peoples and to highlight the value of non-Western knowledges. In documenting and attempting to make sense of my research data, and my less formal interactions with community members, I learned about the responsibility-based approach of various Xuilub members in their effort to continuously strive to be part of the land. In addition to increasing our scholarly understanding of one present-day Indigenous culture's IKs, I believe that this research on the Maya land ethos offers all postcolonial 
researchers some simple but actionable strategies in terms of thinking more critically about how we can, just like the Maya of Xuilub, learn to be part of the land. It would benefit both Indigenous communities and the academy for researchers to become additional members in the webs of infinite relationships on the land where the research is being conducted. In the remainder of this chapter, I discuss some of these practical directions for scholars investigating Indigenous worldviews and outline what exactly adopting a responsibility-based (as opposed to rights-based) approach to Indigenous research means for postcolonial and Indigenous geographies scholars. Finally, I share some personal thoughts and perspectives on some possible future research avenues that I suggest should follow from this research project with the Yucatec Maya.

\subsection{Learning to be Part of the Land: Directions for Scholars Investigating Indigenous Environmental Thinking}

In Chapters 5 and 6, I presented evidence of the responsibility-based Maya land ethos in the statements and actions of Xuilub community members, and demonstrated how this ethos is currently understood by these individuals. Nevertheless, it is important for Indigenous geographies scholars to recognize that IKs have always been in a constant state of flux and change. The Maya environmental ethos of being part of the land is, thus, not fixed or static. As academics, it is important to be highly aware of and sensitive to this reality in order to allow our understanding of these IKs to, likewise, evolve, and not become fixed in time. Changing environmental, social and political factors or forces are constantly reshaping these IKs and land-based philosophies. In Xuilub, there are some key forces that are having an influence on the trajectory of the Maya land ethos and IKs. At the time of my field research, the main ones were: climate change and the exodus of 
youths from the community in search of postsecondary education and/or employment in the tourism sector. Although the Maya environmental ethos of being part of the land and land-use activities discussed in Chapter 5 are at present alive and well in Xuilub and, for that matter, the rest of the Yucatan, it should be noted and understood that the Maya sense of being part of the land and their cultural identity are not static and fixed in time. For any cultural group, cultural meanings and practices continue to change throughout the generations, as they have since the beginnings of Maya culture in the Yucatan. Some of these changes are due to changing environmental conditions while others are due to changing socioeconomic conditions. According to interviewees, these forces are the ones that are most likely to have an impact on the way in which they relate with the land in coming years, and changes in both physical and socioeconomic conditions have an effect on Maya land-use strategies. As Indigenous geographies scholars, we must consider such external and internal factors of change and their impacts on IKs in order to avoid essentializing or romanticizing these cultural knowledges, or judging how they are currently understood or practiced against their so-called "traditional" or "ideal" state. We must instead approach the study of these knowledges and philosophies as living bodies of knowledge that, like any living being, adapt to stimuli and changes through time.

As Indigenous geographies scholars and researchers who seek to work with Indigenous communities to better understand their IKs, we must be mindful of approaching the process of research and knowledge production in a way that is not clouded or influenced by Western discourses, knowledges, concepts, and terminologies (e.g. 'rights,' 'the state,' and 'neoliberalism,' etc.). Indigenist scholars ought to design their research projects according to initial research questions that are more 
epistemologically in line with Indigenous worldviews and concepts. This would possibly help researchers to avoid being influenced by Western ways of knowing when trying to understand and make sense of the information and data that is gained during field research in Indigenous communities like Xuilub. To this end, a practical first step is for us to learn to better recognize the distinctiveness of Indigenous conceptions, meanings, and senses of 'place.' As I have come to learn, the Maya sense of place is shaped by nonhierarchical relationships between all the different beings (both human and other-thanhuman) on the land. Their sense of place is not created solely by the human experience on the land. There is an active effort to understand what other creatures and beings are experiencing and feeling, as well as a recognition of their sentience, purpose, and autonomy outside of what they mean to human beings (as sources of food, medicine, or spiritual inspiration for instance). Other-than-human beings and their respective interests and ambitions are considered just as important to the creation of a collective sense of place as human beings and their values. Indigenous geographies researchers must therefore also learn to adopt or at least be respectful of Indigenous ways of seeing place and their sense of place. To me, recognizing and incorporating such Indigenous conceptualizations of place into academic research is the most effective first step in terms of Indigenizing our way of thinking. Learning to engage with these non-Western understandings and definitions of place as 'relationships between beings on the land,' will help us to avoid imposing (either consciously or unconsciously) non-Indigenous understandings of place and society as concepts that have to do only with the human experience. As I have learned in my research in Xuilub and demonstrated in this dissertation, the Maya, as an Indigenous people, share very different understandings of 
these concepts. To them, place, society are inseparable from the land. If one considers all beings including humans as being part of the land, how can definitions of place, society, and democracy exclude other-than-human beings when all beings are understood as being related and linked together by responsibility-based relationships embedded in the land? This is an example of how Indigenous ways of knowing and thinking about society and the position of human beings in relation to the land and other beings differ fundamentally from Western ways of knowing. Moreover, spirituality and emotional connections to the land and an understanding of having familial bonds with all beings have great influence in shaping the Maya (and other Indigenous groups') sense of place. Indigenous geographies scholars must continue to learn to engage with and appreciate these emotional connections between individuals and the land in Indigenous communities, and to attempt to develop some of our own. This, in my view, would go a long way in allowing us, as a collective, to meaningfully Indigenize our approach to research and the ways in which we process and find meaning in IK-related information and data.

\subsection{Rights- vs. Responsibility-Based Thinking: Implications for Indigenous Geographies Scholars}

Another important application of what I learned about the Maya land ethos in Xuilub relates to how these responsibility-based IKs differ from Western academic rights-based approaches to emancipating Indigenous groups from different forms of (neo)colonial economic and sociopolitical oppression. As I have argued in this dissertation, current Indigenous geographies disciplinary perspectives have to do with assisting Indigenous peoples in their struggle for rights and the exercise of those rights in practice. Much of the current research focuses on identifying the ways in which political 
states, multinational corporations, or other private interests continue to infringe upon the right of Indigenous peoples to autonomy and to protect their territories from reckless development. I want to reiterate that I believe this effort to be well intentioned and commendable, as it is hard to overstate the impact of repressive colonial governance practices on Indigenous cultures and societies. Indeed, I encourage scholars and activists whose mission is to contribute to redressing the injustice and discrimination to which Indigenous groups have been subjected over the centuries since first contact with Europeans in the Americas. However, as socially conscious scholars, we must be careful not to filter our understandings of Indigenous societies and their IKs through rights-based concepts and discourses.

If we as Indigenous geographies scholars initiate a shift from the current rightsbased to a more responsibility-based view of research and knowledge production, and think critically about the ways in which we, on an individual basis, can also learn to be part of the land, I believe we will be more credibly and effectively mobilizing Indigenous worldviews and knowledges. By doing so, we can learn to become more active and engaged actors in the process of renegotiating and broadening, little by little, our current anthropocentric conceptions of rights, society, and democracy — the pillars of modern Western societies around the world — which alienate the human being from her "familial" relations with all other beings and the land. In my estimation, such an Indigenization of scholarly thinking would reflect a more profound and long-lasting process of decolonization and "reconciliation," which have heretofore almost exclusively been framed and negotiated in terms of the Indigenous struggle for rights and in reference to other similar and historically non-Indigenous concepts and terminologies. As 
indispensable as the concept of Indigenous rights (and many socially conscious scholars' mission to assist Indigenous groups in having these rights recognized and respected) has become, I believe that we must also try to learn more about how Indigenous land-based philosophies and IKs, including the responsibility-based Maya ethos of being part of the land, can inspire and provide insights into how geographical scholarship can evolve in terms of our disciplinary way of knowing and thinking, benefitting us, as scholars, as much as the Indigenous groups that we are so passionate about helping. This process begins with opening a broader academic discussion about our own individual and collective (as a society) responsibilities to the land and all our relations on it. The fundamental question we should now ask ourselves, as researchers and citizens, is: how can I learn to be part of (or belong to) the land? And not, "how can the land belong to me?” Asking oneself this simple question can perhaps allow one to see and understand her position in relation to the land and her relationships under a more responsibility-based light, which I consider one of the greatest contributions of Indigenous thinking to the rest of humanity.

\subsection{Future Research Directions}

Since finishing my formal field research in Xuilub, I have often found myself contemplating about how to continue my learning journey. I am deeply committed to building on the philosophical and ethical principles of Indigenous environmental thinking that I have expounded in this dissertation. Through several periods of intense reflection over the last few months, I have identified two areas of future research that I believe to be particularly promising. I now offer some reflections about those two future research avenues. 


\subsubsection{Situating the Mayan Land Ethos within the Indigenous (Responsibility-Based) Legal Literature}

In recent years, there has been a growing body of literature related to investigating the concept of customary Indigenous legal orders. According to authors like Borrows (2002), these legal orders stand in contrast to current Eurocentric understandings of law, founded which are closely related to (in fact, founded on) the Western principles of rights as they are defined in Chapter 2. The scholarship concerning Indigenous legal orders is explicit in the view that Indigenous legal orders are based on duties, obligations and responsibilities to the land and all beings, including humans, animals, plants, future generations and the departed/ancestors (ibid.; 2010a; 2010b; 2016). In a similar vein, Craft (2014) writes about her Anishinaabe inaakonigewin, or spiritual laws centred on the values of responsiblity and accountability to the land, and how these differ, in theory and in practice, from Western law, which is based on "universal" principles, with little consideration for the local environmental context. Authors like Craft and Borrows have elucidated these Indigenous understandings about how their land-based responsibilities act as the foundation of how humans must operate according to the land on which they live and depend, and love as their Mother. Koschade and Peters (2012) offer some useful perspectives with their comparative study of Western and Algonquin understandings of law in the context of Canadian environmental protection. The authors call for a decolonization of dominant Canadian rights-based legal approaches to environmental issues and concerns, suggesting that indigenous land knowledges are valuable to mainstream society and, consequently, must be preserved. According to Koschade and Peters, the set of normative and regulatory principles that stems from 'Algonquin law' is 
fundamentally different from the one contained in its Canadian counterpart. Algonquin law reflects the Algonquin principle of responsibility toward the land and beings. On the other hand, Canadian law stems from the Eurocentric concept of democratic rights (and their protection). The authors' recognition of the Algonquin alternative to Eurocentric legal understandings and practices affords the geographic discipline valuable glimpses into Indigenous worldviews and their relevance to contemporary spatial organization and environmental protection cogitations. I consider that the scholarship on Indigenous legal orders has much significance in terms of providing a legal framework for Indigenous peoples to (re)assert their responsibility-based territorial governance strategies. If arguments for Indigenous territorial autonomy are based on investigations of customary Indigenous legal systems and approaches, then Indigenous groups may eventually be able to circumvent Western legal mechanisms. In this scenario, these groups would thus be able to exercise their responsibilities to and relationships with their territories (including land and water bodies). Such a radical shift would create avenues for these groups to (re)develop and rely on their own (responsibility-based) laws and legal orders.

As these questions were not in the purview of my doctoral studies and research project, unfortunately at this stage I have little valuable ideas to share with regard to Maya understandings of customary law. What is clear, and that the reader may note, with the above discussion in mind, is that many Maya in Xuilub have articulated ideas that hint at evidence of a Mayan responsibility-based legal order in Xuilub and the Yucatan. Many of their statements included in this dissertation speak to a concept of a "legal" obligation to carry out their responsibilities to the land and all its human and other-thanhuman peoples. In my future research with the Maya (and other Indigenous groups), I am 
therefore keen to draw on the Indigenous legal orders scholarship and study the Maya concept of law, and the ways in which it may be different and/or similar to mainstream legal approaches in Yucatan and Mexico. I believe that such an exercise would yield very valuable information and would allow groups like the Maya to develop their own legal strategies to reassert their customary governance philosophies and practices across the Maya homeland of the Yucatan — and not just in their ejidos. In this way, the investigation Maya legal orders can allow the non-Maya society, and especially government officials and policymakers, to finally begin to understand the value in IKs

and their relevance in terms of land-use planning in an era when ethical extensionism and the rights of nature are beginning to become entrenched in the constitutions and institutions of certain countries in Latin America (e.g. Bolivia and Ecuador) and the rest of the world (e.g. New Zealand).

\subsubsection{The Need for (Further) Comparative Studies on Different Indigenous IKs}

One of the broader contributions of this research project was to build on the theoretical framework that considers the key ways in which IKs can inform the creation of more holistic and integrated environmental governance approaches and strategies. This is increasingly seen as an emerging disciplinary frontier in environmental managementthe next step in decolonizing our ways of relating with space (Coombes et al., 2012). Indeed, a growing contingent of Indigenous and non-Indigenous geographers agree that deconstructions and critiques of colonialism, which have afforded us innumerable insights and useful perspectives on colonial legacies and trajectories, cannot stand alone. These now need to be complemented by reflections that seek to rebuild rather than deconstruct, and which aspire to (re)learn Indigenous knowledges for their own sake and 
value, rather than in relation to dominant Eurocentric discourses and representations

(Deloria, 1992; Sioui, 1992; Tuhiwai Smith, 1999; McGregor, 2004). This approach is

gaining momentum through its increasing number of adherents, both Indigenous and non-

Indigenous. A thorough knowledge exchange between geographers and environmental

thinkers and planners, regardless of their cultural background, is now required, as well as

to empower Indigenous peoples to speak about their philosophies, cultures and

relationships with the natural environment—-for themselves.

One useful and practical way of answering this call is through the establishment of a new

geographical sub-discipline informed by Sioui's (1992) concept of 'Americity':

"Americity" implies fostering in our students and in the academe, as well as in our globalized society, an ability to see the American continent through the Indigenous American cosmologies. Like the other continents, America has ways of being and seeing that make it ideologically unique [...] I and many others also believe and have said and written that because of its isolated geographical situation until relatively very recently, it can be affirmed that the American continent, with the possible addition of Australia, possesses a worldview surpassing in originality that of all other continents. As to the practical and ideological value represented by this properly American philosophical system for the rest of the human community, I am suggesting that ample proof of such value is found in the fact of the irresistible appeal, indeed, the fascination that the American continent has had for countless individuals of all regions of the world, since 1492. [...] From this viewpoint, Americanism appears as the ideology that has, until now, usurped the true spiritual visage of America, which I am suggesting we name "Americity". Americity, then, implies the character of a spirituality and thus, of a social ethics that are America's own. It is the consciousness of a power, as well as of a duty belonging to this continent, to define and to offer to the rest of the human and cosmic family a vision of life and of the universe that can help transform our human world into a truly unified, universalized society. Essentially, Americity signifies the formulation, for the benefit of all beings of all orders, of the reasons why and especially, of the ways how to adopt the circular and matricentric worldview so markedly characteristic of America [...] This worldview has enabled America to be a haven of tolerance and hope for very many human beings (Sioui 2016, p. 226-227).

Given my personal interest in Indigenous environmental ethics and IKs in the Americas, I propose that one possibly useful and practical way of answering this call is 
through the establishment of a school (or perhaps first an academic journal) of Indigenous environmental thought. This school would call on scholars from around the world, Indigenous and non-Indigenous alike, to explore and investigate the importance and relevance of American continental Indigenous land-based knowledges, and the ways in which they can potentially influence global philosophy, politics and environmental governance. Historically represented as the New World in the colonial discourse of "discovery" (see Davidson, 1997), to me the significance of Indigenous cultures of the Americas, and of their land-based knowledges, lies in their original "disconnectedness" from the rest of the world (Sioui, 2008). The school of environmental Americity would allow for a much wider exchange of land-based ideas, knowledges, and experiences between Indigenous groups across the Americas. I have found that there has thus far been too little collaboration and knowledge exchanges between Indigenous groups in the American continent, who often cannot communicate due to linguistic differences (i.e. English in most of Canada, the United States, and many regions in the Carribbean, French in Quebec, Spanish in much of Latin America, and Portuguese in Brazil). This international effort would work toward connecting these disparate groups to one another, as well as a network of engaged academics, for the purpose of empowering Indigenous peoples across the American continent to reassert their customary relationships, roles, and responsibilities on their traditional lands. The outcomes of this research will also be useful to the non-Indigenous (academic) collective. The other part of the rationale for this field of study is to draw inspiration from Indigenous land-based epistemologies and knowledges in providing usable models for policymakers to develop more sustainable and effective environmental policies, as well as identifying key principles of IKs that are 
reconcilable with mainstream environmental management objectives. I have crafted my course GG300 - Indigenous Environmental Knowledges of the Americas (at Wilfrid Laurier University) to be the first practical exercise in investigating land-based Americity. To show the reader how my course relates to this long-term project, I share with you the instructions for the final term project, taken from the syllabus: .

Each student must submit a research paper investigating the ways in which the land-based (or environmental) philosophy of a certain Indigenous group (anywhere in the Americas) is translated into concrete and observable land-use practices. This assignment will reflect one of the overarching goals of this course: to increase our understanding of the body of Indigenous land-use knowledges across the Americas. The purpose of this exercise is to gain insights into the ways in which different and vast Indigenous cosmologies and environmental philosophies are put into practice in land-use and management practices, and can provide valuable perspectives for mainstream environmental management policy and practice.

I am greatly thankful for the opportunity to share my passion and life purpose with my (Indigenous and non-Indigenous) students, and so far it has been tremendously encouraging to me to observe, through their assignments and comments, that many of them share a sincere belief that Indigenous cultures have much to teach the world.

I wholeheartedly believe that the lessons learned from future investigations on Indigenous environmental thinking will be relevant to a variety of different actors. Not only will this effort help Indigenous groups in across the Americas that are struggling for cultural survival in the face of development on their traditional lands, but it will also allow policymakers and planners, in both the Indigenous and non-Indigenous contexts, to deal with increasingly complex environmental management issues. By helping Indigenous groups to build wider and more far-reaching knowledge-exchange and collaboration networks, my hope is to empower Indigenous peoples to then independently mobilize themselves and develop their own land-use and management policies more 
reflective of their culturally distinct knowledges - for the benefit of humanity and our collective Great Circle of Peoples around the world. 


\section{Bibliography}

Acosta, A. (2013). El Buen Vivir: Sumak kawsay, una portunidad para imaginar otros mundos. Barcelona: Icaria.

Adelson, N. (2005). The embodiment of inequity: Health disparities in Aboriginal Canada. Canadian Journal of Public Health/Revue Canadienne de Sante'e Publique, 96(2), pp. S45-S61.

Alfred, T. (2009). Peace, Power, Righteousness: An Indigenous Manifesto (Second Edition). Toronto: Oxford University Press.

Alfred, T., \& Corntassel, J. (2005). Being Indigenous: Resurgences against contemporary colonialism. Government and Opposition, 40(4), pp. 597-614.

Anaya, S. J. (2004). Indigenous Peoples in International Law. New York : Oxford University Press.

Anderson, E. N. (2005). Political ecology in a Yucatec Maya community. Tucson: University of Arizona Press.

Anderson, E. N., Medina Tzuc, F. (2005). Animals and the Maya in Southeast Mexico. Tucson: University of Arizona Press.

Ankli, A., Sticher, O., \& Heinrich, M. (1999). Yucatec Maya medicinal plants versus nonmedicinal plants: indigenous characterization and selection. Human Ecology, 27(4), pp. 557-580.

Antochiw, W. (1999). Mitos y leyendas de los cenotes de Yucatan. In Gobierno del estado de Yucatan (Ed.), Cenotes y Grutas de Yucatan (pp. 16-29).

Armitage, D., Berkes, F., Dale, A., Kocho-Schellenberg, E., \& Patton, E. (2011). Comanagement and the co-production of knowledge: Learning to adapt in Canada's Arctic. Global Environmental Change, 21(3), pp. 995-1004.

Armstrong-Fumero, F. (2009). Old jokes and new multiculturalisms: Continuity and change in vernacular discourse on the Yucatec Maya language. American Anthropologist, 111(3), pp. 360-372.

Ashcroft, B., Griffiths, G., \& Tiffin, H. (2000). Post-colonial studies: The key concepts. Routledge. 
Aswani, S., Lauer, M. (2006). Incorporating fishermen's local knowledge and behaviour into geographical information systems (GIS) for designing marine protected areas in Oceania. Human Organization, 65(1), pp. 81-102.

Atkinson, P., \& Hammersley, M. (1994). Ethnography and participant observation. In N. Back, W. (1995). Water management by early people in the Yucatan, Mexico.

Environmental Geology, 25(4), pp. 239-242.

Balam, P., \& Quintal Avilés, E. F. (2016). Con poder para tratar con los vientos : jmeeno'ob, aluxo'ob y waayo'obCON: jMEEno'ob, aluxo'ob y waayo'ob entre los Mayas de la Peninsula. Retrieved from Universidad Nacional Autónoma de Mexico http://www.historicas.unam.mx/publicaciones/publicadigital/libros/poder/008_balam.pdf

Barker, A. J., \& Pickerill, J. (2012). Radicalizing relationships to and through shared geographies: Why anarchists need to understand indigenous connections to land and place. Antipode, 44(5), pp. 1705-1725.

Barnett, C. (1997). "Sing along with the common people": politics, postcolonialism and other figures. Environment and Planning D: Society and Space, 15(2), pp. 137-154.

-(2006). Postcolonialism: space, textuality, and power. In S. Aitken \& G. Valentine (Eds.), Approaches to Human Geography (pp. 147-159). London : Sage.

Barrera-Bassols, N., Toledo, V. M. (2005). Ethnoecology of the Yucatec Maya:symbolism, knowledge and management of natural resources. Journal of Latin American Geography 4(1),

Bartlett, C., Marshall, M., \& Marshall, A. (2012). Two-eyed seeing and other lessons learned within a co-learning journey of bringing together Indigenous and mainstream knowledges and ways of knowing. Journal of Environmental Studies and Sciences, 2(4), pp. 331-340.

Barrow, I. J. (2004). Making History, Drawing Territory: British Mapping in India, c. 1756-1905. New Delhi: Oxford University Press.

Battiste, M. A. (2000). Reclaiming Indigenous Voice and Vision. Vancouver: UBC Press.

Bebbington, A. (2009). The new extraction: rewriting the political ecology of the Andes. NACLA Report on the Americas, 42(5), pp. 12-20.

Benedict, F. G., \& Steggerda, M. (1936). The Food of the Present-Day Maya Indians of Yucatan.

Benitez, F. (1985). Lazaro Cardenas y la Revolucion Mexicana, III: El Cardenismo. Mexico: Fondo de Cultura Economica. 
Berkes, F. (2008). Sacred Ecology. New York: Taylor and Francis.

Berkes, F., Colding, J., \& Folke, C. (2000). Rediscovery of traditional ecological knowledge as adaptive management. Ecological Applications, 10(5), pp. 1251-1262.

Bhabha, H. (1994). The Location of Culture. London: Routledge.

Blunt, A., \& McEwan, C. (Eds.). (2003). Postcolonial Geographies. London: Continuum International Publishing Group.

Boccara, M. (2017). Tradition, improvisation and modernity in Yucatecan Mayan shamanism: The suhuy art of Juan Cob, h-men of Yaxcabá. Salud colectiva, 13(3), pp. 429-442.

Boehmer, E. (2005). Empire, the National, and the Postcolonial, 1890-1920: Resistance in Interaction. Oxford : Oxford University Press.

Borrows, J. (2002). Recovering Canada: The Resurgence of Indigenous Law. Toronto : University of Toronto Press.

— (2010a). Canada's Indigenous Constitution. Toronto : University of Toronto Press.

—(2010b). Drawing out Law: A Spirit's Guide. University of Toronto Press.

-(2016). Freedom and Indigenous Constitutionalism. University of Toronto Press.

Brainerd, G. W. (1956). Changing living patterns of the Yucatan Maya. American Antiquity, 22(2Part1), pp. 162-164.

Briggs, J. (2005). The use of indigenous knowledge in development: Problems and challenges. Progress in Development Studies, 5(2), pp. 99-114.

Brody, H. (1983). Maps and Dreams. Markham: Penguin Books.

Brown, D. F. (1999). Mayas and tourists in the Maya world. Human Organization, 58(3), pp. 295-304.

- (2007). The spatial and temporal dimensions of rural landscape: the Yucatec Maya k'ax. The Canadian Geographer, 51(1), pp. 91-109.

- (2013). Tourists as colonizers in Quintana Roo, Mexico. The Canadian Geographer/Le Géographe canadien, 57(2), 186-205. 
Budhwa, R., \& McCreary, T. (2013). Reconciling Cultural Resource Management with Indigenous Geographies: The Importance of Connecting Research with People and Place. In J. T. Johnson \& S. C. Larsen (Eds.) A Deeper Sense of Place: Stories and Journeys of Indigenous--Academic Collaboration (pp. 195-214). Corvallis : Oregon State University Press.

Cafaro, P. (2001). Thoreau, Leopold, and Carson: Toward an environmental virtue ethics. Environmental Ethics, 23(1), 3-17.

Cajete, G. (2000). Native Science: Natural Laws of Interdependence. Sana Fe: Clear Light Books.

Cameron, E., de Leeuw, S., Greenwood, M. (2009). Indigeneity. In R. Kitchin \& N. Thrift (Eds.), International Encyclopedia of Human Geography (pp. 352-357). London: Elsevier.

Campbell, C. J. (2016). Space, Place and Scale: Human Geography and Spatial History. Past and Present, 239(1), pp. 23-45.

Carey, D. (2001). Our elders teach us: Maya-Kaqchikel historical perspectives. University of Alabama Press.

"Case of Indigenous Communities Affected by the Release on the Environment of Genetically Modified Soybeans." Comparative and International Standards on the Right to Free, Prior and Informed Consent English Summary. Supreme Court of Justice of Mexico Supreme Chamber (30 September, 2015 ), https://cdp-hrc.uottawa.ca/sites/cdphrc.uottawa.ca/files/amicus_sept302015_geneticallymodifiedsoybeans_englishsummary. pdf

Castellanos, M. B. (2004). Ethics of Aboriginal research. International Journal of Indigenous Health, (1)1, pp. 98-114.

-(2010). A Return to Servitude: Maya Migration and the Tourist Trade in

Castree, N. (2004). Differential geographies: place, indigenous rights and 'local'resources. Political Geography, 23(2), pp. 133-167.

Chakrabarty, D. (1992). Postcoloniality and the Artifice of History: Who Speaks for "Indian" Pasts?. Representations, (37), pp. 1-26.

-(2000). Provincializing Europe: Postcolonial Thought and Historical Difference. Princeton: Princeton University Press.

Chan, K. (2011). Ethical extensionism under uncertainty of sentience: duties to nonhuman organisms without drawing a line. Environmental Values, 20(3), pp. 323-346. 
Childs, P., \& Williams, P. (1997). Introduction to Post-Colonial Theory. New York: Prentice Hall.

Chilisa, B. (2011). Indigenous Research Methodologies. Thousand Oaks : Sage Publications.

Clayton, D. (2003). Critical Imperial and Colonial Geographies. In K. Anderson, M.

Domosh, N. Thrift \& S. Pile (Eds.), The Handbook of Cultural Geography (pp. 354-368).

Clenninden, I. (1993). Maya and Spaniard in Yucatan, 1614-1812. Stanford: Stanford University Press.

Comeliau, C. (2000). The limitless growth assumption. International Social Science Journal, 52(166), pp. 457-465.

Cook, G., \& Offit, T. (2009). Pluralism and transculturation in indigenous maya religion. Ethnology: An International Journal of Cultural and Social Anthropology, 47(1), pp. 45-59.

Coombes, B., Johnson, J. T., \& Howitt, R. (2012). Indigenous geographies I: Mere resource conflicts? The complexities in Indigenous land and environmental claims. Progress in Human Geography, 36(6), pp. 810-821.

- (2012b). Indigenous geographies II: The aspirational spaces in postcolonial politicsreconciliation, belonging and social provision. Progress in Human Geography, 37(5), pp. 691-700

Coulthard, G. (2010). Place Against Empire: Understanding Indigenous AntiColonialism. Affinities: A Journal of Radical Theory, Culture, and Action, 4(2), pp. 7983.

Craft, A. (2014). Living treaties, breathing research. Canadian Journal of Women and the Law, 26(1), pp. 1-22.

Cresswell, T. (2009). Place. In N. Thrift \& R. Kitchen (Eds.) International Encyclopedia of Human Geography, Vol. 8 (pp. 169-177). Oxford : Elsevier.

-(2014). Place: an introduction. John Wiley \& Sons.

Curry, S. (2004). Indigenous Sovereignty and the Democratic Project. Farnham: Ashgate.

Curtis, J. H., Hodell, D. A., \& Brenner, M. (1996). Climate variability on the Yucatan Peninsula (Mexico) during the past 3500 years, and implications for Maya cultural evolution. Quaternary Research, 46(1), pp. 37-47. 
Dahlin, B. H. (1990). Climate and prehistory on the Yucatan peninsula. Climatic change, 5(3), pp. 245-263.

Davidson-Hunt, I., \& Berkes, F. (2003). Learning as your journey: Anishnaabe perception of social-ecological environments and adaptive learning. Conservation Ecology, 8(1), pp. 5-26.

de Frece, A., \& Pool, N. (2008). Constructing livelihoods in rural Mexico: milpa in Mayan culture. The Journal of Peasant Studies, 35(2), pp. 335-352.

de La Cadena, M., \& Starn, O. (Eds.). (2007). Indigenous Experience Today. New York: Berg.

de la Cerda, H. E. C., \& Mukul, R. R. G. (2008). Homegarden production and productivity in a Mayan community of Yucatan. Human Ecology, 36(3), pp. 423-433.

de la Peña. (2006). A new Mexican nationalism? Indigenous rights, constitutional reform and the conflicting meanings of multiculturalism. Nations and Nationalism, 12(2), pp. 279-302.

Deloria, V., Jr. (1992). God is Red: A Native View of Religion. Golden: North American Press.

Denzin, K., \& Lincoln, Y.S. (Eds.) (1994). Handbook of Qualitative Research. London: Sage.

Desbiens, C. (2004). Producing North and South: a political geography of hydro development in Québec. Canadian Geographer/Le Géographe canadien, 48(2), pp. 101118.

Des Jardins, J. R. (2006). Environmental ethics: An Introduction to Environmental Philosophy (4th edition). Belmont: Wadsworth Publishing Company.

Diemont, S. A., Bohn, J. L., Rayome, D. D, Kelsen, S. J. \& Cheng, K. (2011).

Comparisons of Maya forest management, restoration, and conservation. Forest Ecology and Management, 261(10), pp. 1696-1705.

Donald, D. (2012). Indigenous Métissage: A decolonizing research sensibility. International Journal of Qualitative Studies in Education, 25(5), pp. 533-555.

Dumond, D. E. (1985). The talking crosses of Yucatan: A new look at their history. Ethnohistory, 32(4), pp. 291-308. 
Duncan, (2009). “Representation.” In Kitchin, R. \& Thrift, N. (Eds.), International Encyclopedia of Human Geography.

Early, J. D. (2006). The Maya and Catholicism: An Encounter of Worldviews. Gainesville University Press of Florida.

Echazarreta, C. M., Quezada-Euán, J. J., Medina, L. M., \& Pasteur, K. L. (1997). Beekeeping in the Yucatan peninsula: development and current status. Bee World, 78(3), 115-127.

Emery, K., Brown, L. (2012). Maya Hunting Sustainability: Perspectives from Past and Present. In R. Chacon \& G. Mendoza (Eds.), The Ethics of Anthropology and Amerindian Research (pp. 79-111). New York: Springer.

Escobar, A. (1995). Encountering Development: The Making and Unmaking of the Third World. Princeton: Princeton University Press.

Estévez, M. G. (2002). Cosmovisión dualista de los mayas yucatecos actuales. In (M. de la Garza Camino \& M. I. Najera Coronado (Eds.), Religión Maya (pp. 365-386). Madrid : Editorial Trotta.

Etherington, N. (Ed.). (2007). Mapping Colonial Conquest: Australia and Southern Africa. Crawley: UWA Publishing.

Etikan, I., Musa, S. A., \& Alkassim, R. S. (2016). Comparison of convenience sampling and purposive sampling. American Journal of Theoretical and Applied Statistics, 5(1), pp. 1-4.

Evia Cervantes, C. (2002). "Baño de cenote". Unicornio, Suplemento Cultural del periódico Por Esto! Domingo 2 de Junio, 3-9, Mérida, Yucatán.

Evia, C. (2006). Seleccion de Mitos. Merida : Ediciones de la Universidad Autonoma de Yucatan.

Farriss, N. M. (1984). Maya Society Under Colonial Rule: The Collective Enterprise of Survival. Princeton: Princeton University Press.

Faust, B. B., Anderson, E. N., \& Frazier, J. G. (Eds.). (2004). Rights, Resource, Culture, and Conservation in the Land of the Maya. Westport: Praeger Publishers.

Faust, B., \& Bilsborrow, R. (2000). Maya culture, population, and the environment on the Yucatan Peninsula (Research Report). International Institute for Applied Systems Analysis (14), pp. 73-107. 
Frantz, K., \& Howitt, R. (2012). Geography for and with indigenous peoples: indigenous geographies as challenge and invitation. GeoJournal, 77, pp. 727-731.

Fulmer, A. M., Godoy, A. S., \& Neff, P. (2008). Indigenous rights, resistance, and the law: Lessons from a Guatemalan mine. Latin American Politics and Society, 50(4), pp. 91-121.

Gabbert, W. (2000). Violence and ethnicity in the Caste War of Yucatán. In Prepared for delivery at the 2000 meeting of the Latin.

-(2004). Becoming Maya: Ethnicity and Social Inequality in Yucatán Since 1500. Tucson: University of Arizona Press.

Gadgil, M., Berkes, F., \& Folke, C. (1993). Indigenous knowledge for biodiversity conservation. Ambio, 22(2/3), pp. 151-156.

García-Frapolli, E., Ayala-Orozco, B., Bonilla-Moheno, M., Espadas-Manrique, C., \& Ramos-Fernández, G. (2007). Biodiversity conservation, traditional agriculture and ecotourism: Land cover/land use change projections for a natural protected area in the northeastern Yucatan Peninsula, Mexico. Landscape and Urban Planning, 83(2-3), pp. 137-153.

Gibson, B. (2006). Decolonizing the production of geographical knowledges? Reflections on research with indigenous musicians. Geografiska Annaler B, 88(3), pp. 277-284.

Gómez González, I. (2016). A Honey-Sealed Alliance: Mayan Beekeepers in the Yucatan Peninsula versus Transgenic Soybeans in Mexico's Last Tropical Forest. Journal of Agrarian Change, 16(4), pp. 728-736.

Gomez Hernández, A. (2005). La asamblea ejidal: diferenciación social y estrategias de poder en una localidad tojolabal (Master's thesis). México: Centro de Estudios Superiores de México y Centroamérica, Universidad de Ciencias y Artes de Chiapas.

Gomez-Pompa, A., Allen, M. F., Fedick, S. L., \& Jimenez-Osornio, J. J. (2003). The Lowland Maya area: Three Millennia at the Human-Wildland Interface. London: Routledge.

González, M. (2015). Indigenous territorial autonomy in Latin America: An overview. Latin American and Caribbean Ethnic Studies, 10(1), pp. 10-36.

González-Iturbe, J. A., Olmsted, I., \& Tun-Dzul, F. (2002). Tropical dry forest recovery after long term Henequen (sisal, Agave fourcroydes Lem.) plantation in northern Yucatan, Mexico. Forest Ecology and Management, 167(1-3), pp. 67-82. 
Gregory, D. (1998). Power, Knowledge and Geography: The Hettner Lecture in Human Geography. Geographische Zeitschrift, 86(2), pp. 70-93.

Grosfoguel, R. (2002). Colonial difference, geopolitics of knowledge, and global coloniality in the modern/colonial capitalist world system. Utopian Thinking, 25(3), pp. 203-224.

Guimond, E., Kerr, D., \& Beaujot, R. (2004). Charting the growth of Canada's Aboriginal populations: problems, options and implications. Canadian Studies in Population, 31(1), pp. 55-82.

Haraway, D. (1991). Simians, Cyborgs, and Women: The Reinvention of Nature. New York: Routledge.

Harris, C. (2004). How Did Colonialism Dispossess? Comments from an Edge of Empire. Annals of the Association of American Geographers, 94, pp. 165-182.

Harris, M. (2001). The rise of anthropological theory: A history of theories of culture. Lanham : Alta Mira Press.

Herman, R. D. K. (2008). Reflections on the importance of indigenous geography. American Indian Culture and Research Journal, 32(3), pp. 73-88.

Howard Jackson, R. (1999). Race, Caste and Status: Indians in Colonial Spanish America. Albuquerque: University of New Mexico Press.

Howitt, R., \& Jackson, S. (1998). Some things do change: Indigenous rights, geographers and geography in Australia. The Australian Geographer, 29(2), pp. 155-173.

Howitt, R., Muller, S., \& Suchet-Pearson, S. (2009). Indigenous geographies. In N. Thrift, \& R. Kitchin (Eds.), International Encyclopedia of Human Geography (pp. 358364). Amsterdam: Elsevier.

Hunt, L. (1996). The French Revolution and Human Rights: A Brief Documentary History. Boston/New York: Bedford Books of St. Martin's Press.

Huntington, H. P. (1998). Observations on the utility of the semi-directive interview fordocumenting traditional ecological knowledge. Arctic, 51(3), pp. 237-242.

Hutchison, A. (2014). The Whanganui river as a legal person. Alternative Law Journal, 39(3), pp. 179-182.

INEGI Mexico. (2010). La Poblacion Hablante de Lengua Indigena en Yucatan. Aguascalientes : Instituto Nacional de Estadistica, Geografia e Informatica. Interciencia, 33(5), pp. 345-352. 
Jackson, R. H. (1999). Race, Saste, and Status: Indians in Colonial Spanish America. Albuquerque : University of New Mexico Press.

Jimenez Castillo, M. (1990). El aprendizaje de la historia oral por las nuevas generaciones en la zona oriental maya de Yucatan. Estudios Sobre las Culturas Contemporaneas - Universidad de Colima, 3(009), pp. 115-126.

Johannes, R. E. (1989). Traditional Ecological Knowledge: A Collection of Essays. Cambridge: IUCN.

Johnson, J. T., Cant, G., Howitt, R., \& Peters, E. (2007). Creating anti-colonial geographies: Embracing Indigenous peoples' knowledges and rights. Geographical Research, 45(2), pp. 117-120.

Jorgensen, D. L. (1989). Participant Observation : A methodology for Human Studies.Thousand Oaks: Sage.

Juarez, A. M. (2002). Ecological degradation, global tourism, and inequality: Maya interpretations of the changing environment in Quintana Roo, Mexico. Human Organization, 61(2), pp. 113-124.

Kafle, N. P. (2011). Hermeneutic phenomenological research method simplified. Bodhi: An interdisciplinary journal, 5(1), pp. 181-200.

Keal, P. (2003). European conquest and the rights of indigenous peoples: The Moral Backwardness of International Society. Cambridge : Cambridge University Press.

Kicza, J. E., \& Horn, R. (2016). Resilient Cultures: America's Native Peoples Confront European Colonialization 1500-1800. London : Routledge.

Kirk, C. R. (1982). Haciendas en Yucatan. Mexico: Instituto Nacional Indigenista.

Koschade, B., \& Peters, E. (2006). Algonquin notions of jurisdiction: inserting indigenous voices into legal spaces. Geografiska Annaler: Series B, Human Geography, 88(3), pp. 299-310.

Kovach, M. (2010). Indigenous methodologies: Characteristics, Conversations, and Contexts. Toronto : University of Toronto Press.

- (2015). Emerging from the Margins: Indigenous Methodologies. In S. Strega \& L. Brown (Eds.) Research as Resistance: Revisiting Critical, Indigenous, and AntiOppressive Approaches (pp. 43-64). Toronto: Canadian Scholars' Press. 
Kulchyski, P., McCaskill, D., \& Newhouse, D. (1999). In the words of Elders. Toronto : University of Toronto Press.

Kunow, M. A. (2003). Maya Medicine: Traditional Healing in Yucatan. Albuquerque : University of New Mexico Press.

Kuokkanen, R. (2011). Reshaping the University: Responsibility, Indigenous Epistemes, and the Logic of the Gift. Vancouver : UBC Press.

-(2012). Self-determination and indigenous women's rights at the intersection of international human rights. Human Rights Quarterly, 34, pp. 225-250.

LaDuke, W. (1999). All Our Relations: Natural Struggles for Land and Life. Cambridge: South End Books.

Lambert, L. (2014). Research for Indigenous Survival: Indigenous Research Methodologies in the Behavioral Sciences. Lincoln : University of Nebraska Press.

LaRochelle, S., \& Berkes, F. (2003). Traditional ecological knowledge and practice for edible wild plants: Biodiversity use by the Rarámuri, in the Sirerra Tarahumara, Mexico. The International Journal of Sustainable Development \& World Ecology, 10(4), pp. 361-375.

Larsen, S. C. (2006). The future's past: politics of time and territory among Dakelh first nations in British Columbia. Geografiska Annaler: Series B, Human Geography, 88(3), pp. 311-321.

Larsen, S. C., \& Johnson, J. T. (2012). In between worlds: place, experience, and research in Indigenous geography. Journal of Cultural Geography, 29(1), pp. 1-13.

Larsen, S. C., \& Johnson, J. T. (2017). Being Together in Place: Indigenous Coexistence in a More Than Human World. Minneapolis : University of Minnesota Press.

Leatherman, T. L., \& Goodman, A. (2005). Coca-colonization of diets in the Yucatan. Social Science \& Medicine, 61(4), pp. 833-846.

Legg, S. 2007. Beyond the European province: Foucault and postcolonialism. In Crampton and Elden (Eds.), Space, Knowledge, and Power (pp. 265-289). Farnham: Ashgate.

Léon, P., \& Montiel, S. (2008). Wild meat use and traditional hunting practices in a rural Mayan community of the Yucatan Peninsula, Mexico. Human Ecology, 36(2), pp. 249257. 
Li, T. M., 2010. Indigeneity, Capitalism, and the Management of Disposession. Current Anthropology, 51(3), pp. 385-414.

Lindlof, T. R., \& Taylor, B. C. (2002). Qualitative Communication Research Methods $\left(2^{\text {nd }}\right.$ Edition). Thousand Oaks: Sage Publications.

Louis, R. P. (2007). Can you hear us now? Voices from the margin: using indigenous methodologies in geographic research. Geographical Research, 45(2), pp. 130-139.

Louise Barriball, K., \& While, A. (1994). Collecting Data using a semi-structured interview: a discussion paper. Journal of Advanced Nursing, 19(2), pp. 328-335.

Low, S. M., \& Lawrence-Zúñiga, D. (2003). Anthropology of Space and Place: Locating Culture. Malden: Blackwell.

MacSwiney, M. C., Vilchis, P., Clarke, F. M., \& Racey, P. A. (2007). The importance of cenotes in conserving bat assemblages in the Yucatan, Mexico. Biological

Conservation, 136(4), pp. 499-509.

Mander, J., Tauli-Corpuz, V. (2006). Paradigm Wars: Indigenous Peoples' Resistance to Globalization. San Francisco: Sierra Club Books.

Martínez Coria, R., \& Haro Encinas, J. A. (2015). Derechos territoriales y pueblos indígenas en México: una lucha por la soberanía y la nación. Revista Pueblos y Fronteras Digital, 10(19), pp. 228-256.

Markiewicz, D. (1993). The Mexican Revolution and the limits of agrarian reform, 19151946. Boulder: Lynne Rienner Publishers.

Martello, M. L. (2008). Arctic indigenous peoples as representations and representatives of climate change. Social Studies of Science, 38(3), pp. 351-376.

Martinez-Balleste, A., Martorell, C., \& Caballero, J. (2008). The effect of maya traditional harvesting on the leaf production, and demographic parameters of sabal palm in the Yucatan Peninsula, Mexico. Forest Ecology and Management, 256(6), pp. 13201324.

Mason, R. J. (2000). Archaeology and Native North American oral traditions. American Antiquity, 65(2), pp. 239-266.

Massey, D. B. (1994). Space, place, and gender. Minneapolis: University of Minnesota Press. -(2005). For Space. London: Sage. 
Mazzocchi, F. (2006). Western science and traditional knowledge: Despite their variations, different forms of knowledge can learn from each other. EMBO Reports, 7(5), 463-466.

McClintock, (1995). Imperial Leather: Race, Gender, and Sexuality in the Colonial Contest. London: Routldedge.

McEwan, C. (2003). Material geographies and postcolonialism. Singapore Journal of Tropical Geography, 24(3), pp. 340-355.

-(2008). Postcolonialism and Development. London: Routledge

- (2009). Postcolonialism/Postcolonial geographies. In R. Kitchin \& N. Thrift (Eds.), International Encyclopedia of Human Geography (pp. 327-333). London: Elsevier.

McGregor, D. (2004). Coming full circle: Indigenous knowledge, environment, and our future. The American Indian Quarterly, 28(3-4), pp. 385-410.

- (2013). Indigenous Women, Water Justice and Zaagidowin (Love). Canadian Woman Studies, 30(2/3), pp. 71.

McGregor, D., Bayha, W., \& Simmons, D. (2010). Our responsibility to keep the land alive": voices of northern Indigenous researchers. Pimatisiwin: A Journal of Aboriginal and Indigenous Community Health, 8(1), pp. 101-123.

McSwiney, G. M. C., Vilchis, L. P., Clarke, F. M., \& Racey, P. A. (2007). The importance of cenotes in conserving bat assemblages in Yucatan, Mexico. Biological Conservation, 136(4), pp. 499-509.

Medin, T. (1997). Ideología y praxis política de Lázaro Cárdenas. México: Siglo XXI

Medina Chemor, A. (Ed.). (2008). Cenotes: Imprints of Water and Light in the Jungle. Cancun: Pixel Press.

Menzies, C. R. (2001). Reflections on research with, for, and among Aboriginal people. Canadian Journal of Native Education, 25(1), pp. 19-36.

Mexico. (1961). Constitution of the United Mexican States, 1917 (as amended). Washington: Pan American Union.

Meyers, A. D., \& Carlson, D. L. (2002). Peonage, power relations, and the built environment at Hacienda Tabi, Yucatan, Mexico. International Journal of Historical Archaeology, 6(4), pp. 225-252. 
Moore-Gilbert, B., Stanton, G., Malley, W. (Eds.). (1997). Postcolonial Criticism. London: Longman.

Moreton-Robinson, A. (2004). Whitening Race : Essays in Social and Cultural Criticism. Canberra : Aboriginal Studies Press.

Morgensen, S. L. (2011). The biopolitics of settler colonialism: right here, right now. Settler Colonial Studies, 1(1), pp. 52-76.

Muir, C., Rose, D., \& Sullivan, P. (2010). From the other side of the knowledge frontier: Indigenous knowledge, social-ecological relationships and new perspectives. The Rangeland Journal, 32(3), pp. 259-265.

Munro, P. G., \& Melo Zurita, M. D. L. (2011). The Role of Cenotes in the Social History of Mexico's Yucatan Peninsula. Environment and History, 17(4), pp. 583-612.

Negra, C., \& Manning, R. E. (1997). Incorporating environmental behavior, ethics, and values into nonformal environmental education programs. The Journal of Environmental Education, 28(2), pp. 10-21.

Neulinger, K., Vogl, C. R., \& Alayón-Gamboa, J. A. (2013). Plant species and their uses in homegardens of migrant Maya and Mestizo smallholder farmers in Calakmul, Campeche, Mexico. Journal of Ethnobiology, 33(1), pp. 105-124.

Ortega Canto, J. (2006). Géneros y generaciones: conducta reproductiva de los Mayas de Yucatán, México. Salud Colectiva, 2(1), pp. 75-89.

Page, M. E. (Ed.). (2003). Colonialism: An International, Social, Cultural, and Political

Panelli, R. (2008). Social geographies: encounters with Indigenous and more-thanWhite/Anglo geographies. Progress in Human Geography, 32(6), pp. 801-811.

Patch, R. W. (1976). La formación de estancias y haciendas en Yucatán durante la colonia. Boletín de la Escuela de Ciencias Antropológicas de la Universidad de Yucatán, 19, pp. 21-61.

— (1994). Maya and Spaniard in Yucatan: 1648-1812. Stanford University Press.

Paterson, M., \& Higgs, J. (2005). Using hermeneutics as a qualitative research approach in professional practice. The Qualitative Report, 10(2), pp. 339-357.

Peloquin, C., \& Berkes, F. (2009). Local knowledge, subsistence harvests, and socialecological complexity in James Bay. Human Ecology, 37(5), pp. 533-545. 
Pierotti, R., \& Wildcat, D. (2000). Traditional ecological knowledge: the third alternative (commentary). Ecological Applications, 10(5), pp. 1333-1340.

Preus, A. (2005). Did the Ancient Greeks have a Concept of Human

Rights?. International Journal of Decision Ethics, I.2:, pp. 43-64.

Radcliffe, S. A. (1997). The geographies of indigenous self-representation in Ecuador: Hybridity, gender and resistance. Revista Europea de Estudios Latinoamericanos y del Caribe/European Review of Latin American and Caribbean Studies, 63, pp. 9-27.

Radcliffe, S. A. (2005). Development and geography: towards a postcolonial development geography?. Progress in Human Geography, 29(3), pp. 291-298.

Quezada-Euán, J. J. G., de Jesús May-Itzá, W., \& González-Acereto, J. A. (2001). Meliponiculture in Mexico: problems and perspective for development. Bee World, 82(4), pp. 160-167.

Radcliffe, S. A. (2012). Development for a postneoliberal era? Sumak kawsay, living well and the limits to decolonisation in Ecuador. Geoforum, 43(2), pp. 240-249.

Ramírez-Barajas, P. J., Torrescano-Valle, N., Tecpa-Jiménez, A., \& Vázquez-Rodríguez, J. (2001). Importancia y uso del entorno natural en una comunidad indígena maya (Petcacab, Quintana Roo, México). Revista Especializada en Ciencias QuímicoBiológicas, 4, pp. 61-71.

Ramírez Carrillo, L. A. (2006). Impacto de la globalización en los Mayas yucatecos. Estudios de cultura maya, 27, pp. 73-97.

Re Cruz, A. (1996). The Two Milpas of Chan Kom: Scenarios of a Maya Village Life. Albany: State University of New York Press.

Reed, N. A. (2001). The Caste War of Yucatan. Stanford: Stanford University Press.

Remmers, G. G. A., \& De Koeijer, H. (1992). The T'OLCHE', a Maya system of communally managed forest belts: the causes and consequences of its disappearance. Agroforestry Systems, 18(2), pp. 149-177.

Rebollar-Domínguez, S., Santos-Jiménez, V. J., Tapia-Torres, N. A., \& Pérez-Olvera, C. D. L. P. (2008). Huertos familiares, una experiencia en Chancah Veracruz, Quintana Roo. Polibotánica, 25, pp. 135-154.

Reyes-García, V., Guèze, M., Luz, A. C., Paneque-Gálvez, J., Macía, M. J., OrtaMartínez, M., Pino, J., \& Rubio-Campillo, X. (2013). Evidence of traditional knowledge loss among a contemporary indigenous society. Evolution and Human Behavior, 34(4), pp. 249-257. 
Reyna-Hurtado, R., O’Farrill, G., Chávez, C., Serio-Silva, J. C., \& Castillo-Vela, G. (2015). Large terrestrial mammals. In Biodiversity and Conservation of the Yucatán Peninsula (pp. 227-255). Cham : Springer.

Rico-Gray, V., Garcia-Franco, J. G., Chemas, A., Puch, A., \& Sima, P. (1990). Species composition, similarity, and structure of Mayan homegardens in Tixpeual and Tixcacaltuyub, Yucatan, Mexico. Economic Botany, 44(4), pp. 470-487.

Rico-Gray, V., \& García-Franco, J. G. (1992). Vegetation and soil seed bank of successional stages in tropical lowland deciduous forest. Journal of vegetation science, 3(5), pp. 617-624.

Rivero, P. P. (1999). La comunidad domestica de la hacienda henequenera de Yucatan, Mexico. Mexican Studies/Estudios Mexicanos, 15(1), pp. 1-33.

Robbins, P. (2011). Political Ecology (2 ${ }^{\text {nd }}$ edition)(Critical Introductions to Geography). Oxford: Wiley-Blackwell.

- (2012). Research is theft: Environmental inquiry in a postcolonial world. In S. Aitken \& G. Valentine (Eds.), Approaches to Human Geography (pp. 311-324). London: Sage.

Rodríguez, M., Montiel, S., Cervera, M. D., Castillo, M. T., \& Naranjo, E. J. (2012). The practice and perception of batida (group hunting) in a Maya community of Yucatan, Mexico. Journal of Ethnobiology, 32(2), pp. 212-227.

Rose, G. (1997). Situating knowledges: positionality, reflexivities and other tactics. Progress in human geography, 21(3), pp. 305-320.

Rousseau, J. J. (1999). Oxford's World Classics: Discourse on the Origin of Inequality. New York : Oxford University Press.

Rugeley, T. (1996). Yucatan's Maya Peasantry and the Origins of the Caste War. Austin: University of Texas Press.

Rundstrom, R. A., Deur, D., Berry, K., \& Winchell, D. (2003). American Indian Geography. In G. L. Gaile \& C. J. Willmott (Eds.), Geography in America at the Dawn of the $21^{\text {st }}$ Century (pp. 600-615). Oxford: Oxford University Press.

Sabatier, P. A., Focht, W., Lubell, M., Trachtenberg, Z., Vedlitz, A., \& Matlock, M. (2005). Swimming upstream: Collaborative approaches to watershed management. Cambridge: MIT press.

Said, E. 1978. Orientalism, New York: Vintage. 
Sallenave, J. (1994). Giving traditional ecological knowledge its rightful place in environmental impact assessment. Northern Perspectives, 22(1), pp. 16-19.

Santos-Fita, D., Naranjo, E. J., \& Rangel-Salazar, J. L. (2012). Wildlife uses and hunting patterns in rural communities of the Yucatan Peninsula, Mexico. Journal of Ethnobiology and Ethnomedicine, 8(1), pp. 38-55.

Sauer, C. O. (1925). The Morphology of Landscape. Berkeley : University of California Press.

Scott, C. (Ed.). (2011). Aboriginal Autonomy and Development in Northern Quebec and Labrador. Vancouver : UBC Press.

Shaw, J. M. (2008). White Roads of the Yucatan: Changing Social Landscapes of the Yucatec Maya. Tucson: University of Arizona Press.

Shaw, W. S., Herman, R. D. K., \& Dobbs, G. R. (2006). Encountering Indigeneity: Reimagining and decolonizing geography. Geografiska Annaler. Series B. Human Geography, 88(3), pp. 267-276.

-(2008). Dishonour of the Crown: The Ontario Resource Regim in the Valley of the Kiji Sibi. Winnipeg, MB: Arbeiter Ring Publishing.

Sillitoe, P. (1998). The Development of Indigenous Knowledge: A New Applied Anthropology 1. Current anthropology, 39(2), pp. 223-252.

Simpson, L. (2002). Indigenous environmental education for cultural survival. Canadian Journal of Environmental Education (CJEE), 7(1), pp. 13-25.

Singleton, S. (2009). Native people and planning for marine protected areas: how "stakeholder" processes fail to address conflicts in complex, real-world environments. Coastal Management, 37(5), pp. 421-440.

Sioui, G. E. (1992). For an Amerindian Autohistory: An Essay on the Foundations of a Social Ethic. Montreal and Kingston: McGill-Queen’s University Press.

-(1999). Huron-Wendat: The heritage of the circle. Vancouver : UBC Press.

- (2008). Histoires de Kanatha : vues et contées/Histories of Kanatha : Seen and Told. Ottawa: University of Ottawa Press.

—(2013). Seawi. New Orleans : Diálogos Books/Lavender Ink. 
- (2016). Presentation to the Calacs (Canadian Association for Latin American and Caribbean Studies) University of Costa Rica, July 8-10, 2015. The Canadian Journal of Native Studies, 36(1), pp. 225-230.

Sioui, M. (2012). Asserting Miyo-Pimaadiziwin on Unceded Algonquin Territory: Experiences of a Canadian 'Non-Status' First Nation in Re-establishing its Traditional Land Ethic (master's thesis, University of Ottawa).

Sioui, M., \& McLeman, R. (2014). Asserting mino pimàdiziwin on unceded Algonquin territory: Experiences of a Canadian "non-status" First Nation in re-establishing its traditional land ethic. AlterNative: An International Journal of Indigenous Peoples, 10(4), pp. 354-375.

Smith, D. A., Herlihy, P. H., Kelly, J. H., \& Viera, A. R. (2009). The certification and privatization of indigenous lands in Mexico. Journal of Latin American Geography, 8(2), pp. 175-207.

Smith, L. T. (1999). Decolonizing Methodologies: Research and Indigenous Peoples. New York: Zed Books.

Smith, N. (1994). Geography, empire and social theory. Progress in Human Geography, (18)4, pp. 491-500.

Sosa, P. B. (1988). Haciendas y ganado en el noroeste de Yucatan. Historia Mexicana, 37(4), pp. 613-639.

Spivak, G. C. (1988). Can the Subaltern Speak? In C. Nelson \& L. Grossberg (Eds.), Marxism and the Interpretation of Culture (pp. 271-316). Urbana: University of Illinois Press.

Stavenhagen, R. (2008). Human Rights in the Maya Region: Global Politics, Cultural Contentions, and Moral Engagements. Durham : Duke University Press.

Steward, J. H. (1972). Theory of Culture Change: The Methodology of Multilinear Evolution. Champaign: University of Illinois Press.

Stocks, A. (2005). Too much for too few: Problems of indigenous land rights in Latin America. Annual Review of Anthropology, 34, pp. 85-104.

Stoner Chamberlain, R. (1966). The Conquest and Colonization of the Yucatan, 15171550. New York: Octagon Books.

Sweetwood, R. V., Terry, R. E., Beach, T., Dahlin, B. H., \& Hixson, D. (2009). The Maya footprint: soil resources of Chunchucmil, Yucatán, México. Soil Science Society of America Journal, 73(4), pp. 1209-1220. 
Taylor, S. J., Bogdan, R., \& DeVault, M. (2015). Introduction to Qualitative Research Methods: A Guidebook and Resource. Hoboken : John Wiley \& Sons.

Timmer, D. E. (1997). Providence and perdition: Fray Diego de Landa justifies his inquisition against the Yucatecan Maya. Church History, 66(3), pp. 477-488.

Toledo, V. M., Ortiz-Espejel, B., Cortés, L., Moguel, P., \& Ordoñez, M. D. J. (2003). The multiple use of tropical forests by indigenous peoples in Mexico: a case of adaptive management. Conservation Ecology, 7(3): p. 9.

Tongco, M. D. C. (2007). Purposive sampling as a tool for informant selection. Ethnobotany Research and Applications, 5, pp. 147-158.

-(1977). Space and Place: The Perspective of Experience. Minneapolis: University of Minnesota Press.

Tuck, E., \& Yang, K. W. (2012). Decolonization is not a metaphor. Decolonization: Indigeneity, education \& society, 1(1), pp. 1-40.

Tuhiwai Smith, L. (1999). Imperialism, History, Writing, and Theory. In Decolonizing Methodologies (pp. 19-41). London: Zed Press.

Turner, N. J., Ignace, M. B., \& Ignace, R. (2000). Traditional ecological knowledge and wisdom of aboriginal peoples in British Columbia. Ecological applications, 10(5), 12751287.

Universal Declaration on the Rights of Mother Earth. First proposed at the World People's Conference on Climate Change and the Rights of Mother Earth (Cochabamba, Bolivia), retrieved at http://therightsofnature.org/wp-content/uploads/FINALUNIVERSAL-DECLARATION-OF-THE-RIGHTS-OF-MOTHER-EARTH-APRIL-222010.pdf

UN General Assembly, United Nations Declaration on the Rights of Indigenous Peoples : resolution / adopted by the General Assembly, 2 October 2007, A/RES/61/295, retrieved from: http://www.un.org/esa/socdev/unpfii/documents/DRIPS_en.pdf

Vasquez Castillo, M. T. (2013). Land Privatization in Mexico: Urbanization, Formation of Regions, and Globalization in Ejidos. New York: Routledge.

Villanueva, N. B. V. (2014). La concepción de los aluxes, según niños de ascendencia maya yucateca. Temas antropológicos: Revista científica de investigaciones regionales, 36(2), pp. 97-125. 
Villanueva-Gutiérrez, R. Moguel-Ordóñez, Echazarreta-González, C. M. \& Arana-López, G. (2009). Monofloral honeys in the Yucatán Peninsula, Mexico. Grana, 48(3), pp. 214223.

Villanueva-Gutiérrez, R., Roubik, D. W., \& Colli-Ucán, W. (2005). Extinction of Melipona beecheii and traditional beekeeping in the Yucatán peninsula. Bee World, 86(2), pp. 35-41.

Virtual Museum of Canada (Producer). (2012). The Story Continues (The St. Lawrence Iroquoians): Testimony $-\mathrm{F}$. Henry Lickers. [Video file]. Retrieved from http://www.virtualmuseum.ca/sgc-cms/expositions-exhibitions/iroquoiensiroquoians/descendants_fh_licker-story_continues_fh_licker-eng.html

Wainwright, J. (2008). Decolonizing Development: Colonial Power and the Maya. Malden: Blackwell.

Wainwright, J., \& Bryan, J. (2009). Cartography, territory, property: postcolonial reflections on indigenous counter-mapping in Nicaragua and Belize. Cultural Geographies, 16(2), pp. 153-178.

Warren, K. B., \& Jackson, J. E. (2003). Indigenous Movements, Self-Representation, and the State in Latin America. Austin: University of Texas Press.

Watanabe, J. M. (1990). From saints to shibboleths: Image, structure, and identity in Maya religious syncretism. American Ethnologist, 17(1), pp. 131-150.

Wildcat, D. R. (2009). Red alert!: Saving the Planet with Indigenous Knowledge. Golden : Fulcrum.

Wilson, S. (2001). What Is an Indigenous Research Methodology?. Canadian Journal of Native Education, 25(2), pp. 75-79.

- (2003). Progressing toward an Indigenous research paradigm in Canada and Australia. Journal of Native Education, 27(2), pp. 161-178.

-(2008). Research Is Ceremony: Indigenous Research Methods. Halifax and Winnipeg: Fernwood.

Wilson, E. M. (1980). Physical geography of the Yucatan Peninsula. In Moseley, E. H. \& Terry, E. D. (Eds.), Yucatan: A World Apart (pp. 5-40). Tuscaloosa: University of Alabama Press.

Williams, D. R., Alvarado, F., Green, R. E., Manica, A., Phalan, B., \& Balmford, A. (2017). Land-use strategies to balance livestock production, biodiversity conservation and carbon storage in Yucatán, Mexico. Global Change Biology, 23(12), pp. 5260-5272. 
Wootton, D. (2003). Divine Right and Democracy: An Anthropology of Political Writing in Stuart England. Indianapolis: Hacket Publishing Company.

Yashar, D. J. (1998). Contesting citizenship: Indigenous movements and democracy in Latin America. Comparative Politics, 31(1), pp. 23-42.

-(1999). Democracy, indigenous movements, and postliberal challenge in Latin America. World Politics, 52(1), pp. 76-104.

-(2005). Contesting Citizenship in Latin America: The Rise of Indigenous Movements. New York: Cambridge University Press.

Zimmerer, K. S. (2000). Rescaling irrigation in Latin America: The Cultural images and political ecology of water resources. Cultural Geographies, 7(2), pp. 150-175.

- (2012). The Indigenous Andean Concept of Kawsay, the Politics of Knowledge and Development, and the Borderlands of Environmental Sustainability in Latin America. PMLA, 127(3), pp. 600-606.

-(2015). Environmental governance through "Speaking Like an Indigenous State" and respatializing resources: Ethical livelihood concepts in Bolivia as versatility or verisimilitude? Geoforum, 64, pp. 314-324.

Zimmerer, K. S., \& Bassett, T. (Eds.). (2003). Political Ecology: An Integrative Approach to Geography and Environment-Development Studies. New York: Guildford.

Zinga, D., \& Styres, S. (2011). Pedagogy of the land: Tensions, challenges, and contradictions. First Nations Perspectives, 4(1), pp. 59-83.

Zoomers, A. (2000). Searching for a New Land Policy: Options and Dilemmas (pp. 289303). Amsterdam : Royal Tropical Institute, KIT Publishers. 


\section{Appendices}

\section{Appendix A}

\section{Interview Questions}

\section{List of Possible Interview Questions:}

Yucatec Maya identity and culture and relationships with the land:

-Tell me about yourself, your childhood, your family history.

-Tell me about your own understanding/interpretation of your Mayan culture.

-What does it mean to you to be a Maya?

-What is the importance of/What does the land mean to you as a Maya?

-How does your understanding of the landscape influence the way you live your life and your relationship with the land?

-What kinds of activities, according to you, constitute Mayan land use/management in the Yucatan?

-Are there any spiritual/cultural motivations behind your own personal relationship with the land?

-Describe your view of appropriate land use.

-What are the ways in which your culture and what you know about the land influence and guide your own personal relationship and interaction with the land?

-Who taught you what you know about Mayan land-use activities (such as apiculture, hunting, farming, cattle ranching)?

-If you were to produce a land use/management strategy for Yucatan (or Mexico), what would be its main objectives and what are the steps it would take in order to achieve its goals? 


\section{Appendix B}

\section{Written Consent Form ${ }^{1}$}

Funding Source: Dr. Derek Smith (research grant)

Dear Sir or Madam,

My name is Miguel Sioui and I am a third-year PhD student in the Department of Geography and Environmental Studies at Carleton University. I am working on a research project under the supervision of Prof. Derek Smith.

I am writing to you today to invite you to participate in a study on Yucatec Maya land use knowledges. The study aims to document and interpret the Yucatec Maya land ethic and describe how it is currently understood and practiced by community members.

I am seeking your permission to accompany you while you perform Mayan land-based activities such as apiculture, milpa farming, or cattle ranching. I also intend to have informal discussions about the nature of the task(s) that you perform. If possible, I would also like to have a semi-formal interview with you about the deeper motivations behind your concrete land management practices. I can provide you with a list of interview questions that I will ask, should you require one, prior to our interview. The interview will not last more than 60 minutes and it will take place in a mutually convenient, safe location. With your consent, interviews will be audio-recorded. Once the recording has been transcribed, the audio recording will be destroyed.

This project does not carry any additional professional and emotional risks, and care will be taken to respect confidentiality. This will be done by keeping all responses anonymous and allowing you to request that certain responses not be included in the final project.

You will have the right to end your participation in the study, for any reason, up until one month of our interview. If you choose to withdraw, all the information you have provided will be destroyed. Once the project is completed, all research data will be kept indefinitely under the same secure conditions, and only I will continue to have access to this information. I may use it for other academic projects (i.e. publications) on this same topic, but not for any other purposes

As a token of appreciation, I will be providing you with refreshments during the interview. No other compensation will be provided.

All research data, including audio-recordings and any notes will be encrypted. Any hard

\footnotetext{
${ }^{1}$ This document was translated into Spanish.
} 
copies of data (including any handwritten notes or USB keys) will be kept in a locked cabinet in my office at Carleton University. Research data will only be accessible by the researcher.

This ethics protocol for this project was reviewed by the Carleton University Research Ethics Board, which provided clearance to carry out the research. Should you have questions or concerns related to your involvement in this research, please contact:

\section{REB contact information:}

XXXX

If you would like to participate in this research project, or have any questions, please contact me at (insert Carleton University phone number) or (insert Carleton University email address).

Sincerely, Miguel Sioui 


\section{Appendix C}

\section{Oral Consent Form ${ }^{2}$}

Researcher : Miguel Sioui, PhD candidate (Department of Geography and Environmental Studies)

My name is Miguel Sioui and I am a third-year PhD student in the Department of Geography and Environmental Studies at Carleton University. I am working on a research project under the supervision of Prof. Derek Smith.

I am writing to you today to invite you to participate in a study on Yucatec Maya land use knowledges. The study aims to document and interpret the Yucatec Maya land ethic and describe how it is currently understood and practiced by community members.

I am seeking your permission to accompany you while you perform Mayan land-based activities such as apiculture, milpa farming, or cattle ranching. I also intend to have informal discussions about the nature of the task(s) that you perform. If possible, I would also like to have a semi-formal interview with you about the deeper motivations behind your concrete land management practices. I can provide you with a list of interview questions that I will ask, should you require one, prior to our interview. The interview will not last more than 60 minutes and it will take place in a mutually convenient, safe location. With your consent, interviews will be audio-recorded. Once the recording has been transcribed, the audio recording will be destroyed.

This project does not carry any additional professional and emotional risks, and care will be taken to respect confidentiality. This will be done by keeping all responses anonymous and allowing you to request that certain responses not be included in the final project.

You may withdraw at any time within one month of our interview. If you choose to withdraw, all the information you provided will be destroyed.

All research data, including audio-recordings and my notes will be encrypted and kept in my laptop computer. Research data will only be accessible by me.

Once the project is completed, all research data will be kept indefinitely under the same secure conditions, and only I will continue to have access to this information. I may use it for other academic projects (i.e. publications) on this same topic, but not for any other purposes.

If you would like a copy of the finished research project, please let me know. I will then provide you with an electronic copy.

\footnotetext{
${ }^{2}$ This document was translated into Spanish.
} 
The ethics protocol for this project was reviewed by the Carleton University Research Ethics Board, which provided clearance to carry out the research.

You can also reach me at XXXX. My supervisor can be reached at dereka.smith@carleton.ca. Do you have any questions or need clarification?

Do I have your permission to begin:

Do you agree to be audio-recorded: $\_$Yes No No

Date:

Participant's name/Pseudonym/Initials:

Researcher's Signature: 